Connecting Grammaticalisation 


\section{Studies in Functional and Structural Linguistics (SFSL)}

Taking the broadest and most general definitions of the terms functional and structural, this series aims to present linguistic and interdisciplinary research that relates language structure - at any level of analysis from phonology to discourse to broader functional considerations, whether cognitive, communicative, pragmatic or sociocultural. Preference will be given to studies that focus on data from actual discourse, whether speech, writing or other nonvocal medium. The series was formerly known as Linguistic \& Literary Studies in Eastern Europe (LLSEE).

For an overview of all books published in this series, please see http://benjamins.com/catalog/sfsl

Founding Editor

John Odmark

\section{Honorary Editors}

$\begin{array}{ll}\text { Eva Hajičová } & \text { Petr Sgall } \\ \text { Charles University } & \text { Charles University }\end{array}$

\section{General Editors}

Yishai Tobin

Ben-Gurion University of the Negev
Ellen Contini-Morava

University of Virginia

\section{Editorial Board}

Alexandra Y. Aikhenvald

La Trobe University

Joan Bybee

University of New Mexico

Nicholas Evans

University of Melbourne

Victor A. Friedman

University of Chicago

Anatoly Liberman

University of Minnesota

James A. Matisoff

University of California, Berkeley
Jim Miller

University of Auckland

Marianne Mithun

University of California, at Santa Barbara

Lawrence J. Raphael

CUNY and Adelphi University

Olga Mišeska Tomić

Leiden University

Olga T. Yokoyama

UCLA

\section{Volume 65}

Connecting Grammaticalisation

by Jens Nørgård-Sørensen, Lars Heltoft and Lene Schøsler 


\title{
Connecting Grammaticalisation
}

\author{
Jens Nørgård-Sørensen \\ University of Copenhagen \\ Lars Heltoft
}

Roskilde University

Lene Schøsler

University of Copenhagen

John Benjamins Publishing Company

Amsterdam/Philadelphia 
The paper used in this publication meets the minimum requirements of American National Standard for Information Sciences - Permanence of Paper for Printed Library Materials, ANSI z39.48-1984.

\section{Library of Congress Cataloging-in-Publication Data}

Nørgård-Sørensen, Jens.

Connecting grammaticalisation / Jens Nørgård-Sørensen, Lars Heltoft, Lene Schøsler.

p. cm. (Studies in Functional and Structural Linguistics, ISSN 0165-7712 ; v. 65) Includes bibliographical references and index.

1. Grammar, Comparative and general--Grammaticalization. 2. Structural linguistics. I. Heltoft, Lars. II. Schøsler, Lene, 1946- III. Title.

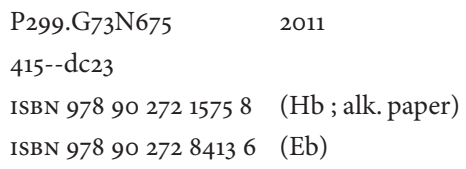

(C) 2011 - John Benjamins B.V.

No part of this book may be reproduced in any form, by print, photoprint, microfilm, or any other means, without written permission from the publisher.

John Benjamins Publishing Co. · P.O. Box 36224 1020 ME Amsterdam · The Netherlands John Benjamins North America · P.O. Box 27519 · Philadelphia PA 19118-0519 • USA 


\section{Table of contents}

Introduction

Part I. Grammaticalisation and paradigmatic structure

CHAPTER 1

Morphology

1. Grammaticalisation and morphology 3

2. Basic concepts 10

3. The cline of grammaticality: Deficiencies of the theory $\mathbf{1 1}$

4. Morphological change 17

5. The cline revisited 20

6. Words and clitics 22

7. The grammatical system 25

8. Analogy 33

9. Markedness and productivity 34

9.1 Paradigmatic markedness 35

9.2 Variational markedness 36

9.3 Markedness of context 39

9.4 Markedness and productivity 40

CHAPTER 2

Topology (word order)

1. Introduction 43

2. Paradigms and word order 45

3. Innovative topology 51

4. Reanalysis from earlier topology 52

4.1 Principles of topological analysis 53

4.2 Verb second and Wackernagel 53

4.3 Old English synchrony and a possible scenario for Scandinavian verb second 57

5. Degrammation of word order paradigms? 58

6. Examples of topological oppositions integrated in hyperparadigmatic structures $\mathbf{6 3}$

6.1 Complex constituent formation $\mathbf{6 3}$

6.2 Wackernagel's law in Latin 65

6.3 Old French topology and the tonic - atonic pronominal system an example of connecting grammaticalisation 67 
CHAPTER 3

Constructions

1. Introduction 71

2. Definitions and motivations for introducing the level of constructions 72

2.1 Definition and exemplification of constructions 72

2.2 Constructions are language specific 76

2.3 The transitive construction $\mathrm{S}-\mathrm{V}-\mathrm{O} \quad \mathbf{8 0}$

2.4 Overview of paradigmatic oppositions between constructions $\quad 81$

2.4.1 Telicity in objects $\mathbf{8 2}$

2.4.2 Ergativity in purely constructional paradigms $\quad 82$

2.4.3 Nonspecificity of objects $\mathbf{8 2}$

2.4.4 Augmenting from two arguments to three 83

2.4.5 Telicity in free indirect object constructions 84

2.4.6 Types of construction 84

2.5 Morphological marking instead of constructional oppositions 86

2.6 Hyperparadigmatic organisation 90

2.7 Conclusion of Section 292

3. Constructions and language change 92

3.1 Regrammation of constructions 92

3.2 Lexical change and constructional change 94

3.2.1 Causative morphology and causative constructions 94

3.2.2 Reinterpretation and regrammation of constructions 96

3.2.3 Ejection of non-prototypical verbs 97

3.3 Further examples of relexicalisation between constructions $\quad 98$

3.3.1 Voler 98

3.3.2 Forbid 99

3.3.3 Verbs of electronic communication $\quad 100$

3.4 Conclusion of Section $3 \quad 101$

CHAPTER 4

Connecting grammaticalisation

1. Grammation, regrammation and degrammation of complex paradigms $\quad 105$

2. Grammation, regrammation and degrammation of parallel (sets of) paradigms 107

2.1 One content system in more than one expression system 107

2.2 Semantically complementary systems 108

3. Connecting paradigms vs. layering 109 


\section{Part II. Case studies}

\section{CHAPTER 5}

Patterns of connecting grammaticalisation in Russian

Jens Nørgård-Sørensen

1. Old Russian syntax $\mathbf{1 1 6}$

2. Animacy as a gender $\mathbf{1 2 9}$

2.1 Animacy in Modern Russian 129

$\mathbf{2 . 2}$ The problem $\mathbf{1 3 2}$

2.3 From Old Russian to Modern Russian 132

2.3.1 The syntax of the Old Russian noun phrase 132

2.3.2 The rise of animacy as a gender $\quad 144$

3. Aspect 149

4. Parallel grammaticalisation as a type of connecting grammaticalisation 167

CHAPTER 6

Word order change as grammaticalisation

Lars Heltoft

1. Introduction $\mathbf{1 7 1}$

1.1 The principles of topological analysis $\mathbf{1 7 2}$

$\mathbf{1 . 2}$ Overview $\mathbf{1 7 5}$

2. Verb second in Scandinavian - paradigms and changes in Danish $\mathbf{1 7 6}$

2.1 Verb second in Old Scandinavian $\mathbf{1 7 6}$

2.2 Modern Danish verb second order and its simple paradigmatic organisation $\mathbf{1 7 7}$

2.3 Verb second as subspecifications of the mood system $\mathbf{1 7 9}$

2.4 Indicative contrasts: Old Danish verb second and Old French verb second $\mathbf{1 8 0}$

2.5 The internal reanalysis of verb second clauses as mood $\mathbf{1 8 5}$

2.6 The external reanalysis as mood: Illocutionary frame as a combination of mood and syntactic hierarchy $\quad \mathbf{1 8 7}$

2.7 Conclusion of Section 2191

3. The rise of SVO order in Scandinavian from Old Scandinavian

OV order in non-finite VPs 192

3.1 The meaning of Old Scandinavian verb second 194

3.2 Positional analysis 195

3.3 Iconic focus 197

3.4 Positional reanalysis of cohesive elements 201 
3.5 Functional motivation 203

3.6 Adverbials as false friends $2 \mathbf{1 1}$

3.7 The loss of OV (XV) 212

3.7.1 Reanalysis to VO-structure 213

3.7.2 Details of the reanalysis to VO 215

4. The origin of subjective main clauses $\mathbf{2 1 6}$

4.1 Emotive verb second main clauses and their replacement 217

4.2 SVO main clauses and illocutionary particles 220

5. Conclusions and perspectives 225

5.1 A brief overview of the topological changes from Old Scandinavian to Modern Mainland Scandinavian 226

5.2 Harris and Campbell: A non-semantic concept of syntactic reanalysis 227

5.3 The need for a content based approach $\quad 230$

5.4 The need for complex paradigms and connecting grammaticalisation

Sources 235

CHAPTER 7

Scenarios of grammatical change in Romance languages

Lene Schøsler

1. Introduction 237

1.1 The development of the case system 238

1.2 From Latin to the Romance languages 239

1.3 Constructions 242

1.3.1 Lexicalist account or constructionist account? 242

1.3.2 Definitions of constructions 243

1.3.3 Views on how constructions come into existence and how they may change $\mathbf{2 4 5}$

1.4 Conclusion of Section $1 \quad 248$

2. An illustration of connecting grammaticalisation processes:

The marking of the second and the third argument $\quad 248$

2.1 The development of the dative as marker of the third argument in Romance languages 250

2.1.1 Latin, stage $1 \quad 250$

2.1.2 Late Latin and Early Romance languages, stage $2 \quad 255$

2.1.3 Early Romance languages, stage $2 \quad 257$

2.1.4 Later periods, stages 2 and $3 \quad 258$

2.2 The development of the second argument in Romance languages

2.2.1 From Latin to Romance $\mathbf{2 6 5}$

2.2.2 Potential merger of the second and the third argument, stages 3 to $4 \quad 269$ 
2.3 The development of the personal pronouns:

Cross-reference phenomena 271

2.3.1 The development of cross-reference in Romance languages $\quad 272$

2.3.2 The development of Romance clitics. Discussion concerning a possible typological shift due to the generalised use of clitics 275

2.3.3 The distinction \pm human in clitics, stage 3 for French, Italian (and Catalan) $\quad 278$

2.4 Conclusion of Section $2 \quad 281$

3. Formation of construction paradigms: The dative as second argument in French $\mathbf{2 8 2}$

3.1 Latin 283

3.2 Old and Middle French 286

3.3 The development of the verb aider from 1500-1799 293

3.4 Modern French, standard and advanced 297

3.5 Conclusion of Section $3 \quad 301$

4. The importance of absence: Constructional alternation between expressed and unexpressed second argument 303

4.1 Latin 305

4.2 Old French 306

4.3 Middle French 308

4.4 Classical French 310

4.5 Modern Standard French and Colloquial French 312

4.6 Conclusion of section $4 \quad 316$

5. Conclusion 318

5.1 Simple paradigmatically organised constructions $\quad 318$

5.2 Creation and reorganisation of complex paradigms 319

5.2.1 The creation of the dative A2 paradigm in French 320

5.2.2 Reorganisation of the non-subject argument paradigm in Peninsular Spanish 321

5.3 Implications for the theory of language change 322

5.3.1 Theoretical implications: Chains of grammaticalisation and connecting grammaticalisation 322

5.3.2 Theoretical and methodological implications 323

Sources 324

References

Language index

Subject index 



\section{Introduction}

In the present book we offer an overall view of grammaticalisation (grammatical status and grammatical change) radically different from the standard view(s) centering around what is called the cline of grammaticality. Morphology is the traditional core area of grammar, and the standard view basically complies with tradition in terms of the background assumption that grammaticalisation processes are directed towards morphological status, or if already there, towards enhanced morphological status.

Given that our subject is grammatical change, this traditional focus is indeed a narrow one. Important insights and knowledge have been downgraded, in particular:

1. The great majority of morphological changes are changes from one morphological system to another. Although morphological systems can be expanded or reduced and can certainly undergo typological changes, such processes are normally not enhancement processes, but rather changes from one obligatory system to another.

2. Grammar, of course, comprises constructional syntax and word order systems, and much of our effort in the first three chapters is devoted to constructions and word order as interacting but discernible parts of grammar. However, we do not think that constructional systems and word order systems are generally less grammaticalised than morphological systems. Strikingly, not even the oftquoted Meillet seems to have held such views of grammar (see Chapter 2).

Grammar is a complex sign system, and by definition grammatical change will always comprise semantic change. We see no point in claiming modular organisation of grammar. There is no autonomous syntactic module and no isolated morphological component. Nor do we see any point in binding up syntax with linearity from the outset, but we treat syntax as construction syntax and word order as topology, since we view both as sign systems in their own right.

These views are presented and unfolded in Chapters 1-3. At present, we emphasise the main idea only.

- Morphology, topology and constructional syntax are subsystems of the overall grammatical sign system. What unites them is their paradigmatic organisation.

- All of grammar is organised in closed sets of alternations (paradigms), and our key claim is that the traditional concept of an inflexional paradigm can be generalised as a structuring principle of word order systems and constructional systems also. 
- All paradigms structure sign systems and must be understood as packages of content and expression. As such, they are language specific.

- Grammatical change takes the form of grammation, regrammation and degrammation of paradigms (Andersen 2006a).

This general view of grammar is presented in Chapter 1-3, in a perspective that is both synchronic and diachronic. To say what has changed into what, we need synchronic descriptions of grammatical phenomena, and any scenario of a process of grammatical change presupposes synchronic and panchronic analyses of the elements involved.

Much of our background originates in functional European linguistics, in particular Danish Functional Linguistics (Engberg-Pedersen, Fortescue, Harder, Heltoft \& Jakobsen (1996), Harder (1996)), hence our focus on semantic and pragmatic issues. Danish functional linguistics shares its interest in usage with American functional linguistics, but it has another foot firmly placed in Saussurean European structuralism with its focus on the relation between content and expression (Jakobson, Hjelmslev). For recent examples of this discussion, see Boye and Harder (2007) and Heltoft (2010). Both articles discuss and exemplify the relation between usage and structure from the stance that - in the coinage of Boye and Harder (2007: 570) - "structure is distilled out of, but simultaneously presupposed by, usage". In addition to this, Heltoft's focus is on (esp. paradigmatic) structure as a "measure against which we can identify usage processes symptomatic of a change and make sense of them" (2010: 161).

Where models and views of grammatical change and of linguistic change in general are concerned, we are deeply indebted to Henning Andersen, see the reference list.

Our emphasis is on the generalised concept of a paradigm, its structuring role in grammar and its importance for a theory of linguistic change. In this lies what we see as our own main contribution to the subject. Paradigmatic structure is common to morphology, topology (word order) and constructional syntax; all grammatical changes involve paradigmatic restructuring.

The book endeavours one more theoretical step, however tentative, namely the claim that, on the basis of our concept of a paradigm, we need a concept of connecting grammaticalisation. Morphological, topological and constructional paradigms very often connect to form complex paradigms, so-called hyperparadigms (developed in Christensen 2007, written in Danish), and grammaticalisation processes include the formation, restructuring and dismantling of such complex paradigms. Although the idea is relatively simple, we have chosen to introduce this concept little by little in Chapters 1-3, and to return to it in principle in a short separate Chapter 4, which may serve as a platform from where to identify and explore examples of connecting grammaticalisation.

A possible alternative coining of 'connecting grammaticalisation' would be a sequential one in which chains of grammations, regrammations and degrammations 
are seen as one connected process, in the sense that change $\mathrm{A}$ is a precondition for $\mathrm{B}$, which again is a precondition for $\mathrm{C}$ and $\mathrm{D}$, etc. Such analyses need explications of the concept of preconditioning, since, for instance, most attempts to link two changes A and $\mathrm{B}$ as universally conditioned have up till now been easy to disprove empirically.

The layout of the book is then as follows:

Chapters 1,2, and 3 present our view on the paradigmatic organisation of grammar: the concept of a paradigm, applied to (1) morphology and morphological change, to (2) topology and word order change, and (3) to constructions and constructional change. In 4 our view of connecting grammaticalisation is presented and exemplified.

Chapters 5-7 are separate studies by the individual authors, each of whom makes connecting grammaticalisation a central point. Chapter 5, "Patterns of connecting grammaticalisation in Russian: syntax, animacy, and aspect” (by Jens NørgårdSørensen), is an extensive study of aspect and case in Russian. It is claimed that Russian aspect and animacy developed as connected changes, their semantic organisation being related in an interesting way. Chapter 6, "Word order change as grammticalisation. Paradigmatic structure and change in Scandinavian." (by Lars Heltoft), is a study of Scandinavian verb second and its semantic and syntactic change from the Middle Ages to the present day, especially of word order paradigms and their hyperparadigmatic organisation. And finally, Chapter 7, "Scenarios of grammatical change in Romance languages" (by Lene Schøsler), deals with the reinterpretation of the Latin case system in the Romance languages, particularly in French, and its integration in constructional paradigms.

The languages studied are Slavic (mainly Russian), Germanic (Mainland Scandinavian, esp. Danish), and Romance (with a focus on French). 

PART I

Grammaticalisation and paradigmatic structure 



\section{CHAPTER 1}

\section{Morphology}

\section{Grammaticalisation and morphology}

Grammaticalisation studies were closely associated with morphology at an early stage. These studies often cite Meillet (1965 [1912]) for having introduced the term grammaticalisation, with reference to the observation that many morphological affixes developed from lexical units. However, the fundamental insight behind this observation is much older than the intensified grammaticalisation studies of recent years and, as will soon be clear, we do not take the idea that "today's morphology is yesterday's syntax" (Givón 1971:413) as covering the field of grammaticalisation in any coherent or exhaustive way.

As already mentioned in the introduction, our idea of grammaticalisation by definition includes paradigmatic restructuring. As a simple and hopefully clarifying introduction to this idea and to our approach in general, we shall begin by considering a fairly transparent example of a change in the Russian case system.

In Common Slavic, as reflected in the oldest Slavic texts of Bulgarian (Old Church Slavonic) and Russian origin, there were a number of noun declensions with different desinences. For the genitive singular the $o$-stems took the desinence $-a$; the $\breve{u}$-stems took the desinence $-u$. Before eventually ceasing to exist as a separate declension the $\breve{u}$-stems exerted a remarkable influence on the $o$-stems. The $o$-stems took in several $\breve{u}$-stem desinences, one of which was the genitive singular $-u$. Consequently, $o$-stem nouns started appearing with a genitive singular $-u$, along with the inherited $-a$, cf. (1).

(1) Genitive singular (Common Slavic - as reflected in Old Russian)

$$
\begin{array}{ll}
o \text {-stem forms (inherited) } & \breve{u} \text {-stem forms (new) } \\
\text { polon- } a \text { 'prisoners' (collective) } & \text { polon- } u \\
\text { sneg- } a \text { 'snow' } & \text { sneg- } u
\end{array}
$$

This is a process of analogy, i.e. a simple change of expression not affecting the content. Though there is evidence that even in the oldest texts the two desinences were not randomly distributed (Šachmatov 1957:240-45), the process should be recognised as analogical in its origin, allowing the two genitive singular desinences to occur as variants, possibly stylistically distributed, in connection with a number of $o$-stem nouns. 
The two forms continue to exist side by side in Modern Russian, but with a semantic distribution unknown to Old Russian. In Modern Russian, mass nouns of the 1st declension masculine (the former masculine $o$-stems) appear with two different genitive singular desinences, cf. (2).
(2) kačestvo čaj-a stakan čaj-u/čaj-a quality tea-GEN.SG glass tea-GEN.SG 'the quality of the tea' 'a glass of tea'

The standard genitive singular desinence for the 1st declension masculine is $-a$, cf. čaj-a. An additional desinence $-u$ is used for mass nouns, cf. the genitive-attribute $\check{c} a j-u$ as a possible alternative to $\check{c} a j-a$ in (2). Under specific circumstances the genitive, and in particular the $u$-genitive appears as the direct object (argument 2, henceforth A2) along with the accusative, cf. (3).
(3)
a. vypit' ̌́aj
drink tea-ACC.sG
'drink tea/the tea'
b. vypit' čaj-u
drink tea-GEN.SG
'drink (some) tea'

As appears from the tentative translations of the examples, the desinence $-u$, being restricted to mass nouns, expresses (indefinite) quantity. This is why in its attributive function it combines only with nouns denoting a measurement of quantity (cf. in (2) stakan 'glass'), but not with nouns without this property (cf. in (2) kačestvo 'quality'). Further, in the A2 slot the $u$-form unequivocally refers to an indefinite quantity - as opposed to the unmarked accusative. Thus, while still included in the general case paradigm, the two genitive forms constitute a subparadigm of the Modern Russian case system, cf. Table 1.

Table 1. Modern Russian: The genitive $-a /-u$ distinction

Domain: Mass nouns, 1st decl.gen.sg.masc.

Frame: Quantification

\begin{tabular}{lll}
\hline Expression & Content & Markedness \\
\hline$-a$ & neutral & unmarked \\
$-u$ & quantified & marked \\
\hline
\end{tabular}

This paradigm is productive within its domain of mass nouns. ${ }^{1}$ This appears from a number of loan words having entered Russian throughout the last two to three

1. On productivity, see Section 9 below. 
centuries, allowing for the formation of a $u$-genitive, e.g. limonad 'lemonade', šokolad 'chocolate', sprajt 'Sprite', cf. (4).

$[\ldots]$ sprajt-u v dva raza bol`se čem kol-y
Sprite-GEN.SG in two times more than Coke-GEN.SG
'... there is twice as much Sprite as Coke'
(http://www.nivovod.ru - 07.01.09)

As mentioned, the Modern Russian paradigm in Table 1 was unknown to Old Russian, where the distribution of the two genitive singular desinences was unclear. This allows us to conclude that at a certain language stage the genitive singular $-a /-u$ distinction was reanalysed to express quantification. Although we have ignored possible intermediate stages, the example serves as a transparent and representative illustration of how a grammatical, in this case morphological, distinction comes into existence.

A grammatical paradigm - of which a morphological paradigm is merely a subtype - consists of signs, i.e. a set of distinct forms expressing a set of content distinctions. This understanding of grammar as containing paradigmatic sign distinctions is deeply rooted in the tradition of structural linguistics.

Grammatical change, then, will involve paradigmatic change. Nevertheless, reinterpretation in terms of paradigmatic change has not been on the agenda of grammaticalisation studies.

At a given stage of development, a grammatical paradigm can be identified through the following features.

First, a grammatical paradigm is in principle closed, the number of members being fixed. Binary oppositions such as in the above example are frequent, and multimembered paradigms often exhibit some kind of internal hierarchical structure. Table 1 serves as an illustration of this fact, being a subparadigm of the Modern Russian case system.

Second, it is in principle possible to specify the domain of the paradigm, i.e. the syntagmatic context where the paradigm applies. In Table 1 the domain of the paradigm is constituted by the stems of masculine mass nouns of the 1st declension. In close correspondence with the domain, the paradigm will have a semantic frame within which the content of the specific members of the paradigm is defined. The frame of the paradigm in Table 1 can be identified in broad terms as quantification, with one form $(-a)$ being neutral with respect to quantification, whereas the other form $(-u)$ presents the referent as an indefinite quantity.

Third, the choice between the members of the paradigm is obligatory in the sense that speakers cannot avoid picking one or the other when they produce an utterance activating the domain and thus the frame of the paradigm. This choice may be free or bound, but will ultimately be determined by the content of the forms constituting the paradigm. The choice between the two forms in Table 1 is determined by what the 
speaker intends to modify. Due to the character of the syntagmatic context, this is an example of a bound choice.

Fourth, grammatical paradigms are asymmetric, distinguishing marked and unmarked members, possibly in a hierarchical structure. This asymmetry is very clear in Table 1 where only one of the two forms opposed carries a positive semantic load which, thus, should be identified as the meaning of the affix. The unmarked member is the one without this specific semantic load, in other words, it is semantically "neutral" in relation to the "quantification" frame.

We have developed this point in some detail because the concept of markedness has been used in more than one sense in the literature. In Section 9 we shall return to the question of markedness and give an overview of the relevant specifications of this concept.

Throughout this presentation we shall pursue the view sketched above on the core of grammaticality and grammaticalisation as based on paradigmatisation, and we shall develop this concept in relation not only to morphology, but also to word order (topology) and syntax (constructions).

Not all grammaticalised paradigmatic oppositions will conform to the strict paradigm as exemplified in Table 1. There are language elements exhibiting the kind of obligatoriness and predictability of use characteristic of paradigmatically organised grammatical markers, though they cannot in any reasonable way be analysed in terms of our format of a paradigm. Obvious examples are found among derivatives, i.e. morphemes systematically employed as category shifters, for instance suffixes formating nouns from verbal stems, adjectives from noun stems, adverbs from adjectival stems and so on. In accordance with tradition, we consider such elements grammatical. Consequently, the development of such elements should be considered instances of grammaticalisation.

We shall illustrate this difference by considering a simple, often cited example of a morphological affix developed from a lexical item: the adverbialising suffix -mente in Italian and its equivalents in other Romance languages (French -ment, etc.). This suffix goes back to the Latin noun mens in the ablative case, cf. (5)-(6) (examples from Maiden (2003:93)).

(5) Latin and Early Romance: adj. + mente (abl. of mens 'mind')
a. laet- $\bar{a} \quad$ ment-e
happy-ABL.SG mind-ABL.SG
'happily' (lit. 'with a happy mind')
b. laet- $\bar{a}$ et felic- $i$ ment-e
happy-ABL.SG and cheerful-ABL.SG mind-ABL.SG
'happily and cheerfully'




$$
\begin{array}{lll}
\text { c. laet- } \bar{a} & \text { can-it } & \text { ment-e } \\
\text { happy-ABL.SG } & \text { sing-PRs.3sG } & \text { mind-ABL.SG } \\
\text { 'he/she is singing happily' } &
\end{array}
$$

(6) Italian: adj. + suffix -mente lieta-mente 'happily'

In Early Romance the form mente was still a noun, and in (5a-c) it is the nucleus of a noun phrase with one or more attributive adjectives laeta and felici appearing in the feminine singular ablative by agreement. That it is a simple noun phrase is confirmed by the possibility of adding more attributes (5b) and treating the phrase as discontinuous $(5 \mathrm{c})$.

In Italian, on the other hand, we find a suffix -mente which may be added to an adjective to form an adverbial. This derivational pattern is a productive grammatical means of adverbial formation, cf. (7).
(7) lieta 'happy' lietamente 'happily' naturale 'natural' regolare 'regular' naturalmente 'naturally'
regolarmente 'regularly'

To clarify what it means to say that the words in the two columns belong to different categories, the focus should be on their basic grammatical status. The words in the left column are adjectives, i.e. modifiers of nouns. This function (modifying a noun) is encoded in the stem and will thus be dominant whenever there is no marker for an alternative function, as in the given case of the suffix -mente. With no such marker of category, the word will be used in a way corresponding to its lexical coding. The words in the right column are adverbs. This category-establishing function is encoded in the suffix, thus overruling the basic grammatical value of the stem.

This opposition is systematic and paradigmatic, but it does not form a paradigm in the sense illustrated in Table 1. The layout of a paradgim presupposes the existence of an identifiable semantic frame, but in the present case there is probably no such frame: There is no opposition between a zero element and the derivative -mente with a stable semantic contrast. We shall return to the status of zero elements elsewhere, but nevertheless stress here that zero elements cannot be postulated in paradigms unless they carry well-defined meaning.

The example given in (5)-(7) illustrates how a lexical item may develop into a morphological item. Following Andersen (2006a), we shall refer to a transition of this kind, from a lexical item to a grammatical morpheme, as a grammation process, or simply a grammation. Grammations are regularly occurring, but it should be acknowledged that they are also fairly rare phenomena. A language may undergo a number of morphological changes without any lexical material being reanalysed into grammatical morphemes. More often, a morphological or otherwise grammatical 
change takes the shape of a reanalysis of existing grammatical material, i.e. a transition from one grammatical status to another. Following Andersen (2006a) once more, we shall refer to a transition of this kind as a regrammation, cf. the following, also much discussed example (8).

(8) French: the development of the future tense form

$\begin{aligned} \text { Early Romance } & \text { canta-re habe-o } \\ & \text { sing-INF have-PRS-1SG } \\ & \text { 'I will sing' }\end{aligned}$

French chanter-ai

'I will sing'

Latin had a synthetic future with portmanteau desinences expressing person and number, cf. the first person singular canta-bo. In Early Romance a combination of the infinitive and a finite form of habere 'have', cf. cantare habeo, appeared. It must be assumed that this phrase arose as a combination of the lexical verb habere (in the appropriate finite form) with the infinitive with a pragmatically determined content (obligation or the like, Schwegler 1990: 126-127), and that habere only later was reanalysed as an auxiliary to form a periphrastic future tense form together with the infinitive. This transition was a grammation process, a reanalysis of the lexical verb habere into a grammatical word, an auxiliary, in the given context. There are two points to be emphasised in this connection.

First, that the phrase was reanalysed as a periphrastic future actually means that it entered the tense paradigm of the language at the given stage of development. In other words, its function was defined in opposition to those of other tense forms, synthetic and periphrastic. This point can even be sharpened: When the periphrastic form developed a usage as a future marker, this process would in itself call for a delimitation of its usage potential through semantic oppositions to other forms of the paradigm. That the tense system already contained a synthetic future cantabo does not invalidate this point. We shall return to a possible interpretation of the relation between the two futures in Section 9.2 below.

Second, the new function of habere is limited to the context when it combines with the infinitive. In other contexts the verb lived on as an independent lexical item.

The further development of the form from Early Romance to French - with parallels in other Romance languages, e.g. Italian canterò - leads to a new synthetic form with a desinence directly descended from the auxiliary. It involves a number of transitional stages, probably including transitions from auxiliary to verbal clitic and from verbal clitic to inflection. Ignoring the details, we can say that these transitions were all regrammations (rather than grammations), since they took the form of reanalyses of grammatical forms into other grammatical forms. It is worth noticing that a true structural change, here referred to as a reanalysis (see below), will involve a change of 
the paradigmatic relations of the form in question. It will take the shape either of the form entering a new paradigm or of a restructuring of the paradigm of which the form is a member. Restructuring took place when the segment in question was reanalysed as an inflection entering the paradigm of tense markers.

The widely discussed development sketched above has clear parallels in other languages, for instance Polish, cf. (9).

(9) Polish: perfect

$\begin{array}{ll}\text { Old Church Slavonic } & \text { pisa-l-a jesm̌̌ } \\ & \text { write-PTCP-F be-1sG } \\ & \text { 'I (woman) have written' } \\ \text { Polish } & \text { pisa-t-a-m } \\ & \text { write-PST-F-1sG } \\ & \text { 'I (woman) wrote/have written' }\end{array}$

As in the Romance example in (8), only the initial change, the transition of byti 'be' (1sg jesmi) from lexical verb to auxiliary, was a grammation. All the following changes, eventually leading to the modern form, were regrammations, i.e. changes from one grammatical status to another. In our perception the crucial point is not the distinction between grammation and regrammation, but rather the fact that all stages of development, grammations and regrammations, take the shape of paradigmatisations and thus involve more forms than those considered in the sketchy presentations (8)-(9). When, for instance, the former lexical verbs were reanalysed as auxiliaries, they came to play a role as a marker of paradigms at several levels, the paradigm of auxiliaries and, at a higher level, the paradigms of tense forms and finite forms in general. We shall return to the Polish example later to illustrate this point.

The few examples considered so far are sufficient to illustrate that grammaticalisation is not so much a question of transition from lexical to grammatical status. Rather it has to do with reorganisations of paradigms, accompanied by a redistribution of morphemes and constructions or simply a change of content. In the following we shall only use the term grammaticalisation as a broad term covering either the field of investigation or the phenomenon of grammatical development from an overall point of view. The individual structural changes will be referred to as grammations and regrammations, respectively.

2. Old Church Slavonic, the oldest Slavic written language (9th century), was actually a variety of the South Slavic language Old Bulgarian and thus not a pre-stage of the West Slavic language Polish. However, as regards the forms considered here, it is assumed to reflect prehistoric Common Slavic fairly closely. 


\section{Basic concepts}

At this point we shall briefly consider language change in more general terms and specify our understanding of a couple of fundamental concepts in addition to the already introduced grammaticalisation, grammation and regrammation. That a language change is a complex event has been emphasised by Andersen (2008:32):

The normal course of events through which a new expression originates, gains currency and becomes established as part of a tradition of speaking is the following: one or more speakers (i) make a (primary) innovation and (ii) actualize it in usage; other speakers (iii) adopt the new expression and (iv) actualize it in their usage; if the new expression is used widely and long enough, new cohorts of speakers (v) will acquire it as an integral part of their competence and (vi) actualize it in their usage; the new expression becomes generalized in the community through repeated cycles of (iii)-(vi). One can speak of such series of overlapping kinds of innovation as a 'change scenario' and of the constituent innovation types (i)-(vi) as 'subchanges'.

We have cited this description of a change scenario in extenso not only because it offers an excellent picture of the complexity of language change, but also because it allows us to introduce and consider a few more basic concepts. The citation makes clear, first, that changes originate in individual speakers' language behaviour and, second, that only innovations that are adopted by broad groups of speakers will be generalised to such an extent that we can speak of a change having taken place in the given language. The presumably numerous innovations that never get beyond the usage of a limited group of speakers, cf. (i)-(ii), are largely ignored by historical linguists.

As clearly appears from the citation, innovations must be made by individual speakers. This is so because language structure is part of the individual speaker's competence. Andersen (2008:32-33) lists four basic types of innovation: neologism, extension, adoption and reanalysis. Our focus is on reanalysis, i.e. a change in language structure, for instance in grammar, by abduction (Andersen 1973). Reanalyses are involved in subchanges (i), (iii) and (v) in the citation above, i.e. the events in which the grammar of one or more speakers undergoes a structural innovation. Only as consequences of such a series of reanalyses can the grammar of a language (la langue, i.e. as a collective phenomenon), be said to have undergone a change. Although it is true that language as a collective phenomenon is intangible, we shall stick to tradition and accept the formulation that a given language undergoes changes. Correspondingly, we define a reanalysis as a structural change that has passed through all of the subchanges (i), (iii) and (v) and has thus been generalised in the language in question. As this definition makes clear, grammations and regrammations are reanalyses.

A reanalysis is followed by an actualisation. As stated in the citation, subchanges (ii), (iv) and (vi), i.e. all subchanges following directly after reanalyses, are 
actualisations. An actualisation process is a spread in usage of a reanalysed expression element. As in the case of reanalysis, we will speak of actualisation in a generalised way as something affecting language as a collective phenomenon. Thus, in what follows the term actualisation will be used to refer to a change that has passed through all of the subchanges (ii), (iv) and (vi), i.e. the resulting stage where actualisations are manifested in language structure.

Works on language change and in particular on grammatical changes tend to ignore the difference between reanalysis and actualisation. We find this distinction essential to the understanding of grammaticalisation, and in the present volume we shall systematically distinguish between reanalysis (covering both grammation and regrammation) and actualisation.

\section{The cline of grammaticality: Deficiencies of the theory}

By now, readers familiar with the discussion on grammatical change will probably have associated the examples considered above with the so-called cline of grammaticality (Hopper \& Traugott 1993: 7; Heine \& Kuteva 2002; Heine 2003; Haspelmath 2004; Fisher, Norde \& Perridon (eds.) 2004). However, in our introduction to the topic we have downplayed this influential theory because of its narrow focus on what we take to be just one aspect of grammatical change. We motivate our view in this section.

We start with a short introduction to what we shall refer to as the cline theory. As mentioned in the previous section, it must be assumed that the verbal phrases considered in (8) and (9) arose as combinations of the lexical verbs habeo and jesmi (in the appropriate forms) with an infinite form (infinitive or participle), and that these verbs were later reanalysed as auxiliaries to form the periphrastic tense forms found in Early Romance and Common Slavic. In other words, these segments undergo the following sequence of changes, $\mathrm{cf} .(10)$.

(10) lexical verb $\rightarrow$ auxiliary $\rightarrow$ clitic $\rightarrow$ inflection

Within the framework of the cline theory, these will be taken as instances of 'movements down' the cline ${ }^{3}$ of grammaticality, cf. (11).

(11) Cline of grammaticality

content item $\rightarrow$ grammatical word $\rightarrow$ clitic $\rightarrow$ inflectional affix

3. The idea of a language element moving 'up' and, typically, 'down the cline' has even been reflected in the title of the anthology by Fischer, Norde and Perridon (eds)(2004). 
The movement of a segment down this cline is largely considered to be unidirectional (e.g. Haspelmath 2004) and accompanied by:
a. phonetic reduction ("erosion")
b. increased syntactic bonding
c. desemanticisation ("bleaching")
d. use in new contexts and increasing frequency ("extension")

Roughly the same generalisations are found in Heine and Kuteva (2002:2) and Heine (2003:578-79).

The cline of grammaticality may appear to be a reasonable generalisation of a number of different changes involving different parts of speech and a number of content categories. However, as a general model of grammaticalisation it has achieved its status on false premises. In the following we shall first consider the problems of the model and then suggest a plausible explanation for its general appeal (Section 5).

It appears already from a comparison with our earlier example (5)-(7) that the generalisations $(12 \mathrm{a}-\mathrm{d})$ do not generally hold true. The change from the case form mente to the suffix -mente does not involve any phonetic reduction. The segment merely undergoes the phonetic modifications predicted by general sound changes having taken place in Italian. Thus, the change from lexical to grammatical status does not trigger any phonetic reduction by itself.

More fundamentally, as pointed out by Andersen (2006a:232), the mechanisms (12a-d) supposedly characterising each transition as a complex can occur individually as well, a fact also confirmed by our introductory example. Correspondingly, they should be studied individually as different kinds of transition. In our conception, for a segment to be grammatical it must be a sign, possibly a complex sign, forming a paradigm with one or more segments to which it is opposed. Likewise, a (re)grammation involves a reorganisation of paradigm(s). The changes (12a-d) may involve paradigm reorganisations, but they do not necessarily do so.

The cline-based approach to grammaticalisation has also been questioned by Joseph (2003), who emphasises that morphology has more than one source. Morphological distinctions can arise as a result both of the development of syntactic structures and of processes originally affecting the sound system alone (sound laws). While syntax as a source of morphology is covered by the cline (and actually constitutes the essence of the cline), the phonetic source is ignored by this tradition. Joseph and Janda (1988:197) point to a number of well-known developments (Germanic umlaut, reduplication in Sanskrit, consonant mutations in Celtic, accent shifts in Modern Greek), arising as pure sound laws, but eventually providing the material for morphologically conditioned distinctions. Wurzel (1980) describes three such cases: the morphologisation of the Old High German umlaut rule with the masculine 
$i$-declension is one of the examples, cf. the two stages of development illustrated in (13) (Wurzel 1980:448-51).

A.

$\begin{array}{lll} & \text { SG } & \text { PL } \\ \text { Nom } & \text { gast 'guest' } & \text { gesti } \\ \text { Gen } & \text { gastes } & \text { gestio } \\ \text { Dat } & \text { gaste } & \text { gestim } \\ \text { Acc } & \text { gast } & \text { gesti } \\ \text { Inst } & \text { gestiu } & - \\ & \text { SG } & \text { PL } \\ \text { Nom } & \text { gast } & \text { gesti } \\ \text { Gen } & \text { gastes } & \text { gestio } \\ \text { Dat } & \text { gaste } & \text { gestim } \\ \text { Acc } & \text { gast } & \text { gesti } \\ \text { Inst } & \text { gastiu } & -\end{array}$

At the early Old High German language stage (A), we find the original, phonetically determined distribution of the root vowels $-a$ - (non-umlauted) and $-e$ - (umlauted). The umlaut form $-e$ - is the variant that appears when the vowel is followed by one or more consonants plus [i] or [j].

At the following stage of development (B), the umlauted form of the instrumental singular has been replaced by the non-umlauted form. This is undoubtedly a case of morphological levelling linking the non-umlauted root to the singular and the umlauted to the plural. The distribution of the two root variants is now morphologically determined. The umlaut/non-umlaut distinction has been reanalysed as part of the expression system of a grammatical paradigm, cf. (14).

(14) Domain: masc. $i$-stems (later broader subcategory of nouns)

Frame: number

$\begin{array}{ll}\text { Expression } & \text { Content } \\ \text { non-umlaut } & \text { singular } \\ \text { umlaut } & \text { plural }\end{array}$

There are three important points to be made in this connection. First, the reanalysis establishing the paradigm (14) could only take place after the sound law, responsible for the distribution of umlauted and non-umlauted forms at language state (A), had ceased to operate. When the sound law was no longer in operation, the resulting form distinctions were open to reanalysis. Second, the paradigm (14) has a limited domain. It does not concern the distribution of umlauted and non-umlauted forms in general, but applies only within the domain of the masculine $i$-declension. Third, the number marking of the paradigm (14) is redundant, since the relevant nouns have portmanteau desinences unequivocally signalling number. However, redundancy is a 
widespread phenomenon in morphology, and this fact does not weaken the argument. With the desinence being the primary marker of number, the umlaut distinction is indexical rather than symbolic (cf. Andersen 1980).

In addition to examples of the kind considered above, cases of resegmentation can serve as an example of phonetic material being reanalysed as part of a grammatical marker. Old Russian had a handful of productive verbal suffixes with the function of deriving procedural verbs (Aktionsarten) and possibly other forms with an aspectual meaning. One of them was $-v a$ - as in da-ti 'give' $>d a-v a-t i$. A new suffix -ivaappeared in the 11th century, and in the following centuries it was to gain ground at the expense of the other suffixes (Nørgård-Sørensen 2006:301-302). It is assumed that the suffix -iva- is the result of a resegmentation of the relatively numerous verbs with a stem final $-i$ - in combination with the older suffix -va- (Kuznecov 1953:262; Silina 1987: 198) cf. (15). ${ }^{4}$

$$
\begin{aligned}
& \text { po-bi-ti 'beat' }>\text { po-bi-va-ti } \rightarrow \text { po-b-iva-ti } \\
& z a-l i-t i \text { 'pour (over)' }>z a-l i-v a-t i \rightarrow z a-l-i v a-t i
\end{aligned}
$$

The segment $-i-$, which used to be a part of the stem with no independent morphematic status, changed into a part of a grammatical suffix. The example is far from unique. A similar kind of resegmentation can be observed in the development of the agglutinative morphology of Danish nouns. We shall consider the morphology of Danish nouns later in the present chapter (Section 7).

In the present context we shall not go into the phonological and other details of this case of resegmentation. They will be considered in Chapter 5. However, the sketchy presentation above is sufficient to allow a comment on paradigm establishment. Once having been established by resegmentation, the suffix -iva- was introduced into other verb classes, i.e. verbs with stem finals other than - $i-$-, especially - $a$ - and exceptionally - $e-$, cf. the Modern Russian derivatives in (16b-c).

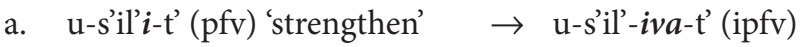
b. ras-str'el' $a$-t' (pfv) 'shoot' $\rightarrow$ ras-str'el'-iva-t' (ipfv)
c. vy-zdorov' $\boldsymbol{e}$-t' (pfv) 'recover' $\rightarrow$ vy-zdoravl'-iva-t' $(\mathrm{ipfv})$

The suffix also appears where the derivational source does not contain any thematic vowel, cf. (16d).

4. ">" marks a derivation; “ $\rightarrow$ " a reanalysis, in the given case taking the shape of a resegmentation.

5. In addition to the deletion of the stem final vowel, this derivation is also marked by two stem alternations: $o \rightarrow a$ and $v^{\prime} \rightarrow v l$. They are not relevant to our points and will not be considered in the present context. 


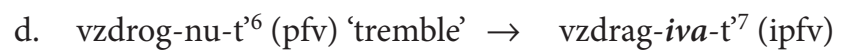

This correlation can be accounted for in terms of a morpho-phonological rule of vowel deletion. If the stem of the derivational source (in $(16 \mathrm{a}-\mathrm{c})$ the perfective verbs in the left column) is taken to be the basic stem of the verbs, the rule can be formulated as follows: When two vowels become adjacent across a stem-desinence boundary, one must be deleted, cf. $(17 \mathrm{a}-\mathrm{c})$, illustrating the formation of the iva-verbs from a synchronic point of view.
a. u-s'il'i-iva-t'
$\rightarrow \quad \mathrm{u}-\mathrm{s}^{\prime} \mathrm{il}-\mathrm{i} v a-\mathrm{t}^{\prime}$

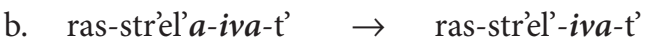
c. vy-zdorov'e-iva-t' $\rightarrow$ vy-zdoravl'-iva-t'

The examples considered reflect the fact that a paradigm of the form specified in Table 2 was established sometime during the 12 th century:

Table 2. Old Russian: the distinction iterative vs. non-iterative

Domain: V

Frame: iterativity

\begin{tabular}{ll}
\hline Expression & Content \\
\hline$-\varnothing-$ & non-iterative \\
$-i v a-$ & iterative \\
\hline
\end{tabular}

Once introduced, this paradigm was open to semantic reinterpretation. Probably around 1400 it was reanalysed as a marker of aspect in connection with a multi-faceted structural change establishing, among other things, the aspectual system known from Modern Russian (Chapter 5 and Nørgård-Sørensen 2006:300-303), cf. Table 3.

Table 3. Modern Russian: verbal aspect

Domain: V

Frame: verbal aspect

\begin{tabular}{ll}
\hline Expression & Content \\
\hline$-\varnothing-$ & perfective \\
$-i v a-$ & imperfective \\
\hline
\end{tabular}

Correspondingly, in the Modern Russian examples (17a-d) we have used “(pfv)” and "(ipfv)" for perfective and imperfective aspect.

6. $-n u$-is a perfectivizing suffix, not appearing in the imperfective verb.

7. The vowel alternation $o \rightarrow a$ in the root can be ignored in this context. 
Note that this reanalysis is purely semantic. It is not accompanied by any change of expression. Thus, the prediction of the cline theory - that grammatical change should be marked by a change of expression - proves to be incorrect. All that happens in the change scenario presented here is that the two members of the paradigm come to signal a different distinction of content. This regrammation is linked neither to phonetic reduction (or even phonetic change) nor to increased bonding. One could possibly speak of desemanticisation (bleaching) and extension of the contexts evoking the iva-form, but the main point is that this form occurs with a different content and correspondingly in other syntagmatic contexts. The reanalysis cannot be identified at the level of expression, but only through an analysis of language usage. It is especially revealing to follow the actualisation process showing that within a relatively short period of time the suffix -iva-became the basic means of deriving imperfective verbs from perfective verbs, cf. Chapter 5 .

There is another interesting thing about this example that has an impact on the theory of grammaticalisation. The reanalysis of the paradigm in Table 2 as the one illustrated in Table 3 involves a shift of markedness. In the former system the -ivaform was marked whereas the zero form is marked in the latter. The general point to make is that markedness establishment is inherently involved in any (re)grammation, a point following from the fact that grammatical oppositions are asymmetric. Further, the stages of development do not appear to be accidental. When it first appeared (through resegmentation), the suffix -iva- was marked and entered a simple paradigm where it was opposed to its own absence (zero). This relation of expression and content was replaced by a system where the zero form became marked, i.e. carrying a specific semantic load ('perfective aspect'), opposed to the now unmarked -iva- form ('imperfective aspect').

The remarks on paradigm establishment in connection with (16)-(17) and Tables 2 and 3, are not trivial but illustrate two general points. First, new grammatical items, whether formed by means of resegmentation or otherwise, do not appear out of the blue. They are born as members of paradigms, i.e. as system elements. Second, once established, a paradigm may undergo a semantic reanalysis without any change of the forms involved. Thus, purely semantic reanalysis can only be revealed through an analysis of usage.

Cases like the one described in this section where morphological items are formed in part or in full from simple sound material, are not predicted by the cline approach to grammaticalisation. But there is another, more general problem with this approach. A one-sided focus on the cline of grammaticality as a reflection of a prototypical grammatical change tends to limit the notion of grammar to a question of morphology alone. But grammar - and thus grammaticality and grammaticalisation is much more than morphology. It also includes word order patterns (Chapter 6 and Heltoft 1996: 474-76), constructions (Chapter 7) and prosodic patterns. In the 
present volume we claim that word order patterns and constructions may be organised in paradigms in much the same way as morphological items.

\section{Morphological change}

Keeping in mind that grammar and grammaticalisation involve not just morphology and that it is thus misleading to identify grammaticalisation with the cline, we shall now return to considering morphological change in general terms. The crucial point about morphological change is not the immediate origin of the affixes: lexical, morphological or phonological. As in the case of any other type of grammatical change, one should proceed from the paradigms the items in question enter - before and after the change. In other words, to grasp a presumed reanalysis of a morphological item one must analyse the grammatical system before and after the reanalysis in order to reveal the paradigmatic relations of the item in question at each of the two stages. To illustrate this point, let us return to the Polish past tense forms presented in (9), cf. (18).

a. Tense in Old Church Slavonic (reflecting Common Slavic)

(1sg and, where relevant, masculine)

\begin{tabular}{|c|c|}
\hline Present & $p i \check{s}-Q$ \\
\hline Aorist & pisa-xц̆ \\
\hline Imperfect & pisa-axŭ \\
\hline Perfect & pisa-l-ŭ jesmi \\
\hline Pluperfect I & pisa-l-ŭ běx \\
\hline Pluperfect I & pisa-l-ц̌ běaxü \\
\hline
\end{tabular}

b. Tense in Modern Polish

$\begin{array}{ll}\text { Present } & \text { pisz-ę } \\ \text { Preterite } & \text { pisa-t-e-m } \\ \text { Future (imperfective verbs) } & \text { będę pisa-t/będę pisa-ć }\end{array}$

The Common Slavic paradigm is somewhat simplified in this presentation; for instance, possible periphrastic future forms have been excluded. We shall refrain from a detailed analysis of the two paradigms and concentrate on the impact they have on a description of the transition presented in (9) from the Common Slavic perfect to the Polish preterite. In Common Slavic the perfect is a member of a fairly complicated tense paradigm consisting of both simple and periphrastic forms. All periphrastic forms are formed by combining an active participle containing the formant $-l$ - (the so-called $l$-participle) with a form of the verb byti 'be'.

The paradigm is open to several subdivisions. The most obvious one is the division into two distinct subparadigms: simple and periphrastic forms, cf. (18c). 
c. Simple forms

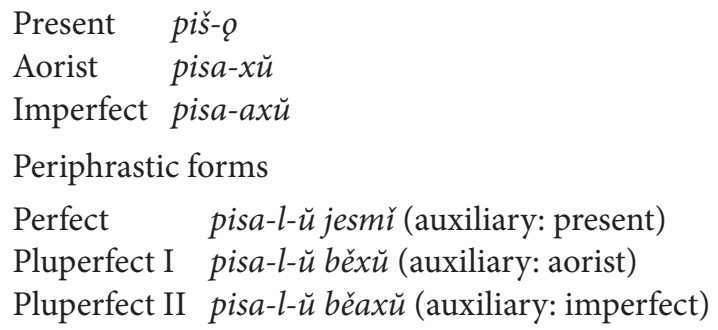

There is a formally marked correspondence between the three periphrastic tense forms (the perfect and the two pluperfects) on the one hand and the simple forms on the other. The periphrastic forms contain auxiliaries in the three simple forms: the present, the aorist and the imperfect. In other words, the three periphrastic forms mirror the three simple forms. This formal correspondence would be expected to signal a distinction of content. One should proceed from a functional analysis of each individual form in order to attain a full and adequate description of the content side of the subparadigm. Such a functional analysis would presumably support the traditional interpretation of the three periphrastic tense forms as conveying relational tense meanings in a one-to-one correspondence to the non-relational meanings of the three simple tenses (perfect - with the auxiliary in the present tense - being the relational counterpart to the present, etc.), cf. Prokopova (1991:48), Andersen (1987:23-24).

This sketchy presentation is sufficient to illustrate our point: it is only possible to identify the Common Slavic perfect as a past tense with relational meaning signalled by its periphrastic structure (as opposed to the simple present tense) through a detailed analysis of its paradigmatic relations. Likewise, the very different general past tense meaning of the corresponding form in Modern Polish can only be detected in the light of the Modern Polish tense paradigm. We can now compare this paradigmatic approach with the cline approach referred to above in connection with (10)-(12). The cline approach allows us to state that a lexical verb has developed into an auxiliary and, in Modern Polish, into a clitic, presumably in the process of becoming a desinence. ${ }^{8}$ On the basis of generalisations of changes in many languages, it further helps us to

8. Modern Polish person/number markers like $-m$ in pisa- $t$ - $a$ - $m$ etc. (cf. 17b) are actually clitics, capable of occupying two positions as attached either to the verb or the first member of the clause (Wackernagel), cf. from Szober (1963:270):

Książkę pisała-m 'I (woman) wrote a book'

Książkę-m pisała

These person/number markers tend to become more and more closely attached to the verb and may be on their way to becoming desinences, cf. Andersen (1987:29-34). However, the present status of the person/number markers is not essential to our argument. 
see that the phonetic erosion and increased bonding observed in connection with the development are frequent, though not necessary, concomitant phenomena of morphological change. However, though normally accompanied by remarks on semantic generalisation, expositions of the cline approach do not fully clarify the functional and semantic essence of the change. In order to describe the semantic change, synchronic analyses of the form, including its paradigmatic relationships, must be taken as a point of departure at different (at least two) stages of development. This is the only way to reveal that the form in question has developed from a relational past tense form in a complicated tense structure to the sole past tense in a drastically simplified system.

Let us sum up what has been said in relation to Modern Polish. We recall that the cline approach to the Polish preterite pisa- $-e-m$ would be limited to a statement about the former auxiliary jesmř changing into a clitic, marking person and number. This change can be established as involving phonetic reduction, desemanticisation as well as increased bonding and frequency, and would be considered an excellent illustration of the explanatory force of the cline model. However, a description along these lines fails to grasp the most crucial part of the change. The paradigm approach reveals that the number of tense forms has been drastically reduced. In Modern Polish there is only one periphrastic tense form, the future. That this form is an innovation in historical time is known from the sources, but it also appears indirectly from its form: unlike the Common Slavic periphrastic forms, the Modern Polish future may be formed both on the basis of the "l-form" (the former participle) and the infinitive. Further, the future is functionally restricted, appearing only with imperfective verbs. This indicates that the future takes the maximally marked position in the tense system, allowing us to set up a complex tense paradigm like the one in Table 4 for Modern Polish.

Table 4. Modern Polish tense

Domain: Verb

Frame: Tense

\begin{tabular}{lll}
\hline Expression & Content & Markedness \\
\hline piszę, etc. & $\begin{array}{l}\text { present } \\
\text { non-present }\end{array}$ & $\begin{array}{l}\text { unmarked } \\
\text { marked }\end{array}$ \\
\hline & & \\
\hline Domain: Verb & & \\
Frame: Non-present tense & Content & Markedness \\
\hline Expression & past & unmarked \\
\hline pisa-t-em, etc. & future & marked \\
będępisa- - $/$ pisa-ć, etc. & r
\end{tabular}

There are no traces, either in expression or in content, of the distinction between relational and non-relational forms. On this background, it is not surprising that the auxiliaries signalling this distinction have been lost (together with the periphrastic 
forms), and that their segmental remains have been reanalysed as something different (person-number markers). Likewise, the participial marker $-l$ - has been reinterpreted as a marker of non-present.

The transition from the Common Slavic to the Modern Polish tense system is a complicated process involving a number of intermediate stages, some of which are reflected in the sources while others must be reconstructed. However, the material presented will suffice to demonstrate our point. A reliable description of the content of a form at a given historical stage of development presupposes a thorough analysis of the paradigms the form enters. The essence of the change from the Common Slavic perfect to the Polish preterite is the semantic shift from a highly specified tense form to a general past tense form. As we have seen, this change must involve parallel and connected semantic reinterpretations of all other forms in the paradigm. We claim that this case is an illustration of a universal principle: a reanalysis of a grammatical form is actually part of a reanalysis of the underlying paradigm.

\section{The cline revisited}

As mentioned above (Section 3), a fundamental problem with the cline of grammaticality is that the generalisations it involves do not seem to hold. Even in a standard example like (5)-(7), the transition from the Latin ablative mente to the Italian adverbial suffix -mente, does not in itself seem to involve any phonetic reduction. The form merely undergoes regular sound changes. Neither does it make sense to describe the shift in content as bleaching. More precisely, the segment mente has lost its lexical meaning and obtained the grammatical content of modifying a verb or an adjective, cf. (6)-(7). Moreover, it probably did so as a carry-over of the original inflexional content of the ablative case to the now unanalysable segment mente. Finally, it is highly questionable whether anything sensible can be said about the relative frequency of the two forms.

This leaves us with increasing bonding as the only feature consistently characterising the movement of a segment "down the cline". The alleged cline of grammaticality should rather be considered a simple bonding cline. An interpretation along these lines will throw light on both the applicability of the cline model to a number of different morphological changes and its failure as a general model of grammaticalisation and even of morphologisation. The main problem is that the cline model implies an understanding of grammaticality as a continuum, a question of more or less. In studies based on the cline it is customary to speak of linguistic items being more or less grammatical, e.g. Lehmann's (1985:203) definition of grammaticalisation: "Under the diachronic aspect, grammaticalization is a process which turns 
lexemes into grammatical formatives and makes grammatical formatives still more grammatical". However, no one - to our knowledge - has attempted to specify what it means to be more or less grammatical. There seems to be a consensus that the degree of grammaticality is directly proportional to the position of the item in question on the cline, in which case the whole idea of 'more' and 'less' grammatical rests on a circular definition.

If one follows the idea we have advocated here: that the grammatical system consists of (largely intersecting) paradigms - it would hardly make sense to speak of various degrees of grammaticality. A segment may be more or less bound, and its degree of bonding can be tested by the use of well-established criteria (notably its ability to hold various syntagmatic positions). But any segment, whether bound or unbound, that enters a grammatical paradigm is part of the grammatical system. What is the background for claiming that, for instance, an auxiliary is less grammatical than a verbal inflection? As we have seen, they may enter one and the same tense paradigm, at least as parts of distinct subparadigms. For a description of the grammatical system both are equally essential. The idea of more and less grammatical further leads to the fairly absurd conclusion that so-called analytic languages, i.e. languages with a morphology dominated by periphrastic forms, are less grammatical than synthetic languages.

Even critics of the cline approach seem to tacitly accept the idea of different degrees of grammaticality, cf. “(...) there is no necessary correlation between an item's place on the cline and its degree of grammatical involvement" (Joseph 2003:475, our italics). We would go a step further and claim that there is no way of measuring the degree of grammatical involvement - or grammaticality. Grammatical involvement is not a question of degree. If a linguistic form, whether a segment, an intonational pattern, a word order pattern or a construction, fulfils a role in the grammatical system, it is grammatical - otherwise it is not. One cannot ignore an element of a grammatical system without the description becoming incoherent. In the Common Slavic tense system presented in (18a), the periphrastic forms are no less grammatical than the simple forms. All elements are equally essential for a full comprehension of the grammatical system.

The above considerations should not be taken as a rejection of the relevance of the idea behind the cline. The cline of grammaticality reflects essential generalisations about the development of morphological systems, namely (a) that a grammatical word, for instance an auxiliary, may come from a lexical word, (b) that a clitic may come from a grammatical word, and (c) that an inflection may come from a clitic. These statements can be thought of as essential elements of a theory of how grammatical systems, especially morphological form systems, develop. Thus, they may serve as the background for reconstructing grammatical changes in languages for which we only have modern data. In the following section we take a closer look 
at words, clitics and inflections, key concepts in the specification of morphology and morphological change.

\section{Words and clitics}

Morphology has been defined as "the branch of grammar that deals with the internal structure of words" (Matthews 1993 [1974]:9). To become fully operational this definition calls for a specification of several concepts, first and foremost an answer to the question: What is a word?

We shall refrain from reviewing the discussion of this question; for a historical account of the discussion of the morphology-syntax distinction, see Matthews 206-22.

There is hardly any uniform definition of the concept of a word that is fully applicable to all languages. Nevertheless, this theoretical vagueness seldom causes problems in relation to analyses of particular languages or language groups, for instance: Germanic, Romance and Slavic, the languages in focus in this book. There is evidence that the word fulfils a basic role as the unit filling the slots of syntactic structures. We shall assume that the word has mental reality for the speakers, both as a system unit, i.e. a lexeme with a set of inflectional forms, and as a discourse unit, i.e. a word form with a specific set of morpho-syntactic properties.

The question of how to define a word has to do with the distinction between morphology and syntax - a much debated distinction, the relevance of which is not even recognised by all linguists. With regard to grammaticalisation studies, the distinction is closely related to the transition from clitic to inflection. Later, in Chapter 2, Section 6, we introduce an extended concept of clisis, but in the present section we focus exclusively on the type of clitic considered in traditional presentations, since it is those that potentially become fixed to a word stem and thus converted into inflections. When a clitic, a syntactic unit, converts into an inflection, it becomes a constituent part of a word and thus a morphological unit, cf. the examples considered above in (8)-(9). We claim that an inflection differs from a clitic in being an inseparable part of a word. It cannot move around in the clause and it cannot be removed without leaving the word incomplete. A clitic, on the other hand, may be removed without leaving its host incomplete and, in many languages, it may take more than one position in the clause, thus preserving some of the mobility characteristic of individual word. However, as we shall see in the more extensive discussion in Chapter 2, Section 6, a clitic is prosodically reduced and thus needs a host with which it forms a prosodic unit. In a number of languages, including Bosnian/Croatian/Serbian, there are strict rules for the order of clitics when they occur in a cluster (Browne 1993:345), and many clitics may only occur in two positions, for instance, the Russian hypothetical marker by which appears 
either in second position (preserving its original Wackernagel position), cf. (19a) or attached to the constituent (often the verb) it modifies, cf. (19b).
a. Esli by Aleksandr priše-l,...
if IRR Alexander come-PST
'if Alexander had come,...'
b. Esli Aleksandr prišel by,...
c. * esli Aleksandr by prišel,...

The distinction between a clitic and an inflection is, however, not always clear-cut. In Portuguese we find clitics of the kind illustrated in (20b).
a. dar-ei
give-FUT.1SG
'I will give'
b. dar=te-ei um livro
give=you.DAT-FUT.1SG INDEF book
'I will give you a book'

The segment - $e i$ is a portmanteau morpheme coding tense (future), person and number. It can only be attached to a stem of a specific category (in casu a verbal stem); in other words it is an inflection. However, if a clitic pronoun is added to the future it is placed between the verb stem and the future marker, cf. the dative marker te in (20b). In a position like this the clitic pronoun is traditionally referred to as mesoclitic, that is, something that is put in between. The idea behind this term would seem to be that the future marker as an inflection is part of the word, and that the pronoun forces its way in between the morphemes making up the word.

Hock (2003:450) proposes an alternative interpretation of the parallel structure in Old Spanish. He considers examples (21ab) and takes both the pronoun and the future tense marker to be clitics; we render our own analysis:
a. veer-he
see-FUT.1SG
'I will see'
b. veer-lo-he see=it.ACC-FUT.1sG
'I will see it'

Examples of this kind seem to cause problems for the distinction between clitics and inflections and thus for the delimitation of morphology and syntax. However, these are problems of how to deal with various types and degrees of bonding. The morphosyntactic status of the individual grammatical markers is not of any crucial importance for an understanding of the grammatical system as a network of paradigms. What is essen- 
tial is to identify the morphemes as members of paradigms, and describe the relations between them. In (20) and (21) the grammatical segments considered will be members of tense paradigms and pronominal paradigms respectively. As already emphasised, paradigms consist of signs and thus represent oppositions of content. (Re)grammations are paradigm restructurings, and as such they inevitably involve changes of content.

Cliticisations are considered grammaticalisation phenomena - in historical linguistics apparently without exception, the cline theory being a prominent example. Nevertheless, for a cliticisation to be a grammaticalisation it must be accompanied by a change of content. By definition, cliticisations are changes of expression syntax, and many cliticisations are undoubtedly accompanied by semantic changes as well and will thus qualify as (re) grammations. However, to answer the question if a given cliticisation is a grammaticalisation an empirical investigation of the case is necessary. There is, for instance, no evidence that the transition of the Russian by from auxiliary to verbal particle, which was clearly a grammaticalisation, coincided with this form undergoing cliticisation from auxiliary to particle (see further Chapter 2, Section 6.2). To our knowledge this question has never been investigated, but it seems highly probable that the cliticisation of the form by took place already when it was an auxiliary, i.e. an inflected form, and thus did not coincide with its transition to an uninflected particle.

The same is true about the transition from clitic to inflection, which by itself is also merely a change of expression. We have seen that in Modern Polish the person-number markers are clitics, cf. (22).

$$
\begin{aligned}
& \text { a. my pisa-l-i-śmy } \\
& \text { we write-PST-PL.VIRIL }=1 \text { PL } \\
& \text { 'we wrote' } \\
& \text { b. my-śmy pisa-l-i }
\end{aligned}
$$

Investigations of Modern Polish (cf. Andersen 1987:29-30, 1990:3-7) have shown an ongoing tendency to favour affixation of the person-number markers to the verb as in (22a). It is reasonable to interpret this tendency as reflecting a transition of the person-number markers from clitic to inflectional status. It is, however, worth noticing that this increase of degree of bonding does not seem to be accompanied by any semantic change. The person-number marking function of the morphemes in question is stable and not in any way influenced by their status as clitics or inflections. In other words, this movement 'down the cline' - from clitic to inflection - does not qualify as a grammation.

In our understanding, a language constitutes a phonological system and a system of interwoven lexical, morphological, syntactic and prosodic structures expressing semantic structures, i.e. structures of content elements. It follows that the content and function of a linguistic unit depends on its systemic relations to other linguistic units. A description must proceed from (a part of) the system and not from the individual linguistic unit in isolation. A narrow focus on the individual linguistic unit involves 
the risk of ignoring decisive features of both its synchronic status and its historical development. We have already illustrated this point in connection with examples above. In the following we provide further arguments through a consideration of some other fundamental concepts of grammar.

\section{The grammatical system}

The discussion above calls for a specification of grammatical system and grammaticality. In our understanding a key concept is the paradigm, more specifically, the grammatical paradigm. As appears from the above discussion, a grammatical paradigm is in principle closed, the number of members being fixed and relatively restricted. It is homogeneous in that it is made up of linguistic forms capable of reflecting one or more content distinctions. Content distinctions, signalled by the forms of a grammatical paradigm, are relatively abstract as compared to the generally more concrete content of lexical units.

In morphology the idea of system has been associated with the inflectional paradigm. Inflection offers particularly transparent examples of paradigms with the members consisting of two clearly demarcated elements, a constant (the stem) and a variable (the desinence). However, the inflectional paradigm of traditional grammar description tends to reflect the system fairly superficially, if not wrongly. In traditional grammar description a paradigm has often been interpreted as the full set of inflectional forms of a given lexeme. We shall consider the implications of this interpretation on the background of two types of morphological systems, fusional and agglutinating.

The first example concerns Slavic noun declension. Both in the oldest attested varieties of Slavic and in most modern Slavic languages ${ }^{9}$ the case system closely resembles that of Proto-Indoeuropean. There are at least six cases: nominative, accusative, genitive, dative, instrumental and locative, ${ }^{10} \mathrm{cf}$. the slightly simplified chart of Modern Russian noun declension in Table 5.

As can be seen, Russian noun desinences are typical portmanteau morphemes, i.e. grammatical markers coding more than one grammatical value. All desinences in Table 5 unequivocally express both a number value and a case value. In the plural and in the 1st declension masculine singular the desinences also express a special kind of gender, viz. animacy (animate/inanimate), a fact to which we return shortly. It is characteristic of fusional morphology that since the grammatical markers code at least two values, these may only be expressed in symbiosis. It is not possible to isolate an expression element exclusively coding only one of them, cf. (23).

9. The only exceptions are Bulgarian and Macedonian which lost their case systems.

10. Most Slavic languages also have a vocative. 
Table 5. Modern Russian noun declension

\begin{tabular}{|c|c|c|c|c|c|}
\hline \multirow[t]{3}{*}{ Singular: } & \multicolumn{3}{|c|}{ 1st declension } & \multirow{3}{*}{$\frac{\text { 2nd declension }}{\text { Fem, masc }}$} & \multirow{3}{*}{$\frac{3 \text { rd declension }}{\text { Fem (masc, neut) }}$} \\
\hline & \multicolumn{2}{|c|}{ Masc } & \multirow[t]{2}{*}{ Neut } & & \\
\hline & Animate & Inanimate & & & \\
\hline Nom & \multicolumn{2}{|c|}{$-\varnothing$} & -0 & $-a$ & $-\varnothing$ \\
\hline Acc & $-a$ & $-\varnothing$ & $-o$ & $-u$ & $-\varnothing$ \\
\hline Gen & \multicolumn{2}{|c|}{$-a$} & & $-i$ & $-i$ \\
\hline Dat & \multicolumn{2}{|c|}{$-u$} & & $-e$ & $-i$ \\
\hline Inst & \multicolumn{2}{|c|}{-om } & & $-o j$ & $-j u(-o m)$ \\
\hline Loc & \multicolumn{2}{|c|}{$-e$} & & $-e$ & $-i$ \\
\hline
\end{tabular}

\begin{tabular}{lcc}
\hline Plural: & Animate & Inanimate \\
\hline Nom & $-\boldsymbol{i},-\boldsymbol{a},-e^{13}$ & \\
Acc & $-\boldsymbol{o v} \sim-\boldsymbol{e j},-\varnothing$ & $-i,-a$ \\
Gen & $-\boldsymbol{o} \boldsymbol{v} \sim-\boldsymbol{e} j^{14},-\varnothing$ & \\
Dat & $-a m$ & \\
Inst & $-a m^{\prime} i$ \\
Loc & $-a x$ \\
\hline
\end{tabular}

(23) Noun in a syntactic position triggering the accusative

$\begin{array}{rll}\text { Animacy } & \text { Number } & \text { Case } \\ \text { animate } & \text { singular } & \text { nominative } \\ \text { inanimate } & \text { plural } & \text { accusative } \\ & & \begin{array}{l}\text { genitive } \\ \text { dative }\end{array} \\ & & \text { instrumental } \\ & & \text { locative }\end{array}$

11. Of the three nominative plural desinences only two, $-i$ and $-a$, are inherited as accusative plural desinences of inanimate nouns. The reason is that $-e$ is only employed with animate nouns, more specifically with a subcategory of person-denoting nouns.

12. The symbol " $\sim$ "indicates complementary distribution: noun stems in a palatalised ("soft") or palatal consonant (except for -j-) take -ej; others take -ov (Švedova (ed.) 1980,I: 498-99). Thus, the desinences -ov and -ej should be considered allomorphs of one and the same inflectional morpheme. 
Though necessarily linked, the three grammatical values can easily be distinguished. Animacy is lexically coded, in other words it is a grammatical value inherent in the noun stem (and thus, incidentally, a gender). The desinence $-i$ functions as an index of the animacy value. Number, on the other hand, is referential, reflecting quantitative features of the (real or imagined) referent. Finally, case is closely linked to the syntactic construction.

As has been shown, the three grammatical categories are coded at different levels; in Hjelmslev's terms, they have different commutation conditions. Thus, although the two or more grammatical values in a fusional morphological system cannot be distinguished at the level of expression, they are clearly differentiated with respect to function.

Nevertheless, in a somewhat simplified formulation, a chart like Table 5, including the full list of desinences for the given part of speech (here the noun), is traditionally simply labelled a paradigm. However, in addition to the case and number values that are coded by all forms of the Russian noun, there are a number of subparadigms hidden in the inflectional system. We shall now briefly consider some of them.

First, the introductory example of this chapter on the Modern Russian genitive singular opposition $-a /-u$ is an instance of a subparadigm within the complex paradigm of Modern Russian noun inflection. The distinction is restricted not only to a specific case, but also to a specific gender (masculine) and a semantic subclass (mass nouns), cf. the domain specification in Table 1.

Second, a description of the Russian noun paradigm further involves an examination of the nominative-genitive and accusative-genitive distinction, expressing existence/ non-existence. Since these distinctions are restricted to specific constructions, they will be dealt with in the chapter on construction paradigms (Chapter 3, Section 2.5).

Third, the most prominent subparadigm of Modern Russian noun inflection has to do with animacy. In the 1st declension masculine and in all plurals, the form of the accusative depends on the lexical meaning of the noun: animate nouns, i.e. nouns denoting living beings, take an accusative identical to the genitive, while inanimate nouns take an accusative identical to the nominative. This system of syncretism appears from the following excerpt from the presentation of the Russian noun declension in Table 5, cf. Table 6.

The development of this system will be considered in Chapter 5. In the present context it suffices to point out that Modern Russian has a subparadigm, reflecting the animacy/inanimacy distinction, within the accusative.

This subparadigm was established in historical time, presumably around 1400 (Nørgård-Sørensen 2006:293, cf. also Krys'ko 1994:103-26), by a reanalysis of what was earlier a variation between the accusative and the genitive in first-complement position, cf. Chapter 5. The animacy/inanimacy distinction is actually a gender category, in other words a distinction between two classes of noun lexemes that has been grammaticalised in Russian. 
Table 6. Modern Russian noun declension. Animacy-marking syncretism

Singular, 1st declension, masculine:

\begin{tabular}{lcc}
\hline & Animate & \multicolumn{2}{c}{ Inanimate } \\
\hline Nom & $-\varnothing$ & $-\varnothing$ \\
Acc & $-a$ & $-\varnothing$ \\
Gen & $-a$ & $-a$ \\
\hline
\end{tabular}

Plural:

\begin{tabular}{lcc}
\hline & Animate & \multicolumn{1}{c}{ Inanimate } \\
Nom & $-i,-a$ & $-i,-a$ \\
Acc & $-o v \sim-e j,-\varnothing$ & $-i,-a$ \\
Gen & $-o v \sim-e j,-\varnothing$ & $-o v \sim-e j,-\varnothing$ \\
\hline
\end{tabular}

Table 7. Modern Russian animacy

Domain: Accusative, masculine singular and all plural, irrespective of gender

Frame: Animacy

\begin{tabular}{ll}
\hline Expression & Content \\
\hline Acc $=$ Nom & inanimate \\
Acc $=$ Genitive & animate \\
\hline
\end{tabular}

Summing up the discussion of subparadigms in connection with Russian noun inflection, it can be stated that a (re)grammation affects not a single form in isolation, but - as a minimum - a set of paradigmatically related forms. Such a set of forms, a subparadigm with a specific function, may be part of a hyperparadigmatic structure. Further, an apparent multiple-membered paradigm may include subsystems of more distinctive oppositions. Finally, a (re)grammation may have the character of a semantic reinterpretation and thus a functional redistribution of forms without leaving any traces on the inventory of forms and on the forms themselves. It may also affect a part of a paradigm, a whole paradigm or a complex of paradigms.

These changes all contribute to the maintenance and development of the fusional system of Russian nominal morphology. As mentioned, all Russian noun desinences code at minimum a number and a case value. As a result of the changes considered, some accusative desinences further code animacy, and in specific contexts nominative, accusative and genitive desinences code quantification. Thus, the analysed data cannot be taken to indicate that a change of morphological type is on 
its way (contrary to what has been assumed by Valgina 2003, Il'ina 1996, Glovinskaja 1996, and others).

Having considered a fusional system, we now turn to an example illustrating an agglutinating morphological system. The full set of inflectional forms of the Danish noun bord 'table', based on the analysis in Heltoft (2001), is presented in Table 8.

Table 8. Danish noun declension ( $-e$ is for schwa)

\begin{tabular}{|c|c|c|c|c|c|c|}
\hline & & number & definiteness & gender & number & "case"15 \\
\hline Indef.sg. & bord & & & & & \\
\hline Indef.sg.gen. & bord & & & & & $-s$ \\
\hline Def.sg. & bord & & $-e-$ & $-t-$ & & \\
\hline Def.sg.gen & bord & & $-e-$ & $-\mathrm{t}-$ & & $-s$ \\
\hline Indef.pl. & bord & $-e-$ & & & & \\
\hline Indef.pl.gen. & bord & $-e-$ & & & & $-s$ \\
\hline Def.pl. & bord & $-e-$ & $-e-$ & $-n-16$ & $-e-$ & \\
\hline Def.pl.gen. & bord & $-e-$ & $-e-$ & $-n-$ & $-e-$ & $-s-$ \\
\hline
\end{tabular}

The frame delimits the article which, it should be noted, is a complex morpheme in Danish. As can be seen, the article includes a plural marker -e, identical to the plural marker of the noun. This is an agglutinating system of four sequentially ordered grammatical suffixes, cf. (24). ${ }^{15}$

$$
\begin{aligned}
& \text { bord-e-n-e-s } \\
& \text { table-PL-[DEF-UTER-PL]-GEN } \\
& \text { 'of the tables' }
\end{aligned}
$$

The set of forms in (24) might be presented as the paradigm of the Danish noun bord 'table', pl. borde 'tables' (the plural $-e+$ the definiteness morpheme $-e$ are

13. As will appear from the following, the distinction zero vs.-s is not a standard case category. However, we shall use the term for convenience.

14. For an interpretation of $-n$ - in the plural as a marker of uter, the semantic gender denoting individuation and thus countability, see Heltoft 2001:73.

15. We adopt Heltoft's (2001) analysis of the morphology of Modern Danish nouns. However, the points we want to make do not hinge on this analysis and might have been reached on the basis of the traditional view, according to which the form in (24) should be analysed as follows: 
morphophonetically reduced to one single $-e$ ). However, this understanding of the term paradigm calls for a number of modifications, in particular the following two.

First, it is evident that the set of forms presented reflect four grammatical oppositions, cf. Table 9.

Table 9. Danish noun declension: grammatical oppositions

\begin{tabular}{llll}
\hline Definiteness & Gender & Number & “Case” \\
\hline indefinite/definite & neuter/uter & singular/plural & neutral/genitive \\
$-\varnothing-/-e-$ & $-t-/-n-$ & $-\varnothing-/-e-$ & $-\varnothing /-s$ \\
\hline
\end{tabular}

Unlike fusional systems such as that of the Russian noun where one and the same desinence codes several grammatical values, there is a specific expression system for each grammatical distinction in the agglutinative system of Modern Danish nouns. As a minimum, a morphological reanalysis affects one of the four paradigms combining to form the complex Danish noun inflection. As already mentioned, a reanalysis is never restricted to a single form in isolation.

Further, once the grammatical oppositions have been sorted out they can be examined separately, and it may be revealed - among other things - that they have different domains. As has long been recognised by specialists of Scandinavian languages, the case opposition is not a feature of the noun, but rather of the noun phrase, cf. (25).
a. mand-e-n
med skægg-e-t-s kone
man-[DEF-UTER-SG] with beard-[DEF-N-SG]-GEN wife
'the wife of the man with the beard'
b. Analysis:
[manden med skægget]s kone

This means that the desinence $-s$, which at an earlier stage of development was a number-case marker of the portmanteau type attached to the noun, has undergone a reanalysis affecting the domain as a minimum. This insight calls for a modification of the maximal set of word forms (the "paradigm") of the lexeme bord. The -s forms, which are no longer real case forms, will only be attached to the noun if the noun does not happen to be followed by an attribute. The segment $-s$ is actually attached not to the noun but to the noun phrase. It is a grammatical morpheme that is not a constituent part of any word. In other words, it is an item on a structural level different from that of the other inflections considered.

The clitic $-s$ can be traced back to an Old Norse genitive. Ignoring the long historical development connecting the two stages of development, Old Norse and Modern

16. The number value must be repeated after the gender marker in definite forms. 
Danish, we shall briefly consider the systemic position of $-s$ at each of these stages. In Old Norse $-s$ was the genitive case marker of singular $a$-stems, cf. Table 10.

Table 10. Old Icelandic noun declension

\begin{tabular}{|c|c|c|c|c|}
\hline \multirow[t]{2}{*}{$\mathrm{Sg}$} & \multicolumn{2}{|c|}{$a$-stems } & \multirow{2}{*}{$\begin{array}{l}u \text {-stems } \\
\text { Masc }\end{array}$} & \multirow{2}{*}{$\begin{array}{l}\overline{\boldsymbol{o}} \text {-stems } \\
\text { Fem }\end{array}$} \\
\hline & Masc & Neut & & \\
\hline & 'horse' & 'land' & 'plain' & 'sun' \\
\hline Nom & hest-r & land & völl-r & sól \\
\hline Acc & hest & land & völl & sól \\
\hline Dat & hest $-i$ & land $-i$ & vell $-i$ & sól-u \\
\hline Gen & hest-s & land-s & vall-ar & sol-ar \\
\hline
\end{tabular}

As a portmanteau case desinence, $-s$ was opposed to the desinences of the other cases (within the same declensions) on the one hand, and to the genitive singular desinences of the other declensions on the other. On the vertical axis on the chart (for instance hest- $r$, hest- $\emptyset$, hest- $i$, hest-s), the desinences form a paradigm constituting the basis for the description of the semantics of each individual case, including the genitive. On the horizontal axis (for instance for the genitive: hest-s, land-s, vall-ar, sol-ar), the desinences $(-s,-a r)$ are in complementary distribution, thus determining the domain of $-s$ in relation to the other genitive singular desinence (vall-ar, sol-ar). In other words, the meaning of $-s$ should be deduced from its function in relation to the other case forms. The domain of $-s$, on the other hand, appears from the distribution of the two singular genitive desinences $-s$, -ar. On this background, the domain of $-s$ as a genitive singular marker can be delimited to a specific subset of the nouns.

Turning to Modern Danish, we discover that neither of the two axes of opposition characteristic of the segment $-s$ in Old Norse are relevant. The Modern Danish noun has no case system. The segment $-s$ is still in use, but its systemic relations are of a different kind. While in Old Norse it was restricted to a subset of nouns in the singular, its domain is now that of the noun phrase (number being irrelevant). Further, though the origin of $-s$ is reflected in its meaning, which is still clearly related to that of the genitive, the change of domain has been accompanied by a change of meaning and function. The Modern Danish $-s$ has a more restricted meaning and function than the original genitive: it turns a noun phrase into a dependant nominal, typically a determiner or a predicative (Heltoft 1996:481). In Modern Danish a noun phrase, marked by $-s$, may only fulfil the function of an attribute or a nominal predicate, while in Old Norse the genitive could also be governed by verbs, adjectives, and prepositions.

Ignoring transitional stages, the change from Old Norse to Modern Danish can be illustrated by the following paradigms for each of the two stages, both including the segment $-s$. 
Table 11. Old Icelandic: a-stems singular

Domain: Nouns, a-stems singular

Frame: Case

\begin{tabular}{ll}
\hline Expression & Content \\
\hline$-r /-\varnothing$ & Nom \\
$-\varnothing$ & Acc \\
$-i$ & Dat \\
$-s$ & Gen \\
\hline
\end{tabular}

Table 12. Modern Danish: $-s$ as a non-argument marker

Domain: Noun phrase

Frame: Argument status

\begin{tabular}{ll}
\hline Expression & Content \\
\hline$-\varnothing$ & Argument \\
$-s$ & $\begin{array}{l}\text { Non-argument } \\
\text { (determinative/predicative) }\end{array}$ \\
\hline
\end{tabular}

The development of the former genitive $-s$ in English and Scandinavian languages (Herslund 2001; Rosenbach 2004) has been referred to as an example of degrammaticalisation (Norde 1997) or antigrammaticalisation (Haspelmath 2004:29) on the basis that, contrary to the predictions of the cline approach, it represents a development of an item from affixal to a less bound, clitic-like status and thus, allegedly, from a more grammatical to a less grammatical status. As we have already made clear, we fail to see the foundation of a graduation of grammaticality of such a kind. The $-s$ marker has not become any less grammatical, but simply changed its grammatical function from governed nominal case to the function of "translatif" (Tesnière 1976 [1959]:364) (involving a change of both content and domain).

We have considered this example in some detail in order to illustrate the general point that a superficial examination of the meaning of a grammatical unit is insufficient to detect the system relations and thus the character of the changes that have affected the item in question. Likewise, a focus on the "paradigm" - in the traditional sense of the full set of inflectional forms of a given lexeme - may lead to an insufficient and even misleading description. Rather, one should proceed from the minimal paradigms, i.e. minimal pairs (sets) of forms distinguished by one grammatical feature alone. How this should be done has been demonstrated on both a fusional and an agglutinating system above. For instance, the result of the change considered above was a modification of the domain of $-s$ (from a subset of nouns to 
the noun phrase) in combination with a specification of meaning. This looks like a change affecting one single morphological segment, but in reality it was a broader system change. A change appearing as a modification may in fact be part of fundamental system reanalyses. What is reanalysed is not the individual form but the system it enters.

The grammatical system may be imagined as a network of intersecting and semantically interconnected paradigms. While the paradigms are of various types, they all meet the demand of being closed from a synchronic point of view. It is characteristic that grammatical options cannot be side-stepped; speakers cannot opt out of using a grammatical form when the context calls for it (Jakobson 1971 [1959]: 489). For every grammatical paradigm there are contexts where a member must be used, the choice either being bound or depending on the content the speaker wants to convey. A speaker of a language needs not be in command of the whole lexicon (and nobody actually is, partly because there is no way to demarcate the lexicon of a living language), but he or she must be close to fully mastering (a version of) the grammatical system in order to communicate in a fully satisfactory way.

In relation to grammatical change this means that what is reanalysed is not the individual form, but as a minimum a paradigm, often a complex of paradigms in a process of connecting grammaticalisation. Any morpheme influenced by a reanalysis of, for instance, a morphological system changes grammatical status. This does not only mean that it changes meaning. In changing meaning it renews its relationships to other grammatical markers. It comes to fill a slot in an opposition of content of a new kind, established as a result of the change.

\section{Analogy}

There are changes of grammatical forms that do not affect the grammatical system as such. This is the case when one form is replaced by another by analogy. An analogical process is often based on identity of function, e.g. a form of one declension or conjugation replacing the corresponding form of another declension or conjugation.

As clearly appears from the oldest Slavic texts (going back to the 9th century), in Common Slavic certain desinences of the $\breve{u}$-stem nouns spread to the $o$-stems (Bräuer 1969:47). For instance, for the genitive plural the $o$-stem desinence $-\breve{u}$ was widely replaced by the $\breve{u}$-stem desinence -ov $\breve{u}$ (Modern Russian -ov). Sticking to the traditional way of presenting an analogical change in the form of an equation (Paul 1975 [1880]: 106-20, Bynon 1993 [1977]:33), the process can be illustrated as in (26). 
(26) Common Slavic

\begin{tabular}{|c|c|c|}
\hline & $o$-stems & $\breve{u}$-stems \\
\hline & bereg- $\breve{u}$ 'coast' & syn-ŭ 'son' \\
\hline
\end{tabular}

Analogical process

\begin{tabular}{|c|c|c|}
\hline NomSg & bereg-ü 'coast' & syn-ŭ 'son' \\
\hline GenPl & $\mathrm{x}$ & syn-ovŭ \\
\hline
\end{tabular}

This process does not affect the function of the genitive plural or the case and number system in any other way. It is a simple change in the morphological material filling the slots in the system: one marker of the genitive plural is substituted for another. In our understanding of linguistic change it is important to emphasise that the grammatical paradigm remains the same. No regrammation has taken place.

On the other hand, the outcome of analogical processes may provide the material for subsequent regrammations. An example is the above-considered spread of another Common Slavic $\breve{u}$-stem desinence, the genitive singular $-u$, to $o$-stem nouns, cf. (1), repeated here as (27):

(27) Genitive singular (Common Slavic - as reflected in Old Russian)

$o$-stem forms (inherited) $\breve{u}$-stem forms (new)

polon-a 'prisoners' (collective) polon- $u$

sneg-a 'snow' sneg-u

- and the subsequent reanalysis of this distinction of expression as a marker of quantification in Russian, cf. (2), repeated here as (28).

$$
\begin{aligned}
& \text { kačestvo čaj-a } \\
& \text { stakan čaj-u/čaj-a } \\
& \text { quality tea-GEN.SG glass tea-GEN.SG } \\
& \text { 'the quality of the tea' 'a glass of tea' }
\end{aligned}
$$

Even these limited data allow us to conclude that a form differentiation appearing as the result of an analogical process may provide the expression material for a ( $\mathrm{re}$ ) grammation, i.e. a reanalysis establishing or modifying a grammatical paradigm. Thus, although in principle not affecting the grammatical system, analogical processes should be studied as one of the factors that prepare the ground for subsequent grammaticalisation.

\section{Markedness and productivity}

The concepts of markedness and productivity are fundamental to our understanding of language, grammaticality and language change, including grammaticalisation. 
Unfortunately, linguists often fail to specify these concepts and tend to employ them in a loose sense. In this section we attempt to achieve a more precise understanding of markedness and productivity through a more detailed examination of some of the examples considered above.

Andersen (2001b:25) emphasises that the linguistic concept of markedness should be seen in the light of "markedness as a principle of cognitive organisation that is reflected in human behaviour and apparently fundamental to it". He provides evidence for this claim not only in language but also in rituals and other kinds of cultural behaviour in different human societies. The claim, in a modified formulation, is that human beings conceptualise the world in the shape of asymmetric oppositions, i.e. oppositions consisting of a marked and an unmarked member. In a subtle analysis he resumes the Hjelmslevian stance that even logically symmetrical (exclusive) distinctions, like contradictories (e.g. male - female), converse opposites (e.g. father - mother) and contraries (e.g. wide - narrow) are conceptually treated as asymmetric, just like the logically asymmetric inclusive distinctions (e.g. flower - rose). The cognitive reality, it is further argued, is not that asymmetry is in any way imposed on symmetrical oppositions, but "that markedness arises in the initial cognition of any and all distinctions thanks to the inherently asymmetrical, inclusive relation that obtains between any concept that is formed (M) and the conceptual space that surrounds it (U)" ( Andersen 2001b:45). ${ }^{17}$ In other words, human beings form their concepts not in a vacuum, but on the background of a conceptual space in relation to which the newly formed concept is marked. This is the foundation for the cognitive representation of all distinctions, whether logically symmetrical (exclusive) or logically asymmetrical (inclusive) and hence for all oppositions in language.

Thus, the foundation of markedness in language is fundamentally always the same, but on the basis of what the concept is applied to we can distinguish at least three manifestations of markedness which we shall label paradigmatic markedness, variational markedness and markedness of context.

\subsection{Paradigmatic markedness}

Paradigmatic markedness is the relation between the members of a grammatical category, reflected in a paradigm. The distinctions making up grammatical categories are generally asymmetric, one member being unmarked in opposition to another, or more members being marked in relation to a maximally unmarked member. The most transparent examples are binary categories, reflected in paradigms with only two members. In many languages number is such a category with plural as the marked

17. $\mathrm{M}=$ marked, $\mathrm{U}=$ unmarked. 
member and singular as the unmarked member. Another example is verbal aspect in Slavic and other languages, with the perfective aspect as marked and the imperfective aspect as unmarked. In our understanding the marked member contains a semantic feature in addition to the content it shares with the unmarked member. As an illustration, to say that the additional feature characterising the plural as the marked number value is plurality is tantamount to saying that this feature will be reflected by any plural form and that whenever the speaker wants to mark the feature of plurality, he or she must pick the plural form. The unmarked member is left with a less specific content and, correspondingly, a somewhat broader extension. As the unmarked number value, the singular is the form occurring in the case where the feature of plurality is not applied (for instance, because reference is made to a single item) or where the question of plurality does not even arise (as in the case of abstract nouns and mass nouns). It should be emphasised that this presentation of the category of number is excessively schematic and does not pretend to be universal or even exhaustive in relation to any particular language. ${ }^{18}$

The situation is somewhat more complex when it comes to grammatical categories with more than two members, for instance, case in Indo-European and other languages. However, it will often be possible to break up a case system or another multi-membered system in binary distinctions with a clear asymmetric distribution. A comprehensive investigation of a multi-membered paradigm will leave one form, sometimes referred to as the default form, maximally unmarked. The default member is the one occurring when no more specific rule requires another form; in other words, the default form is unmarked in relation to the specific features conveyed by the other forms in the paradigm. Again, the presentation is simplified, but it suffices to illustrate the point that multi-member systems are also asymmetric, and that there are no grammatical distinctions that are indifferent to paradigmatic markedness.

\subsection{Variational markedness}

Variational markedness is the relation between two or more expressions filling the same slot in the system and thus appearing as expression variants with close to identical content. The distribution of the variants will be determined by the markedness relation between them. In order to approach variational markedness, let us return to the series of changes briefly considered in example (8), the rise and fall of future tense forms in the development from Latin to French. In a simplified form, ignoring several

18. As revealed in contrastive studies (e.g. Nørgård-Sørensen 1999), even an apparently simple binary distinction like singular/plural is language-specific. Languages exhibit considerable systematic variation in the distribution of singular and plural forms. 
intermediate phases, this development can be described as proceeding through a number of stages, cf. (29).
a. Classical Latin canta-b-o sing-FUT-1SG
'I will sing'
b. Early Romance canta-re habe-o sing-INF have-PRS.1SG alongside with: canta- $b-o$
c. Classical French chanter-ai sing-FUT.1sG
d. Modern French je vais chant-er I go-PRs.1SG sing-INF alongside with: chanter-ai

This example has been widely referred to in the literature on grammaticalisation (Sihler 1995; Bybee, Perkins og Pagliuca 1994), and for good reasons. It offers a unique illustration of how linguistic changes may, so to speak, repeat themselves at successive stages of development. As mentioned in connection with (8) above, the French future chanterai (and equivalents in other Romance languages, e.g. Italian canterò) has developed from the Early Romance periphrastic cantare habeo, the stem corresponding to the former infinitive and the desinence to the former auxiliary. If we go back in history, we see that the Latin future canta- $b$-o has a similar origin. The suffix - $b$-comes from the Common Italic root ${ }^{*} b h u$ - 'be, become', so the form cantabo must originate in a periphrastic form consisting of an infinite form of the lexical verb and an auxiliary. Returning to Modern French, we observe that alongside with the synthetic chanterai a new periphrastic form with future reference has arisen: vais chanter.

We shall now explore the question of markedness and productivity in relation to (29). In Modern French the periphrastic future vais chanter is widely used alongside with the synthetic chanterai. Written varieties of the language, in particular, prefer the synthetic chanterai. The situation is too complex to be dealt with here in any detail (see e.g. Hansen and Strudsholm (2006) for a recent quantitative investigation of the French and Italian futures), but the data seem to reflect a situation where the periphrastic form is stylistically marked in relation to the synthetic chanterai which, consequently, should be seen as the unmarked member of the form pair vais chanter/ chanterai.

The situation must have been similar when the periphrastic cantare habeo appeared in Early Romance. At the beginning this form would have been limited to informal registers and thus stylistically marked in relation to the unmarked synthetic cantabo. However, the further development reveals that at a certain time this markedness relation was reversed. The periphrastic cantare habeo was reanalysed as the unmarked 
future, leaving the synthetic cantabo a marked form, presumably limited to formal registers. The new markedness relation motivated an actualisation process where the use of the synthetic form would have been more and more restricted until it eventually fell out of use. A similar process may be on its way in Modern French.

Though it has seldom been acknowledged, markedness, and in particular variational markedness, is somehow related to the question of productivity. A grammatical system can be thought of as a system of productive rules and models, allowing the speakers to produce word forms, syntactic constructions, word order sequences and other grammatical patterns. In French the rules for producing the two future forms chanterai and vais chanter are both clearly productive. Both may be formed from practically all verbs in a fully predictable manner. The same must have been the case with the forms cantabo and cantare habeo at a certain stage of the development of Early Romance.

In addition to the productive paradigms, there will often be paradigms not conforming to the productive rules. These unproductive paradigms may exist in the language for long periods of time. They are crucial elements of natural languages and cannot simply be neglected as peripheral. The strong verbs in Germanic languages, for instance, English find - found, drink - drank - drunk; German finden - fand - gefunden, bitten - bat - gebeten, constitute a well-known example of unproductive patterns. These inflections have been unproductive for more than a millennium. That they are unproductive means that in principle they are limited to closed lexical groups where they are employed by convention. The modification 'in principle' should be emphasised. For instance, it has been shown (Dahl, personal communication) that the group of strong verbs in Swedish has not only been declining over the centuries; the language has also taken in a few new verbs, leaving the total number of strong verbs at a relatively stable low level.

This, however, does not mean that the concept of productivity is irrelevant or inapplicable to the analysis of language structure and language change. It is true that the group of strong verbs in Swedish (and, presumably, in other Germanic languages, too) has been supplemented, but it should be emphasised that this has taken place in a fully unpredictable manner. Productive patterns are activated in a predictable manner. When a new lexical item enters a language, it will be adapted to the productive patterns prescribed for it, e.g. the conjugation of the loan verbs mail-e 'to email' chatte 'to chat (on the web)' in Danish:

(30) Examples of productive verbal endings in Danish

$\begin{array}{lll}\text { Present } & \text { mail-er } & \text { chatt-er } \\ \text { Past } & \text { mail-ede } & \text { chatt-ede } \\ \text { Perfect participle } & \text { mail-et } & \text { chatt-et }\end{array}$

An existing or a new lexical item occasionally behaves differently and, by analogy, enters an unproductive pattern. This has happened to a limited number of verbs 
in Swedish which adopted a strong-verb pattern in historical time. Note, however, that such cases are limited in number and, more importantly, that they are unpredictable.

Thus, there is no problem distinguishing between productive and unproductive patterns. Nevertheless, the question of the striking stability of certain unproductive patterns, e.g. the strong verbs in Germanic languages, is interesting and deserves more attention and further investigation.

While, as we have seen above in connection with the Early Romance and French futures, two productive forms may be systemically connected to each other in a markedness relation (as a marked and an unmarked form), unproductive forms will inevitably be marked. They will be somehow limited in use: to specific contexts or to a specific group of lexemes.

Variational markedness offers a more precise interpretation of the phenomenon occasionally referred to, somewhat unfortunately, as competition between grammatical forms and constructions. Even if the term competition is used in a metaphorical sense, we find it misleading to speak of two or more forms filling the same slot in the system as competitors. As we have seen, variants are distributed according to regulations (concerning style, text type, registers and the like) specific to the individual case and determined in a regular fashion by the markedness relation between them.

\subsection{Markedness of context}

Andersen (2001b:31-36) extends the concept of markedness to contexts in a broad sense, introducing the distinction between marked and unmarked context (or environment). He refers to marked vs. unmarked context in examining the distinction between internally and externally motivated changes. This theoretical point hinges on Andersen's more general Principle of Markedness Agreement, according to which symbolic elements - in rituals, discourse or any other manifestation of cultural behaviour - are organised so as to form groups of elements that are homogeneous in markedness: marked terms go with other marked terms; unmarked with unmarked. Applied to innovations in language, the Principle of Markedness Agreement predicts that if the innovated element is externally motivated and thus marked (in one of the above senses, i.e. either as an element of a grammatical paradigm or as a variant), it is first favoured in marked contexts and then spreads to unmarked contexts. If, on the other hand, the innovated element is internally motivated, it is first admitted to unmarked contexts from where it spreads to marked contexts.

As an illustration of the idea of markedness of context, Andersen (2001b:32-33) refers to the above considered development of the auxiliary of the Old Slavic perfect (cf. example (9): pisa-l-a jesmı̆ 'I (woman) have written') into an enclitic person-number marker in Polish (pisa-k-a-m 'I (woman) wrote/have written'). This development has still not been completed. In Modern Polish the person-number marker may occur 
either agglutinated to the verb or in Wackernagel position, cf. example (22): my pisa$l$-i-śmy/my-śmy pisa-l-i 'we (men) wrote/have written'). Investigating the development towards agglutination to the verb (and thus towards affixation), Andersen observes that it occurs earlier in unmarked environments than in marked environments, cf. (31), slightly modified from Andersen (2001b:32).

\begin{tabular}{|c|c|c|}
\hline & \multicolumn{2}{|c|}{ Oppositions of markedness of contexts } \\
\hline & Unmarked & Marked \\
\hline a. & present (of być 'be') & preterite \\
\hline b. & indicative & subjunctive \\
\hline c. & 1st person & 2nd person \\
\hline d. & singular & plural \\
\hline e. & main clause & subordinate clause \\
\hline f. & asyndetic & syndetic \\
\hline g. & lexical NP & pronoun \\
\hline h. & prose & poetry \\
\hline i. & expository & artistic \\
\hline j. & speech & writing \\
\hline k. & casual & formal \\
\hline
\end{tabular}

In other words, the agglutination of the person-number marker to the verb occurred earlier in the present than in the preterite, earlier in the indicative than in the subjunctive, and so on. It is worth emphasising (as does Andersen) that in this example the unmarked/marked contexts (or environments) have been specified with reference to different types of categories: morphological (a-d), syntactic (e-f), lexical ( $g$ ), and pragmatic $(\mathrm{h}-\mathrm{k})$. The only feature uniting these categories is their markedness specification. Since agglutination, which is actually a development towards the highest degree of bonding, appears as an internally motivated change, it occurs earlier in unmarked than in marked environments, as predicted by the theory.

Andersen's theory of a link between, on the one hand, external/internal motivation for change and, on the other, marked/unmarked context has been applied to a few more studies (Nørgård-Sørensen 2005; Kragh 2006; Bascuñán 2006ab) with promising results. However, the still somewhat sketchy presentation of this theory clearly calls for further elaboration, for instance, of the fundamental problem of criteria for distinguishing marked and unmarked contexts. We shall leave this topic for now and consider the implications that the various types and levels of markedness may have for the grammatical paradigm.

\subsection{Markedness and productivity}

It was stated above that paradigms signal asymmetric distinctions, i.e. distinctions between marked and unmarked features. Notice that all manifestations of markedness 
(not only the latter one considered) should be understood in their relevant context. Linguistic features can be marked or unmarked with respect to style, genre, pragmatic context etc., but where grammatical distinctions are concerned, the context is first and foremost the system. A grammatical distinction is an integrated part of the grammatical system and will be shaped, formally and semantically, on this background. This should encourage linguists to look for links between various parts of the grammatical system. Likewise, when investigating change, the linguist should look for links between apparently distinct developments in a search for what we have labeled connecting grammaticalisation.

As mentioned above, the coregrammatical system is made up of productive paradigms, including a number of asymmetric distinctions. Changes may take the form of reanalyses whereby markedness relations are redefined and may be reversed or abolished. In this way there is an intricate connection between markedness and productivity. They are both essential features of the grammatical system and should be considered in both synchronic grammar descriptions and examinations of grammatical change.

One point should be especially emphasised. We have referred to languages (at specific synchronic stages of development) as if we were speaking of a uniform collective phenomenon. However, native language proficiency is a matter of the individual native speaker, as are the markedness relations examined. In other words, if the markedness relations in a particular language at a particular time appear quite blurred in opposition to the clear-cut picture proposed above, the reason may be that speakers disagree on them. Language changes - like the markedness reanalyses discussed - appear in the speech of individual speakers and gradually spread to others, eventually - if they are successful - to all native speakers of the given language (see Section 2. Basic concepts, above). Taken as a whole, the speech activity of a language community will reflect such transitional stages as variation in the use of certain forms. 



\section{CHAPTER 2}

\section{Topology (word order)}

\section{Introduction}

Word order is often treated in grammars in ways that lead linguists to discard any relationships of theoretical interest between morphology and word order, either because of the classical bipartition between semantic and grammatical morphemes, or simply because of the preferred modular structure of certain grammatical models. Grammaticalisation studies reflect such thinking, too, when yesterday's syntax is distinguished in principle from today's morphology, not only as stages of development, but also as qualitatively different degrees of grammaticalisation. Concluding his article, however, Meillet (1965 [1912]) draws a parallel between morphological systems and distinctions expressed through word order, thereby implying that word order change can in principle be analysed as instances of grammatical change. Meillet's actual point is not just the trivial one that grammatical relations can be expressed by fixed word order systems, but that word order systems are analogous to morpheme systems. In Modern English and Modern French,

un ordre de mots devenu habituel pour quelque raison a pris le charactère de "morpheme", c'est-à-dire de marque d'une catégorie grammaticale. La valeur expressive de l'ordre des mots, que l'on observe en latin, a été remplaceé d'une valeurgrammaticale. Le phenomène est de même ordrequela "grammaticalisation" de tel ou tel mot; au lieu que ce soit un mot employé en groupe avec d'autres qui prenne le charactère de "morpheme", par un effet de l'habitude, c'est une manière de grouper les mots. Ici encore, il y a vraiment création d’outils grammaticaux nouveaux, et non pas transformation. ${ }^{19}$

19. “...a word order pattern that has for some reason become habitual, has acquired the character of a "morpheme", that is, of a mark of a grammatical category. The expressive value of word order found in Latin has been replaced by a grammatical value. This phenomenon is ranked equal to the "grammaticalisation" of this or that word; instead of a word bearing, by some customary effect, the role of a "morpheme", forming a group with other words, the job is done by a way of grouping the words. Also in this case, we actually find the creation of new grammatical tools, and not a transformation" (our translation). 
What precise views Meillet might have held had he developed these thoughts is, of course, not the issue. However, Meillet certainly did not define grammaticalisation along the lines now prevailing in the study of grammaticalisation processes. On the contrary, he stresses the similarities between word order and morphology. The idea that word order change is a grammaticalisation process of the same order of magnitude as grammaticalisation of word stems or word forms calls for a number of additional questions to be raised and answered.

1. Since word order outputs can be similar to those of morphemes, we are led to ask whether word order is organised in ways similar to the paradigmatic structure of morphology, and if so, to what extent. We suggest that word order can and should be described in terms of paradigmatic oppositions between alternating linear options.

2. Since word order can mark a grammatical category, it must in general be considered part of sign systems that parallel the paradigmatic structure of morphemes. Within the range of languages studied, we find word order not only as expression systems of semantic frames of traditional inflexional case systems, but also of traditional mood systems (Scandinavian, esp. Danish).

Parallel to morphological systems, word order systems are language specific, and since they have content, they have language specific content. If reorganised paradigmatically, a characteristic word order pattern will change at the level of content, but not necessarily at the level of word order expression. Consequently, we hold that syntactic change will always imply change at the content level and in many cases at the expression level, too. Good cases are found in the history of Danish.

3. Word order systems can arise as fully innovative structures in the development of languages, but can they - and we would expect a yes - be the output of reanalyses of earlier word order systems? Following again Meillet's mention of French and English, these languages have earlier stages with different word order organisation. Hence the question can be reformulated as the quest for instances of word order change that lend themselves to an explication in terms of reanalysis and subsequent actualisation.

4. Do we find instances of word order change as a degrammation process? We disregard relatively uninteresting cases of fossilised word order patterns and focus on word order patterns that lose (part of) their content functions only to end as patterns of regulated prosodic features such as stress reduction.

5. In the light of our interest in connecting grammaticalisation, the question of interaction with other systems must be raised. In Section 6 examples of integration of prosody and topology will be given, in 6.1 Danish pronouns, and in 6.2 the reflections of Wackernagel's law in Latin. Finally, in 6.3 the morphology of Old French 
personal pronouns serves as an example of a paradigm connecting morphology, prosody and topology.

Furthermore, in Chapter 6 Lars Heltoft addresses the following two questions through an analysis of the development of verb second patterns, mainly in Danish as an instance of the Scandinavian development.

A. Are there instances of parallel grammaticalisation in the sense that word order paradigms and affixal and constructional paradigms are - in a synchronic view - alternative or cooperative systems sharing the semantic frame that they grammaticalise?

B. Are there instances of synchronic, complex grammaticalisation to the extent that morphological systems, word order, and constructions cooperate in forming what we shall call hyperparadigms - complex paradigms connecting word order options and/or morphological or constructional options?

We rely on the same set of assumptions about the study of grammatical change as set out in the section on morphology. Any hypothesis about change by one particular language will presuppose and depend on synchronic analyses of the structure of the developmental stages of this language. Thus, any hypothesis about word order change within one language will presuppose an analysis of the grammatical functions entrenched in word order at relevant stages of its development. And again, it will depend both on a theory of word order organisation and the role word order can play in language, and on the methods applied in actual analyses of word order.

The topological assumptions behind this approach will be set out in detail below.

\section{Paradigms and word order}

Different word order patterns can form paradigmatic oppositions in the sense of alternations between members of a limited set of complex signs. We open our discussion of this issue by considering Danish - as an example of Mainland Scandinavian verb second order (or short V2 in examples and tables). In Heltoft (1996), the word order contrast between interrogative and declarative potential was used to generalise the concept of a paradigm to also comprise closed oppositions of word order. We shall elaborate this analysis by pointing out that such paradigms are really best understood as complex paradigms uniting more than one set of oppositions. In examples ( $1 \mathrm{ab})$, the 'emic' difference between interrogative and declarative potential is expressed by a combined syntagmatic and paradigmatic opposition. The initial position (Dik (1989 and later): P1, Diderichsen (1946): F for 'fundamental field') either holds a full constituent or it is empty. In the latter case, the subject position $S$ (3rd position) must hold the subject. 'Part' is the field for particles and sentence adverbials. 
(1) Declarative
a. F V S Part
Så spis-te hun
then eat-PST she.NOM
'Then she ate'

b. Hun spis-te (-) så
she.Nom eat-Pst
'She ate, then'

(2) Interrogative
F V
S
Part
(-) Spis-te hun så?
eat-PST she.NOM then
'Did she eat, then?'

Any material of propositional character may function as the initial constituent. The subject is the unmarked filler, but situational and cohesive adverbials are frequent. Objects are found as well.

Traditionally, the content of the opposition (1) vs. (2) is labelled realis vs. non-realis (irrealis meaning 'counterfactuality'). For reasons that will become clear in Chapter 6, we shall speak of the opposition as Realis vs. Conditioned realis. It is found both in main clauses and in subordinate clauses, but we shall restrict ourselves here to main clauses, see Chapter 6 and Christensen (2007) for the full picture.

The point is that present-day Danish word order connects with mood. To be operational, this paradigm presupposes the choice of non-imperative mood, either in the form of the indicative in -er, or through the preterite (distal) form, which is non-imperative by default. The imperative mood is incompatible with the contrast documented between zero filling of $\mathrm{F}$ and a positive filling of $\mathrm{F}$. In other words, for the word order contrast to apply, the right mood must be selected. In fact imperative sentences have no F. The imperative can be preceded by a cohesive adverb, as in (3ac), but omitting this adverb (3bd) has no semantic consequence similar to the contrast in (1) vs. (2).
(3)
a. Så spis dog!
then eat-IMP PARTICLE
'Then eat'
b. Spis dog!
c. Så spis du bare!
then eat-IMP you.SG PARTICLE
'Then just eat'
d. Spis du bare! 
A topological analysis of these examples is shown in (4).

(4) Cohesive adverb V S Part

Så spis dog!

Så spis $d u$ bare!

Spis du bare!

The point is that the position Cohesive adverb has no sign function similar to $\mathrm{F}$, and therefore, it is not part of the paradigm expressed through F. This means that the word order template for the imperative sentence is different from the non-imperative (declarative) template at both levels: expression and content.

The opposition within the imperative sentences between (5ab) and ( $5 \mathrm{~cd})$ unfolds another aspect of this complex paradigm. An explicit 2nd person subject is possible, but this has the semantic consequence of specifying the illocutionary potential of the imperative to a subset of the directives, namely those that have the preparatory rule that 'the receiver has an interest in the realisation of the propositional content of the speech act': permitting, offering, encourageing, giving advice (Searle 1969:67). ${ }^{20}$

(5)
a. Så spis du!
b. Spis du!
c. Så spis!
d. Spis!

The choice of the imperative form automatically entails another set of options. There is no realis paradigm, but another paradigm opens, namely that of an explicit 2nd person subject vs. a zero subject. Given this stance, it makes no sense to say that the imperative follows the verb second pattern, since the topological codings are so markedly different.

Looking back in history, we find earlier codings of verb second patterns that comprised both imperative and non-imperative clauses. In middle Danish, the imperative could occur both in main clauses and in subordinate clauses, and subjects and at least some other propositional constituents could precede the imperative verb.

$$
\begin{aligned}
& \text { a. Ac bith thoe at thu tac min sial oc } \\
& \text { I pray-1sg you.oBL that you take-IMP.SG my soul and } \\
& \text { lat mic ondoe min strith } \\
& \text { let-IMP.sG me.obL end my struggle } \\
& \text { 'I pray thee that thou takest my soul and let me end my struggle' }
\end{aligned}
$$

(Legend of St. Christina. GL 285, 31-33)

20. Promising has this preparatory rule as well (Searle 1969:58), but is taken to be a commissive, not a directive (Searle 1979). 
b. 〈'Since I have to commit this sin, then it must remain absolutely secret'〉: thy lat giøra vppe $i$ tornit et hemelikt hws... therefore let-IMP.sG make up in the tower a secret room...

$i$ hwilko som wi magh-om hemeliga blifva in which that we can-1PL secretly remain

'Therefore have a room made up in the tower in which we can dwell in secret'

(SjT 68, 29-30)

We have found no mention of this in Nygaard (1905) Old Norwegian and Old Icelandic, and none either in Faarlund (2004) ${ }^{21}$ We take this to be a shortcoming, since examples are easily found:

(7) Nu vil ek bjóða pér lög, segir Gunnlaugr, at pú now will I offer you the conditions, says G., that you gjalt mér fé mitt eða gakk á compensate-IMP.sG me my belongings, or go-IMP.sG at hólm við mik holm with me.

(Gunnlaugs saga, Wimmer Oldnordisk læsebog 86)

We do not claim that medieval verb second is paradigmatically identical to the modern language; on the contrary, our point is that they differ, see Chapter 6. It is quite likely that the relation of the imperative to verb second was different in the medieval language (probably parallel to the subjunctive, see Chapter 6).

These findings are in accordance with the view that the verb second pattern of earlier periods was not similar to the present day verb second system. The medieval system did not code Realis vs. Conditioned Realis. In particular, the XV pattern (with the initial position $\mathrm{X}$ filled in) ${ }^{22}$ did not code Realis, let alone assertive illocutionary potential. It is likely that Old Scandinavian verb second order coded a textual opposition and not an illocutionary dimension, see Chapter 5. Verb second word order occurred e.g. in conditional contexts that would create inconsistency with the verb second pattern of the modern language. Examples of now impossible verb second in subordinate clauses are (8ab). Note that conjunctions and subjunctions do not count in the topological balance-sheet:
a. Æn vm hin orcar
sey thre marc oer
but if he is able to not three marks that

21. Falk \& Torp (1900:192) treat Dano-Norwegian, but include an Icelandic example. For sources to Chapter 2, see Chapter 6.

22. The modern $\mathrm{F}$ for fundament ('predication base') is dispreferred for the old language, since the initial position does not code any such function. 
brutit hafuir. tha...

offended has, then ...

'but if the offender cannot provide three marks, then..'

(Scanian Ecclesiastical Law 4. GL 11, 6-8)

b. Æn vm rop far centwigice man. cellar

but if bad reputation-ACC has either man-NOM or

kun-a. vm swa vrthit mal. schoer-e

woman-NOM about such happened case exculpate-PRS.SBJV

sic moeth iarne.

REFL with iron

'If either a man or a woman has the bad reputation of having

done such a thing 〈witchcraft $\rangle$, he/she must exculpate himself/herself with iron'

(Scanian Ecclesiastical Law 11. GL 14, 24-26)

In clauses like these, the subjunction is outside the topological frame. The initial positions in (6)-(8) are shown in (9):

(9)

\begin{tabular}{|c|c|c|c|c|c|}
\hline & $\mathrm{x}$ (INITIAL) & $\mathrm{v}$ & $\mathrm{s}$ & NEG & PROPOSITION \\
\hline \multirow[t]{2}{*}{ at } & thu & tac & & & min sial \\
\hline & thy & lat & & & $\begin{array}{l}\text { giøra vppe i tornit et } \\
\text { hemelikt hws }\end{array}$ \\
\hline at & pú & gjalt & & & mér fé mitt, \\
\hline еða & & gakk & & & á hólm við mik \\
\hline $\mathrm{vm}$ & hin & orcar & & æy & thre marc \\
\hline $\mathrm{vm}$ & rop & far & $\begin{array}{l}\text { æntwigiæ man } \\
\text { ællar kuna }\end{array}$ & & \\
\hline
\end{tabular}

Notice the two verb second signals in (8ab): the position of sentence adverbials and focus operators (negation) after the finite verb (8a), and secondly, the possibility for an object to topicalise ( $8 \mathrm{~b}){ }^{23}$

No similar clauses can be found in the modern language (10ab); for (10a), we must have (10c), and (10b) must be (10d):
a. *hvis skyldneren kan ikke betale renterne if the debtor can not pay the interest

23. We disagree with Scandinavian generative grammar about their separating cases like these from so-called stylistic fronting. From this it follows that we do not share their view that main clauses have the finite verb in COMP, subordinate clauses in I. 
b. *hvis det omdømme får en mand at... if the reputation gets a man that...

c. hvis skyldneren ikke kan betale renterne

d. hvis en mand fär det omdømme at...

In a generalised form: the modern language would not allow verb second in these cases, but demands S(Advb)VO, sentence adverbials necessarily preceding the finite verb.

Lars Heltoft will return to this development in detail in Chapter 6. At present, we shall underscore the character of this development as it already appears from the scanty data considered. Modern declarative verb second must be seen as a specification of a relatively open or unmarked verb second found in the old Scandinavian languages and, strikingly, also in Old French, cf. Chapter 6. The modern realis-interpretation follows from a specification of the pattern to manifest illocutionary potential ('assertive potential'), whereas the old language also allowed declarative interpretations of clauses with an empty fundamental field and an indicative mood:

(11) Ey vilde $i$ tilscrifte gange eyfaste ey almusse gerninge gørce Not would you confess, not fast not acts of charity do mon var-e $i \quad$ lygner och vdoediss moen

but be.PST-PL you.2PL liars and crooks

$i$ alt eters liffdag

in all your livingday

'You would not confess, nor fast, nor do acts of charity, but you were liars

and crooks all your lives'

(Torment of St. Paul GL 355, 22-23)

\section{CONJUNCTION $\mathrm{X} \quad \mathrm{V}$ S NEG PROPOSITION}

\begin{tabular}{|c|c|c|}
\hline \multicolumn{3}{|r|}{ til scrifte gange } \\
\hline & ey & faste \\
\hline & ey & almusse gerninge gøræ \\
\hline mæn & vare $\mathrm{i}$ & lygner och vdædiss mæn i alt eters liffdag \\
\hline
\end{tabular}

Example (11) has an empty fundamental field, namely in the fourth clause: mon vare $i$ lygner oc (...), but is nevertheless a declarative sentence. It follows that zero fundaments are not 'emic' signals of conditioned realis, in contrast to the modern language, see Chapter 6.

Thus, we stress the importance of accurate analyses of topological paradigmatic organisation as a prerequisite for the study of grammatical word order change. Such processes resemble morphological change in the sense that they consist in paradigmatic 
reshaping of content, normally accompanied by changes of expression, that is: of word order rules. In what follows, we shall show instances of topological change as grammation, regrammation and degrammation.

\section{Innovative topology}

Old Germanic word order as exemplified by Old English and Old Scandinavian allowed the order of objects to vary according to the needs of information structure, to some extent comparable to the scrambling rules still operative in modern German. Both orders $\mathrm{IO}+\mathrm{DO}$ and $\mathrm{DO}+\mathrm{IO}$ were found in the Old Scanian dialect, for example (idealised):
a. gifua clostr-e nokot give monastry-DAT something 'to give a monastry something'
b. gifua nokot clostr-e give something monastry-DAT 'to give something to a monastry'

Only one (pronominal) case paradigm survives in Modern Danish, and neither Ns, nor Adjs, nor NPs in general inflect for case. Only the order IO + DO is possible, presumably an indexical semantic system (Andersen 1980) that repeats S (V) O order where possible. SVO is behind IO + DO in the sense that the latter reflects the order of predications containing $f a ̊$ ' $g e t$ '.
a.
$\left[\begin{array}{lll}X & \text { får } & Y\end{array}\right]$
$\mathrm{X}$ gets $\mathrm{Y}$
b. Z gives $\left.\begin{array}{rrr}\mathrm{X} & & \mathrm{Y} \\ {[\mathrm{X}} & \mathrm{P} & \mathrm{Y}\end{array}\right]$

This Modern Danish organisation of the IO - roughly similar to the result of the development in English - is again included in a paradigmatic opposition between an upgraded IO vs. a downgraded (prepositional) IO.
a. han overdrog sin datter opgaven he entrusted his daughter the task 'He entrusted his daughter with the task'
b. han overdrog opgaven til sin datter he entrusted the task to his daughter 'He entrusted the task to his daughter' 
The expression system of this paradigm must be described as two-dimensional: one dimension constructional, namely the ranking system of the opposition zero NP 'upgraded constituent' vs. Prep + NP 'downgraded constituent', the other one topological. To form a paradigm, they must have some common semantic frame, and this is the semantic role of a Receiver. The paradigm can be rendered as (15), showing the expression system. The full paradigm is Table 1.

$$
\begin{array}{ll}
\text { Upgraded member: } & \mathrm{IO}(\mathrm{NP})+\mathrm{DO}(\mathrm{NP}) \\
\text { Downgraded member: } & \mathrm{DO}(\mathrm{NP})+\mathrm{IO}(\text { Prep } t i l+\mathrm{NP})
\end{array}
$$

Table 1. The indirect object

Domain: V A

Frame: Receiver

\begin{tabular}{ll}
\hline Expression & Content \\
\hline $\mathrm{NP}+\mathrm{NP}$ & 'A3 precedes A2' \\
$\mathrm{NP}+$ til NP & 'A2 precedes A3' \\
\hline
\end{tabular}

A paradigm like this one grammaticalises topological and constructional differences in one more complex paradigmatic structure, with the semantic role of a Receiver as the common background. Since the expression system contains both a topological and a morphoconstructional dimension (preposition vs. zero), the paradigm will qualify as a hyperparadigm, cf. Christensen (2007).

We shall return to the opposition between upgraded and downgraded indirect objects later to show that this paradigm codes more content than merely the instructions to identify the arguments.

Historically, whatever the exact relation was between the use of dative NPs and accusative NPs in the old language, the expression difference was not a topological one. The development of a topologically based paradigm is an innovation ${ }^{24}$ and thus an instance of a grammation process, cf. Meillet's programmatic statement quoted above.

\section{Reanalysis from earlier topology}

Accepting that word order systems can arise as fully innovative structures, we are still under an obligation to show that word order change can be the output of reanalyses of

24. Saying that it is an innovation does not imply that everything is brand new in the paradigm. The order IO $>$ DO is probably an indexical reflection of the order 'Subject precedes Object', implying that from another stance, the order A3 > A2 has come about through generalisation of $\mathrm{A} 1>\mathrm{A} 2$. The point is that word order is new in the paradigm of the Receiver. 
earlier word order systems as instances not of innovative grammation, but of regrammation (Andersen 2001b, 2003). To perform this task, however, we need to clarify some principles of word order analysis, and we do so on the basis of Old English material (taken mainly from Pintzuk 2003), since Old English will provide data to handle a scenario for the invention and redevelopment of verb second syntax.

\subsection{Principles of topological analysis}

Pintzuk (2003:519) says that the Old English finite verb "can appear in almost any position in both main and subordinate clauses", and the examples following in 3.2 document that it could hold at least four positions: final, second, third, and fourth.

From our stance, however, Pintzuk's analysis is not a structural one, but a list of positions in tokens. Danish topological analysis offers a strategy for identifying strutural positions, namely that of generalising from maximally long examples to shorter and therefore less transparent ones (Diderichsen 1943). We use Pintzuk's examples as an illustration of this principle, and for ease of further exposition of the verb second issue we try to systematise and relate topologically some word order patterns found in Old English. We do not discuss the content of these Old English patterns, but only demonstrate how word order analysis can be carried out at the expression level. Where Old English is concerned, a major function of word order is probably to signal articulations of topic and focus structure, but we do not go into this issue. For a view of Danish focus articulation, historically and synchronically, see Heltoft (2003).

\subsection{Verb second and Wackernagel}

In some hypotheses of Germanic word order development, verb second is seen as originating from verbs in Wackernagel's position, i.e. the second position of the IE sentence as the position for atonic material, including verbs, see further mention in 6.2. A discussion of the rise of verb second is beyond the scope of the present text, but we shall demonstrate how the patterns found in Old English relate to each other when seen through the prism of topology. Old English is not a verb second language, as is Middle English, but it allows finite verbs to occupy the second position. For ease of exposition - the verb second issue is our focus of interest - we shall first contrast examples showing the finite verb in the second position with examples that do not.

\footnotetext{
a. eow sceolon deor abitan (V2)

you shall beasts bite at 'beasts shall devour you'

b. poet se eorðlica man sceolde gepeon (V2) that the earthly human being should enjoy 'that earthly man should prosper'
} 
a. poet he ahof upp pa earcan (V2)

that he lifted up the chest

'that he lifted up the chest'

b. poet he his stefne up ahof(-V2)

that he his voice up lifted

'that he lifted up his voice'

(18) a. Wilfred eac swilce of breotan ealonde wes onsend(-V2)

Wilfred also in this way from Britons' island was sent

'In this way Wilfred was also sent away from the island of the Britons'

b. swa swa sceap from wulfum and wildeorum

just as sheep from wolves and wild beasts

beoð fornumene (-V2)

are taken

'just as sheep are taken by wolves and wild beasts'

(19)

a. him por se gionga cyning pos oferforeldes

him there the young king this.GEN crossing-GEN

forwiernan mehte (-V2)

prevent could

'there the young king could prevent him from the crossing'

b. pa Apollonius afaren wees (-V2)

when Apollonius departed was

'when Apolllonius had departed'

Where a token oriented approach would here register verb second for (16ab) and (17a), it would register many instances that could not be verb second, namely: SOV for (17b), SXVv for (18ab), SvV for (19b), and finally for (19a) OASOvV, a complex case of SOV. Such apparently unsystematic examples can be related in a topological frame, generalising on the background of maximally filled examples. We start with (16) and (17):

\begin{tabular}{|c|c|c|c|c|c|}
\hline $\mathrm{C}$ & $\mathrm{X}$ & V & Middle Field & V & Postfield \\
\hline $16 \mathrm{a}$ & eow & sceolon & deor & abitan & \\
\hline 16b pæt & $\begin{array}{l}\text { se eorðlica } \\
\text { man }\end{array}$ & sceolde & & gepeon & \\
\hline $7 \mathrm{a}$ pæt & he & ahof & & upp $^{25}$ & pa earcan \\
\hline b pæt & he & & his stefne & up ahof & \\
\hline
\end{tabular}

25. We prefer this analysis as a generalisation from example (17b). An alternative analysis would be to consider ahof upp as one topological unit in the first V, pa earcan could then be in the middle field. We need not take this debate in the present context. 
We identify the position for verb second and place the remainder of the constituents represented in positions relative to that position. There are at least two positions for finite verbs, namely verb second and the later $\mathrm{V}$, which can also hold non-finite verbs, and, in fact, complex verbal constituents consisting of finite $\mathrm{V}$ and non-finite $\mathrm{V}(\mathrm{s})$. We can show this by adding (18b) and (19b), which show that finite and non-finite verbs can be contiguous.

$(21)$

\begin{tabular}{|c|c|c|c|c|c|c|}
\hline & $\mathrm{C}$ & $\mathrm{X}$ & $\mathrm{V}$ & Middle Field & $\mathrm{V}$ & Postfield \\
\hline $16 a$ & & eow & sceolon & deor & abitan & \\
\hline $16 b$ & pæt & $\begin{array}{l}\text { se eorðlica } \\
\text { man }\end{array}$ & sceolde & & gepeon & \\
\hline $17 \mathrm{a}$ & pæt & he & ahof & & upp & pa earcan \\
\hline $17 \mathrm{~b}$ & pæt & he & & his stefne & up ahof & \\
\hline $18 b$ & swaswa & sceap & & $\begin{array}{l}\text { from wulfum } \\
\text { and wildeorum }\end{array}$ & $\begin{array}{l}\text { beoð } \\
\text { fornumene }\end{array}$ & \\
\hline l & pa & Apollonius & & & afaren wæs & \\
\hline
\end{tabular}

This topological exercise, it will be noted, has not revealed any specific position for subjects. The absence of such a position would probably be a major point in a topological analysis of Old English. In principle, a language need not identify its subjects topologically.

We are now in a position to try and add a set of maximally complex examples, of a type that are in fact decisive with regard to determining topological structure. The strategy is to subsume the examples above having the finite verb in second position under a more general topology that will also comprise examples where the finite verb is not in that position. We started out by taking the second position to be the pivot (Heltoft 1992, 'the point of orientation that brings maximal order to the topological charts'). For Old English, this analysis hinges on the possibility of generalising it to cases where the second position is not filled by a verb but by light adverbs or unstressed pronouns. Insofar as these categories are mutually exclusive in this position, this strategy will allow us to treat the second position for verbs as identical with a different position not containing any verbal material. We name this unified position W to refer to Wackernagel's analysis of the second position as the IE position for pronouns, particles, conjunctions, atonic verbs and other types of atonic material. But notice that this result is in fact gained by means of systematic topological analysis. It is a synchronic reality of Old English to allow pronouns and atonic adverbs in the second position. 


\begin{tabular}{|c|c|c|c|c|c|}
\hline $\mathrm{C}$ & $\mathrm{X}$ & W & Middle Field & V & Postfield \\
\hline $18 \mathrm{a}$ & Wilfred & eac & $\begin{array}{l}\text { swilce of } \\
\text { breotan ealonde }\end{array}$ & wes onsend & \\
\hline $19 \mathrm{a}$ & him & pær & $\begin{array}{l}\text { se gionga } \\
\text { cyning pæs } \\
\text { oferfæreldes }\end{array}$ & $\begin{array}{l}\text { forwiernan } \\
\text { mehte }\end{array}$ & \\
\hline $16 a$ & eow & sceolon & deor & abitan & \\
\hline pæt & $\begin{array}{l}\text { se eorðlica } \\
\text { man }\end{array}$ & sceolde & & gepeon & \\
\hline pæt & he & ahof & & upp & $\begin{array}{l}\text { pa } \\
\text { earcan }\end{array}$ \\
\hline pæt & he & & his stefne & up ahof & \\
\hline swaswa & sceap & & $\begin{array}{l}\text { from wulfum } \\
\text { and wildeorum }\end{array}$ & $\begin{array}{l}\text { beoð } \\
\text { fornumene }\end{array}$ & \\
\hline pa & Apollonius & & & afaren wæs & \\
\hline
\end{tabular}

Not all verb second examples have an atonic verb and especially (17a) seems to have a full verb. But the point here is, of course, that the finite verb in second position has been generalised as a possible verb position (cf. Lass 1994:216-227), and this process can take place on top of the remnants of older word order principles and rules without necessarily removing them.

Old English is sufficiently archaic to give an impression of some intermediate stages between Wackernagel Indo-European and later old Germanic languages. The overview to follow is largely identical to Lass (1994). The template for Old English is given in Tables 2 and 3, with an overview of the Old English types of word order represented:

Table 2. Word order template for Old English

\begin{tabular}{llll}
\hline $\mathrm{X}$ & $\mathrm{W}$ & $\begin{array}{l}\text { Middle } \\
\text { Field }\end{array}$ & $\begin{array}{l}\text { Post } \\
\text { Field }\end{array}$ \\
\hline $\mathrm{V}$ & & \\
PRON. & & \\
ADV. & & \\
$\ldots$ & & \\
\hline
\end{tabular}

Table 3. Overview of Old English types of word order represented

\begin{tabular}{lllll}
\hline $\mathrm{X}$ (Initial) & W & Middle field & V & Postfield \\
\hline S & ADV & ADV ADV & Vf Vi & $18 \mathrm{a}$ \\
O & PRON.ADV & SO & Vi Vf & $19 \mathrm{a}$ \\
\hline
\end{tabular}


Table 3. (Continued)

\begin{tabular}{lllll}
\hline X (Initial) & W & Middle field & V & \multicolumn{2}{c}{ Postfield } \\
\hline O & Vf & S & VI & $16 \mathrm{a}$ \\
S & Vf & & VI & $16 \mathrm{~b}$ \\
S & Vf & O & Dir.part Vi & $17 \mathrm{a}$ \\
S & Vf & & Dir.part. & O \\
S & & ADV & Vf Vi & $17 \mathrm{~b}$ \\
S & & & Vi Vf & $19 \mathrm{~b}$ \\
\hline
\end{tabular}

\subsection{Old English synchrony and a possible scenario for Scandinavian verb second}

We shall not pursue the issue of verb second for English, but the Old English types offer a clear basis for the reanalysis bringing about Old Scandinavian structure. We may hypothesise, then, that Scandinavian verb second arose from Wackernagel structures that came under pressure from reanalyses of $\mathrm{W}$ (= atonic verb second etc.) as a general position for finite verbs, the synchronic point being that the only way to formulate such a hypothesis is through analyses of possible preceding synchronic word order systems, like the one sketched for Old English. The template XW...OV will produce tokens including $\mathrm{XV}_{\text {fin }} \ldots \mathrm{OV}$. This token will be open for reanalysis of the sequence $\mathrm{XV}_{\text {fin }}$ as the general position for finite verbs. In the long run, this will lead to the obsolescence of $\mathrm{OV}_{\text {fin }}$ (hence of SOV) and of $\mathrm{W}$ as a general position for unaccented constituents (constituents with stress reduction or pitch reduction, see briefly W.P. Lehmann 1993:58-61). Moreover, tokens like $\mathrm{XV}_{\text {fin }} \ldots \mathrm{O}$, originally reduced versions of potential $\mathrm{XV}_{\text {fin }} \mathrm{OV}$, are susceptible to reanalyses, leading to a general possibility for a verbal nucleus - finite or non-finite - to be followed by its valency-bound arguments. In other words, $\mathrm{V} 2 \ldots \mathrm{O}$ could have been reanalysed as an instance of a general word order option V...O, thus yielding the general topological structure for the verbal complements of Old Scandinavian:

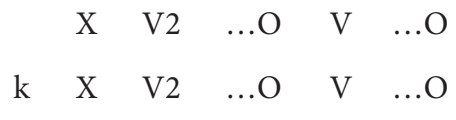

Old Scandinavian is an obligatory and symmetrical verb second language, that is, a language with verb second in both main clauses and in subordinate clauses. Examples to show both that extension of $\mathrm{V} 2 \ldots \mathrm{O}$ to $\mathrm{V}$... O has taken place and the symmetrical character of the verb second structure are presented in (23)-(26). Examples (23)-(24) show XV2 in a main clause and a subordinate clause, respectively. 
$(23)$

cen kirke ran ma thoet cy hete. utæn
but church open theft can it not be called, unless

han wil cey repoe.

he will not use ropes

'But this cannot be called open theft from a church, unless he does not wish to measure land with ropes' (Zealand Ecclesiastical Law 6. GL 11:27-29)

(24) En vm hin orcar oy thre marc oer brutit hafuir. tha... but if he is able to not three marks that offended has, then ... 'But if the offender cannot provide three marks, then ...'

(Scanic Ecclesiastical Law 4. GL 11:6-8)

Examples (25)-(26) show zero vs. V2 in a main clause and a conditional, subordinate clause, respectively.

ser thu cei thoet thince afguthoe... hauce ongi craft

see you not that your idols... have no power

'Don't you see that your idols ... have no power'

(Legend of St. Christina. GL 284:32-34)

(26) Falla bj ofna annars mans bj. oc bryta them fall bees upon another mans bees and break them

til døtha. tha...

to death, then ...

'If the bees fall upon another man's bees and put them to death. then...'

(Scanic Law 200. GL 35:28)

Earlier and later verb second in Danish are be compared in detail in Chapter 6, together with a study of the reanalyses and actualisation processes that lead from one to the other.

\section{Degrammation of word order paradigms?}

Topological degrammation consists in processes by which grammatically significant word order differences are abandoned. As an example, we shall discuss the development of Danish anaphoric pronouns, an instance of weak cliticisation. (We return to clitics in Section 6, as part of our examples of complex paradigms).

The term 'weak cliticisation' refers to the fact that linguistic items may depend prosodically on some other item in a clause without losing their topological functions in the clause. An interesting example is found in Danish anaphoric personal 
pronouns and pronominal adverbs. This phenomenon is known in generative grammar as object shift (Holmberg \& Platzack 1995; Vikner 1995; Bjerre, Engels, Jørgensen \& Vikner 2008), although the rules involved probably never applied to objects alone, neither in the old language nor in Modern Danish. Instances are (27a) and (28), stress reduction is indicated by subscript 'o', as in ${ }_{0}$ hende 'her', ${ }_{0}$ det 'it', 'that'.

a. Han fortalte ohende det aldrig he told her it never

'He never told her'

b. Han har aldrig fortalt ohende ${ }_{0}$ det he has never told her it 'He has never told her'

(28) Hun boede oder ikke

she lived there not

'She didn't live there'

Pronouns and pronominal adverbs with stress reduction are contiguous to their governing verb, meaning that they precede negation only if their governing verb does, $\mathrm{cf}$. $(27 \mathrm{ab}, 28)$. They respect illocutionary rules, that is, they respect the positional rules for the illocutionary subject, and they can fill in the initial position to produce a declarative word order pattern. So we have (29a) and not (29b):
a. Fortalte Peter ohende odet aldrig? told Peter her it never 'Did Peter never tell her?'
b. *fortalte ${ }_{o}^{\text {hende }}$ det Peter aldrig told her it Peter never

And the unstressed pronoun has a full function in the initial position, parallel to constituents with a full stress.
a. Forstod du det ikke selv? understood you it not yourself? 'Didn't you understand it yourself?'
b. Nej, odet forstod jeg ikke selv no it understood I not myself 'No, I didn't understand it myself'

Unlike English, Danish allows anaphoric unstressed pronouns in the intital position. Examples (30ab) have been deliberately formed with a focus constituent (selv 'myself, yourself' etc.) different from the anaphoric pronoun to prevent focus readings of the pronoun. 
We would find it a plausible solution to say that these anaphoric pronouns cliticise in the weak sense not to their governing verb but to the predicational nexus. Enclitic:

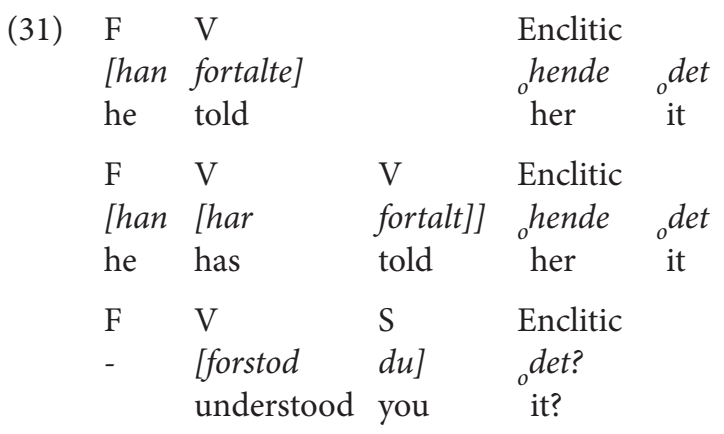

and proclitic to bring the pronoun in the first position:

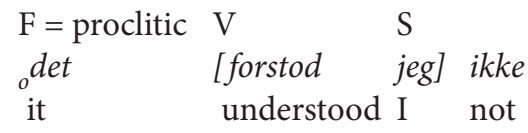

'I didn't understand it'

We shall not make a major point out of this last part of the analysis, since the grammatical nexus is not a concept in fashion in leading grammatical schools and theories. The point that the anaphoric objects and pronominal adverbs serve as topological constituents in their own right will hold, whatever basic truths and grammatical axioms one assumes.

As seen from our stance, to a large extent this is a degrammation process. In the Middle Ages, placing the anaphoric pronouns to the left of the negation was part of a wider system of iconic information structure. NPs and adverbials could generally precede or follow the position for negation. If they preceded the negation, they were sheltered from its scope and hence marked as background or non-focused constituents. Anaphoric pronouns would automatically background, unless stressed. But it should be notes that the rule was more general than the modern rules, since background position and focus was possible for complex NPs and complex adverbials as well. At this stage Old Scandinavian had no specific position for the subject, which could occur in background, focus and neutral position, as expected, with background as the most frequent position.

The topology of the middle field is shown in (33)-(35):

(33) at han giorthe bonda-num oxy mera schatha $i$ thy afhoggi. that he did owner-DEF.DAT not more damage in this cut 'that he did not cause more damage to the owner in this cut'

(Scanic Law 122. GL 25, 22-23) 
$(34)$

tha ma han halfw-an gifwa clostr-e oelloer hwem sum the may he half-ACC give monastery-DAT or who.DAT that han wil oc eig mera...

he will and not more...

'then he may give half (of his fortune) to a monastery or to whom he will, and no more...'

$(35)=(7)$

thy lat giøra vppe $i$ tornit et hemelikt hws...

therefore let-IMP.SG make up in the tower a secret room...

$i$ hwilko som wi magh-om hemeliga blifva

in which that we can-1PL secretly stay

'Therefore have a secret room made up in the tower in which we can dwell in secret'

(36) $\mathrm{F} \quad \mathrm{V}$ background Neg focus $\mathrm{V}$ neutral

$\begin{array}{llllll}\text { (at) han giorthe bondanum } 2 y & \text { mera scatha } & \text { i thy af hoggi } \\ \text { tha ma han } & \text { halfwan gifua clostre } & \text { hemeliga blifva }\end{array}$

The reanalysis to modern Danish is illustrated in Table 4:

Table 4. Topological reanalysis of background positions.

Middle Danish:

\begin{tabular}{llll}
\hline $\mathrm{X} V \quad \begin{array}{l}\text { background } \\
\text { positions }\end{array}$ & $\mathrm{Neg}$ focus \\
& positions & $\mathrm{V}$ neutral \\
positions
\end{tabular}

Modern Danish:

X V S unstressed Neg focus ${ }^{\star}$ ) V neutral pronouns positions positions

${ }^{\star}$ The focus position in the modern language contains free adverbials only, see Chapter 6, Section 3.7

In the modern language, the background positions have developed into the fixed positions for the subject (the background constituent par excellence), and the positions for pronouns with stress reduction. Full valency constituents (objects and PPs) are all in the neutral positions in modern Danish.

The positions for unstressed pronouns in main declarative clauses are what is left of the former iconic word order system that marked the informative status of 
phrases. The particular part of the change that concerns the stress reduced pronouns is a degrammation process, not because it reduces the semantic importance and function of the positions, but because it dismantles former grammatical paradigms. The background vs. focus distinction of the medieval paradigm is gone. The modern unstressed pronouns are background elements in terms of their expression, and their clitic positions cannot be shown to have any independent function in the modern language similar to the old system. Rather, the change of content involved is a change to indexical meaning (Andersen 1980); the positions point to what is already there in the pronominal stems and thus add nothing extra.

This process could also be classified as a regrammation process, since the expression remnants of the background positions are still identifiable and obviously have been ascribed new grammatical functions. But this new grammatical function seems to be one of expression regulation and redundancy alone, and our point in speaking of degrammation here is precisely the loss of paradigmatic structure.

In a wider sense of degrammation, we would expect the total erasing of the specifically clitic positions. Such a process is also documented in the history of the Danish language, namely in southern insular and some south Jutland dialects. In these dialects, unstressed pronouns are treated along with ordinary full objects and adverbs, and clitic positions no longer exist.

I sådan et stormvejr der hitter I aldrig oden
In such a gale there find you never it
'In gale like this, you'll never find it'

KMP Langeland (Standard: der finder I den aldrig)

(38) $O g$ så lige pludselig, så står han jo også der. And then all of a sudden, then stand he part also there 'And then all of a sudden, he was standing there, for sure, too' KMP Lollandsk (Standard: så står han der jo også)

$$
\begin{aligned}
& \text { Jeg misundte ikke ham det } \\
& \text { I envied not him it } \\
& \text { 'I didn't envy him for that' }
\end{aligned}
$$

KMP Langeland (Standard: jeg misundte ham det ikke)

To sum up: if grammation was seen solely as a cline, the development of the clitic pronouns would misleadingly count as an instance of increasing grammation. The point here is that although the unstressed pronouns still take part in the illocutionary word order system, in the present language the former background positions have lost their status as part of an information structural word order paradigm: background, focus and neutral positions. From the point of view of the paradigm theory of grammaticalisation, the development of the Danish clitic pronouns is a 
clear instance of degrammation, since what is preserved in the modern standard language is part of the former expression system functioning as a redundant indexical co-system, all at the level of expression: position pointing to unstressed pronoun, an extra formal indication of the function of the unstressed anaphoric pronouns per se.

\section{Examples of topological oppositions integrated in hyperparadigmatic structures}

In Sections 3 and 4 examples were presented of topological paradigms and a simple example was given of a complex paradigm uniting a topological and a morphological distinction. In this paragraph, such integrative paradigms (hyperparadigms) will be further discussed and exemplified through a discussion of cases where clitics and topology interact with each other - and with constructional hierarchies.

Below we consider a scale of levels of cliticisation - not a continuum, since all steps will be well-defined - and some of these levels will be interesting as instances of connecting grammaticalisation.

To achieve this, we will define clisis as any process that reduces the independence of one constituent in order to signal its grammatical function. The expression side of such a paradigm is some kind of prosodically reduced element; the content is an instruction about how to identify the clitic as part of a larger content syntactic unit.

\subsection{Complex constituent formation}

The breadth of the definition formulated above will allow us to include, for instance, examples of stress reduction as a signal to indicate unity in discontinuous constituents, a phenomenon very common in Danish. In this language, large sets of complex constituents are formed by way of stress reduction on the first of two constituents as a signal that this constituent is the first of two (or more) that together form one complex and possibly discontinuous constituent. Both complex noun phrases and complex predicates are formed this way; we restrict ourselves to instances of predicate complements. In (40) the adverbial predicate complement is preceded by two verbs with stress reduction:

(40) Hun or okommet for sent 'hjem she is come too late home 'She has come home too late'

(41) Hun or 'kommet she is come

'She has come' 
As seen by comparing (40) and (41), the reduction of stress on the finite verb points to the main verb kommet; the full stress on this verb in (41) identifies this form as the predicate nucleus. In (40) the reduction on kommet points to the adverbial complement hjem as the nucleus. The result is a complex expression structure of a likewise complex content syntactic structure: ${ }_{0}$ er $\left[{ }_{0}\right.$ kommet 'hjem]], the present perfect corresponding to the simple present:
Hun okomm-er for sent 'hjem
she come-prs too late home
'She will be home too late'

In many cases this pattern distinguishes predicative constructions from argument locative constructions, or from constructions with a prepositional indirect object. (43a) and (44a) are instances of complex predicate formation and (43b) and (44b) of three-place argument constructions.
a. Hun stillede
she put
vasen til'side
$\mathrm{A}^{1} \underset{\mathrm{P}}{\left[{ }_{\mathrm{o}} \text { stillede }(\mathrm{V}) \text { til 'side (Adv) }\right] \mathrm{P}^{2}}$
the vase to one side
b. Hun 'stillede
$\mathrm{A}^{1} \underset{\mathrm{P}}{[\text { 'stillede }(\mathrm{V})]} \mathrm{A}^{2} \quad \mathrm{~A}^{3}$
vasen $\quad i^{\prime}$ vinduet
she put the vase in the window

(44)
a. De sendte they sent
$\mathrm{A}^{1} \quad\left[{ }_{\mathrm{o}}\right.$ sendte $(\mathrm{V})$ til 'London (Adv) $] \mathrm{A}^{2}$ $\mathrm{P}$
pakken til'London
the parcel to London
$\mathrm{P}$
b. De 'sendte pakken til'Elisabeth they sent the parcel to Elisabeth $\mathrm{A}^{1} \quad[$ 'sendte $(\mathrm{V})] \mathrm{A}^{2} \quad \mathrm{~A}^{3}$

This type of cliticisation straddles parts of discontinuous constituents, at the same time respecting the topological structure of the sentence. At this level, cliticisation takes place without reduction or even alteration of the topologically borne functions of the sentence. Verbs with stress reduction can nevertheless function as verbs second, a precondition for the clause to be marked as a declarative structure, thus making the paradigmatic choice between Realis and Conditioned Realis possible. In the case of unitary stress reduction, the function of stress reduction is solely to interact with the semantactic (content syntactic) hierarchies of the clause.

The analysis of unstressed pronouns in Danish in the present section is a parallel to this point. In neither case does stress reduction rob the pronoun of its topological 
functions, and in this sense we need to include also this type of dependency among the possible defining criteria for clitics. Stress reduction on a syntactic item can signal that this item is part of a complex constituent, typically at the level of semantic syntax, so that the hearer needs to identify its second part, one that carries full stress. In such a case, cliticisation is bound up with semantic syntax, and only secondarily with topology.

\subsection{Wackernagel's law in Latin}

Wackernagel's law illustrates the opposite point about cliticisation. Cliticisation can be bound up with topology alone, establishing a complex opposition between unmarked positions for full constituents and the Wackernagel position for clitics. Notice that the clitics of e.g. Latin are not marked morphologically, contrary to the clitics in later Romance. Some adverbs etc. are born clitics, but there is no opposition between clitic and non-clitic forms of the Latin pronouns, for instance. In Wackernagel's wording, it is the position that is connected with reduction of tonicity: 'die Latinisten /lehren schon lange dass zumal in klassischer Prosa die Stelle unmittelbar hinter dem ersten Wort des Satzes mit Tonschwäche verbunden sei, und die dorthin gestellten Wörter entweder von Haus aus enklitisch seien oder es durch eben diese Stellung werden' (Wackernagel 1892, quoted from Strunk 1973:388). We stipulate that the prosodic system was a pitch system, cf. W.P. Lehmann (1993:60).

The following group, partly from Wackernagel's own material (W), are good examples from Latin of Wackernagel's law.

\section{Utinam me divi adaxint ad suspendium wish me the gods may drive to hanging,} potius quidem quam hoc pacto apud te serviam rather instead than on these conditions with you serve-sBJv.1sG 'Wish the gods may drive me to hang myself, rather than I should serve with you instead'

According to Wackernagel's law, any preceding constituent or element can function as the host of a clitic, and the clitic can consist of material from various types of constituents. The clitical host utinam is an illocutionary particle, potius a comparative adverb, the clitics being a personal pronoun ( $m e$ ) and an adverb (quidem). Similarly:

(46) Av-is me fer-ae consimil-em faciam,

bird-GEN I.ACC wild-GEN similar-ACC make-FUT.1sG

ut praedicas.

as say-PRS.IND.2sG

Plautus Captivi 120

'I shall make myself into a copy of a wild bird, as you are saying' 
According to Wackernagel, the rule is also well-represented in classical Latin, for instance in Cicero:
ita mihi de-os
vel-im
propiti-os.
thus I.DAT gods-ACC want-PRS.SBJv.1sG gracious-ACC

'In this way I would like the gods to be gracious to me'

W 392-93 (Cicero divinatio in Caec.)

(48) sic te diva potens Cypri(..) regat.

Thus you-ACC goddess mighty Cyprus-GEN rule-PRs.sBJv.3sG

'Thus shall the mighty goddess from Cyprus rule over you'

W 393 (Horace Od. 1,3,1)

(49) populus se Romanus erex-it. people refl.ACC roman stand up.PRF-IND.3sG 'The Roman people stood up'

W 390 (Cicero Brutus)

Since the ancient Indo-European languages do not have contiguous groups, (Meillet 1964[1937]:360), the basis can consist of just one single pitch carrying word, for instance: the head of a noun phrase $(46,49)$, an adverb $(47,48)$, a preposition, part of a compound or a derived word (in so-called tmesis) (50) and (51).

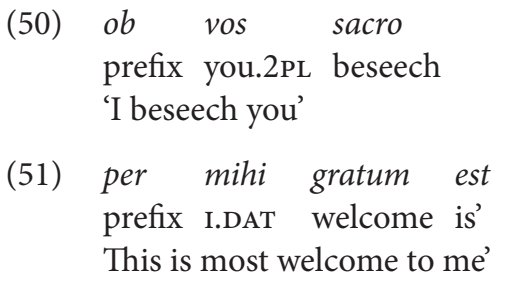

The clitics and the bases in the examples mentioned:

$\begin{array}{lll}\begin{array}{l}\text { host } \\ \text { utinam }\end{array} & \text { clitic } & \\ \text { potius } & \text { quidem } & \text { divi adaxint ad suspendium } \\ \text { avis } & \text { me } & \text { ferae consimilem faciam } \\ \text { ita } & \text { mihi } & \text { deos velim propitios } \\ \text { sic } & \text { te } & \text { diva potens Cypri (..) regat } \\ \text { populus } & \text { se } & \text { Romanus erexit } \\ \text { ob } & \text { vos } & \text { sacro } \\ \text { per } & \text { mihi } & \text { gratum est }\end{array}$

Wackernagel's law does not apply to any specific morphological classes or types of constituent. All types of material that can lose their pitch - or are born clitics - may enter this position. 
Abstract though it may seem, this topological phenomenon will also count as a result of connecting grammaticalisation, the parameters being position and \pm pitch. There is no loss of independence in relation to other syntactic categories. The content of such cliticisation is indexical, that is, a redundancy relation between position and pitch. It is probable that the Wackernagel position also points indexically also to the initial position as a focus position, but we need not pursue this point.

\subsection{Old French topology and the tonic - atonic pronominal system - an example of connecting grammaticalisation}

The examples considered in 6.1-6.2 were all instances of cliticisation 'without morphology', in the sense that the elements involved had no specific expression except for reduced pitch, or reduced stress.

Languages with a specific morphology for clitics are of course well-known, Italian and French being obvious examples. Less well-known is the fact that some languages have complex sets of rules for such morphological clitics in interaction with a topological system. Old French is such a language.

The general character of Old French as a verb second language seems beyond doubt, as documented in prose texts, and V2 topology forms a textual paradigmatic contrast with ' $V 1$ '- examples, see ChapterVI for references. We shall pursue the analysis of Old French by showing how verb second interacts with the Old French pronominal system, as a primary and canonic example of what we call connecting grammaticalisation, in this case a morphological paradigm and a word-order borne distinction of mood. A source of reference is Povl Skårup (1975), a major contributor to Danish topological tradition, who consistently applied the theory and method of Diderichsen to the Old French material.

Old French is a pure verb second language, in contrast to Modern French, which is an SVO language of a particular type. The pronominal systems of the two stages of French differ with respect to morphology, topology and syntax. For Old French, the central issue where topology is concerned is the distinction in the accusative and the dative between atonic and tonic forms of the personal pronouns, especially the 3rd person forms. We list a paradigm, which can be extrapolated from Skårup (1975) and from any good introduction, such as the Old French manual by Thomasset and Ueltschi (1993). As seen from a topological stance, the function of the atonic forms, as described by Skårup, is to act as morphological signals for the topological structure of the clause. These pronouns have been reinterpreted in Modern French as a set of clitic pronouns - or bound pronouns - cliticising in the strict way of never allowing other material to squeeze in between themselves and their verbal head. 
The following is a template for Old French word order:

(52) Conj F V2 3rd V Postfield

F is the fundamental field, the position named ' 3 rd' is the position normally held by a subject that is not already in $\mathrm{F}$. The atonic pronouns may precede the finite verb, and in this case they show their next to proclitic status by not taking up a position in the topological frame but leaning on the verb instead.

In the following examples the sequences underscored are joint fillers of the V2 position only.

$\begin{array}{lllll}\text { Et il respont } & \text { que ce ne feroit } & \text { il pas } \\ \text { and he answer-PRs.3sg } & \text { that this not do-COND.3sg he } & \text { NOT }\end{array}$ 'And he answers that this he would not do'

(Vance 141)

(54) Et de ces trois choses vos dir-é je bien la and from these three things you say.FuT-1sG I well the senefiance significance

'And of these three things I may very well tell you the significance'

(Vance 164)

As they are not clitics, subject pronouns do not glue to the position of the $\mathrm{V}$, but take up their own position, see (55).

(55) quant nos donr-ons abondance dargumens en

when we give.FUT-1PL plenty of arguments in

chascun des eissamples

each of the examples

'When we come to giving plenty of arguments for every single case'

La Rectorique de Marc Tulles Cyceron, 016-1

(56) car je sai bien que l'aventure acheveroiz vos legierement

'for I know well that the result you will easily achieve'

a. et se vos $\underline{\text { ne }} \underline{\text { le faites. }}$.

and if you not it do-PRs.2PL

b. tu an perdr-as la teste

thou from that lose.Fut-2sG the head

'And if you do not do so, thou willst lose thy head in return' (Buridant 422)

This also applies to subject pronouns following the verb.

volz tu un men cunseil celer
Will you.sG a piece of advice of mine hide
'Wouldst thou conceal a piece of advice of mine?'

(Buridant 422) 
(58)

Sire, bien soi-ez vos venu-z!

'Sire, well be.PRS.SBJV-2PL you.PL come.PRF PTCP-PL

'Sire, you are very welcome'

(Vance 144)

(59) Et li rois dis-t que si feroi-t

and the king say-PST that thus do.COND-3s

il volontiers

PRON.3SG with pleasure

'And the king said he would do so with pleasure'

(Vance 160)

Compare also the occurrences of vos in (54) (atonic; the initial position is already filled in) and (56a) (tonic; no other initial constituent).

Thus, the atonic forms do not run counter to the verb second rules of Old French. The tonic subject pronouns cannot intervene between atonic pronouns and their finite verbs, and they must follow the finite verb if position 1 is already filled by some other constituent. In contrast to (54) and (59), we do not find cases like (60)-(62):

(60) Et il respont que ce

a. ${ }^{*}$ ne il feroit pas /

b. ${ }^{\star}$ il ne feroit pas

(61) Et li rois dist que si $\quad \star_{\text {il feroit volontiers }}$

(62) Et de ces trois choses a. *vos je diré bien /

b. $\star_{j e}$ vos diré

As indicated above, the subject pronoun is always a full tonic pronoun, whatever its position in relation to the finite verb. There is, then, a striking asymmetry between the morphology of the oblique case forms - distinguishing tonic and atonic forms systematically - and the subject or nominative form of the pronoun, existing only in a tonic form. The anaphoric contexts occupied by atonic oblique forms, attached to their verbal positions, correspond to zero subject pronoun contexts. Consequently, we include the subject in the pronominal paradigm for tonic and atonic pronouns, by counting zero subject pronouns as the morphosyntactic parallel of the atonic pronominal forms.

This analysis of zero subject pronouns follows from the central role we attribute to paradigmatic organisation. 'Subjecthood' is expressed through 'zero' in its paradigmatic opposition to oblique atonic forms. In no way would we be allowed to count the person-number inflexion of the finite verb as part of the pronominal paradigm; these inflexional paradigms belong to a different sign system with the similar function of instructing the addressee how to identify the subject referent. 
The Old French oblique pronominal system, then, forms a complex hyperparadigm with the system for subject referent identification (63):

(63)

\begin{tabular}{|c|c|c|c|c|}
\hline & \multicolumn{2}{|l|}{ tonic } & \multicolumn{2}{|l|}{ atonic } \\
\hline & 1./2.p & 3.p m/f & 1.2.p & 3.p m/f \\
\hline $\begin{array}{l}\text { nom. } \\
\text { sg }\end{array}$ & $\mathrm{je} / \mathrm{tu}$ & il/ele & -zero- & -zero- \\
\hline acc.sg & \multirow{2}{*}{ moi/toi } & \multirow{2}{*}{ lui/li } & \multirow{2}{*}{ me/te } & le/la \\
\hline dat.sg & & & & li \\
\hline $\begin{array}{l}\text { nom. } \\
\text { pl }\end{array}$ & \multirow{3}{*}{$\begin{array}{l}\text { nos/ } \\
\text { vos }\end{array}$} & il/eles & \multirow{3}{*}{ nos/vos } & -zero- \\
\hline acc.pl & & eus/eles & & les \\
\hline dat.pl & & eus/elles & & leur \\
\hline
\end{tabular}

This hyperparadigm, again, has a third dimension not shown in (63), namely that of connecting to the topological system as a precondition for the word order paradigms to be interpreted in actual text. Morphology and topology must be described as an interactive system, and the content descriptions of the tonic and atonic varieties must include their instructive potential with respect to the application of the topological system.

Italian provides an illuminative contrast. In this language, the position of atonic pronouns are indices of the morphological difference between finite and non-finite verbs: lo vedo 'I see him' vs. vederlo 'to see him', ce la faccio 'I make it' vs. farcela 'to make it. But Italian has no fixed topology for the pronominal system to point to. The Old French system, however, has the additional function of being an indexical cosystem of the verb second system. Notice that the functions of this pronominal system are not identical to the function of the modern French distinction between unbound and bound pronouns. But any analysis of the change from Old French must include the change of semantic interface between pronouns and word order. 


\section{CHAPTER 3}

\section{Constructions}

\section{Introduction}

According to the concept of grammar proposed here, grammatical structures cannot be described without reference to the paradigmatic organisation that lies behind the syntagmatic realisations. In the section on morphology, we discussed the traditional description of a morphological paradigm as the full set of inflectional forms of a given lexeme, including the likewise traditional extension to periphrastic forms. We emphasised our view that the expression structure is linked to a semantic structure, i.e. a structure of content elements. It follows that the content and the function of a linguistic unit depend on its systemic relations to other linguistic units.

In the section on topology, we put forward arguments for considering not only morphology but also word order to be organised in terms of paradigms defined as sign oppositions within one or more semantic domains, such that we find minimal differences of expression (word order distinctions) attached to oppositions of content. In the following we will extend the notion of a paradigm still further to comprise constructions. A more general discussion of sets of options constituting a paradigm is presented by Heltoft (1996), Harder (1996: 207-208, 251-252) and by Andersen (2008), who uses the term paradigm "not in the narrow sense of 'inflectional paradigm, but in the general sense of 'selectional set', a usage that has been traditional since Saussure". In the case of grammatical content, such a selectional set is a closed set of obligatory categories, a grammatical paradigm.

We motivate and illustrate our definition of constructions in Section 2. We intend to clarify the relation between the different levels implied here, i.e. the level of the lexicon including valency as opposed to that of constructions (Section 2.1). According to our definition, we should expect constructions to be language specific signs and not language specific expressions of universal cognitive content, as shown in Section 2.2.

A major point is that we always find paradigmatic oppositions between constructions, an issue to be developed further and summarised in Section 2.4. The languages referred to are mainly Danish, English and French. These are all morphologically relatively poor languages as far as their nominal morphology is concerned, but have 
evolved from richer inflexional stages. We show in Section 2.5 how constructional distinctions in these languages can be expressed differently in inflexional languages such as Finnish, Russian, and Latin.

Given that constructions are part of grammar, we must expect them to participate in grammatical changes. This is investigated in Section 3.

\section{Definitions and motivations for introducing the level of constructions}

\subsection{Definition and exemplification of constructions}

In this section we discuss the status of constructions and develop a proposal by Lars Heltoft that the concept of a paradigm should be extended to the analysis of constructions. If constructions are part of grammar, we should clarify to what extent they are organised according to principles already known from morphological (and topological) parts of grammar. ${ }^{26}$

We put forward and defend the following definition: A construction is a complex sign with an internal syntax and a semantic coding. Its grammatical status is defined by its position in a paradigm, and as in morphology and in topology, we say that a paradigm has both a domain and a frame. The domain of a constructional paradigm is the syntagmatic context in which the paradigmatic relations between two or more constructions apply; the frame is the common semantic denominator for the paradigm (its conceptual zone, 'Begriffszone' in Hjelmslev's sense (1935-37, 1972; see further Heltoft 1996, Christensen 2007). As an example of a domain, take the transitive syntactic pattern satisfied by a set of two place verbs in Danish, see (1a)-(1b). Telicity in Danish will serve as an example of a frame or common semantic denominator. In all paradigms, language specific expression is linked to language specific content.
a. Peter skød Frederik
'Peter shot Frederick'
b. Peter skød på Frederik
'Peter shot at Frederick'

The Danish verb skyde 'to shoot' can be construed in different ways: It can follow a simple transitive pattern with a direct object (1a) or a prepositional pattern with the

26. The view that constructions are paradigmatically organised lies behind Hansen and Heltoft (2011) and is carried out in part in that work, see further Hansen and Heltoft (2005), Heltoft (2008). 
preposition på 'at', (1b). The difference between these constructions can be described in terms of telicity, as the direct construction denotes an action and the prepositional construction an activity (Durst-Andersen \& Herslund 1996). Actions are activities leading to completion, i.e. to a new state. Atelic constructions simply denote an activity and are neutral with respect to the question of completion. Thus, the atelic construction (1b) denotes an activity without including a result of this activity. This means that completion is substantially possible but not relevant for this linguistic option. Thus, the following sentence is grammatical: Peter skød på Frederik, men ramte ham først $i$ tredie fors $ø g$ 'Peter shot at Frederick, but he didn't hit him until the third try'.

Parallel to morphological and topological paradigms, a domain must be identified, namely a syntagmatic context in which the paradigmatic contrast applies. The syntagmatic condition of the present paradigm is transitivity, that is a verbal stem and its A2 (argument 2). The syntagmatic position in which the contrast applies is in square brackets: [A2].

The paradigmatic contrast is between zero and a preposition (in the unmarked case: $p a$ ' at'). The zero option results in the direct object and the simple transitive sentence (1a). The choice of a preposition results in the prepositional object (1b).

Again, the content dimension of the paradigm is called its frame, compare Chapter 1, Table 1 with its explication of this notion. The frame of the present paradigm is 'telicity'.

Table 1. The paradigmatic structure of telicity illustrated by ( $1 \mathrm{a}-\mathrm{b})$

Domain: $\mathrm{V}+[\mathrm{A} 2]$

Frame: Telicity

\begin{tabular}{ll}
\hline Expression & Content \\
\hline zero + NP & telic \\
prep + NP & atelic \\
\hline
\end{tabular}

The paradigmatic opposition of content from (1a) to (1b) is caused neither by the verb skyde, which is identical in the two examples, nor by the number of arguments, which is also identical, but only by the change of construction, from simple to prepositional. Notice that the opposition here is not a case of plain compositional syntax, since this function of $p a ̊$ is not found outside this context and the meaning of (1b) is not local.

Thus, these constructions are paradigmatically organised. The alternation between a simple construction and a prepositional one with $p a ̊$ is very common in Danish. Thus we find the verb skrive 'to write' showing a similar alternation between the direct 
construction designating an action (2a) and the prepositional construction designating an atelic activity (2b):

(2) a. Peter skrev romanen

'Peter wrote the novel'

b. Peter skrev på romanen

'Peter was writing the novel'

Other verbs showing this alternation pattern are bygge 'to build', kommentere 'to comment', male 'to paint', skubbe 'to push', sy 'to sew'. Indeed, this alternation is so productive in Modern Danish, that we even find it in modern loans. The new Danish verb brainstorme, in British English brainstorm as in 'to brainstorm on a topic', is integrated into this alternation. Speakers test different prepositions (3a-b), very frequently the preposition $p a ̊$ ' at' (3a). The following examples are all from google.dk.
a. vi brainstormer på egne og andres ideer we b. ${ }^{27}$ on our own and others' ideas
'we are brainstorming on our own and others' ideas'
b. vi forsøgte at brainstorme over emnet we tried to b. on the topic 'we tried to brainstorm on the topic'

The transitive opposition is found, too, although less frequently (3c):

c. lederen beder deltagerne om at "brainstorme"
the chairman asks the participants to b.
et emne
a topic
'the chairman asks the participants to brainstorm a topic'

What is interesting here is that this new Danish coinage is integrated into the existing system of paradigmatic oppositions between the atelic prepositional construction and the telic direct object construction. In the case of (3c), the verbal construction denotes a complete action including an accomplished state of result. In contrast, we have a prepositional construction denoting an atelic activity with no denotation of a result achieved (3a), just like the meaning expressed by (1b). The examples quoted so far thus show that the constructions illustrated by examples (1a), (2a), (3c), and (1b), (2b), (3a) are paradigmatically organised, and the examples quoted in (3) illustrate the productivity of the paradigm.

The synchronic reality of constructional paradigms is also obvious from the fact that they may also be adopted by existing transitive verbs. This is illustrated by the

27. In (3) the verb is abbreviated as b. in the glosses. 
Danish verb kommentere, 'to comment', traditionally found only in a direct object construction (3d), but which has become increasingly popular amongst Danish politicians in its atelic use $(3 e){ }^{28}$

\section{d. Peter kommenterer sagen \\ 'Peter makes his comments on the case' \\ e. Peter kommenterer på sagen \\ 'Peter is making some comments on the case'}

The existence of a constructional paradigmatic relation does not depend on the number of verbs instantiating the frame of the paradigm but on the presence of an opposition between complex signs. By definition, paradigmatically organised constructions share a syntagmatic domain and belong to a common semantic frame. Thus, constructions that form paradigms will have a systematic relationship between content and expression, to be studied through applications of Hjelmslev's commutation test (1943: 66-67, cf. Siertsema 1955: 166ff.). This is one important point of difference between our view and that of Construction Grammar (e.g. Goldberg 1995) and Radical Construction Grammar (Croft 2001). See further Chapter 7. For a comment on the difference between paradigmatic structure and diachronic layering as used by Paul Hopper and Elizabeth Traugott, see Chapter 4, Section 3.

So far, we have defined and illustrated the following notions of our definition of constructions: complex sign, paradigmatic relation, syntagmatic domain and semantic frame. The examples (1)-(3) show that such alternations should be described as part of grammar and not of the lexicon in the form of valency patterns of individual predicates. ${ }^{29}$ Remember that the verb stem does not signify the telicity contrast and the difference in the type of arguments in (1)-(3). Consequently, it is necessary to distinguish between two levels of analysis: the level of lexicon, including the description of valency patterns for individual verbs, and the level of constructions. We consider the opposition between (1a) and (1b) to be a 'minimal pair' for establishing a construction. In the following subsection we illustrate one further point, namely the language specificity of constructions.

28. The popularity of (3e) may have been favoured by its English equivalent which is, however, always prepositional, and which, accordingly, differs from the Danish verb as it does not have a paradigmatic relation to a direct transitive construction.

29. A clear distinction between valency and non-lexical, compositional dependency structures is found in Eisenberg $(1989,2006)$, a main source of inspiration for Hansen and Heltoft (2011), who distinguish between lexical government (valency) and categorial government (abstract, but language specific dependency relations). Constructions are not lexical units, but compositional ones (further Hansen \& Heltoft 2005; Heltoft 2008). 


\subsection{Constructions are language specific}

According to our definition constructions link language specific expression to language specific content. This is not meant to exclude the possibility that other languages can have similar constructions, see $(4 \mathrm{a}-\mathrm{c})$ below; it means that it need not be so, as illustrated in $(4 \mathrm{~d}-\mathrm{e})$ below.

As appears from the translations of (1a) and (1b), the opposition in Danish between a telic action and an atelic activity is also found in English. Examples from Goldberg $(1995: 4,63)$ are provided in $(4 a-c)$ :
(4) a. Sam kicked at Bill
b. Ethel struck at Fred
c. Ethel shot at Fred

We saw that this construction is paradigmatically organised and productive in Danish. This is, however, not the case in all languages, for instance not in French. The opposition between a telic action and an atelic activity is expressed in French by different verbs, $(4 \mathrm{~d}-\mathrm{e})$ by abattre vs. tirer sur. Consequently, for French we cannot postulate the existence of a paradigmatic organisation of this opposition corresponding to $(1 \mathrm{a}-\mathrm{b})$.
d. Pierre a abattu Frédéric d'un coup de fusil
'Peter shot Frederick' (completed action, telic)
e. Pierre a tiré sur Frédéric
'Peter fired a shot/several shots at Frederick' (atelic activity)

Let us consider another pair of well-known alternating constructions, labelled ergative alternations, illustrated in Table 2 and by the examples in (5). ${ }^{30}$

In morphologically ergative languages, the intransitive subject and the transitive object are marked by the same case form, the absolutive, whereas the transitive subject has the marked ergative case. Danish (and English) express an ergative pattern by way of purely syntactic construction. An intransitive, inergative construction is found in (5a):

(5) a. grenen knokkede

'the branch broke'

30. This extension of the morphologically defined concept of ergativity is from Halliday (1996). 
The example (5a) conveys a change of the state of the referent $(\mathrm{X})$ referred to by the subject argument A1. This subject has the semantic role of Inagent, Incausative. ${ }^{31}$ The transitive, ergative construction (5b) presents the situation differently:

\section{b. Peter knokkede grenen \\ 'Peter broke the branch'}

Table 2. The ergative alternation

Domain: $\mathrm{V}+[\mathrm{A} 1(+\mathrm{A} 2)]$

Frame: Causal relation affecting $A_{x}$

\begin{tabular}{lll}
\hline Expression & Content of A1 & Content of A2 \\
\hline NP1 & Inagent, Incausative & \\
& $A_{x}$ & \\
NP1 NP2 & Agent, Cause & Inagent, Incausative \\
& $A_{y}$ & $A_{x}$ \\
\hline
\end{tabular}

Table 2 reads as follows: The domain of this constructional paradigm is a basic predication involving only one argument. The semantic frame identifies this argument as referring to referent $\mathrm{x}$ and describes the referent as affected by a causal relation. The argument $A x$ is treated in two different ways, namely as the subject argument $A 1$ in the intransitive option, and as the direct object A2 in the transitive option. This constructional paradigm including a neutral verb stem is, in fact, an ergative system: At the level of content syntax it is constructionally ergative; at the level of expression syntax it is morphologically and topologically transitive.

In other words: this is an alternation between an intransitive and a transitive pattern $^{32}$ with a corresponding change of content: incausative ('inergative') process and causative ('ergative') action. This alternation is a constructional paradigm, since both a common semantic frame and a syntagmatic domain can be identified. One further example is $(5 c-d)$ :
c. brødet bagte
'the bread baked'
d. Marie bagte brødet
'Mary baked the bread'

31. The labelling of semantic roles is not at stake. We prefer the labels Causative vs Incausative (from Hansen \& Heltoft 2011), because we consider grammaticalised semantic roles to be specific to constructions, not universal lexical properties.

32. This way of presenting the link between the two constructions is not intended as a derivational link. In (5), the inergative constructions are not to be considered as primary to the ergative constructions nor vice versa. 
The verb is neutral with respect to this alternation. Just as in the telic/atelic-alternation illustrated by (1a) and (1b), this paradigmatic difference is not determined by the verb stem, which remains unchanged in both situations: bag-, nor by the unchanged incausative argument (X): brødet, 'the bread'. Instead, it depends on the choice of construction: if transitive, there is a subject indicating the cause of the activity, if intransitive, no external cause is mentioned of the activity or process.

The ergative alternation is found with a series of verbs, for instance: bøje 'bend', brcende 'burn', dreje 'turn', koge 'cook, boil', stege 'fry', smelte 'melt. It is productive, since loan verbs adopt it, for example: eskalere 'escalate', see (5e-f):
e. krisen eskalerede
'the crisis escalated'
f. de eskalerede krisen
'they escalated the crisis'

This case, then, is comparable to the one presented in ( $1 \mathrm{a}-1 \mathrm{~b})$, as we have a language specific paradigmatic relation belonging to a common semantic frame. On the other hand, the ergative alternation is found only with certain verbs and not e.g. with the verb skyde 'shoot'.

The ergative alternation is found not only in Danish and English but also in French, see (5g) and (5i) - intransitive constructions - and (5h) and (5j) - transitive constructions. The French construction is very frequent according to Boons et al. (1976: 90). It should be noted, however, that the alternation is not found with the same set of verbs in the different languages. Accordingly, even between such closely related languages as Danish, English and French, constructions are not organised in the same way, so there is no straightforward claim that constructions are structured according to universal cognitive principles; rather, we should constantly include language specific semantic differences, however subtle. ${ }^{33}$
g. la branche a cassé
'the branch broke'
h. Pierre a cassé la branche
'Peter broke the branch'
i. le riz cuit, la salade égoutte ...
'the rice is cooking', 'the salad is straining'
j. je cuis le riz, jégoutte la salade...
'I am cooking the rice,' 'I am straining the salad'.

33. Croft (2001:134) also insists upon the language specificity of constructions. For a different view, see Goldberg (1995:5). This point will be discussed further in Chapter 7. 
Let us return to examples ( $5 \mathrm{c}-\mathrm{d})$ with the Danish verb bage 'to bake, presented below as $(6 a-b)$. This verb fits into a set of different constructions, a situation which in a lexicalist analysis would have resulted in several different lexical readings. Let us consider a number of these constructions of which some exist in English as well, discussed by Taylor (1998: 188-191).

(6) a. brødet bagte

'the bread was baking'

b. Marie bagte brødet

'Mary baked the bread'

c. Marie bagte sig et brød

'Mary baked herself a loaf'

d. Marie bagte

'Mary was baking'

First, we shall simply list them without indicating their paradigmatic organisation. They can be described approximately as follows:

- the incausative (a one-argument construction): the subject designates a referent that is described as the patient of the activity or the process (6a).

- the causative (a two-argument transitive construction): the subject designates a referent that is the cause of the activity or the process (6b).

- the free indirect object construction (6c) (a three-argument construction): the indirect object designates its potential referent as a recipient or benefactor, and the direct object designates the entity affected or produced by the action. In Modern Danish this construction is generally restricted to reflexive indirect objects, in contrast to English: Mary baked Sally a cake has no productive modern Danish parallel, see further Sections 2.4.4 and 3.2.2.

- the agentive construction without expression of the direct object views the action as non-specific or generic (6d).

Many verbal stems enter a large number of constructions, even more than the four illustrated in (6). In such cases ${ }^{34}$ the lexicalist would need to multiply the number of lexical entries. ${ }^{35}$

34. We will discuss these and more constructions of the verb bage in subsection 2.4.

35. See Taylor (1998:189) for a critical account of different traditional analyses of double object-constructions and good arguments in favour of a constructional view. A discussion of the disadvantages of a lexical description of these patterns as opposed to the constructional account proposed here is found in Chapter 7. 
We would prefer to distinguish between different lexical verbs only in the case of genuine differences of content, as in the well-known case of the Modern French homonym verbs voler to be discussed later (Section 3.3.1.). Our point is that it is neither useful nor instructive to multiply the number of different lexical entries and thus complicate the structure of the lexicon in cases where a simpler analysis exists. The simpler analysis is the constructional one, implying that the difference between the examples studied so far is a difference of construction.

Such constructional sets must be analysed with respect to their paradigmatic organisation. In the following, the transitive construction S-V-O will serve as an illustration, being a default construction related to many other constructions, yet language specific. In Section 2.4.6. we sum up our results concerning paradigmatic oppositions by illustrating the default position of transitivity in Danish.

\subsection{The transitive construction $\mathrm{S}-\mathrm{V}-\mathrm{O}$}

The transitive construction, labelled S-V-O for ease of exposition, forms oppositions to a number of more specific constructions. It thus enters a set of different paradigms as illustrated earlier in Section 2, for instance (1a) Peter skød Frederik, 'Peter shot Fredrick' and (5b) Peter knoekkede grenen 'Peter broke the branch'. S-V-O allows a great variety of verbal stems. This is clearly the case in English, where the S-V-O-construction is found not only in prototypical cases with verbs having an animate agent provoking a change of state in a patient like (7a), ${ }^{36}$ but also in cases where no such relation between the arguments can be found, like (7b).

(7) a. Peter killed Frederick

b. Peter saw Frederick

English extends the transitive pattern to verbs that differ considerably with respect to the content, understood here as the nature of the relation expressed between the two arguments, as appears from $(7 \mathrm{c})$ and $(7 \mathrm{~d})$ :

\section{c. The hotel forbids dogs \\ d. The tent sleeps six}

The same observation holds, although to a lesser extent, for e.g. Danish and French. The examples below illustrate in (7e-f) a sort of "reversed" relation, i.e. the subject being the patient, whereas we have no agent at all in the examples.

36. Prototypical in the sense of Hopper and Thompson (1980). 


\section{e. Pierre a égaré sa montre \\ 'Peter has lost his watch' \\ f. Pierre a reçu un coup mortel \\ 'Peter has received a mortal blow'}

The more or less extended use of the SVO construction is, however, language specific, so that some languages are less restrictive than others. English is particular in this respect, as this pattern is found more extensively than in related languages. Thus, the equivalents of (7c-d) are found neither in German nor French, see $(7 g-j)$. According to Taylor (1998:187-188), who provides the examples (7c-d) and (7g-h), in general English permits a much wider range of non prototypical transitives than German.

\section{g. ${ }^{\star}$ Das Hotel verbietet Hunde \\ h. $\quad{ }^{\star}$ Das Zelt schläft sechs \\ i. $\quad{ }^{\star}$ L'hôtel défend les chiens \\ j. $\quad{ }^{\star}$ La tente dort six}

According to Tomasello (1998:xviii), the SVO construction in English has been extended to verbs that do not conform to those originally used in this pattern. Thus in English the SVO construction has become more abstract during the development of English than e.g. its German and French counterparts.

The cases discussed so far clearly show that the content of constructions can be very abstract, and specifically that the SVO construction does not directly associate with the prototypical pattern of transitivity proposed by Hopper and Thompson (1980). Neither can we associate semantic roles directly with e.g. the functions of subject or object. ${ }^{37}$ Semantic roles are ascribed through the integration of this construction in specific paradigms.

\subsection{Overview of paradigmatic oppositions between constructions}

In this subsection we will sum up the main paradigmatic oppositions between the constructions in Danish mentioned so far and draw a map of their paradigmatic relations. We shall restrict ourselves to active constructions and make only

37. Cf. the studies of Plank on the category of Object, and Croft (2001: Chapter 4) on the categories Subject and Object; see also very interesting observations in Krefeld (1998) for Italian and French verbs of perception. 
brief mention of the passive later as an instance of complex hyperparadigmatic alternation.

We present four paradigms, illustrated by means of verbs used in the preceding subsections, to which we add a few verbs not yet introduced.

\subsubsection{Telicity in objects}

Table 1 provided the paradigm for telicity in objects, exemplified in (1a) vs. (1b).

(1)
a. Peter skød Frederik
Peter shot Frederick
'Peter shot and killed Frederick'
b. Peter skød på Frederik
Peter shot at Frederick
'Peter shot at Frederick'

\subsubsection{Ergativity in purely constructional paradigms}

In subsection 2.2 we studied the ergative alternation between an intransitive inergative action (5a) and a transitive ergative action (5b), see Table 2.

(5)
a. grenen knokkede, the branch broke
b. Peter knokkede grenen
Peter broke the branch

\subsubsection{Nonspecificity of objects}

The opposition between \pm specificity was shown in (6b) vs. (6d). This opposition is exemplified below in the contrast between (8a) and (8b):
(8) a. han spiste spaghettien he ate the spaghetti
b. han spiste
he ate

Table 3. The paradigmatic structure of specificity in objects

Domain: $\mathrm{V}+[\mathrm{A} 2]$

Frame: Specificity of A2

\begin{tabular}{ll}
\hline Expression & Content \\
\hline $\mathrm{NP}$ & specific object \\
zero & object referent not specified \\
\hline
\end{tabular}


When compared with the practices found in valency grammars (Helbig 1971; Bondzio 1971; Nikula 1976), the present paradigm reveals that this type of construction is not well addressed under headings such as facultative or optional objects. Such observations and notions merely refer to expression phenomena and blur the paradigmatic organisation, in this case between zero object and NP-object. ${ }^{38}$

\subsubsection{Augmenting from two arguments to three}

Three-argument constructions add an extra level of complexity to the level of transitivity. Adding A3 opens up another range of paradigmatic options, one being the addition of an indirect object, coding, for example, the semantic role of a Beneficiary.

For ease of exposition, we shall use the free indirect object construction as an example. In English, free indirect objects ${ }^{39}$ are part of a optional constructional pattern with verbs meaning 'providing something. Here the constructional content adds the meaning that 'this something is intended to be available to the referent of the indirect object', cf. the example Peter baked Sally a cake. The free indirect object has a much more restricted distribution in Danish than in English, since Danish indirect object constructions code transfer relations as the almost only possible interpretation. Indirect objects can denote Receivers but no longer Beneficiaries in the modern language, see Heltoft 2010. We do not claim unacceptability for (9b), but rather the status of now obsolete and with a low frequency. The free indirect object construction has largely been restricted to reflexives, $\mathrm{cf}$. (9c), since providing something for yourself conforms to the transfer reading of indirect objects in general. The prepositional member (9d) is still a Benificiary construction.
a. Peter bagte en kage
Peter baked a cake
b. Peter bagte Sally en kage
Peter baked Sally a cake
c. Peter bagte sig en kage
Peter baked himself a cake
d. Peter bagte en kage til Sally
Peter baked a cake for Sally

38. This paradigm must be distinguished from incorporation, which is a paradigm of argument reduction, not of zero-objects.

39. The term 'free indirect object' is traditional. Such indirect objects are not a conceptually necessary argument of the predicate, but an optional extension. At least in Danish, they do not upgrade to subjects in passive constructions. 


\subsubsection{Telicity in free indirect object constructions}

The free indirect object is open to a telicity contrast roughly similar to that found with A2-objects. Given that A3 has been selected as the indirect object, we again find a telicity paradigm.

The verb skaffe means to 'provide something for somebody in the sense that it is at hand. This particular verb is compatible with a free indirect object in modern Danish:
Peter skaffede Ida bogen
Peter provided Ida the book
'Peter provided Ida with the book'

It also implies that this somebody desires to possess the object referent, and the final product is one of transfer from the subject referent to the IO-referent. So (10) is open to the transfer reading of the IO-construction.

The IO of example (10) alternates with a prepositional expresssion of A3 in (11). The IO construction has two telic relations: one is the 'book provided' and the second the transfer of this object to the IO-referent's possession. However, the prepositional construction in (11) does not imply that the Object referent will ever be possessed by the IO-referent.

\section{(11) Peter skaffede bogen til Ida \\ Peter provided the book for Ida \\ 'Peter provided the book for Ida'}

As in English, the indirect object construction alternates with the prepositional Object marked by the preposition til 'to'. Expression 2 of Table 4 is of course a topological rule, and this paradigm includes both topological and constructional information.

Table 4. The paradigmatic structure of telicity with free indirect objects in Danish

Domain: $\mathrm{V}+\mathrm{A} 2+[\mathrm{A} 3]$

Frame: Telicity

\begin{tabular}{lll}
\hline Expression 1 & Expression 2 & Content \\
\hline zero $(+\mathrm{NP})$ & $\left(\mathrm{NP}_{\mathrm{IO}}\right)$ precedes $\left(\mathrm{NP}_{\mathrm{DO}}\right)$ & Telic \\
prep $(+\mathrm{NP})$ & $\left(\mathrm{NP}_{\mathrm{DO}}\right)$ precedes $(\mathrm{PP})$ & Atelic \\
\hline
\end{tabular}

\subsubsection{Types of construction}

The construction types summarised above are illustrated by a diagram showing the relationship among the different active constructions (Table 5). Each arrow points to the members of a paradigm. 
Table 5. Diagram illustrating the relationship between the different active constructions illustrated in the preceding sections
one-argument
two-argument
three-argument
constructions
constructions
constructions

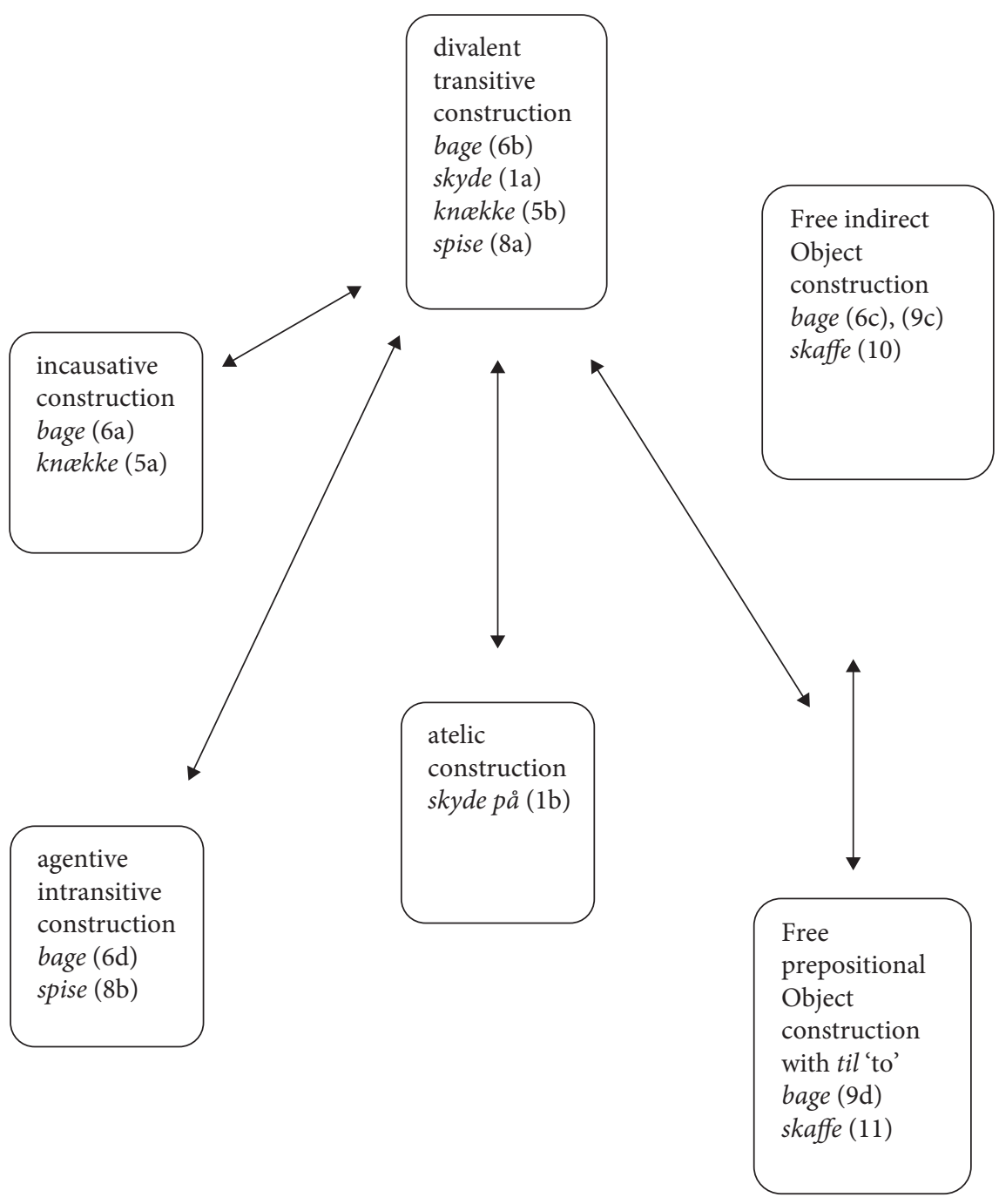

From the perspective of the lexicon, detailed descriptions of the constructional information are superfluous. The lexical entry for a polysemous verb like bage 'to bake' will have references to its constructional range, not to a number of syntactically specified contexts. These are summarised in Table 6. 
Table 6. Overview of constructional range for bage 'bake'

Verb type: bage 'bake'

Causative paradigm (Marie bagte kagen 'Mary baked the cake' vs.

kagen bagte 'the cake baked')

Free IO-paradigm (Marie bagte sig en kage 'Mary baked herself a cake' vs. Marie bagte en kage til Peter 'Mary baked a cake for Peter')

Specificity (Marie bagte kagen 'Mary baked the cake' vs. Marie bagte 'Mary was baking') Increased hierarchy (Marie bagte kagen 'Mary baked the cake' vs. Marie bagte A3 en kage 'Marie baked A3 a cake' / Marie bagte en kage til A3 'Marie baked a cake for A3')

\subsection{Morphological marking instead of constructional oppositions}

In this section, we will see how languages express distinctions similar to the ones studied in the preceding sections, not by means of constructions alone, as seen above, but through morphology. In order to introduce our point concerning alternative marking as clearly as possible, we will refer to Finnish and Russian, as these languages are especially suited to illustrate case-marking as an alternative expression.

The telic-atelic opposition (compare the constructional paradigm for Danish (Table 1) and examples (1a) and (1b)), is expressed in Finnish by differences in case. ${ }^{40}$ The Finnish accusative-partitive opposition forms an inflexional construction, a paradigmatic contrast between a marked, non-negated, atelic construction in the accusative (12a) and a non-marked construction in the partitive case (12bc). The partitive signals an atelic reading (12b) or goes with negation (12c). In the latter case there is no telicity opposition between telic and atelic.
a. kirjoita-n
kirja-n
write-ACT-IND-PRS-1sG book-SG-ACC
'I am writing a/the book (and I shall finish it)'
b. kirjoita-n
kirja-a
write-ACT-IND-PRS-1SG book-SG-PART
'I am writing a/the book'
c. en
kirjoita
kirja-a
not-1SG write-ACT-IND-CONNEG book-SG-PART
'I do not write a/the book/I am not writing a/the book'

40. We wish to thank Outi Merisalo and Peter Juul Nielsen for having provided and discussed these examples with us. 
See also examples (12de), corresponding to examples (1ab):
d. Pekka
ampu-u
Rietu- $n$
Pekka-NOM shoot-ACT.IND.PRS.3SG
Rietu-ACC
'Pekka shoots Rietu [so that he dies]'
ampu-u
Pekka-NOM shoot-ACT.IND.PRS.3SG
'Pekka is shooting at Rietu'
[we don't know whether Rietu is hit].
e. Pekka
Rietu-a
Rietu-PART

In Russian we find a distinction between the use of the nominative and the genitive in subject function, which is often referred to as a choice between (13a) existence (in the nominative case) and (13b) non-existence (in the genitive case):
a. Umenja est' knig-a
with me.GEN is book-NOM
'I have a book'
b. Umenja net knig-i
with me.GeN not book-GEN
'I do not have a book'

It is possible to extend this distinction to examples without negation (14ab) and to direct objects (14cd) where the opposition takes the form of an accusative-genitive distinction. Against this background, the opposition can be described in more abstract terms as an opposition between what is not quantified (nom/acc) and what is quantified (gen), 'non-existence' being interpreted as zero-quantity.
a. Ljud-i sobra-l-i-s'
people-NOM.PL gather-PST-PL-REFL
'people gathered'
b. Ljud-ej sobra-l-o-s'
people-GEN.PL gather-PST-SG.N-REFL
'some people gathered'
c. Ja ne polučil otvet
I not received answer-ACC
'I did not receive (the) answer'
d. Ja ne polučil otvet-a
I not received answer-GEN
'I did not receive any answer'

These standard examples, which are traditionally used in order to illustrate a wellknown case distinction (nominative vs. genitive), can be interpreted in terms of constructions as paradigmatic oppositions between expressions linked to a specific 
content of quantity. The paradigmatic representation behind (14a-d) is presented in Table 7:

Table 7. The paradigm of Gen. vs. Non-genitive

Domain: $\mathrm{A} 1$ and $\mathrm{A} 2^{*}$

Frame: Quantification

\begin{tabular}{ll}
\hline Expression & Content \\
\hline non-genitive form & $\begin{array}{l}\text { non-quantified } \\
\text { genitive form }\end{array}$ \\
\hline
\end{tabular}

*) In 12ab, kniga/knigi is A1; in 13ab ljudi/ljudej is A1; in 13cd otvet/otveta is A2.

The examples above illustrate that in languages like Finnish and Russian, ${ }^{41}$ case alternations can correspond to alternations between syntactic categories in languages that do not have these morphological resources. As Latin is a morphologically richer language than the modern Romance languages, we would expect to find changes from morphological to syntactical marking of constructions. This point will be explored in Chapter 7.

Finnish has other examples of case constructional paradigms. Following the definition in Section 2.1, we find a complex sign (15a) mennä taloon, with internal syntax (verb of movement followed by the illative), linked to a specific content (concrete movement into a place), opposed to another complex sign (15b), mennä talolle, with its internal syntax (verb of movement followed by the allative), having another specific content (concrete movement to a goal, often conceived as an institution; the allative does not necessarily denote transgression of the limits of the goal):

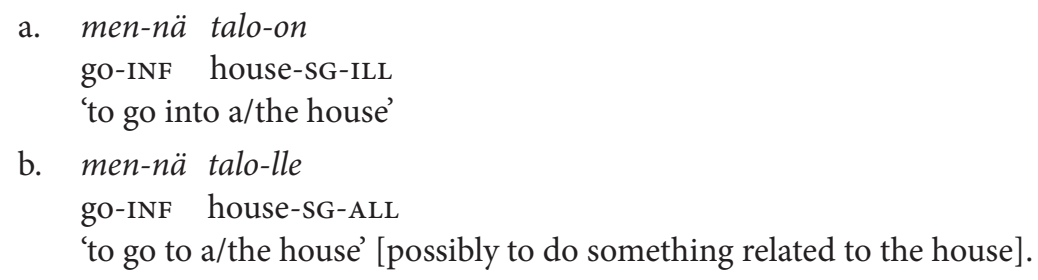

a. men-nä talo-on

go-INF house-SG-ILL 'to go into a/the house'

b. men-nä talo-lle

go-INF house-SG-ALL

'to go to a/the house' [possibly to do something related to the house].

This opposition is a general feature of Finnish, see $(15 \mathrm{~cd})$, and we thus have a paradigmatic opposition between constructions:

41. Old Russian had case construction as its general principle. The modern Russian language has drastically reduced the domains for case construction and replaced them with simpler government relations (Kasusrektion), see Chapter 5. Its genitive syntax is a surviving example of case construction. 

c. men-nä mökki-in
go-INF cottage-SG-ILL
'to go into a/the cottage'
d. men-nä möki-lle
go-INF cottage-SG-ALL
'to go to the cottage' [as a place of leisure]

We have cited Finnish as a language with an elaborate case system that clearly determines the meaning of the constructions. ${ }^{42}$ The Latin case system differs from the Finnish, in that seems to have only relicts of an earlier stage where case construction was a dominant principle. See for instance (16ab), where the case of the proper noun Rome clearly indicates the state of affairs: a movement towards Rome (16a), where the verb eo corresponds to venio, or a movement from Rome (16b) where the verb eo corresponds to exeo; compare (16c) where case and verb indicate location inside Rome:
a. eo Rom-am
I go Rome-ACC
'I go to Rome'
b. eo Rom- $\bar{a}$
I go Rome-ABL
'I go from Rome'
c. Rom-ae sum
Rome-LOC I am
'I am in Rome'

A somewhat similar situation may be found with verbs governing different cases, such as metuo, meaning 'to fear', when combined with the accusative (17a), and 'to worry about', when combined with the dative (17b). Case does in fact pin down the meaning of the polysemous verb metuo 'fear, worry about, care for' in the following examples:
a. qu-em
metu-unt
od-erunt
REL PRON-ACC fear-PRS.IND.3PL hate-PRF.IND.3PL
'whom they fear, they hate'

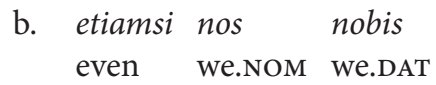
non time-re-mus
not fear-PST.IPFV.SBJV-1PL

42. For a similar situation in Indo-European, see Jakobson (1936). 


$t u \quad$ tibi $\quad$ metu-ere
you.NOM you.DAT.SG worry-INF
deb-u-er-i-s
should-PRF-DIST-SBJV-2SG
'even if we did not worry about ourselves, you ought to worry about
yourself'

We suggest the hypothesis that at an early stage, illustrated by examples like (16a-c), case was primary, very much like Finnish $(12 \mathrm{a}-\mathrm{d})$. At a later stage, the paradigmatic organisation of case was increasingly bound up with the argument hierarchy, in the sense that e.g. the dative acquired a specific range of senses as an A2, another range of senses as an A3, see Chapter 7, Section 2.

\subsection{Hyperparadigmatic organisation}

Constructional paradigms can combine with morphological and/or topological paradigms to form complex, connected paradigms, or hyperparadigms, cf. Chapter 1, Tables 6 and 7 for examples of subparadigms within larger morphological paradigms, and Chapter 2, Section 5 (in particular 5.3) for hyperparadigms integrating topological subparadigms. In many or most languages the category of voice is such a complex paradigmatic structure.

In Latin, for instance, voice is formed morphologically as inflexional paradigms, supplemented by sets of periphrastic passives. A simple Latin (fragment of this) paradigm is excrucio 'I torment, torture':

$\begin{array}{lll} & \text { Active } & \text { Passive } \\ \text { Present } & \text { excrucio } & \text { excrucior } \\ \text { Perfect } & \text { excruciavi } & \text { excruciatus sum }\end{array}$

In full accordance with tradition, a description of the category of voice will include the syntagmatic consequences of the morphological options. Inflexional voice is connected with a constructional opposition determining the position of A1 (the active subject) in the clausal hierarchy. The active morpheme is an instruction to the addressee to interpret arguments $\mathrm{A} 1$ and $\mathrm{A} 2$ as a transitive pattern, or rather the upgraded version of a transitive pattern. ${ }^{43}$ In the passive, by contrast, the argument A1 (nominative with the active) must be downgraded (or demoted, cf. Comrie 1977) to the dative case or, normally, to a prepositional syntagm $(a(b)+$ ablative NP), or even omitted at the level

43. 'Upgrading' and 'downgrading' are just relative notions, they do not denote generative derivations. So the $\mathrm{A} 1$ in an active, transitive clause is upgraded, but downgraded in a passive clause. 
of expression. Generally, but in Latin not necessarily, the A2 may upgrade to a nominative NP.

All this is well known from tradition. We shall restrict ourselves to examples from the passive, showing the possible omission of the argument A1 in the passive (19a), and the manifestation through non-nominative cases (19b: ablative, 19c: dative, 19d: prep. $a+$ ablative):
a. sed fieri senti-o et excruci-or but happen feel-PRS.ACT.1SG and torment-PRS.PASS.1SG 'but I feel that it is happening and I am being tormented'
b. excruciatus (sum) inopi-ā tormented poverty-ABL 'tormented by poverty'
c. id vitium null-i per saecula longa
this chink no-one-DAT for long periods

notatum (est)
note-PRF PTCP (be-PRS.3SG)
(= PRF.PASS.3SG)
'For long periods this chink had been noted by no-one'

In short, the hyperparadigm integrates an inflexional paradigm (voice in the narrow sense) with a constructional opposition concerning the manifestation of A1 and possibly other arguments:
voice $($ hyperparadigm $)=$ inflexional voice + constructional argument organisation.

In languages like English, the task carried out by inflexion in Latin has been taken over by purely periphrastic paradigms, but the category of voice still retains its hyperparadigmatic character.

In French by contrast, there is no specific passive morphological category, the morphological task having been replaced by the predicative complement construction. Voice can thus be a constructional category alone or integrated functionally in some constructional paradigm. Note in (19d) that in Latin gerundive constructions, the constructional part of the hyperparadigm is still there but inflexional voice is not. This has been replaced by a derivational paradigm forming the gerundive.
d. bona qu-ibus est
a vobis
consulendum
goods which-DAT be-PRS.3SG by you.DAT take care of-GERUNDIVE property which ought to have been taken care of by you'

The examples of case construction from Finnish, Russian and Latin given above in examples (12) through (17) are not instances of hyperparadigmatic organisation but of 
simple constructions making use of case oppositions. In the case construction examples, the syntagmatic domain is stable, and only one contrast, the case opposition, is applied. However, in the case of Latin voice two sets of oppositions are fused, one inflexional, the other one constructional.

Our point is that there is nothing extraordinary in the concept of a hyperparadigm. It is a both useful and necessary concept for the description of the cooperative functions between morphology and syntax.

\subsection{Conclusion of Section 2}

In Section 2 we have advanced arguments in favour of considering constructions as being part of the grammar. We have provided definitions and motivations for introducing this level, which should be distinguished from the lexical level. The examples discussed in Sections 2.1 and 2.2 illustrate our definition of a construction as a complex sign with internal syntax and with a paradigmatic relation to other complex signs. Its language specific expression has been shown to be linked to a language specific content. In several cases we have seen that constructions may be productive and thus offer new syntactic possibilities for verbs. And we have pointed to the insight that constructions and morphology can form complex paradigms, so-called hyperparadigms.

Being parts of grammar, constructions must participate in grammatical changes. ${ }^{44}$ This is what we intend to investigate further in Section 3.

\section{Constructions and language change}

In this section, we will first discuss in detail some constructional changes in order to show that they are indeed cases of reanalysis followed by actualisation (Section 3.1). Constructions are part of the grammar; accordingly, they may undergo regrammation, in Henning Andersen's terminology (Section 3.2). In Section 3.3 we discuss some interesting consequences of regrammation. We present a series of variations and changes of verb use in order to identify the processes behind them. In particular, we want to distinguish between individual lexical changes and changes at the level of constructions.

\subsection{Regrammation of constructions}

We define a change as the result of a reanalysis that spread among speakers and which is accepted by the community of speakers. Let us investigate whether this

44. Different views on constructions and on how constructions have come into existence will be discussed in Chapter 7. 
understanding af reanalysis conforms to the changes mentioned above. We will first return to the telic-atelic alternation illustrated in Section 2.1 by the examples (1a) Peter skød Frederik, 'Peter shot Frederick', and (1b) Peter skød på Frederik, 'Peter shot at Frederick. We have seen that it is so productive that loan words can adapt to it. Let us try to reconstruct a plausible scenario for the creation of the atelic meaning in the first place. We propose that the prepositional construction with $p a$ originated as a locative counterpart to the direct object construction in e.g. (20a). The preposition $p a$

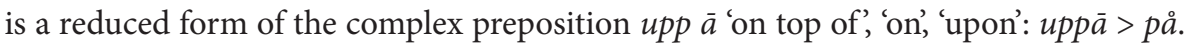
This is the Scandinavian variant $(u p p+\bar{a})$ of Protogermanic ${ }^{\star} a n$, German an, English on. The meaning may well have been 'to build upon', 'to build an addition to'. Example (20b) would then be the starting point for the reanalysis from an exclusively locative to an ambiguous use, locative and atelic.
a. Peter bygger huset
'Peter is building the house'
b. Peter bygger på huset
'Peter is building [on] the house'

Reanalyses first happen at the individual level and it is hypothesised to have happened by abduction: the speaker using the prepositional construction transfers the implications of the use of the preposition (which is that the ongoing activity is atelic) to the construction as such, ruling out the original locative use, according to the well known process of change:

$\mathrm{A}>\{\mathrm{A}, \mathrm{B}\}>\mathrm{B}$, in this case: locative $>$ locative, atelic $\}>$ atelic

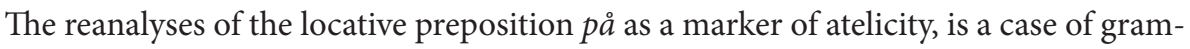
maticalisation. During this process, the locative preposition loses its original lexical meaning and turns into a grammatical element. The important point here is that it is only in this construction that we see a bleaching of the locative preposition.

The reanalysis proposed for the creation of the atelic construction illustrated by the verb bygge is a grammatical change, as the construction achieves a specific content of atelic activity, which supposedly was not there in the first place. We will consider this type of change and its consequences more closely in the following sections.

As proposed by Andersen (2008), we hold that in general changes should be divided into "(i) changes into, (ii) changes within or among, and (iii) changes out of lexical or grammatical paradigms". We classify the creation of the atelic construction, as proposed in the preceding subsection, as a case of (ii), i.e. changes within grammatical paradigms.

A construction may undergo a change and achieve a more specific meaning $(A, B>B)$. In the present case, this change concerns exclusively the content of the 
construction, not the expression, and it is a case of regrammation, as the construction is already part of the grammar.

\subsection{Lexical change and constructional change}

\subsubsection{Causative morphology and causative constructions}

A well-known example of grammaticalised causativity is the reformation of Germanic causative morphological paradigms to constructional paradigms. Germanic formed causatives with the suffix ${ }^{*}$-iya- (-ija-), normally from a stem with an ablaut grade different from that of the intransitive verb.

\section{Intransitive}

$\begin{array}{ll}\text { a. } & { }^{*} \text { wak-a-n } \\ \text { b. } & \text { *set-ja-n } \\ \text { c. } & \text { *far-a-n } \\ \text { d. } & \text { *leg-ja-n } \\ \text { e. } & \text { *knekk-a-n } \\ \text { f. } & \text { *brinn-a-n } \\ \text { g. } & \text { *slekw-a-n } \\ \text { h. } & \text { *tendan } \\ \text { i. } & \text { *springan } \\ \text { j. } & \text { *weltan }\end{array}$

\section{Causative}

'be awake'

'sit'

'move, travel'

'lie'

'break'

'burn'

'go out (of fire)'

'burst in flames'

'spring, run'

'turn over'

$\begin{array}{ll}\text { *wak-ija-n } & \text { 'wake' } \\ \text { *sat-ija-n } & \text { 'set' } \\ \text { *for-ija-n } & \text { 'lead' } \\ \text { *lag-ija-n } & \text { 'lay' } \\ \text { *knakk-ija-n } & \text { 'break' } \\ \text { *brann-ija-n } & \text { 'burn, put on fire' } \\ \text { *slakw-ija-n } & \text { 'put out, extinguish' } \\ \text { *tand-ija-n } & \text { 'light, ignite' } \\ \text { *sprangian } & \text { 'make run' } \\ \text { *walt-ija-n } & \text { 'turn over' }\end{array}$

Some Germanic verbs were, however, neutral with respect to this distinction, and they may have served as a model for the later generalisation.

\section{Intransitive Causative}

k. *aukan 'grow, increase' *aukan 'increase'

Old Scandinavian had lexicalised the intransitive vs. causative distinction to a large extent. Except for i., their lexical meanings have roughly survived to the present day. In Middle Danish some of these verbs merged (letter marking is retained to facilitate comparison: $\mathrm{g}, \mathrm{h}, \mathrm{j}$, and still $\mathrm{k}$ ):

$\begin{array}{lll} & \text { Intransitive } & \text { Causative } \\ \text { a. } & \text { wake } & \text { wækie } \\ \text { b. } & \text { sitie } & \text { sætie } \\ \text { c. } & \text { fare } & \text { føre } \\ \text { d. } & \text { liggie } & \text { læggie } \\ \text { e. } & \text { knække } & \text { knækkie } \\ \text { f. } & \text { brinne } & \text { brænne } \\ \text { g. } & \text { slække } & \text { slække } \\ \text { h. } & \text { tænde } & \text { tænde } \\ \text { i. } & \text { springe } & \text { sprænge } \\ \text { j. } & \text { wælte } & \text { wælte } \\ \text { k. } & ø k e & ø k e\end{array}$


In Modern Danish, some verbs still differ lexically, for instance:

\section{Intransitive}
a. våge
b. sidde
c. fare
d. ligge
i. springe 'burst, split, explode; run'

\section{Causative}

vække

sætte

føre

lægge

sprænge 'cause to burst, blow up;

Many more verbs merge to form a purely constructional opposition by integration in the new causative or ergative constructional paradigm (see Table 2), for instance:

$\begin{array}{lll} & \text { Intransitive } & \text { Causative } \\ \text { e. } & \text { knække } & \text { knække } \\ \text { f. } & \text { brænde } & \text { brænde } \\ \text { g. } & \text { slukke } & \text { slukke } \\ \text { h. } & \text { tænde } & \text { tænde } \\ \text { j. } & \text { vælte } & \text { vælte } \\ \text { k. } & \text { øe } & \text { øge }\end{array}$

In the spoken informal language, the intransitive form ligge has been generalised to also function as the causative form. Similarly, springe and spronge are confounded in both directions.

\section{Intransitive Causative \\ ligge ligge \\ springe springe \\ or: sprænge sprænge}

The lexical adjustment for the construction is part of the actualisation process of the paradigm. The verbs fitting the construction have multiple roots and origins. A number of them are reshaped -ija-causative verbs of Germanic heritage as listed above; some verbs of Germanic origin have different formations: trille (< ${ }^{*}$ trizlōn), no -ijaverb; another group comprise loan verbs interpreted for the causative constructional paradigm: rulle 'roll' (via Ger. rullen, rollen $<$ Fr. rouler $<$ Lat. rotulare), koge (via Germ. koken $<<$ Fr. coquer $<$ Lat. coquere), brakke (from Low German breken, ${ }^{\star}$ brecan is not Norse); and some verbs are formed on the basis of internal Nordic material, for instance stege 'fry, roast' (from steg, stek 'steak').

More verbs may lose their lexical marking to become exclusively constructionally marked. Apparently, the lexical marking has been reanalysed as redundant and is in the process of being abandoned. The result is that only the constructional marking is retained. 
In the Romance languages, changes similar to those described above have taken place, so that we no longer find series of etymologically related pairs such as sto - sisto. These changes can be interpreted as an increase of the importance of constructional marking in Romance languages.

In the course of the actualisation process following a reanalysis into a more specific construction, a change may manifest itself in two possible ways: by the fossilisation of non-prototypical verbs, and/or by the ejection of non-prototypical verbs. These consequences of construction changes will be exemplified in the following subsections.

\subsubsection{Reinterpretation and regrammation of constructions}

Indirect object constructions constitute a central type of A3 construction. This construction has undergone considerable semantic change in Danish from the 18th century to the present day. Ascribing the semantic role of the Recipient to its referent was probably always a central function of the IO, but in the language of the present day this function is practically the only one possible.

\section{(21) Peter gav Ida bogen \\ Peter gave Ida the book \\ 'Peter gave Ida the book'}

The 18th century grammarian Høysgaard lists a wider range of application such as the semantic role of Benefactive (dative of interest: dativus commodi):
a. han skal løse os knuden he must untie us (Io) the knot 'he must untie the knot for us'
b. åbne nogen en dør open somebody (IO) a door 'open a door for somebody'
c. pløje en et stykke jord plough somebody (IO) a piece of land 'plough a piece of land for somebody'
d. skrive en et brev write someone (IO) a letter 'write a letter for somebody (on somebody's behalf)'

(22a-d) are all from Høysgaard (1752: 107-108). Such examples are impossible in the modern language where prepositional constructions only are possible.
a. han skal løse knuden for os he must untie the knot for us 'he must untie the knot for us' 


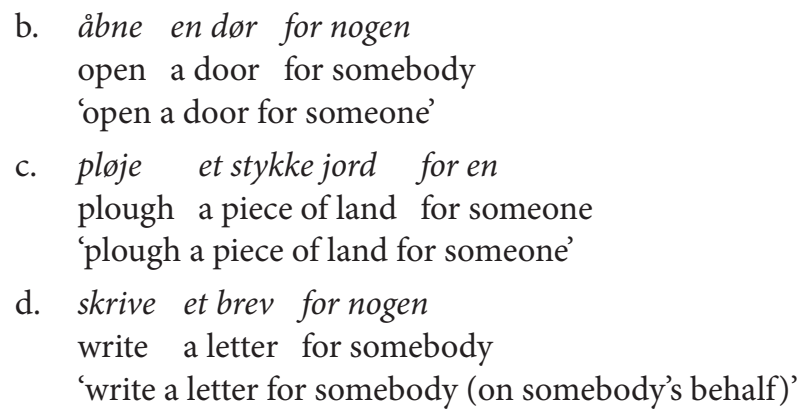

Thus, around 1750, in Danish the indirect object construction was used with a larger range of different verbs than what we find in Modern Danish. Accordingly, the indirect object was less specific in this period. In Modern Danish, the IO is mainly reserved to designate the Recipient of an action of transfer, and the Benefactive uses are obsolete. This implies that during the period 1750-1870 a reanalysis took place of the meaning of the construction, in particular of the indirect object itself. The actualisation process of this change consisted among other things in the exclusion from this construction of certain verbs that did not fit the semantic transfer pattern and thus did not apply the role of receiver to $\mathrm{A} 3$.

\subsubsection{Ejection of non-prototypical verbs}

As stated in the previous subsection, the indirect object construction was found, especially in Early Modern Danish, with verbs expressing no transfer from one person to another, as give-verbs do. However, for a speaker of Modern Danish, the indirect object construction is apparently so closely linked to the meaning of transfer that IO-verbs having a different meaning, like e.g. bebrejde 'to blame', godskrive 'to credit', tilgive 'to forgive', are in the process of adopting a new prepositional pattern. In these cases, the pattern adopted is that exemplified by kritisere 'to criticise', so that we may find innovative usage, e.g. bebrejde nogen for noget, with the preposition for introducing the point of criticism, just as in English. This shows that verbs having a deviant content may be ejected from their original construction. This ongoing change of construction is illustrated below in examples (27)-(29) quoted from google.dk.

(24) Peter bebrejder Ida ulykken

Peter blames Ida the accident

'Peter blames Ida for the accident'

(25) Peter godskriver Ida et beløb på 100 kroner

Peter credits Ida an amount of 100 kroner

'Peter credits an amount of 100 kroner to Ida' 
(26) Peter tilgiver Ida fejltagelsen

Peter forgives Ida the mistake

'Peter forgives Ida for the mistake'

(27) Centret [kan] vurdere og eventuelt godskrive eleven for den

tid der normalt bruges på de ... kurser

'the Centre may evaluate and possibly credit the pupil for the

time that is normally spent on these courses'

(http://www.amunordjylland.dk/digitalAssets/1631_Undervisningsplan\%2 0Bus\%202005.pdf)

(28) Kan man bebrejde hende for at voere sin mors datter?

'Can you blame her for being her mother's daughter?'

http://www.matadoronline.dk/forum/viewtopic.php?t=304andsid=2971156

97219ec6a761e2bcf1fad781b

(29) Tilgive dig for det du har gjort

'Forgive you for what you have done'.

http://digte.dk/digte/poem.asp?digt=339876andForfatter= 16715

This reanalysis of the content of the indirect object construction and the following actualisation took place in Early Modern Danish and during the 19th century, with the result that the content of the construction is now more semantically specific than before. Marginalisation and, possibly, exclusion of deviant verbs is one symptom revealing this change.

\subsection{Further examples of relexicalisation between constructions}

Further examples are given below to illustrate that verbs can be reinterpreted and transferred from one paradigm to another. Once more, this fact confirms the reality of constructions as a level of organisation.

\subsubsection{Voler}

The first case is well known from French: the development of voler 'to steal' or 'to fly' as illustrated in (30) and (31):

(30) Pierre/l'oiseau/l'avion vole

'Peter, the bird, the plane is flying'

(31) Pierre/*l'oiseau/*l'avion vole [de l'argent] [à Marie]

'Peter, ${ }^{\star}$ the bird, ${ }^{\star}$ the plane is stealing money from Marie'

Originally there was only one verb meaning 'to fly', and it belonged to the class of verbs with caused motion alternation, such as (32ab):

a. l'argent vole

'the money is flying away, disappears' 


\section{b. Pierre vole l'argent (à Marie)}

'Peter causes the money to fly away, to disappear (from Marie)'

It was only later that the verb split into two homonyms with distinct valency patterns and different meanings. Therefore, at their origin (30) and (31) shared a common semantic frame, as voler in both constructions was indeed a verb of movement, and they were examples of the intransitive motion construction and the caused motion construction, respectively. The causative use of voler illustrated in (31) has since developed into an independent verb, so that we now have a genuine case of homophony between two verbs - voler_ 1 and voler_ 2 - that to a Frenchman seem unrelated. Consequently, we will not classify these verbs as instantiations of a construction in the sense used here, as (30) and (31) no longer share a common semantic frame in Modern French. The additional argument for not classifying (30) and (31) as alternating constructions is that they constitute an isolated case and not a paradigm found with other verbs.

The case of French voler is an illustration of the removal of a verb from a construction (the caused motion alternation) with subsequent lexicalisation of the transitive use acquiring the meaning of 'to steal'. The removal of transitive voler had no effect on the productivity of this construction.

\subsubsection{Forbid}

The second case concerns an ongoing change in English. To forbid is a performative verb in Standard English, ${ }^{45}$ and it is followed by an infinitive introduced by to, like similar directive verbs such as to order and to command. These verbs have a similar meaning which is 'order (not) to V'. However, to forbid is in the process of changing its pattern in favour of Prep + Gerund instead of an infinitive: the pattern of (33b) appears alternating with the traditional pattern of (33a):
a. they forbade the inmates to read
- the inmates were forbidden to read
b. they forbade the inmates from reading
- they were forbidden from reading
c. they prevented them from reading
- they were prevented from reading

The creation of (33b) is the result of a reanalysis of the content of the verb. Instead of being a performative verb, the verb to forbid has been interpreted by the speakers as a way of preventing somebody from doing something, thus adopting the pattern of to

45. We thank Henning Andersen for having drawn our attention to this example. We reproduce his analysis of the ongoing change. 
prevent (33c). Thus this is a case where a change of expression reveals that a change of content has taken place.

\subsubsection{Verbs of electronic communication}

Recent loan verbs adapt to specific constructions. Let us consider the construction possibilities of newly coined verbs of electronic communication in English and French. These verbs display a number of construction patterns, and the construction possibilities in English and French cannot be explained as cases of simple lexical analogy with the traditional use of English or French verbs of communication. The latter do not present these construction possibilities, nor can the French constructions be explained as calques from English, because there is no direct match. We interpret these cases of synchronic variation as cases of integration of the verbs into different construction paradigms. In each case the lexical meaning of the verb takes a specific colouring from the construction, as we saw in the case of brainstorme (examples (3) quoted above). Thus, English to skype with, see (34), ${ }^{46}$ along with expected constructions to skype somebody or to skype to somebody, and French skyper avec along with skyper à (35), indicate that this is conceived by the speaker as a shared activity, and that accordingly a construction expressing shared activities is chosen, i.e. the one found with e.g. to cooperate with, travailler avec, respectively:

(34) I skyped with James last night

(35) jai skypé avec mes petits chéris à Paris

'I skyped with my little darlings in Paris'

If another construction is chosen, the verbs take a different colouring, e.g. the direct object construction in (36) and (37), turning the verb into a simple transitive like the verb contacter, 'get in touch with':

(36) Bonjour, je pars à l'étranger et je souhaiterai msné et skypé ma copine en france.

'Hello, I am going abroad and I would like to sms and to skype my girl friend in France.

jai mailé Thomas pour qui'il réduise «l'agressivité » (...)

'I emailed Thomas to make him reduce the «aggressiveness»

46. The examples in (33) - including their original typos - are found on the www. They are quoted from a paper presented by the CONTAGRAM research team at "Verb Typologies revisited: A Cross-Linguistic Reflection on Verbs and Verb Classes”, Ghent, 5th-7th February 2009. 
The conclusion to be drawn from these examples is that new verbs are integrated into the construction possibilities of grammar. Indeed, no verb can exist in a language without being integrated in at least one of the possible constructions of that language, much in same way as any new verb must be integrated in the inflexional systems of the category of verbs, i.e. in the paradigmatic structure of the language.

The recent Danish loan verb brainstorme is an obvious example, since no other verb offers itself as a lexical model. Clearly, simple analogy to a lexical model is not what matters here; this is a question of integrating a new item into already existing grammatical structures. This is why this case is relevant for a discussion of grammaticalisation and construction grammar; it is not merely a trivial extension of the lexicon. In the case of brainstorme, the choice between the two constructional possibilities implies that the abstract content of that construction ( \pm telicity) is "added" to the lexical semantics of the particular verb. If we accept a "broad" interpretation of the term analogy, these examples are cases of analogical mappings of expression and content to existing constructions.

\subsection{Conclusion of Section 3}

In Section 3, we have examined cases of variation and changes of verb use in detail. In particular, we have used the verb bygge, 'to build', as an illustration of the proces of reanalysis leading to regrammation. We have shown the consequences of regrammation for verbs that do not conform to the change of content in the lexical group of verbs to which they belong. We have seen that such verbs can be ejected from the construction, e.g. verbs like bebrejde, 'to blame'. Finally, the case of new loan verbs has allowed us to confirm the status of constructions as part of grammar. 



\section{CHAPTER 4}

\section{Connecting grammaticalisation}

The concept of connecting grammaticalisation is intended to capture the fact that two or more simple paradigms can be related to each other in non-trivial ways and that such relations arise as historical formations. A traditional example was mentioned in Chapter 3, Section 2.6, namely the complex organisation in Latin of voice by morphology and construction. English and many other languages have similar complex voice paradigms: a constructional part and a morphological part. What looks like a transformational swap of the expression systems alone as in (1), is in fact the product of complex paradigmatic integration.

\begin{tabular}{|c|c|c|c|}
\hline Active: & $\begin{array}{l}\text { lightning } \\
\mathrm{NP} 1_{\mathrm{x}}\end{array}$ & $\begin{array}{l}\text { struck } \\
\text { Verbal complex } \\
\text { V.ACT }\end{array}$ & $\begin{array}{l}\text { the oak } \\
\mathrm{NP} 2_{\mathrm{y}}\end{array}$ \\
\hline Passive: & $\begin{array}{l}\text { the oak } \\
\mathrm{NP} 1_{\mathrm{y}}\end{array}$ & $\begin{array}{l}\text { was struck } \\
\text { Verbal complex } \\
\text { V.PASs [=AUX (be) }\end{array}$ & $\begin{array}{l}\text { by lightning } \\
\text { by } \mathrm{NP}_{\mathrm{x}} \\
\text { V.PTCP] }\end{array}$ \\
\hline
\end{tabular}

The opposition between active and passive is normally described in terms of morphology, word order and syntagmatic structure, and if semantic oppositions are involved, this is normally done in terms of information structure and Agent demotion (Comrie 1977). Such descriptions are not adequate, since they do not take into account the difference between the active and the passive constructions with respect to semantic role ascription. Constructional grammarians assume that the same set of semantic roles is involved in both constructions, e.g. Croft 2001 AGT (Agent) and PAT (Patient), but behind such analyses lies a failure to observe the difference between semantic roles selected in terms of constructions and in terms of verbal valency. In languages like English and Danish, the active construction has a polysemous subject slot open to a set of semantic roles, whereas the demoted Argument 1 of the passive construction must express the role of Agent or Cause. As an instance, take verbs denoting acts of communication or comprehension. By way of metonymic extension these verbs may take a subject that cannot denote an Agent, but such an extension is impossible in the passive.

(2) a. Hans seneste bog beskriver Toscanas vingårde his most recent book describes Tuscany's vineyards 
b. Toscanas vingårde beskriv-es af *hans

Tuscany's vineyards describe-PAss.s-MOoD by his

seneste bog

most recent book

'Tuscany's vineyards are described by *his most recent book'

In example (3) the passive (3c) is semantically acceptable since the demoted subject denotes an Agent.
a. Et dybt suk udtrykte hans frustration a deep sigh expressed his frustation
b. Hans frustration blev udtrykt af ${ }^{*} e t d y b t$ suk his frustration become-PST express-PRF PTCP by a deep sigh 'his frustration was expressed by *a deep sigh'
c. Hans frustration blev udtrykt af hans kone, der skriver (...) 'his frustration was expressed by his wife, who writes (...)'

Similar relations hold for English, see (4) and the translations of (2)-(3).

(4) a. A lengthy article explained the origins of WW2

b. The origins of WW2 were explained by *a lengthy article

The verb stem is deliberately kept the same to allow us to interpret these differences as symptoms of a semantic difference between the constructions. As in morphological paradigms, moreover, we find an opposition between members of a closed set, in fact two, between a marked term (the passive) and an unmarked term (the active).

The presentation in Table 1 is a simplified description of English voice. It would match neither the Latin situation described in Chapter 3, Section 2.6, nor the Danish situation since Danish allows passives with subject demotion only, that is, passives with intransitive verbs. In addition, it clearly describes the modern situation, not the Old English or Middle English ones, since - as is well known - the development of English subjects has been one of increasing polysemy due to the loss of so-called 'oblique subjects' (the loss of impersonal constructions with Dative or Accusative NPs).

Table 1. Simplified paradigmatic structure of Modern English voice

Voice paradigm

Voice morphology

Domain: V trans

Frame: Causativity, Agency
Voice topology and construction

Domain: V [A1] A2

Frame: Causativity, Agency

\begin{tabular}{|c|c|c|c|}
\hline Expression & Content & Expression & Content \\
\hline $\mathrm{V}$ active & $\begin{array}{l}\text { non-causation / } \\
\text { non-agency }\end{array}$ & $\begin{array}{l}\text { NP1 (subject), } \\
\text { NP2 (direct object) }\end{array}$ & $\begin{array}{l}\text { A1 (subject): } \\
\text { non-cause/ } \\
\text { non-agent }\end{array}$ \\
\hline $\begin{array}{l}b e+\text { V.PASS } \\
(\text { PRF PTCP) }\end{array}$ & $\begin{array}{l}\text { causation / } \\
\text { agency }\end{array}$ & $\begin{array}{l}\text { NP2 (subject), } \\
\text { prep + NP1 }\end{array}$ & $\begin{array}{l}\text { A1 (demoted } \\
\text { subject): } \\
\text { Cause/Agent }\end{array}$ \\
\hline
\end{tabular}


Connecting grammaticalisation - seen as a process of historical grammatical change - is about the development of such integrated and closed sets of paradigmatic systems. We distinguish two types of connecting grammaticalisation: complex and parallel paradigms.

\section{Grammation, regrammation and degrammation of complex paradigms}

Complex paradigms connect simple paradigms to form more complex packages of paradigms. Table 1 is one such example, since voice morphology and voice topology and construction are interdependent and have no content in isolation. Christensen (2007) terms an important subtype of complex paradigms synthetic hyperparadigms, because in their complexity they grammaticalise meaning as senses that are not there in simple subparadigms, but arise in the complex paradigmatic structure only. For further discussion of the synthetic nature of such paradigms, see Chapter 6.

It follows from our views of morphology, topology and constructional syntax that the concept of connecting grammaticalisation applies to all three domains. Paradigms may connect subparadigms of all three kinds into complex paradigms. Grammation processes and regrammation processes can form such complex paradigms, alter them and dismantle them.

A study of one such process (morphological mood and word order systems) is found in Chapter 6, and another (case and construction formation) in Chapter 7.

In Chapter 6 Lars Heltoft addresses the regrammation of verb second patterns in the history of (mainly) Danish as an instance of the wider Scandinavian development. The claim is that the modern Mainland Scandinavian languages have formed a tightly knit topological and constructional paradigm connecting word order oppositions with hierarchical position (main clause status or subordinate clause status). Such paradigms are complex hyperparadigms; their parts do not occur in isolation, but are interdependent. In the terminology of Christensen (2007) the present example is a synthetic one, since its meaning oppositions are not fully predictable from the individual paradigms. The diagram below (Table 2) states the point that in subordinate clauses the word order opposition between verb second (V2) and non-verb second (non-V2) is one of mood (assertion vs. non-assertion), while in main clauses it is one of illocution (or rather, illocutionary potential or illocutionary frame). There is no way we could predict that non-V2 main clauses should express subjective (or emotive) illocutionary frame.

This paradigm is the product of a development from the late Middle Ages to the late 17 th century. It was not present in the medieval language, where verb second was the general and unmarked word order pattern. 
Table 2. Modern Danish word order

Domain: Clausal Word order

Frame: Emotivity and assertivity

\begin{tabular}{lll}
\hline Expression & \multicolumn{2}{c}{ Content } \\
\hline main clause & V2 & assertive illocutionary frame \\
main clause & non-V2 & subjective illocutionary frame \\
subordinate clause & V2 & assertive potential \\
subordinate clause & non-V2 & neutral \\
\hline
\end{tabular}

For further examples involving topology, Chapter 2, Section 5.

Spanish provides an example involving constructions: the use of $a+\mathrm{NP}$ in object functions. Modern Castilian has a striking distribution of the PP $(a+\mathrm{NP})$ alternating with dative forms of the personal pronouns. In two-argument constructions A2 (the direct object) has either the form:

$$
a+\mathrm{NP}(\text { a Fernando) }
$$

or

NP (el libro).

In three-argument constructions it is the A3 (the indirect object) that has the form a + NP a Fernando.

The opposition is between a Fernando 'Fernando' opposed to the non-prepositional form of A2 with a non-human referent: el libro 'the book'.

(5) ¿puedes ir a buscar a Fernando esta tarde?

'can you fetch Fernando this evening?'

(6) ¿puedes ir a buscar el libro esta tarde? 'can you fetch the book this evening?'

If a direct object denotes a human referent, it will be in the prepositional form unless there is an A3 indirect object to supersede the object. We get (7), with cross-reference between the dative pronoun le and A3 a mi hermana 'to my sister', and normally (8):

(7) ¿Le das el libro a mi hermana?

'Will you give the book to my sister?'

(8) Envié el soldado al rey

'I sent the soldier to the King',

rather than Envié al soldado al rey.

Two-argument constructions show the following paradigm: 
Table 3. The paradigmatic structure of A2 in Modern Spanish

Domain: V [A2]

Frame: \pm Human Referent of A2

\begin{tabular}{ll}
\hline Expression & Content \\
\hline$a+\mathrm{NP}$ & $\begin{array}{l}\text { the referent has } \\
\text { the feature +human }\end{array}$ \\
$\mathrm{NP}$ & $\begin{array}{l}\text { the referent has } \\
\text { the feature -human }\end{array}$ \\
\hline
\end{tabular}

The step to three-argument constructions results in a reshaping of this paradigm, see Table 4 . The synthetic character of this paradigm lies in the fact that the opposition +human referent vs. -human referent is now bound up with syntactic hierarchy.

Table 4. Three-argument constructions. The paradigm of a + NP in Castilian Spanish. Opposition between +human referents

Domain: V [non-subject arguments]

Frame: Referentiality

\begin{tabular}{ll}
\hline Expression & Content of A2 / A3 \\
\hline A2 / A3: $a+$ NP or dative form of pron & human referent \\
A2: NP or accusative form of pron & non-human referent \\
\hline
\end{tabular}

\section{Grammation, regrammation and degrammation of parallel (sets of) paradigms}

Parallel paradigms are parallel in the sense that:

- $\quad$ either one and the same content system is expressed in two or more different expression systems (2.1).

- $\quad$ or two content systems with different expression systems are parallel in the sense of being semantically complementary (2.2).

\subsection{One content system in more than one expression system}

Paradigms in different subsystems of grammar can be parallel in the sense that their content systems are variants of one more abstract system, for instance verbal inflectional categories and nominal inflectional categories, or verbal inflectional categories and topological systems. Grammation processes and regrammation processes can form such parallel paradigms and alter or dismantle them. 
Such a parallel system is described by Heltoft \& Falster Jakobsen (1996) where Danish passives and subject positions are claimed to be alternative expressions of the same semantic frame and the same content opposition. They claim that the double passive system in Danish is a modal contrast:
a. der tale-s
dansk $i$ Skåne
there speak-PRS-PASS.s-MOod Danish in Scania
'Danish is spoken in Scania, as the norm' [no longer true] (norm, general state of affairs)
b. der bliv-er tal-t dansk $i$ Skåne
there become-PRS speak-PRF PTCP Danish in Scania 'situations occur where persons in Scania speak Danish' [which is certainly true]
(assertion that in particular situations this occurs)

The same modal contrast is found in active clauses with an indefinite subject. The parallel is relatively easy to show with normative readings, but for the full picture consult Heltoft \& Falster Jakobsen (1996). The elements in bold face manifest the parallels (10a) and (10b), and (11a) and (11b):
a. en landmand arbejd-er
a farmer work-PRS-ACT an average 16 hours
'a farmer will work/works on average 16 hours' (norm, rule)
b. der arbejde-s gennemsnitlig 16 timer there work-PRS-PASS.s-MOOD an average 16 hours 'work lasts/will last on average 16 hours'

(11) a. der arbejd-ede en mekaniker på opgaven there work-PST-ACT a mechanic on the task 'a mechanic was working on the task'
b. der blev arbejd-et på opgaven there become.PST work-PRF PTCP on the task 'work was being done on the task'

\subsection{Semantically complementary systems}

In the present book such a parallel system is studied by Nørgård-Sørensen (Chapter 5), who argues that there is a semantic parallel between verbal aspect and nominal animacy in Russian.

The Modern Russian category of aspect has developed from an earlier verbal distinction between verbs construed to denote actions or non-action. Modern Russian aspect involves a reanalysis of action into two parts, the forerunning activity and the resulting state. Modern Russian perfective aspect asserts the resulting state and 
thus 'the completion of the action'; the imperfective aspect asserts the activity, but it says nothing about the state (Durst-Andersen 1992). The activity vs. state distinction is reflected grammatically at two levels at least: (a) in lexicalisation (activity vs state verbs); (b) in the basic aspect meaning, the imperfective verb asserting the activity and the perfective verb asserting the subsequent state and thus implying the completion of the action.

The nominal correspondent of the activity/state distinction is that of potential actor/non-actor. Where these two asserted - and therefore basic - predications are concerned, the state has a subject denoting a non-actor ${ }^{47}$ and the activity has a subject denoting an actor. There is thus a semantic parallel between aspect and animacy.

Nørgård-Sørensen stresses that the aspect system is the semantic backbone of this similarity and that the animacy system (now generalised as a gender in Russian) provides a distinction that fits neatly into the activity/state opposition. This system is not a hyperparadigm in the sense presented above, but a parallel system in the sense of a verbal and a nominal system being complementary.

\section{Connecting paradigms vs. layering}

Readers from traditions where paradigmatic organisation plays a limited role or no role at all in the layout of grammars may find our content descriptions confusing. To help them stand out more clearly, we compare our paradigms to the concept of layering used by Paul Hopper and Elisabeth Traugott, as laid out in Hopper (1991).

Paradigms as we define them are fundamentally synchronic and they are characterised by stable semantic oppositions framing a semantic domain. They are a part of the descriptive elements necessary for identifying the inputs and outputs of change. A layering as described by Hopper is a functional domain such as tense, modality and aspect, case and reference within which "new layers are continually emerging". Layering is neither clearly synchronic, nor diachronic, but both perspectives are applied. A simple, illustrative example is tense in English, where the modern language preserves three historically different layers. The most recent layer is periphrasis: We have used it; the older layer is affixation: I admired it, and the oldest layer is ablaut: They sang (adapted from Hopper 1991:24). Hopper does not define semantic differences between the layers, and therefore, semantic changes are not approached, especially not those that affect the content only.

47. Possibly in the form of a potential actor, not fulfilling any activity in the situation referred to. 
Complex or connecting paradigms are synchronic phenomena, not diachronic sediments or layers. Connecting paradigms may of course very well contain material from different periods of the language, but their raison dêtre is their contribution to the synchronic organisation of such material, including its synchronic content. Returning to the issue of the Scandinavian passives (also briefly mentioned in Hopper \& Traugott 2003:159-161), the oldest layer is the periphrastic construction. The inflexional passive in $-s$ (Danish and Swedish) is in origin a reflexive form (from the reflexive pronoun $s i k$ ). During the Middle Ages the reflexive form was extended semantically to carry also the passive meaning, but just as one variant out of four (see Dyvik 1980; Kemmer 1995; Heltoft 1996). In Danish, Norwegian and Swedish the reflexive functions became obsolete and lexicalised, leaving the $s$-passive behind as the only productive function of the $s$-form. ${ }^{48}$

By the end of the 16th century, the $s$-form in Danish had specialised to become a modal passive, while its Swedish parallel did not. Mutatis mutandis, Danish and Swedish retain similar oppositions between a periphrastic passive and an inflexional passive where the expression is concerned, but their semantics is different. In Danish, the descriptive passive is the periphrastic form and the s-passive is modal, see examples (9ab) above; in Swedish, the $s$-passive retains its descriptive function.
a. Den danske generalstab blev arresteret the Danish general staff became arrested 'the Danish general staff was arrested'
b. Den danske generalstab arrester-ede-s
the Danish general staff arrest-PRET-PASS.s-MOOD 'the Danish general staff was arrested (as part of somebody's plan or intention)'

Example (12a) is a simple description of an event on the day of the German occupation of Denmark in 1940, but (12b) must be read as an account of the way the Germans carried out their war plan. The $s$-form is modal in the sense of being normative as in (9a), or, as here, in the sense of expressing a view point or some intention different from the speaker's. There is nothing similar in the following Swedish formal parallel, the content of which is parallel to (12a), not to (12b).

48. Hopper \& Traugott (2003:160-61) state that in Danish, the $s$-form has only occasional passive uses and is confined to the written language. From the point of view of grammaticalisation, it is actually the other way round, so that reflexive functions of the $s$-form are impossible, and the reciprocal and intransitive functions have lexicalised, see Heltoft \& Falster Jakobsen 1996; Heltoft 1996. 
(13)
Danska generalstaben grep-s och
Danish-DEF general staff-DEF seize.PRET-PASS and
tog-s $i$ förvaring
take.PRET-PASs into custody
'The Danish general staff was seized and taken into custody'

In terms of layering the Swedish and Danish situations are identical. The passives derive from the same origin, in both languages they have been detached from the reflexives (Hopper might say they have changed domain, we would say a new paradigmatic system has been formed), but the modern synchronic difference between the two languages are stable language-specific semantic differences, and regrammation has turned out differently.

To describe this we need the concept of a complex or connecting paradigm, a paradigm because these grammatical contrasts are stable, and connecting - as explained above - because the relation to active clauses with indefinite subjects must be included as well. 

PART II

Case studies 



\title{
CHAPTER 5
}

\section{Patterns of connecting grammaticalisation in Russian}

\author{
Syntax, animacy and aspect
}

\author{
Jens Nørgård-Sørensen
}

This chapter presents a case study of connecting grammaticalisation in Russian. Drawing on both previous research and empirical investigation of text sources, I shall demonstrate how basic syntactic constructions and the the two prominent morphological categories of aspect and animacy have developed within a frame of mutual dependency leading up to the system of Modern Russian (MR) where the verbal category of aspect and the nominal category of animacy are semantically complementary.

As already pointed out in Chapter 4, Section 2.1, MR verbs reflect the activity/ state distinction at two levels: (a) in lexicalisation (activity vs state verbs) and (b) in the basic meaning of the perfective and the imperfective aspect. Further, the nominal correspondent of the activity/state distinction, that of (potential) actor/non-actor, has been grammaticalised in the so-called category of animacy. MR, in other words, exhibits a parallel system in the sense of the verbal category of aspect and the nominal category of animacy being complementary realisations of an overall semantic distinction. In a diachronic perspective, a complementary system of this kind represents a specific type of connecting grammaticalisation.

Preliminary results of the research to be presented in this chapter were published in Nørgård-Sørensen (2006). The empirical investigations are based on three sources. First, examples have been extracted from the Old Russian Dictionary (Avanesov ed. 1988 and later), listing all tokens of the words from all main sources of Old Russian (OR) writing from the 11th through the 14th century and thus constituting a fundamental tool for philologists and historical linguists. ${ }^{49}$ Second, I have

49. Many examples that will be considered in the following are taken from the Old Russian Dictionary and have also been cited in Krys'ko (1997). Krys'ko (1997) is the hitherto most comprehensive study of OR syntax. In relation to the individual examples I shall neither refer to the Old Russian Dictionary nor to Krys'ko (1997), but restrict myself to mentioning the text source and, when relevant, the approximate time of its origin. The following abbreviations are used in references to the text sources (from the Old Russian Dictionary, for details 
used a representative corpus of OR chronicle texts and, for the later periods, historical narratives. ${ }^{50}$ Historical texts comprise a genre that has remained relatively homogeneous over time. Though originating in the normative Church Slavonic text tradition with its Old Bulgarian roots, it gradually incorporated more and more genuinely Russian linguistic features and can be assumed to reflect the development of the language better than clerical texts. Thirdly, additional evidence has been excerpted from the few markedly oral genres, in particular the Novgorod birch bark letters (Zaliznjak 1995).

For reasons of exposition I have chosen to open the presentation with an examination of OR syntax (Section 1). I then turn to the historical development of animacy (Section 2) and aspect (Section 3), before eventually describing the parallel development in Section 4.

\section{Old Russian syntax}

In the following I shall approach OR syntax with the purpose of overviewing its basic features in contrast to those of MR syntax. The focus will be on constructions, also when referring to their constituent elements: verbs, arguments and adjuncts. I would like to emphasise that the concept of argument - here as in the other chapters of this book - is used in a broad sense. In general, speaking of verbs and their arguments does not necessarily involve the close structural dependency relation referred to as verbal valency. The linguistic concept of valency is employed to refer to a kind of syntactic relationship where the verb determines both the number of arguments and their form. In this sense valency is a feature of MR syntax, but obviously not of OR syntax. As will be shown, OR syntax was construction-based. Still, even in relation to OR constructions, I shall refer to verbs and their arguments. The concept of a verb-argument relation is broad: it may and may not involve the much narrower concept of valency.

Arguments are coded in various ways, in European languages primarily by prepositions or case - or by combinations of these. Since Russian like most other Slavic languages is a case language, I shall start by considering arguments coded by case. The

see Avanesov (ed) 1988, I: 28-68 ): GA = Xronika Georgija Amartola, Gr = Novgorod birch bark letter, LI = Ipat'evskaja letopis', LL= Lavrentjevskaja letopis', LN = Novgorodskaja xaratejnaja letopis', NIL = Novgorodskaja pervaja letopis', $\mathrm{PBP}=$ Pis'ma i bumagi imperatora Petra Velikogo, PR 1383 = Prolog martovskoj poloviny, 1383 g., PrL = Prolog "Lobkovskij" sentjabrskoj poloviny, SbTr XII/XIII, 11ob. = Sbornik slov i poučenij, SbTr XIV/XV, 192 ob. = Čudesa sv. Nikolaja Čudotvorca, USb = Uspenskij sbornik, USt XII/XIII = Ustav studijskij cerkovnyj i monastyrskij.

50. I am indebted to Karin Larsen for making her electronic corpus of Old Russian chronicles available to me. 
overall OR case system has been preserved in MR. Ignoring the vocative (which has been lost and revived in a new shape) and a few secondary forms in both OR and MR, we can state that the six cases, which mark syntactic functions, namely the nominative, the accusative, the genitive, the dative, the instrumental and the locative, have all been preserved. On the other hand, as appears from OR grammar descriptions ${ }^{51}$ as well as from specialised studies of case roles (Schelesniker 1964; Krys'ko 1997; Maier 1997; Dubrovina 2002; Ferm 2005), case functions have undergone a number of remarkable changes in the history of Russian.

In OR, as well as in other case languages, a distinction can be made between adverbial case forms and argument-marking case forms. Some adverbial case functions were identical or close to identical to those of MR. The most striking difference was the extensive use of the OR accusative in a number of adverbial functions, indicating different nuances of location, time, quantity, relation, etc. (Krys'ko 1997: 49-109), cf. (1-3):

(1) $s t a-s ̌ a \quad o b-a \quad$ pol-y

stop-off-AOR.3PL both-ACC.M side-ACC.M.DU

rěk $i \quad$ Vlen-y (LI)

river-GEN.SG Vlena-GEN

'they stopped off at both banks of the river Vlena'

The accusative oba poly 'at both banks' indicates location.
(2) poid-e kotı̌st-ou
svo-emou Kiev-ŭ (LL)
go-AOR.3sg to father-in-law-DAT.SG his-DAT Kiev-ACC
'he went to Kiev to his father-in-law'

The accusative Kievŭ 'to Kiev' indicates direction.
...prišed- $\breve{u}$
Vyšegorod-ou noč- $\breve{l}(\mathrm{USb})$
arrive.PST.PTCP.ACT-NOM.SG.M Vyšegorod-DAT night-ACC.SG
'... having arrived at Vyšegorod at night'

The accusative noč ' 'at night' indicates time.

None of the constructions illustrated can be found in MR where the adverbial function of the accusative is remarkably narrower.

51. Changes in case functions have not been systematically described in traditional OR grammars but appear indirectly from the material presented in them. Most of these descriptions focus not on the function of the cases, but on the development of the case forms as the result of sound changes and analogical processes, e.g. Kuznecov (1953), Šachmatov (1957), Rusinov (1977), Gorškova \& Chaburgaev (1981), Chaburgaev (1990). The same is basically true about the hitherto published volumes of the new co-authored historical grammar of OR (Krys'ko (ed.) 2000-2006). 
For arguments, especially A2, the picture was much more differentiated in OR than it is in MR. The accusative was widely used as A2 - for which it was the unmarked form - but it was not dominant in the way it is in MR. Many verbs were used in constructions with other oblique cases in the A2 slot, and a large number of verbs combined with two or even three different A2 cases.

The choice of case was not determined by the verb as a lexical unit - as would have been the case in a valency system - but by the construction. For instance, in connection with verbs of physical effect and verbs of taking and transfer, the case distinction could be interpreted as expressing a difference between a quantified (genitive) and a non-quantified (accusative) A2. Given this interpretation, the case opposition constituted a construction paradigm, cf. (4).

(4) Domain: V [A2]

Frame: Quantification

\begin{tabular}{ll}
\hline Expression & Content \\
\hline accusative & non-quantified \\
genitive & quantified \\
\hline
\end{tabular}

This opposition, which presumably was inherited from PIE, can be illustrated by the parallel use of genitive and accusative in (5)-(6).

(5) Aleksandr-a i droužin-ou ego kazni

Alexander-GEN and guard-ACC his punish-AOR.3sG

ov-omou nos-a urěza-ša a in-omou

one-DAT.SG nose-GEN.SG cut off-AOR.3PL and other-DAT.SG

oč $-i \quad$ vyima-ša $(\mathrm{LN})$

eyes-ACC.DU tear out-AOR.3PL

'He punished Alexander and his guard. They cut off (some of)

the nose of some of them and tore out the eyes of others'

(6) urěza-ša emu nos-a i

cut off-AOR.3PL he.DAT nose-GEN.SG and

ob-è ruc-è (NIL)

both-ACC.DU hand-ACC.DU

'they cut off (some of) his nose and both of his hands'

In (5) there is a distinction between the genitive A2 nosa 'nose' and the accusative A2 oč 'eyes' that is not motivated by the verbs. The context allows for the interpretation proposed by Krys'ko (1997:160): that the genitive refers to an unspecified quantity of the item ('they cut off some of the nose') while the accusative refers to the items in their totality ('they tore out the eyes (fully)'). As already emphasised, I take this as a reflection of a construction-based rather than a valency-based syntax. 
Example (6) can be interpreted along the same lines as (5): the nose was cut off in part, the hands in full, cf. the translation. Note that the construction distinction can be implemented for two paratactically ordered A2s of one and the same verb. This does not invalidate the technical presentation of the construction above in (4); rather it confirms that the verb does not determine the form of the A2.

Verbs of control, i.e. verbs with the meaning 'govern', 'possess', 'be in control of', do not appear to have changed much during the history of Russian. In MR they combine with an A2 in the instrumental, and this is also the case with the majority of the OR examples, cf. (7).

$$
\begin{aligned}
& \text { [...] oblada-xou sracin- } i \quad \text { jegjupt-omi }(\operatorname{PrL}) \\
& \text { control-IPRF }{ }^{52} .3 \mathrm{PL} \text { Saracen-NOM.PL Egypt-INS.SG } \\
& \text { 'The Saracens gained control of Egypt' }
\end{aligned}
$$

However, while this verb-case combination is obligatory in MR as an instance of verbal valency, the OR material also exhibits examples with the genitive and even the accusative, cf. (8) and (9).

(8) Rodijan-e mor-e oblada-vš-e (GA) Rhodian-PL sea-ACC.SG control-PTCP.PST.ACT-NOM.M.PL 'The Rhodians having gained control of the sea...'
oblast $-i$
toj-a
Ambrosij [...] oblada-še (GA)
district-GEN.F.SG. this-GEN.F.SG Ambrosij
control-IPRF.3SG
'Ambrosij controlled this district'

Since (8) and (9) are taken from one and the same text source, we would expect them to express a semantic distinction. And indeed, as Krys'ko (1997:167-68) suggests in relation to another example from the same source, the genitive can be interpreted as an instance of the construction with a quantified A2, in other words expressing that Ambrosij controlled a certain portion of the district, cf. the paradigm (4). The construction with the accusative, cf. (8), may have been triggered by the contrast to the genitive in examples like (9). The accusative expressed the unmarked, here the nonquantified A2. In sum, the material with verbs of control confirms that the choice of case was not determined by the verb but rather by the choice of construction.

However, not all OR data reflect the supposedly underlying constructions as transparently as the examples considered above. In connection with the verb poxvaliti 'praise', A2 appears in the accusative (10)-(11), the genitive (12) and the dative (13).

52. IPRF has no model in the Leipzig glosses. We use it for a past tense morpheme like German Imperfektum. 
(10)

$\begin{array}{lll}\text { starec- }- \text { [...] } & \text { poxvali } & \text { vel'mi } \\ \text { old man-NOM.SG } & \text { praise-AOR.3sg } & \text { much }\end{array}$

žen-ou svoj-u (SbTr XIV/XV $192 \mathrm{ob})$

wife-ACC.SG his-ACC.SG

'The old man highly praised his wife'

(11) [...]no $i$ poxvali $i(\operatorname{Pr} 1383)$

but also praise-AOR.3sg he.ACC.SG

'... but he also praised him'

[...] $i$ poxvali jego knę(z) (LL)

and praise-AOR.3sg he.GEN ${ }^{53}$ prince-NOM

'.. and the prince praised him'
[...] i vsi poxvali-ša
етu (LI)
and all praise-AOR.3PL he.DAT
'... and all praised him'

Even though the data themselves, including their contexts (not cited), hardly provide sufficient evidence for an interpretation in terms of construction paradigms, these examples do not invalidate the view of $\mathrm{OR}$ as a language with construction-based syntax. First, the accusative-genitive distinction of examples (10)-(12) fits into the interpretation that is considered below (Section 2). Second, representing different periods and genres, the examples may reflect different structures. Third, the case distinctions may have expressed semantic oppositions which we are simply not able to detect on the basis of the data. Fourth, some forms, in particular the apparently fairly infrequent dative, may have been stylistically marked at a certain stage of an actualisation process, eventually ousting the use of the dative in this context, cf. Chapter 1, Section 9.2. Variational markedness.

While the explanations applied to the examples above all appear plausible, there is, on the other hand, nothing to indicate that the verb as a lexeme determined the form of the arguments, as it would in a valency-based system. The data generally support an interpretation in terms of constructions, even though they do not always allow for an exact understanding of the particular distinctions. This is also true for examples of A2s consisting of paratactically ordered nouns in different cases, cf. the clearly interpretable (6) above and the apparently more fuzzy (14).

53. In most treatments of OR pronominal forms like jego, which is the historical genitive form (masc-neut.sg.) of the demonstrative-personal pronoun $j \breve{l}$, are interpreted as the accusative, due to the fact that it spread in all accusative functions in OR and eventually replaced the historical accusative form $j \breve{\imath}$ (masc.sg.) and je (neut.sg.). However, for reasons that shall soon be clear I shall treat this form as a genitive. 
(14)

$$
\begin{aligned}
& \text { bl(a)godar-imú } o(t \bar{u}) c j-a \quad i \quad s(y) n-a \quad i \\
& \text { thank-PRs.1PL father-GEN and son-GEN and } \\
& s(v e) t \text {-oumou } d(u) x \text {-ou (USt XII/XIII) } \\
& \text { holy-DAT spirit-DAT } \\
& \text { 'we thank the Father, the Son and the Holy Spirit' }
\end{aligned}
$$

Below I shall return to the parallel employment of the accusative and the genitive which has a special impact on the further development of OR syntax.

Like all other varieties of early documented Slavic (i.e. from the middle of the 9th century and onwards), OR undoubtedly exhibits a relatively archaic Indo-European structure, especially in its nominal system. And indeed, the expression of one and the same argument by different case forms in OR is strikingly similar to the syntax reconstructed for PIE by Meillet (1964 [1937]). Meillet emphasises that Indo-European did not know any verb-argument government (in a later terminological tradition: valency) of the kind found in modern Indo-European case languages where, basically, a specific argument of one and the same verb is expressed by a specific case. He exemplifies the PIE syntax with the Greek verb klyō 'hear', which could be used with no further specification (simply to denote the hearing activity) or combined with different cases, coding different content, cf. (15a-e) (cited from Meillet 1964 [1937]:358-59).
a. é-kly-on
audē-n
hear-PST.IPFV.3PL voice-ACC.F.SG
'they heard a voice'
Accusative: what is heard
b. é-kly-on aut-oú
hear-PST.IPFV.3PL he-GEN.M.SG
'they listened to him'
Genitive: from where something is heard
c. euxo-mén-ō moi é-kly-on
pray-PRS.PTCP-DAT.M.SG me-DAT hear-PST.IPFV.3PL
'they listened to my prayers'
Dative: for whom/what something is heard

Meillet points out that the accusative, the genitive and the dative are no more dependent on the verb than cases which, from the point of view of modern syntactic theories, fulfil an adverbial function, i.e. the role of an adjunct, cf. (15d-e):

$$
\text { d. oú-asi kly-ō }
$$

ear-DAT.N.PL hear-PRS.1SG

'I hear with my ears'

Dative (originally instrumental): what something is heard with 


\section{e. oíkoi kly-ō \\ at home.ADV hear-PRs.1SG \\ 'I hear at home'}

Adverb (originally locative): where something is heard.

Meillet did not make the distinction between argument and adjunct, but simply emphasised that the choice of case for the subordinate noun did not depend on the verb. He states that the 'autonomy of the word' was the governing principle of the structure of the PIE phrase. The verb had a general meaning and the different case forms added different specifications. In our framework this corresponds to a view of PIE syntax as construction-based. This is also reflected in subsystems of other ancient Indo-European languages, cf. the Latin constructions eo Romam 'I go to Rome', sum Roma 'I am in Rome' in Chapter 3, Section 2.5.

Meillet presents the autonomy of the word as a general syntactic principle for PIE, also applying to noun phrases. I shall return to this point below.

No traditional research on OR syntax has focused on the distinction between construction-based and valency-based syntax. Researchers have tacitly taken the verb to be the determining centre of the sentence and investigated what cases it combined with for the different argument slots. This approach inevitably leaves a picture of OR syntax as a fairly chaotic system, only gradually developing into the more "logical" valency system of MR. It goes without saying that this understanding of the development of Russian, not articulated but nevertheless implied by much research, is inappropriate. On the other hand, there have been a few attempts to offer an overall interpretation of the development from the OR to the MR syntactic systems. I shall now consider two such contributions.

Inspired by Meillet, among others, Krys'ko (1997) interprets the history of case usage in Russian as a transition from a non-transitive system in OR to a transitive system in MR. Krys'ko sticks to the Russian tradition where a transitive system is perceived as involving a distinction between verbs combining with an A2 in the accusative $^{54}$ and verbs not combining with an A2 accusative (i.e. verbs with no A2 or an A2 in a different form). Krys'ko shows how the accusative in the A2 slot has gained ground during the history and presents this as the result of two interconnected processes.

First, Krys'ko (1997:48) assumes that adverbial accusatives through specification could develop into the MR 'direct objects', that is, in our terms, verb-governed A2s in a valency system. However attractive this statement may appear, it would not seem to be supported by the data. Adverbial accusatives of the kind exemplified in (1)-(3) did

54. Krys'ko follows the tradition in referring to the A2 accusative (in MR alternating with the genitive after negation and in constructions expressing quantification) as the direct object. 
and with the paraphrases based on the Old Russian Dictionary (Avanesov ed. 1988 and later).

$$
\begin{aligned}
& \text { gostiti } \\
& -\quad \text { No complement: 'to travel around and do business' } \\
& \text { - ACC: 'to receive somebody as a guest' } \\
& \text { doiti }
\end{aligned}
$$

- No complement: 'to live as a (breast-fed) baby'

- ACC: 'to breast-feed'

- ACC: 'to milk'

blagosloviti

- No complement: 'rejoice'

- ACC or DAT: 'bless'

vrediti 'harm'

- No complement: 'do harm'

- ACC Or DAT: 'harm'

Though representing different theoretical backgrounds and empirical approaches, the investigations by Krys'ko and Durst-Andersen both leave a picture of OR syntax as a system with no strict government relation between verb and noun, i.e. a system where the verb does not have valency in the sense that the number and forms of the arguments are determined by the verb.

As already mentioned, there are clear similarities between OR syntax and the syntax of PIE as reconstructed by Meillet. The question whether there were constructions in OR could, in principle, also be asked in relation to PIE. However, Meillet's Greek examples do not offer sufficient evidence to approach the question of constructions in this language. The five case form extensions of the verb klyō in (15a-e) look conspicuously like a construction paradigm, but all the case forms hardly excluded each other. Rather, they represented not one but several argument slots. However, the scarce evidence provided leaves little doubt that Ancient Greek syntax was construction-based, but it would take more data to set up the construction paradigms.

Although it is beyond the scope of the present investigation to consider the question of constructions in Ancient Greek, the example can be used to turn attention to the criteria for setting up constructions. A construction is a complex sign consisting of two or more words (cf. Chapter 3). A premise that should be satisfied in order to set up a construction is that it should account for content that is not already coded in any of the constituent elements. As emphasised elsewhere in this book, a fundamental feature of constructions is that they are paradigmatically organised and, thus, obtain their specific content from being opposed to other constructions.

On this background I have assumed that OR had constructions. The hypothesis is that the apparent "variation" of case usage exemplified above does not represent 
instances of free variation but rather a system of constructions. For instance, the evidence provided by the dictionaries for the verbs in (18), gostiti 'travel around and do business, etc.' doiti 'milk, etc.' and blagosloviti 'bless, rejoice', vrediti 'harm' allows us to set up a simple construction paradigm, cf. (19).

\begin{tabular}{ll}
\hline Domain: $V[\mathrm{~A} 2]$ & \\
\hline Frame: second-participant specification \\
\hline Expression & Content \\
$\varnothing$ & unmarked \\
$\mathrm{NP}$ & second participant specified \\
\hline
\end{tabular}

For exemplification let us consider the verb gostiti. As a lexeme, the verb has an invariant meaning in the formulation proposed by Durst-Andersen (2006:218): 'be a guest at a certain place'.

Since the verb denotes an activity, there must be at least one argument A1 referring to the individual producing the activity, but otherwise the verb as a lexeme does not code any information about the arguments. This information is provided by the construction paradigm. If the A2 slot is not filled (the unmarked choice), there will be no specification of any second participant. In relation to gostiti, this means that the primary participant A1 (expressed by the nominative if the verb is finite) will be someone simply being a guest, without the circumstances being specified. If the A2 slot is filled, a second participant will be specified in addition. Thus, in relation to the verb gostiti this means that the primary participant A1 will be someone offering the secondary participant A2 (if unmarked (see below), expressed by the accusative) the role of a guest, cf. the translation in (18) 'to receive somebody as a guest'.

This is a clear example of constructions coding information that is not otherwise provided. Note that the meaning of the construction paradigm (19) is formulated broadly enough to cover a number of verbs including doiti, blagosloviti and vrediti, cf. (18). For the two latter verbs the construction paradigm of (19) should either be specified or supplied in order to account for the dative in the A2 slot.

It is outside the scope of this presentation to contribute a broader analysis of OR constructions, but I shall return to the concept of construction in the study of the accusative-genitive distinction below.

The scarce data provided so far indicate that case, as the category marking the syntactic function of the noun, had a broadly defined function allowing for its use and, consequently, specification in different constructions. Since there must be compatibility between the lexical meaning of the verb and the grammatical meaning of the case form(s) it combines with, a given verb will tend to occur regularly with one particular case or with a few particular cases (with or without preposition), cf. (18). However, as already emphasised, there was no obligatory link between lexical classes of verbs 
and specific cases in specific argument positions; in other words, verbs did not have valency.

I shall now return to the construction paradigm expressed by the genitiveaccusative opposition in the A2 slot, introduced above as (4). According to Krys'ko (1997: 160-94), this opposition was found with a number of verb classes, including the following:

(20) - verbs of physical effect ((ou-/po-/ob-)rŭvati 'tear', (ou-)rězati 'cut', vŭzgražati 'build')

- $\quad$ verbs of taking and transfer (kusati 'bite', (pri-/vŭz-)jati 'take', koupiti 'buy', (po-)dati 'give')

- verbs of control (obladati 'be in control of', iměti 'have, possess')

- verbs of visual and auditive perception (slušati 'listen', slyšati 'hear', sŭmotriti, žřěti 'look at, watch')

- verbs of attention and concern (prizirati 'despise', stereči 'take care of', mıstiti 'revenge')

- verbs of aspiration (želati 'wish', žĭdati 'expect', dostignuti 'achieve')

- verbs of withdrawal (ubežati 'fly', otǔstupitisja 'step back')

This brief overview of verbs combining with both the genitive and the accusative in the A2 slot is in full accordance with the tradition of organising the material on the basis of lexical verb classes. Though not spelled out in the literature, a presentation of this kind leaves the impression that the verbs alone determine the domain of a specific kind of case opposition. This impression is undoubtedly the result of an intuitive application to OR of the modern linguistic concept of valency, involving the idea of the verb as the superordinate member determining the form of all subordinate nominals. However, as already emphasised, an interpretation along these lines is misleading. The number of arguments and their forms is determined not by the verb but by the choice of construction. The fact that specific lexical groups of verbs only fit into a few constructions, sometimes only into one, does not invalidate this statement. On the contrary, that so many different verb classes, cf. (20), fit into one and the same construction paradigm confirms that the construction, not the verb, plays a decisive role for the syntax of the sentence.

In MR the verbs in (20), with few exceptions, either take the unmarked accusative A2 (alternating systematically with the genitive after negation and in constructions expressing quantification), or consistently combine with other cases, for instance obladat' 'possess' + A2 in the instrumental. Since MR verbs have valency, the information about the form of the arguments is coded in the MR verb.

Schematically, the fundamental difference between OR and MR verb-argument relations can be illustrated as in (21). 
$(21)$

$\begin{array}{ll}\text { Old Russian } & \text { Construction-based syntax: } \\ \mathrm{V}+\text { ACC/GEN } & \text { Case is constructional } \\ \mathrm{V}+\text { ACC/DAT } & \\ \mathrm{V}+\text { ACC/GEN/DAT } & \\ \text { etc. } & \end{array}$

Modern Russian Valency-based syntax:

$\mathrm{V}+\mathrm{ACC} \quad$ Case is lexically determined

$\mathrm{V}+\mathrm{GEN}$

$\mathrm{V}+\mathrm{DAT}$

etc.

In relation to MR, the unmarked accusative is by far the most common A2 marker, the other cases typically appearing with limited groups of verbs with a specific meaning, e.g. verbs with the meaning 'govern', 'lead' taking the instrumental.

It should be emphasised that (21) is a schematic presentation and only reveals the general picture of OR and MR as representing two different syntactic types. However, language types are probably never pure systems, and a language structure may include subsystems not compatible with the dominant typological features of the language in question. Thus, though Russian has generally switched from a system with constructions to a system of verbal valency, there are still examples of verb-argument constructions in MR. The probably most prominent one is the MR version of the OR construction paradigm expressing quantification with the accusative-genitive opposition in the A2 slot. It still exists in MR within a more limited domain - to which I shall return in the following section.

Another "construction island" in the MR "sea of valency" can be found in modern spoken Russian, where the two reflexive verbs bojat'sja 'fear' and slušat'sja 'obey' take the accusative of animate nouns and the genitive of inanimate nouns, cf. (22).
a. boja-t'-sja pap-u
fear-INF-REFL dad-ACC.SG
'fear one's dad'
b. boja-t'-sja smert-i
fear-INF-REFL death-GEN.SG
'fear death'
c. sluša-t'-sja pap-u
obey-INF-REFL dad-ACC.SG
'obey one's dad'
d. sluša-t'-sja sovest $-i$
obey-INF-REFL conscience-GEN.SG
'obey one's conscience' 
Thus, MR has the construction paradigm presented in (23).

\begin{tabular}{ll}
\hline Domain: $\mathrm{V}[\mathrm{A} 2]$ & \\
Frame: animacy & \\
\hline Expression & Content \\
\hline accusative & animate \\
genitive & inanimate \\
\hline
\end{tabular}

This paradigm, apparently, is only valid for the two verbs mentioned, bojat'sja 'fear' and slušat'sja 'obey'. As mentioned, they are reflexive (marked by the reflexive suffix -sja) - which used to exclude the accusative in the A2 slot. The A2 accusative of reflexive verbs is of relatively new origin (20th century), in other words from a time when Russian was already a well-established valency language. As can be seen, new substructures, not compatible with the dominant typological features of the language, occasionally arise.

In the construction paradigm of (23) it is clearly a lexical-semantic feature of the A2 noun that determines its form - though in a valency system the case forms of the arguments are supposed to be determined by the verb. In this case the situation is so that the lexical-semantic features of the verb, the superordinate member of the construction, limit the object position to the accusative-genitive domain, while the lexical-semantic features of the noun, the subordinate member, determine the specific choice of case. It is hardly accidental that in this recently established construction paradigm it is the most prominent grammatical distinction of the MR noun, animate/inanimate, that is expressed. Further, what triggers a change of this kind, running counter to the basic syntactic system of the language, is, without a doubt, the unmarked status of the accusative as A2 marker. The accusative is the form with the greatest potential of spreading in the A2 slot.

As already indicated, both in the OR construction-based system and in the MR valency-based system the accusative is the unmarked A2 case. Still, there are clear differences. The accusative is generally far more dominant in MR than in OR as the result of the actualisation of the valency-based system reflected in the above-mentioned investigations of 'verbal government' (Maier 1997; Dubrovina 2002; Ferm 2005). As appears from previous investigations, in particular Krys'ko (1997), a large number of OR verbs allowed for the genitive along with the unmarked accusative. In other words, the accusative-genitive opposition was particularly common, potentially expanding and open to reanalyses. Thus, it is not surprising that the accusative-genitive opposition formed the domain where animacy appeared as a grammatical category, cf. the following sections. 


\section{Animacy as a gender}

\subsection{Animacy in Modern Russian}

Gender is a noun classification category. Not all languages have genders, but if there is a gender category in a given language, it means that a noun will inherently belong to a particular gender.

MR is a language with two gender categories. On the one hand, the Indo-European gender distinction between masculine, feminine and neuter is fully preserved. The overwhelming majority of Russian nouns have a gender in this classical sense. The exception is constituted by pluralia tantum nouns which, as a result of the lacking gender specification in the plural declension of MR, have no gender.

On the other hand, during historical time the distinction between animate and inanimate nouns has been grammaticalised and has achieved the status of a gender category. Any MR noun (without exception) is inherently either animate or inanimate, and this grammatical feature is reflected in the inflection of both the noun itself and of subordinate words. Animacy is assigned on the basis of a purely lexical-semantic criterion: animate nouns are those denoting living individuals; all other nouns are inanimate.

Although both categories are in fact gender categories, I shall consistently employ the traditional terms gender and animacy in order to avoid confusion.

The MR animacy category developed in historical time. I shall soon go into some of the details of this development, but already at this point it should be emphasised that MR animacy is not a continuation of the assumed PIE animacy distinction, described by Meillet (1964 [1937]:339-41). Meillet provides evidence for the hypothesis that the gender system of ancient Indo-European languages related unequivocally (and probably developed from) a binary animate-inanimate distinction in the following way, cf. (24).

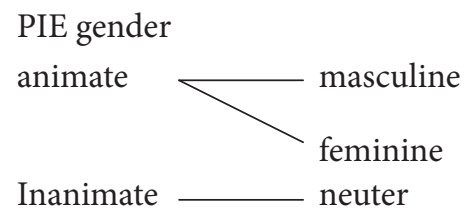

However, in Slavic, as in other Indo-European languages, this correspondence between animacy and gender was already blurred in the oldest texts, and eventually it was lost. The new animacy category appeared on a different background, which will be described below. It is further worth noticing that the two oppositions are not identical. In PIE animate were all nouns denoting something acting in a very broad, even figurative, sense (cf. the examples in Meillet 1964 [1937]:340). In MR, on the other hand, 
animacy presupposes individuation. For a noun to be animate it is not sufficient that it denotes something with a potential of acting; it must denote a potentially acting individual. For this reason nouns like pravitel'stvo 'government', kommissija 'commission', garem 'harem' and stado 'herd' are inanimate though denoting living beings.

The two gender categories are in principle independent of each other. All logically possible combinations of gender and animacy values are possible, cf. (25).

$\begin{array}{ll}\begin{array}{l}\text { M.Anim } \\ \text { M.Inanim }\end{array} & \begin{array}{l}\text { slon (1.decl.) 'elephant', djadja (2.decl.) 'uncle' } \\ \text { F.Anim }\end{array} \\ \begin{array}{l}\text { babuška (2.decl.) 'grandmother', voš (3.decl.) } \\ \text { 'louse' }\end{array} \\ \text { F.Inanim } & \begin{array}{l}\text { komnata (2.decl.) 'room', krepost' (3.decl.) 'fortress' } \\ \text { N.Anim }\end{array} \\ \text { čudovišče 'monster' } \\ \text { N.Inanim } & \begin{array}{l}\text { slovo 'word' }\end{array}\end{array}$

However, when two gender categories exist side by side in one and the same language they must somehow be interconnected, and - contrary to the traditional view of animacy as a subgender (Corbett 1991: 165-68) - I claim that in MR the younger category of animacy has taken the dominant position. This appears from a number of facts. ${ }^{55}$ In the present context I cannot go into details with these facts (for a more elaborate argumentation, see Nørgård-Sørensen 1997c, 2011), but they all, individually and in combination, point to animacy as the primary inherent category of Russian nouns. The ultimate argument in favour of this interpretation is, not surprisingly, semantic. Unlike gender, which is assigned to the noun on the basis of both formal and semantic criteria, animacy is based on the lexical meaning alone: animate nouns are those denoting living individuals and all other nouns are inanimate. Gender, on the other hand, partly depends on declension.

As a gender category, animacy is an inherent feature of the noun stem. It finds its formal reflection in a pattern of syncretism with the accusative in focus. While the accusative of animate nouns is identical to the genitive, the accusative of inanimate nouns is identical to the nominative. This pattern of syncretism is an index of the

55. The dominance of animacy over gender is reflected in various subsystems. First, as already mentioned, while there are nouns without gender, all nouns have an animacy value (i.e. they are inherently either animate or inanimate). In other words, animacy, unlike gender, is prominent in any occurrence of a Russian noun. Second, in assignment patterns animacy sometimes dominates gender, while the reverse is never the case. Third, persondenoting nouns, a subcategory of animate nouns, constitute a noun class with their own specific set of grammatical features tending to spread to animate nouns in general. Fourth, certain types of gender variation can be shown to be dependant on the animacy distinction (Nørgård-Sørensen 2011). 
inherent animacy value of the noun stem. It has a broad but still restricted domain. It is characteristic of the so-called 1st declension masculine (historically the masculine $o$-stems) and of all plurals, cf. Chapter 1, Table 6, repeated below as (26).

(26) Russian noun declension: animacy-marking syncretism Singular, 1st declension, masc.:

\begin{tabular}{lcc} 
& \multicolumn{1}{c}{ Anim } & \multicolumn{1}{c}{ Inanim } \\
Nom & $-\varnothing$ & $-\varnothing$ \\
Acc & $-a$ & $-\varnothing$ \\
Gen & $-a$ & $-a$
\end{tabular}

Plural:

\begin{tabular}{lll}
\multicolumn{1}{c}{} & \multicolumn{1}{c}{ Anim } & \multicolumn{1}{c}{ Inanim } \\
Nom & $-i,-a,-e$ & $-i,-a$ \\
Acc & $-o v \sim-e j,-\varnothing$ & $-i,-a$ \\
Gen & $-o v \sim-e j,-\varnothing$ & $-o v \sim-e j,-\varnothing$
\end{tabular}

It should be stressed that the individual desinences are still traditional portmanteau inflections, expressing number and case. Like gender, animacy is lexically encoded and thus inherent in the noun stem. Animacy is not expressed by any individual desinences, but the patterns of syncretism, marked by the boxes in (26), are indices of the animacy values coded by the noun stem.

As can be seen, unlike most other Slavic languages Russian marks animacy in all plural nouns. This is tantamount to saying that animacy is an inherent feature of all Russian nouns, i.e. of the noun as a part of speech. Since this argument may not be persuasive by itself, it will be developed a little further. Above it was argued that, as a category of the noun, gender is marginally defective, since a group of nouns, pluralia tantum, have no gender. By definition these nouns only take plural forms, which in MR are not specified for gender.

Now, it might be assumed that a similar argument could be applied to animacy. While gender is never expressed in the plural, animacy is only partly expressed in the singular, so singularia tantum nouns, not belonging to the 1st declension masculine, have no formal reflection of animacy. However, singularia tantum nouns are either abstract nouns (l'ubov' 'love'), mass nouns (kartof'el' 'potatoes', neft' 'oil') or collectives (narod 'people' (in one of its readings)), none of which are individuated (in the sense of denoting individual items). Since in MR animacy presupposes individuation (animate nouns are all individual-denoting and thus take both a singular and a plural form), singularia tantum nouns must all be inanimate.

MR differs from most other modern Slavic languages where animacy plays a less prominent role. For instance, Bosnian/Croatian/Serbian only knows an animacy 
distinction in the masculine singular, expressed by a syncretism pattern roughly corresponding to the upper part of (26). Being delimited to the masculine singular, animacy is clearly a subgender in this language (Corbett 1991:161-65). On the other hand, for MR the conclusion to be drawn from the above analysis is that while a few MR nouns have no gender, all nouns have an animacy value. This and all other facts concerning animacy and its relationship to gender point to animacy as the dominant inherent grammatical feature of the MR noun.

\subsection{The problem}

As we have seen, OR was a language with only one gender category - the classical Indo-European masculine/feminine/neuter distinction. Thus, the question is when the new category of animacy was established and what were the conditions motivating this grammatical change.

Pursuing this question, one should look for instances of the genitive form in syntactic slots where the accusative would be expected, and investigate when the use of this form takes a regular pattern like the one known from MR. In this connection one should further consider whether, for each period investigated, the historical genitive form, when occurring where the accusative would be expected, should be considered an accusative or a genitive form.

\subsection{From Old Russian to Modern Russian}

\subsubsection{The syntax of the Old Russian noun phrase}

The statement made above - that OR was a language with only one gender category: the inherited masculine/feminine/neuter distinction - is actually controversial. Even in the oldest Slavic texts, handed down in copies reflecting originals from the middle of the 9th century, there are clear cases of genitive forms of animate nouns where the accusative would be expected, ${ }^{56}$ especially in the A2 slot. This is also the case in the slightly younger OR texts. What has been referred to as the genitive in slots where the accusative would be expected (mainly A2), first appeared with animate masculine singular o-stems, compare (27) and (28), both from the Codex Laurentianus (CL) (1377), including the oldest preserved copy of the Primary Chronicle (Nestor Chronicle), which found its final compilation at the beginning of the 12th century.

56. In the following I shall repeatedly use the informal formulation that "(some case) should be expected" in a certain syntactic position. It is true that this formulation is controversial in the sense that as descriptive linguists we have no right to "expect" other forms than the ones actually occurring in the texts. Anyway, I shall use the formulation in situations where some non-accusative case, especially the genitive, occur as A2 in connection with verbs known to widely combine with an unmarked $\mathrm{A} 2$ accusative. 
(27)

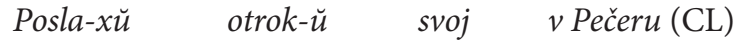
send-AOR.1sg servant-ACC his-ACC to Pečera
'I sent my servant to Pečera'

I prisla Volodimer- $\breve{u} \quad$ otrok-a
And send-AOR.3sg Volodimer-NOM
servant-GEN
svoj-ego Bjandjuk-a $(\mathrm{CL})$
his-GEN Bjandjuk-GEN
'And Volodimer sent his servant Bandjuk'

In (28) the A2 phrase consists of a masculine noun otrok- $a$ 'servant' with an attributive pronoun svoj-ego and an apposition Bjandjuk- $a$, all with genitive desinences (- $a$ for the nouns, -ego for the pronoun). In (27), on the other hand, we find the same verb and the same noun otrok- $\breve{u}$ in the A2 slot, but in a form that can be identified as the historical accusative, i.e. the accusative that would be predicted from regular sound changes.

As a result of sound changes in prehistoric time, the Slavic syllable was restructured fairly drastically and a number of desinences, inherited from PIE, were reduced. The nominative and accusative singular of the masculine $o$-stems (as well as of the $\breve{u}$ - and $i$-stems) were left identical, cf. (29).

$$
\begin{aligned}
& \text { o-stems: masculine, singular } \\
& \text { PIE Early written Slavic } \\
& \text { Nom } \quad \text { os otrok- } \breve{u}^{57} \text { 'servant' } \\
& \text { Acc } \quad \text { om otrok- } \breve{u}
\end{aligned}
$$

It has been assumed that this nominative-accusative syncretism led to the expansion of the genitive in positions where the accusative would be expected (Iordanidi 1995: 284, inter al.). The $o$-stems contained a large number of frequently used persondenoting nouns, and in an A1 - V - A2 sentence there would, in principle, be no way to distinguish A1 from A2 if both were masculine $o$-, $\breve{u}$ - or $i$-stems.

Further, it has been assumed that a situation where the subject is not formally distinguished from the object is likely to cause structural disharmony in a language marking arguments by case. The problem - the argument runs - did not really arise if one noun was animate and the other inanimate. Animacy would provide sufficient

57. The nominative singular $-\breve{u}$ was hardly the result of regular sound changes. Presumably it appeared by analogical levelling under the joint influence of the accusative singular of the $o$-stems and the nominative singular of the $\breve{u}$-stems. In this context we need not go further into this development; neither do we need to consider the specific North-West Russian desinence $-e$ for the o-stem nominative singular (Zaliznjak 1995:82-85). For my argument it suffices to state that the syncretism shown in (29) was characteristic of all varieties of early written Slavic (excluding North-West Russian, i.e. the Old Novgorod dialect). 
information for an unequivocal functional differentiation: the animate noun would be perceived as A1, the inanimate as A2. However, if both nouns were animate, and especially if both denoted persons, there would be no formal indication of their syntactic status, cf. the constructed examples for early OR in (30).

$v l \breve{u} k-\breve{u} \quad u b i \quad$ otrok- $\breve{u}$
wolf-NOM/ACC kill-AOR.3sg servant-NOM/ACC
'the wolf killed the servant'/'the servant killed the wolf'
ot $\breve{i} c-\breve{l} \quad v i d i-t \breve{\imath} \quad s y n-\breve{u}$
father-NOM/ACC love-PRs.3sG son-NOM/ACC
(reconstruction in Krys'ko 1994: 156)
'the father loves the son'/'the son loves the father'

It should be emphasized that in this and most other varieties of Slavic the word order does not play any significant role in signalling the syntactic function of noun phrases.

If a genitive was used as one of the arguments in an A1 - V - A2 sentence, there would be no "problem" of the kind described. The genitive would be perceived as A2. As we have seen, genitive in the A2 slot was not alien to native speakers of OR.

This evidence indicates that the "critical" A1 - V - A2 sentence was where the development started, and that it started not as a reanalysis of the grammatical system but as an adjustment of the distribution of the case forms within existing constructions - a point to which I shall return.

Though the idea of the spread of the A2 genitive as being motivated by A1-A2 confusion may appear attractive, it is also problematic in the light of other instances of A1-A2 form identity having existed and still existing in Russian. Below I shall propose an alternative interpretation of the $\mathrm{A} 2$ genitive in terms of a regular sign distinction.

The origin of the pattern found in the oldest Slavic texts can be reconstructed as follows. A large group of verbs combined with the accusative, which already at this language stage was the unmarked case for the A2 slot. Another relatively large number of OR verbs (many more than in MR) combined regularly with an A2 genitive. A third, also relatively large group of verbs combined both with the accusative and with the genitive (cf. the OR verb classes mentioned in (20) above). Note that I am only considering constructions with the accusative or the genitive as the A2. In other words, we are apparently concerned with a system of paradigmatic organisation of two-argument constructions, expressed by these two cases, cf. (31).

$$
\begin{aligned}
& \text { A1 - V - A2.ACC (unmarked) } \\
& \text { A1 - V - A2.GEN (marked) }
\end{aligned}
$$

At a certain point in the prehistory of Slavic animate masculine nouns in the singular (mostly $o$-stems, but also $\breve{u}$ - and $i$-stems) started to generally favour the genitive for the A2 slot - independently of the verb. This indicates that a construction paradigm of the shape of (32) had appeared. 
$(32)$

\begin{tabular}{ll}
\hline $\begin{array}{l}\text { Domain: } \mathrm{V}[\mathrm{A} 2] \\
\text { Frame: animacy }\end{array}$ \\
\hline Expression & Content \\
\hline accusative & inanimate \\
genitive & animate \\
\hline
\end{tabular}

This happened on the basis of the Common Slavic accusative-genitive opposition for the A2 slot expressing quantification. Both OR (examples (5) and (6) above) and other older varieties of Slavic, in particular Old Church Slavonic, confirm that the A2 accusative-genitive opposition was still used to express quantification, cf. the construction paradigm (4), repeated below.

(4) Domain: V [A2]

Frame: Quantification

\begin{tabular}{ll}
\hline Expression & Content \\
\hline accusative & non-quantified \\
genitive & quantified \\
\hline
\end{tabular}

The parallel use of one and the same case distinction for expressing two patently different semantic distinctions is indeed intriguing. I believe that we must look to the lexical semantics of the nouns for a clue to the problem. This will take us through the following steps of interpretation.

First, let us turn to the opposition quantified/non-quantified. Though this opposition has been expressed by the genitive-accusative distinction all through history from prehistoric Slavic to MR, there is a difference between its manifestation in OR and MR that seems to have escaped the attention of linguists. In MR the expression of quantification by means of the genitive vs. the accusative is limited to what is generally referred to as collective nouns and mass nouns, cf. (3) in Chapter 1, repeated below, slightly modified, as (33).

$$
\begin{aligned}
& \text { vypit' čaj } \\
& \text { drink tea-ACC.sG } \\
& \text { 'drink tea/the tea' } \\
& \text { vypit' čaj-a/čaj-u }{ }^{58} \\
& \text { drink tea-GEN.sG/tea-GEN.SG } \\
& \text { 'drink (some) tea' }
\end{aligned}
$$

58. As mentioned in Chapter 1 , the noun $\check{c} a j$ 'tea' is among the ones allowing for two genitive singular forms $-a$ and $-u$, of which the latter is restricted to expressing quantification. This is not relevant to the present context where we focus on the accusative-genitive distinction. 
As we have seen above, OR did not know any limitation of this kind. Even objects, in a broad sense, like a nose (cf. (5)-(6)) and a district (cf. (9)), could be thought of as quantified. Now recall, from the definition in Section 2.1, that "animate nouns are those denoting living individuals", in other words, MR animacy presupposes individuation: only nouns denoting individuals (informally: objects as opposed to masses and collectives) can be animate.

It follows that the grammar of MR nouns is partly based on the individual/nonindividual distinction. ${ }^{59}$ On the other hand, there is no indication that this lexicalsemantic distinction played any significant role for the grammatical categories of Old and Common Slavic nouns. This means that at a certain point the grammar of the nouns must have undergone a reanalysis rendering the formally less prominent individual/non-individual distinction part of the basis for one or more grammatical features. This could have happened in connection with the establishment of animacy as a gender category (to which I shall return shortly), but the promotion of the individual/non-individual distinction could also have a broader basis. That the expression of the quantification distinction is limited to non-individual-denoting nouns (mass nouns and the like) in MR obviously has the new prominence of the individual/ non-individual distinction as a precondition. This allows for setting up the following change scenario, described in terms of logical steps, not necessarily corresponding to consecutive steps in the actual change scenario.

1. The lexical-semantic distinction individual/non-individual was established by reanalysis. As a result, any noun would be thought of as either individual-denoting or non-individual-denoting.

2. The expression of the distinction quantified/non-quantified by means of the genitive vs. the accusative was limited to non-individual-denoting nouns. Given that the individual/non-individual distinction had become prominent, this was a wellmotivated development.

3. As a result, the accusative-genitive distinction was deprived of content when applied to individual-denoting nouns in the A2 slot.

4. The genitive/accusative distinction was reanalysed as expressing the opposition animate/inanimate in the domain of individual-denoting nouns in the A2 slot. Given that within this domain the genitive/accusative distinction had been left semantically empty by the previous development, this was a well-motivated development.

59. Elsewhere (Nørgård-Sørensen 2011) I have offered a detailed description of the foundation for the lexical semantics of MR nouns, based on a hierarchy of four semantic features, among others the individual/non-individual distinction. 
This change scenario implies that the OR genitive/accusative distinction in the A2 slot expressing quantification, cf. (4), was modified to form the paradigm of (34). (Note the specification of the domain).

\begin{tabular}{ll}
\hline Domain: V [non-individual A2] \\
Frame: Quantification \\
\hline Expression & Content \\
\hline accusative & non-quantified \\
genitive & quantified \\
\hline
\end{tabular}

If one were to think of a lexical-semantic group of nouns which from the outset do not motivate a quantification reading, it would be those inherently denoting individuals - with an individual interpreted as an item with clear-cut limits and heterogeneous internal structure (Nørgård-Sørensen 2011). ${ }^{60}$ It is well-motivated that, in a limitation of the domain of where quantification can be expressed, individual-denoting nouns are excluded.

As part of the same change scenario a new construction paradigm, giving content to the 'expressional vacuum' left by the limitation of the quantification distinction, arose. This is actually the paradigm already presented as (32), the domain of which must now be specified, cf. (35).

\begin{tabular}{ll}
\hline $\begin{array}{l}\text { Domain: V [individual A2] } \\
\text { Frame: animacy }\end{array}$ \\
\hline Expression & Content \\
\hline accusative & inanimate \\
genitive & animate \\
\hline
\end{tabular}

With the clear distribution of their domains, the paradigms (34) and (35) are complementary. Though 'exploiting' the accusative/genitive distinction for quite different purposes, they are not in disharmony and can be part of one and the same system. One might wonder why the genitive, having been associated with the feature quantified even back into prehistoric time, was 'chosen' to express the feature animate (individual) as a result of the change scenario sketched above. These features cannot in any way be perceived as associated with each other. However, there is an alternative

6o. Nouns of this kind are often defined as countable - somewhat unfortunately, because countability is rather a syntactic symptom of the underlying noun meaning than a part of the meaning itself. This appears from the large number of nouns capable of being treated as both countable and uncountable. 
explanation that makes better sense: in both paradigms the genitive is marked. Rather than semantic associations, the markedness relation indicated in (31) was decisive for the content ascribed to the two case forms.

If the paradigms (34) and (35) are taken to be part of the system at a certain stage of development on the background of a change scenario like the one described above, they offer a reasonable explanation both of examples with a clear distribution of the accusative and the genitive and of examples with an apparently vague use of the two case forms. In this connection it should be acknowledged that the establishment of (35) was a regrammation that would spread only gradually in an actualisation process. Further, considering the stylistic differentiation, the proposed interpretation appears to account fairly well for the data.

Though, as can be seen, the paradigm of (35) was the result of a system reanalysis affecting only the content, not the form - it did not by itself represent a very fundamental system change. The change that I have referred to as the establishment of paradigm (35) is the one that has been interpreted as the introduction of animacy as a grammatical category. This interpretation presupposes that the genitive in these constructions was reanalysed as an accusative (Krys'ko 1994:171-72). However, as I see it, the change merely represented a specification of the system of A2 marking as being dependent on the lexical semantics (in particular the individual/non-individual and the animate/ inanimate distinctions) of the nouns involved. The accusative-genitive opposition was reanalysed as expressing a new distinction of content within a domain for which the older quantification distinction had become irrelevant. In other words, the historical genitive form selected for animate nouns was presumably still a genitive at this stage of development.

It is of interest to compare this change to the one that recently (20th century) took place in MR in connection with the verbs bojat'sja 'fear' and slušat'sja 'obey', cf. (22)-(23) above. As reflexive verbs they used to govern the genitive. In the 20th century the dominant use of the accusative as the $\mathrm{A} 2$ case was extended to these verbs - again under the condition that the noun is animate (or, more specifically, person-denoting). The essential point is not only that in both cases animacy is the decisive factor, but that the extension of the verb-noun combination model is dependant on the lexical meaning of the subordinate noun.

As mentioned, the proposed interpretation of OR syntactic development is partly a reconstruction. Reconstructions have traditionally been concerned with phonetics and morphology while syntax has largely been neglected. Reconstructing prehistoric syntax is a complicated endeavour potentially leading to inaccurate or even defective results. A way to test the validity of a syntactic reconstruction is to focus on its logical consequences and investigate whether they can be observed in older varieties of Slavic, including OR. A consequence of the proposed reconstruction is that the genitive of animate nouns in the A2 slot was still a genitive at the time of the changes examined 
and not, as assumed by many linguists (Krys'ko 1994:171-72; Klenin 1983:103), an original genitive reinterpreted as the accusative. The question is, in other words, if the form otrok- $a$ in (28) should be interpreted as a genitive or an accusative in the OR system. In the MR system the parallel form would, without a doubt, be an accusative. I shall now consider a few more OR data in order to throw light on this question.

In my preliminary investigation above of the A2 genitive I only provided examples with the most common type of animate direct objects, i.e. noun phrases consisting of a masculine $o$-stem noun as head and, possibly, one or more attributes. I shall now consider some other types of A2s, viz. noun phrases with appositions, noun phrases with masculine $a$-stems and prepositional phrases.

Examples (36)-(37) illustrate the case use in A2 phrases including appositions.

(36) Jaroslavŭ ... knjazj-a ix oubi Moislav-ŭ (LL)

Jaroslav ... prince-GEN their killed Moislav-ACC 'Jaroslav killed their prince Moislav'
poja Jaroslavŭ... za syn- $\breve{u} \quad$ svoi
took Jaroslav for son-ACC his-ACC
za Volodimir-a Vseslavlju dčeř̆ (LI)
for Volodimir-GEN Vseslav's daughter
'Jaroslav took Vseslav's daughter as wife for his son Volodimir'

In (36) the A2 phrase consists of a common noun knjazja 'prince' in the genitive with a proper noun Moislavŭ 'Moislav' functioning as an apposition and appearing in a form that has been glossed as the accusative, but which could also count as the nominative, cf. the historical merger of these two cases exemplified in (29). If we take the latter form to be a nominative, the construction seems to make good sense: it is quite common for case languages, including several Slavic languages, to allow for appositions (especially proper nouns) in the nominative, irrespective of the case of the head noun.

However, in (37) it is the other way around: the common noun synŭ svoi 'his son' is in the accusative and the proper noun Volodimira 'Volodimir' is in the genitive. It is true that this example exhibits iteration of the preposition ( $z a$ 'for') - a very common feature of OR to which I shall return - but in combination the examples seem to indicate that A2s with apposition referring to animate individuals allowed for different kinds of accusative-genitive combination.

Another interesting picture is revealed in A2s containing animate masculine $a$-stems, cf. in (38) the accusative ounošju (for junoš-u, nom. junoš-a 'young man'), and in (39) the accusatives Kuzm-u (nominative Kuzm-a) and mečenošju (for mečenoš-u, nom. mečenoš- $a$ 'sword-carrier').

$$
\begin{array}{lll}
\text { obrět-oxŭ } \quad \text { ounoš-ju } & \text { dobr-a }(\mathrm{USb}) \\
\text { find-AOR.1sG } & \text { young man-ACC } & \text { good-GEN } \\
\text { 'I found a good young man' } &
\end{array}
$$




$\begin{array}{lll}\text { Vsevolod posla ... } & \text { Kuzm-u Ratǐšič-a } \\ \text { Vsevolod sent } & \text { Kuzma-ACC } & \text { Ratǐšič-GEN } \\ \text { mečenoš-ju } & \text { svo-ego (LL) } \\ \text { sword carrier-ACC } & \text { his-GEN } \\ \text { 'Vsevolod sent Kuzma Ratišič, his sword-carrier' }\end{array}$

First it should be emphasised that OR $a$-stem nouns, whether feminine or masculine, never appeared in the genitive in A2 slots where the accusative could also be used. Hereby masculine $a$-stems differed from all other classes of masculine animate nouns: $o$-, $\breve{u}$ - and $i$-stems. It is generally, and undoubtedly correctly, assumed that the reason is that the $a$-stems had separate desinences for the nominative, accusative and genitive singular (as in MR, cf. Table 5 in Chapter 1). They thus never exhibited the nominative-accusative syncretism that is supposed to have been motivating for the spread of the genitive in the A2 slot in connection with animate masculine $o-$, $\breve{u}$ - and $i$-stems. Also from a more general point of view this makes sense within a syntactic system like that of OR. As we have seen, the case of an argument in OR was basically determined by the construction but could in addition be influenced by the noun itself.

OR texts do not provide a large amount of data of the type exemplified in (38) and (39). As in MR, masculine $a$-stems were limited to person-denoting nouns, i.e. a subclass of animate nouns. In discourse person-denoting nouns often carry sufficient information in themselves, so in most contexts there is little need for the kind of semantic specification provided by attributive adjectives. As can be confirmed both by empirical studies (Krys'ko 1994: 135-36) and by the Old Russian Dictionary (Avanesov (ed) 1988 etc.), which lists all tokens of the words from all main sources of OR writing, there are few cases of masculine $a$-stems combining with adjectives in the OR texts, and all of them - without exception - exhibit the same word order pattern as (38) and (39). The ( $a$-stem) noun occupies the first position in the noun phrase and is followed by a specifying nominal, either an adjective (dobra in (38)), an apposition (Ratišiča in (39)) or a pronoun (svoego in (39)).

If the postponed specifier is an adjective, as, for instance, dobr-a in (38), it occurs in the so-called nominal form. From Common Slavic OR inherited a system with two parallel adjective forms: the nominal (or short) form, with the same inflection as the nouns of the dominant declensions (o-stem desinences for masculine and neuter and $a$-stem desinences for feminine), and the pronominal (or long) form, consisting of the nominal form extended by the appropriate form of the demonstrative pronoun $j$-, cf. (40).

$$
\text { nominal (short) form pronominal (long) form }
$$
F.Sg.Nom
dobr-a 'good'
dobr-a-j-a 
A nominal extended by a demonstrative pronoun looks conspicuously like a grammaticalised expression of definiteness, and in prehistoric Slavic the opposition between the short and the long form was undoubtedly one of indefiniteness-definiteness (Tolstoj 1957; Flier 1974). In the history of Russian the use of the long form was gradually extended to include all adjectives in attributive position and some adjectives in predicative position, leaving the short form a marked choice in the predicative position. The development of the opposition between short and long adjectives in Russian has been investigated by Larsen $(2005,2006,2007,2009)$. Among other things, Larsen points out that (i) the short form is kept longest in postponed position, and (ii) the short form is favoured by contexts where the noun and the adjective in combination are perceived as referring to a representative of the item denoted by the noun, which in addition, so to speak, has the feature denoted by the adjective (Larsen 2009). In combination these two facts indicate that at a certain point of development of OR the short adjective was used in a broad predicative, or predicative-like, function, independently of the argument position. This is confirmed by numerous examples in OR chronicles of the type of (41).

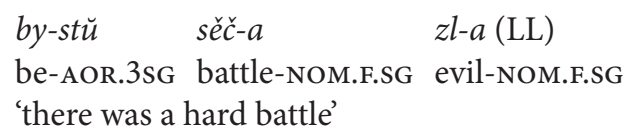

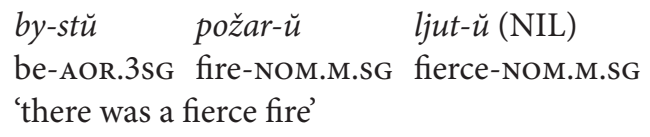

From a modern point of view the examples in (41) allow for an interpretation of the adjectives both as attributive and predicative, cf. 'there was a hard battle' vs. 'there was a battle that was hard. The distinction expressed by these two translations into English was hardly relevant to OR, and there are reasons to believe that the latter interpretation is the one that comes closest. As in the case of dobra in (38), the postponed adjective was not part of the referential noun phrase. The reference was made by the noun alone, and the short postponed adjective added a feature to the referent. It played what I have called a broad predicative function. This indicates a loose syntactic connection between the noun and the adjective.

The same low degree of syntactic dependency can be assumed to have been characteristic of appositions which are also postponed, cf. Ratǐšiča in (39). Postponed nominals are generally loosely connected, predicative-like, elements of the noun phrase with a relatively independent syntactic status. It can be assumed that this loose syntactic relationship within the noun phrase allows for the use of different cases for the head noun and the specifier - just as we have seen it to be the case in paratactically ordered noun phrases like the ones in (5)-(6) and (14). However, for a noun phrase 
one would expect to find what is normally referred to as agreement relations - i.e. an indexical 'repetition' in the inflection of specifiers of grammatical features of the head noun. In the OR noun phrase there was agreement in gender and number, but not in case. The case of an argument would basically be determined by the construction, but in addition there were rules depending on what was referred to. For nominals referring to masculine singular animate individuals, the A2 case would be accusative if distinct from the nominative (in practice, $a$-stems), and genitive if the accusative was identical to the nominative (o-, $i$ - and $\breve{u}$-stems and pronouns). Thus, there was an agreement relation gluing together the elements of the noun phrase, but unlike in MR it did not take in the category of case.

I shall return to the question of the structure of the noun phrase after having considered prepositional phrases, cf. (42)-(43).

$$
\begin{aligned}
& i \quad \check{c} \text { to ... tober bylo gněv-a na posadnik-a... (Gr 1268) } \\
& \text { and what you.DAT was anger-GEN on governor-GEN } \\
& \text { 'and what anger you felt against the governor' }
\end{aligned}
$$

$$
\begin{aligned}
& \text {...drougyi na bra-tŭ pomyšlja-etĭ (SbTr XII/XIII, } 11 \text { ob.) } \\
& \text { other on brother-ACC think-PRs.3sG } \\
& \text { '... others think of their brother' }
\end{aligned}
$$

As can be seen, prepositions that are traditionally taken to govern the accusative, actually allowed for both the accusative, cf. (43), and the genitive, cf. (42), of animate masculine nouns in the singular. This pattern is particularly widely documented for the prepositions $n a$ 'on' and $z a$ 'for' but is also represented for $v \breve{u}$ 'in(to)' and $p o$ 'on, by'. The reason why the evidence is clearer for the two former prepositions than for the two latter is most likely pragmatic: by virtue of their lexical meaning the prepositions $n a$ 'on' and $z a$ 'for', are more likely to combine with animate nouns than $v \breve{u}$ 'in(to)' and $p o$ 'on, by'. The fact that the genitive appears in connection with prepositions has been used as an argument in favour of interpreting this form as an accusative (Krys'ko 1994: 172). I shall return to this discussion shortly and provide some counterarguments. For the time being it suffices to emphasise the following characteristic feature of the examples provided and, it would seem, of all prepositional phrases with the genitive after prepositions otherwise combining with the accusative: all of these prepositional phrases are syntactic extensions of verbal phrases or predicative words. They are linked to verbs, cf. pomyšljaetĭ in (43), or words with an inherent predicative function like gnèv- $a$ in (42). This means that the nouns are arguments, connected to the predicate not directly but by means of a preposition. There would seem to be no prepositional phrases in adverbial function in the material. This is not surprising. Adverbial prepositional phrases are normally used to refer to time, location, reason, etc. and it is hard, not to say impossible, to imagine an animate noun in a phrase with such a function. For the argumentation to follow it is, however, essential to make this point. 
The data above may leave a rather confusing picture of OR syntax. I shall now summarise the evidence provided, both from the literature and from my own investigations, in an attempt to offer a more coherent interpretation of the OR syntactic system.

OR syntax was construction-based with no strict verb-argument dependency relation. The case form of an argument was determined by the construction, but the meaning and reference of the nominal could play an additional role. Compared to MR there were more accusatives with an adverbial function, signalling location, time, quantity, relation, etc. Among the A2s the accusative, though unmarked, was less dominant than in MR; other oblique cases were frequent. Since the syntax was construction-based, many verbs combined with different cases in different - or similar - contexts, and there were especially many verbs occurring with both the accusative and the genitive in the A2 slot.

Above I considered the internal structure of the noun phrase and reached the conclusion that it was characterised by a similar kind of weak dependency as the sentence as a whole. This is in keeping with available knowledge, partly reconstructed, about Old and Common Slavic nominals. There was no clear noun-adjective distinction in Old and Common Slavic. As already mentioned, so-called adjectives had the same declension as so-called nouns: they took $o$-stem desinences (masculine and neuter) and $a$-stem desinences (feminine). In other words, they adapted to the default inflection of the respective genders. This can be taken to indicate that in prehistoric Slavic (Old and Common Slavic) there were not nouns and adjectives, but simply nominals. It is true that two types:

- $\quad$ item-denoting nominals (later nouns) and

- characterising nominals (later adjectives)

were distinguished on the basis that the latter could be used in all three genders, since by themselves they did not denote any 'item' but rather a 'feature. On the other hand, it can be hypothesised that all nominals had an independent syntactic status and were potentially referential in the sense that in discourse they could all be used to point out a referent. Agreement, i.e. the indexical reiteration of features of the head in the inflection of subordinate nominals, was limited to gender and number. Unlike case, which is a syntactic marker, gender and number reflect features associated with the denotatum and are thus the strongest candidates for agreement. In sum, the OR noun phrase exhibited a somewhat looser structure than that of MR with its strict agreement involving all grammatical categories of the noun. For each nominal in the OR noun phrase, a case could be picked anew under the conditions described: animate masculine singular $o$-, $i$ - and $\breve{u}$-stem nominals (nouns and adjectives) tended to appear in the genitive in the A2 slot, and this case use would be applied even if, within the same noun phrase, there were masculine $a$-stems in the accusative. 
The strong tendency of preposition reiteration in connection with appositions, cf. (37), also points to a more independent status of the elements of the noun phrase than in MR.

An interpretation of OR syntax along these lines appears to explain the data better than traditional descriptions. Neither verb phrases nor noun phrases exhibited a structure of strict subordination. From the point of view of connecting grammaticalisation, this parallel structure of verb and noun phrases can be taken as additional evidence in favour of the proposed interpretation of the noun phrase. In verb phrases the verb was certainly the structural centre, but the case forms of the arguments were determined by the construction and, in certain cases, also influenced by the semantics of the nouns. The fact that all nominals shared one and the same declensions is a formal indication of their relatively independent syntactic status, which should be reconstructed for Old and Common Slavic and which was still reflected in the oldest varieties of Slavic, including OR.

\subsubsection{The rise of animacy as a gender}

After the general characterisation of the OR syntactic system in previous sections, I now return to the problem formulated above concerning the appearance of animacy as a grammatical category. In previous descriptions the category of animacy has mostly been seen as developing gradually - with the genitive in positions where one would expect an accusative, appearing first in connection with a very limited group of masculine nouns denoting persons of high rank (with the meaning 'God', 'Lord', 'prince', etc.) and spreading in the following order:

- Proper nouns (masc.sg.)

- Other nouns denoting men (sg.)

- Nouns denoting men (pl.)

- Nouns denoting animals (masc.sg.)

- Nouns denoting women (pl.)

- Nouns denoting animals (pl.)

The question of the interpretation of the historical genitive is often left out of consideration, but when it is considered (e.g. Krys'ko 1994:4) the form is taken to represent the accusative of the nouns in question, even in its relatively limited use in the oldest texts. The arguments provided in favour of this interpretation have already been mentioned. For convenience, they are repeated below.

First, it is argued that the appearance of the historical genitive after prepositions, cf. (42)-(43) is an indication that the form was perceived as an accusative. Whereas in the A2 slot it can be difficult to determine if we have to do with a genitive or an accusative, it is claimed that the prepositions did not allow for any such case variation. 
Second, it is emphasised that accusatives of animate singular masculine $a$-stems (with the desinence $-u$, which is an unequivocal accusative marker) regularly appeared with attributive adjectives and pronouns in the historical genitive, cf. (38)-(39). The forms of the attributes are considered to be determined by agreement with the noun and therefore, it is argued, in this context the historical genitive must be interpreted as an accusative.

However, both of these arguments tacitly presuppose an understanding of OR syntax as resting on the same principles of strict subordination as MR syntax. In the previous sections I have questioned this understanding, and in my alternative interpretation of OR syntax the arguments above appear less convincing. As I have pointed out, even in the position after prepositions the nouns examined are arguments (A2), allowing for the same case usage as in arguments without prepositions. There are reasons for claiming that, when we have to do with noun phrases referring to animate individuals, there is nothing special about both the accusative and the genitive occurring after prepositions in a system where this case usage is generally characteristic of A2.

The second of the above-mentioned arguments - that concerning noun phrases with $a$-stems in the accusative and specifiers in the historical genitive (traditionally interpreted as the accusative) - presupposes an understanding of the noun phrase as strictly hierarchically organised with subordinate adjectives agreeing with the head noun. This understanding has been challenged above. In OR texts masculine $a$-stem nouns exclusively appear with adjectives and other inflected attributes postponed, cf. (38)-(39). This word order noun - specifier indicates a low degree of syntactic dependency. If the specifier was an adjective (a characterising nominal) and thus not denoting an entity, it would take its gender and number value from the noun (the nominating nominal), thus exhibiting gender and number agreement. However, it is worth emphasising that, unlike in MR, there was no case agreement along with the gender and number agreement.

In the light of the interpretation that not only the construction but also the noun itself influenced the choice of case, it is not surprising that $a$-stems with their distinct accusative desinence consistently shunned the genitive in the A2 slot, while other nominals - even within the same noun phrase - allowed for it or even favoured it. The limited material with noun phrases including masculine $a$-stems seems to indicate that the genitive had been conventionalised for postponed $o$-stem nominals attributed to $a$-stem masculine nouns. In the rare cases where the referent of a masculine $a$-stem was perceived as inanimate, the historical accusative could still appear, cf. (44) (Meillet 1897; Krys'ko 1994: 135).
(44)

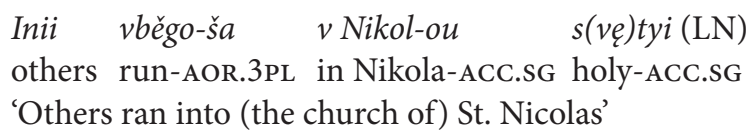


The analysis of OR syntax supports the assumption that the historical genitive of animate nouns in the A2 slot was actually still a genitive. On this background I shall now return to the central question of when animacy was established as a gender. In other words, how and when, approximately, was the OR paradigm - presented above as (35) reanalysed as the MR paradigm (45)?

Old Russian

Domain: V [individual A2]

Frame: animacy

\begin{tabular}{ll}
\hline Expression & Content \\
\hline accusative & inanimate \\
genitive & animate \\
\hline
\end{tabular}

(45) Modern Russian

Domain: Accusative, plural and masculine singular ${ }^{63}$

Frame: animacy

\begin{tabular}{ll}
\hline Expression & Content \\
\hline $\mathrm{ACC}=$ NOM & inanimate \\
ACC $=$ GEN & animate \\
\hline
\end{tabular}

The most striking thing about this reanalysis is that it changes a construction paradigm into a morphological paradigm. The essential point is that the animacy distinction is linked to a systematic syncretism pattern, cf. (26), functioning as an index of the features animate and inanimate encoded in the noun stems. Both the domain and the expression-content relation undergo a change.

The domain is extended from individual-denoting A2s to all (plural and masculine singular) accusatives.

The changes on the expression side include a reinterpretation of the genitive of animate nouns as a form shared by the accusative and the genitive. The accusativenominative syncretism inherited from the OR system became an index of the feature inanimate of the noun stem, while the newly established accusative-genitive syncretism became an index of the feature animate.

It has not been appreciated in the tradition that in early OR the spread of the A2 genitive of animate nouns was merely a change of usage rules. The system change establishing paradigm (35) apparently took place no later than in Common Slavic

61. Indeclinable nouns have no inflection and, consequently, do not reflect the syncretism patterns characteristic of this paradigm. Neither do the historical masculine a-stems (2nd declension). As in OR they have distinct desinences for the nominative, the accusative and the genitive. 
(prehistoric times), and what can be observed in OR is a spread of the A2 genitive in an actualisation process.

What we must look for is the point when the genitive form of animate nouns was reinterpreted as also representing the accusative, thus establishing the MR patterns of syncretism inherent in (45) and illustrated in (26). Only then may we speak of a new gender distinction, that of animate-inanimate, having been established.

The theory of language change here advocated predicts that the spread in the language community of the reanalysis that lead to paradigm (45) will take the form of an actualisation process where the new animate accusative (identical to the genitive) clearly expands, eventually causing the old accusative (identical to the nominative of animate nouns) to disappear.

I shall now attempt to track this actualisation process in order to pinpoint the approximate time when the reanalysis was generally adopted in the language community. Table 1 below provides an overview of the absolute chronology of the development of the genitive in positions where the accusative would be expected (mainly based on Krys'ko 1994 and 1997). Note that in Table 1 the 'genitive' refers to the genitive form. ${ }^{62}$ In other words, it is not indicated at which point this form was reanalysed as also representing the accusative of animate nouns, cf. paradigm (45). By an accusative I mean an 'accusative' form matching the predictions of regular sound developments, cf. otrokŭ 'man' in (27) - as opposed to the genitive form otroka in (28).

As can be seen, the genitive in slots where one would expect the accusative, initially only A2, spread from the singular animate $o$-stems first to the plural animate $o$-stems (11th c.) and later to all plural animate nouns (14th c.). The reason for the latter step was that the earlier distinct plural declensions merged into one. I shall leave out the details of this development; it suffices to point out that by the 14 th century there were practically no plural desinences left identifying the nouns as belonging to one particular declension of the ones still distinguished in the singular. As a consequence of the merging of the plural declensions, the use of the genitive in positions where the accusative would be expected spread from the plural $o$-stems to all plural nouns.

I have identified two motivating factors in the historical process in my attempt to interpret the reanalysis of the OR system with both the accusative and the genitive in

62. As already mentioned, the genitive in slots where one would expect the accusative could be found with all singular masculine nouns with phonological merging of the nominative and the accusative (Krys'ko 1994:35, 51-52, 68). These were primarily $o$-stems, but they also included some $\check{u}$-stems and $i$-stems. In early historical times the $\check{u}$-stems were adapted to the $o$-stem pattern and ceased to exist as an independent declension. The $i$-stems lost their masculine nouns and were basically left as a feminine declension. This allows us - for reasons of simplification and clarity - to treat the development as concerning the $o$-stems, corresponding to the 1st declension of MR. 
Table 1. The history of the genitive form in slots where the accusative would be expected

Common Slavic (before 800)

M.sg.anim

(mainly $o$-stems, some $\breve{u}$ - and $i$-stems):

Genitive or accusative

11th c.:

M.sg.anim (o-stems) and

M.pl.anim (o-stems):

Genitive or accusative

14th c.:

M.sing.anim (o-stems) and

all pl.anim:

Genitive or accusative

15th c.:

Informal language:

M.sg.anim and all pl.anim:

Genitive

18th c.:

Formal language:

M.sg.anim and all pl.anim:

Genitive

the A2 slot, cf. paradigm (35), as the MR animacy-marking patterns of syncretism, cf. paradigm (45),

First, in combination with the widely used A2 genitive, the merging of the nominative and the accusative in the masculine singular in prehistoric Slavic motivated the nouns affected by this merging to be distributed according to their animacy value: animate nouns would appear in the genitive and inanimate nouns in the accusative. I have presented this as a reanalysis resulting in paradigm (35). This change did not affect the gender system.

Second, the merging of all plural declensions in 14th century Russian had the drastic consequence of extending the genitive in A2 function from $o$-stems to the entire noun lexicon. In itself this was merely an adjustment of usage rules, but it opened the way for the following reanalysis.

The genitive form was reanalysed as the (only) accusative form of animate nouns in the plural and in the singular of masculine $o$-stems (=1st declension in MR). As a consequence, a systematic differentiation of animate and inanimate nouns in the shape of syncretism patterns covering the entire noun lexicon was achieved. This marked the introduction of a new general noun classification (animate-inanimate), in other words a new gender distinction.

This is a specification of the transition from (35) to (45) above. It is worth noting that this reanalysis did not affect the case system as such. It did not involve any changes 
in the function of individual cases. In relation to case the reanalysis was a surface phenomenon only affecting the expression: certain case forms were replaced by others.

On the other hand, the reanalysis affected the gender system. As a result of the reanalysis, a new gender distinction animate-inanimate appeared in addition to the inherited masculine-feminine-neuter distinction. This development is specific to Russian as opposed to most other Slavic languages. For instance, in Bosnian/Croatian/ Serbian the syncretism patterns expressing animacy (nominative-accusative for inanimate nouns, accusative-genitive for animate nouns) never spread beyond the masculine singular. In this language, animacy is actually a subgender with a limited domain. In Russian, on the other hand, the animacy distinction is prominent for all nouns (Nørgård-Sørensen 2011).

As already mentioned, the merger of the OR plural declensions into one was a logical precondition for this reanalysis. This means that the reanalysis must have been spreading in the language community in the early 15 th century. That the merger of the plural declensions into one was a precondition for the reanalysis of the genitive as also representing the accusative does not mean that it would necessarily lead to a reanalysis of this kind; nor does it mean that it was the only motivating factor for the reanalysis. An additional and, as I see it, decisive motivating factor was the parallel to another major change in the grammatical system taking place more or less simultaneously. This change will be investigated in the following section.

\section{Aspect}

Having considered the basic features of OR syntax and the origin of animacy, I shall now turn to the question of how verbal aspect developed during the same period of time. Verbal categories underwent fundamental changes in the history of Russian. The tense system was simplified in essentially the same way in East and West Slavic languages, compare the overview of the development in Polish in Chapter 1, Section 4, example (18), with the Russian development sketched in (46) below.

(46) a. Tense in Old Church Slavonic (reflecting Common Slavic)

(1sg and, where relevant, masc)

\begin{tabular}{|c|c|}
\hline Present & $p i \check{s ̌}_{-} Q$ \\
\hline Aorist & pisa-xŭ \\
\hline Imperfect & pisa-axŭ \\
\hline Perfect & pisa-l-ŭ jesmı̌ \\
\hline Pluperfect I & 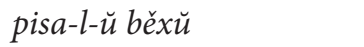 \\
\hline Pluperfect II & 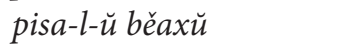 \\
\hline Future I & pisati imamĭ/xočo/nač̌̆ng \\
\hline Future II & pisa-l-ŭ bodo \\
\hline
\end{tabular}


b. Tense in Modern Russian

$\begin{array}{ll}\text { Present } & \text { piš-u } \\ \text { Preterite } & \text { pisa-l } \\ \text { Future (ipfv verbs) } & \text { budu pisa-t' }\end{array}$

Comparing the verbal grammar of MR to that of Common Slavic, we discover that of the many tense forms enumerated for Common Slavic only three are left: the present, the future and the perfect. In MR, as in Modern Polish, grammar descriptions the historical perfect is referred to as the 'preterite'. As appears from the paradigms, the MR (and Modern Polish) preterite is the only past tense form in the system, and one would expect it to have a much broader extension and a much more abstract meaning than the Common Slavic perfect - which is actually the case.

Verbal aspect is more complex. There is no doubt that the distinction between perfective and imperfective aspect is an essential feature of MR verbal grammar. Unlike a number of ancient Indo-European languages, including Greek, and some modern languages like French and English, where aspectual distinctions are expressed in the inflection of one and the same verb, the Slavic aspect is lexically encoded: a verb is either imperfective or perfective. For reasons of exposition I adopt the traditional view that Slavic aspect is lexically encoded, thus ignoring the discussion whether the systematic and predictable formation of imperfective verbs from perfective verbs by suffixation (for instance, Russian za-pisa-t' (pfv) > za-pis-yva-t' (ipfv) 'write down') should be described as inflection or derivation. This discussion is not essential to our purposes. It suffices to state that a formation of this kind is grammatical, shaping a paradigm of perfective and imperfective forms.

Both perfective and imperfective verbs are inflected, forming parallel sets of inflectional forms with certain systematic gaps, in particular that only imperfective verbs take the periphrastic future, cf. (47).

\begin{tabular}{lll} 
present.1sg & $\begin{array}{l}\text { imperfective } \\
\text { zapisyvaj-u 'write down' } \\
\text { past.m.sg. } \\
\text { future.1sg }\end{array}$ & $\begin{array}{l}\text { perfective } \\
\text { zapiš-u } \\
\text { budu zapisyva-t' } \\
\text { zapisa-l }\end{array}$ \\
\hline infinitive & zapisyva-t' & zapisa-t'
\end{tabular}

This chart includes only the three MR tense forms and the infinitive, leaving out the subjunctive, the imperative, the participles and the adverbial participles. The forms presented are sufficient to illustrate the parallelism of the imperfective and perfective forms of so-called aspect pairs.

An essential feature of the MR aspect system is that on the one hand there are aspect pairs, each consisting of an imperfective and a perfective verb with, presumably, 
identical lexical meaning, e.g. - besides zapisat' (pfv)/zapisyvat' (ipfv) 'write down' dat' (pfv)/davat' (ipfv) 'give' and pisat' (ipfv)/napisat' (pfv) 'write'; on the other, there are perfective tantum verbs, e.g. pospat' 'sleep for a short while, take a nap', as well as imperfective tantum verbs, e.g. stojat' 'stand'.

Aspect is usually taken to be a category of OR as well, and, indeed, the verbal derivation systems of OR and MR are formally identical. A slightly simplified version of this derivational system is shown in (48).

(48) The basic system of verbal derivation, common to OR and MR

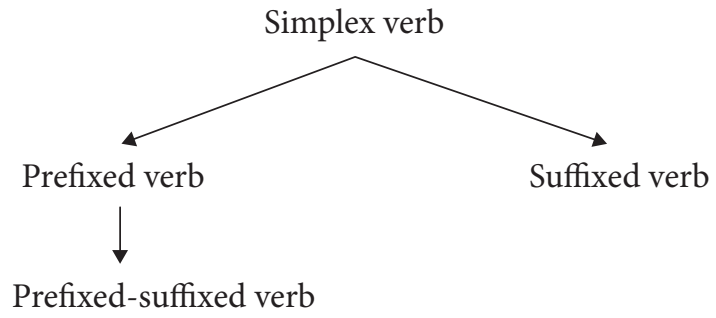

In MR this system of verbal derivation serves the double purpose of deriving new verb lexemes and new aspect pairs. The arrows represent the three derivational paths of the system. They can all be employed to form aspect pairs. First, an aspect pair can be derived by suffixation of a simplex perfective verb, cf. (49).

(49) MR derivation of aspectual pairs I

Simplex verb

$d a-t$ ' (pfv) 'give'

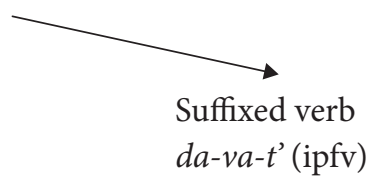

Second, an aspect pair can be derived by prefixation of an imperfective simplex verb, cf. $(50){ }^{63}$

63. This model is not acknowledged by all Russian aspectologists as a means to derive "pure" aspect pairs, cf. Isačenko (1975:360-63) who claims that prefixation always marks a difference of lexical meaning. Here we shall stick to the traditional point of view acknowledging all three models of aspect pair derivation. 
(50) MR derivation of aspectual pairs II

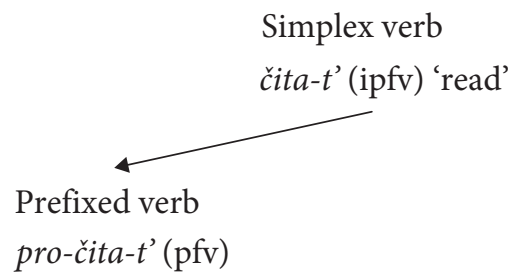

Third, an aspect pair can be derived by suffixation of a prefixed perfective verb, cf. (51). (Aspectual derivation in bold; the derivation govorit' > ugovorit' is lexical and a precondition for the aspectual derivation).

(51) MR derivation of aspectual pairs III

Simplex verb

govori-t 'talk'

Prefixed verb
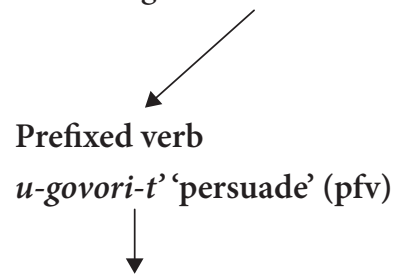

Prefixed-suffixed verb

$u$-govar-iva-t' 'persuade' (ipfv)

This is the dominant productive model. Note the difference in lexical meaning between the simplex verb govori- $t$ ' 'talk' and the aspect pair $u$-govori-t'/u-govar-iva- $t$ ' 'persuade'.

The presentation of MR aspect will be based on Durst-Andersen (1992), who proposes an interpretation in terms of situation types defined in relation to the figureground distinction of Gestalt psychology. According to Durst-Andersen, one can distinguish between three lexical classes of verbs in MR: state verbs (e.g. stojat' 'stand', sidet' 'sit'), activity verbs (e.g. rabotat' 'work', guljat' 'walk'), and action verbs (e.g. dat' 'give', ugovorit' 'persuade'). The argument runs, somewhat oversimplified, as follows: the distinction between activity, state and action has universal status, since it is based on a description of how human beings conceptualise real situations in different types of images - or pictures. States correspond to stable pictures (with the figure being stable in relation to the ground), and activities correspond to unstable pictures (with the figure moving in relation to the ground). Unlike a state and an activity, which are the two possible simple situations, an action is complex in that it corresponds to a combination of an activity and a state, cf. (52). 
(52)

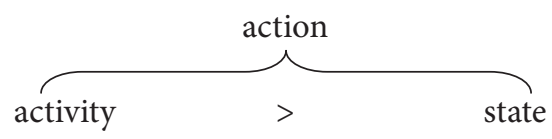

In the action description the state is perceived as the natural effect of the activity, a feature referred to as telicity (goal-directedness).

Durst-Andersen further argues that verbs denoting actions (rather than activities and states) are the verbs that must be represented by an aspect pair in MR. When referring to a single action, the perfective partner is used to assert the state description, thus presupposing the activity leading to this state, cf. (53) (the assertion highlighted in bold).

(53) MR action verbs: the perfective aspect

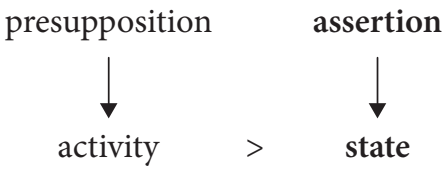

For instance, the perfective aspect partner ugovorit' 'persuade' asserts the state, understood as the inherent goal of the (persuasion) activity. In other words it is asserted that the individual towards whom the activity is directed actually reaches the state of being persuaded.

The imperfective aspect partner is used to assert that the activity obtains, thus treating the state as a standard implicature, cf. (54).

(54) MR action verbs: the imperfective aspect

assertion standard implicature

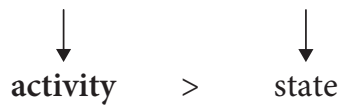

Note, however, that though the state is prominent as a standard implicature, the imperfective verb does not provide any indication of whether the state was reached or not.

In (53) and (54) the assertion, i.e. the semantic focus, of each of the two MR aspects in an aspect pair is marked in bold. This is what the aspectual forms directly assert - rather than convey indirectly by presupposition or implicature. This information is of crucial importance to the way the OR material will be approached below. The semantic charts for the perfective and imperfective aspect partners in (53) and (54) will form the background against which it will be tested whether Russian verbs at earlier stages of the development of the language fulfilled the same aspectual functions as MR verbs. 
As already mentioned, the semantic specification of the two aspects takes its point of departure in the semantically complex action verbs, represented in Russian as aspect pairs. Without going into details we can state that - with a few non-essential additions - it is also representative of the aspectual function of non-paired verbs (cf. Durst-Andersen 1992:175). The perfective aspect is marked since it asserts the state unlike the imperfective aspect that leaves the question whether the state is reached or not unanswered (Durst-Andersen 1992: 100).

The particularly characteristic features of MR as a language with aspect are the following.

First, since as a grammatical category with the verb as its domain aspect is obligatorily expressed, every verb must be either perfective or imperfective.

Second, while state verbs and activity verbs are unpaired and imperfective tantum, ${ }^{64}$ action verbs are paired. An action verb is formally a combination of an imperfective and a perfective verb, cf. the above mentioned examples zapisat' (pfv)/ zapisyvat' (ipfv) 'write down', dat' (pfv)/davat' (ipfv) 'give', pisat' (ipfv)/napisat' (pfv) 'write' and ugovorit' (pfv)/ugovarivat' (ipfv) 'persuade. This means that when a new perfective action verb occurs (most frequently in the form of a prefixed verb), an imperfective partner must also be formed.

Third, action verbs are often transitive, a fact connected to their complex structure (Durst-Andersen 1992:68). While in the prototypical case A1 will refer to the performer of the activity (in Durst-Andersen 1992 " $p$-theme"), A2 will refer to the carrier of the state (in Durst-Andersen 1992 " $q$-theme"). For instance, in an active construction with the transitive paired verb ugovorit' (pfv)/ugovarivat' (ipfv) 'persuade', A1 will be the individual performing the activity, and A2 will refer to the one entering - potentially or actually - the state of having been persuaded.

The fact that there is a link between aspect and transitivity in MR has consequences for the interpretation of the historical development. MR aspect presupposes valency, i.e. a system with the lexical verb determining the form and number of constituents and the accusative being the unmarked A2. Since, as we have seen, OR syntax was not of this kind, it can be hypothesised that Russian syntax was reorganised no later than - possibly, simultaneously with - the establishment of the specific kind of aspect characteristic of MR. I shall come back to this important point in the conclusion.

64. State and activity verbs can also derive so-called procedurals (Aktionsarten) by prefixation and/or suffixation, e.g. spat' (ipfv) 'sleep' > po-spat' (pfv) 'sleep a while, govorit' (ipfv) 'talk' > za-govorit' (pfv) 'begin to talk. Though most procedurals are perfective they do not constitute aspect partners of the simplex verbs they are derived from since they modify their meaning (Durst-Andersen 1992:175-76). 
Having outlined the grammar of the verb in OR and MR, I shall now trace the development leading from the old to the new system.

The simplification of the tense system, leaving the perfect the only past tense form, took place in most North Slavic languages (a common name for East and West Slavic). The tenses that were lost in the course of history - the imperfect, the aorist and the pluperfect - were gradually restricted to more and more marked functions (semantically and stylistically) before eventually disappearing.

In the West Slavic language Polish, they all seem to have disappeared fairly early. Even in the earliest texts from the 14th century (presumably copies of older texts), the perfect is already close to the status of a general preterite. The pluperfect is rare and functionally not distinguishable from the perfect; there are altogether only 26 occurrences of the aorist and the imperfect, some of them questionable (Klemensiewicz et al. 1955:367-373).

In Russian, on the other hand, the pluperfect, the imperfect and especially the aorist appeared regularly until about the middle of the 18th century, but only in formal registers. Considering the Russian data, one should appreciate that Russian - unlike Polish - was under heavy influence from Old Church Slavonic up to as late as the 18th century. Old Church Slavonic, in fact a variety of Old Bulgarian, came to Russia in connection with the adoption of Christianity in the 10th century as the Slavic language into which the Bible and other religious as well as secular texts had been first translated. Naturally, Old Church Slavonic was established as the norm that in principle should be observed in all varieties of written language. This meant that scribes had to use the original tense forms which were fully preserved in Bulgarian-based Old Church Slavonic.

The Old Church Slavonic influence makes it extremely complicated to investigate the development of the Russian tense/aspect system. However, since about 1950 archaeologists have excavated almost a thousand letters written on birch bark in Novgorod and other ancient Russian cities (Zaliznjak 1995). These are almost all informal messages on everyday matters. For this reason, the authors refrain from observing the Old Church Slavonic norm and obviously stick to their oral language. In the birch bark letters, even in the earliest ones from the 11th century, the perfect is totally dominant, also in contexts where one would expect another tense form according to the Old Church Slavonic norm. ${ }^{65}$ This indicates that the perfect was established as the general preterite earlier than hitherto believed, cf. Remneva (1995: 138).

65. The few aorists and imperfectives in the birch bark letters appear almost exclusively in the few letters with a more official content, e.g. in wills. 
The question is now, when was aspect established in Russian? In NørgårdSørensen (1997a, 1997b), I have argued that this question is best investigated on the basis of contexts where the MR aspect forms have a marked reading. This is the case with certain negated perfective forms. On the basis of the interpretation of MR aspect presented above, we can state that when a MR perfective verb is negated, the negation will only have the asserted state as its scope. The activity, presupposed by the perfective aspect, will not be affected by the negation, cf. (55), which is the negated correspondent of (53).

Perfective verbs: negation scope

$$
\text { negation }
$$

activity $>$ state

If, on the other hand, an imperfective verb is negated, the negation will be directed towards the activity, but since the description of the state is implied by the description of the activity, the negation will extend its scope to the description of the state as well, cf. (56), which is the negated correspondent of (54).

(56) Imperfective verbs: negation scope ${ }^{66}$ negation

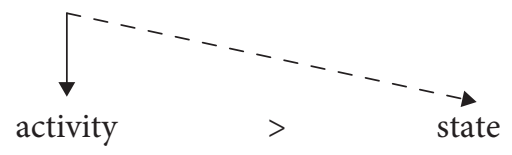

Thus, in order to negate the action as a whole one must use the imperfective verb in MR. In connection with negation the imperfective verb is the neutral, unmarked choice. The limited negation scope in connection with perfective verbs has consequences for the pragmatic interpretation of the utterance. The following standard example (57) provides an illustration of the pragmatic consequences of negating a perfective and an imperfective verb, respectively.

$$
\begin{aligned}
& \text { a. ja ne ubežda-l ego } \\
& \text { I not convince.IPFV-PST.SG.M he.ACC.SG } \\
& \text { 'I did not (try to) convince him' } \\
& \text { (= I did not even plan to or make any effort to convince him) }
\end{aligned}
$$

66. The un-dotted line indicates the scope proper of the negation, the dotted line its logical extension. 
b. ja ne ubedi-l ego
I not convince.PFV-PST.SG.M he.ACC.SG
'I did not convince him/succeed in convincing him'

The translations speak for themselves. In (57a) with an imperfective verb, the negation takes the entire action as its scope. In (57b) with the perfective verb, it is merely negated that the state (of the referent of A2 being convinced) was achieved, while it is still conveyed - by presupposition - that the activity somehow took place. A possible interpretation is that the referent of A1 engaged in an attempt to convince but did not succeed.

Similarly, a perfective imperative must be interpreted as a request not to let the expected state come true (however, presupposing that the activity takes place). Pragmatically, this can only be interpreted as a warning. A warning is issued in a situation when an activity potentially leading to a non-desired state is already somehow taking place.

A negated perfective verb in the present tense also has a marked reading. It carries the presupposition that the activity, being outside the scope of the negation, takes place, but it also asserts that the expected state (the natural result of the activity) does not obtain. Pragmatically, this corresponds to readings like, "does not succeed in ...", "after all does not ..., etc.

In Nørgård-Sørensen (1997a, 1997b) I have provided evidence that in OR (represented by the birch bark letters, in order to avoid the influence of Church Slavonic as far as possible) the prefixed verbs did not convey the marked readings characteristic of the formally corresponding MR aspectual forms, cf. (58)-(59).

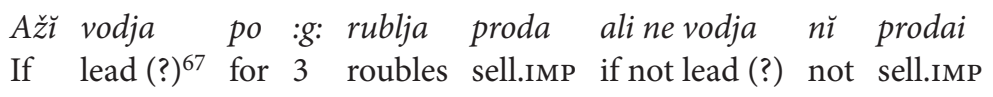

(Birch bark letter 65, 1281-99)

'If ?, then sell for three roubles; if not ?, then don't sell'

$$
\begin{aligned}
& \text { Čemu ne vosol-eši četo ti es-emo [...] } \\
& \text { Why not send-PRs.2sG what you.DAT be-PRs.1sG } \\
& \text { vodala kovati } \\
& \text { given forge-INF } \\
& \text { 'Why don't you send me what I have given you to forge?' }
\end{aligned}
$$

67. The sense of the verb voditi 'lead' is unclear in this context. However, there is no doubt that the utterance consists of two parallel conditional constructions (if-constructions), and that the interpretation of the antecedent clauses of these constructions is irrelevant. 


$\begin{array}{lllll}\text { A ne sestr-a ja va-mo ože tako } & \text { ja } \\ \text { And not sister-NOM } & \text { I.NOM } & \text { you-DAT if so } & \text { if } \\ \text { děla-ete ne isprav-iť } & \text { mi } & \text { ničetože } \\ \text { do-PRs.2PL not make-PRs.2PL } & \text { I.DAT } & \text { nothing }\end{array}$

(Birch bark letter 644, 1110-30)

'And I won't be your sister if you behave like that and don't do anything for me'

In (58) we find two parallel conditional clauses, the first with a non-negated imperative (pro- $d a$ ) in the consequent clause, the second with a negated imperative of the same verb (ň pro-dai) in the consequent clause. The two imperatives are forms of the prefixed verb (pro-da-ti 'sell'). The MR prefixed verb with the same morphological structure (pro-da-t' 'sell') is perfective, so a negated imperative of this verb would only allow for a 'warning' reading (something like 'be careful you do not sell'). In the OR example (58) the context does not allow for such an interpretation. This is simply an order what to do - and what not to do - in case of explicitly specified conditions.

In (59) we find two negated present tense forms of prefixed verbs, but again they cannot be interpreted in line with the marked use of the corresponding MR forms. Rather, they represent unmarked negations of the actions referred to.

Even from the few examples above from the Novgorod birch bark letters, it can be concluded that certain fundamental and very specific characteristics of the MR aspect system were alien to OR. At this point the traditional procedure of a scholarly presentation would be to let the text mirror the empirical investigation by first analysing a representative selection of examples from different periods and then, by induction, draw the conclusion about the structure of OR aspect. However, I have chosen to turn this procedure upside down. I shall first present my view on OR aspect and then demonstrate the explanatory force of this view on selected material. In this way the presentation will not only gain in clarity; it will also be clear from the outset how OR aspect differs from MR and, thus, what kind of reanalysis must be assumed to have taken place.

The three situation types on which Durst-Andersen (1992) bases his analysis of MR aspect, activity, state and action, are features of perception and cognition and, thus, universal rather than language-specific. What is language-specific is the way these features are grammaticalised. Above, it was emphasised that MR aspect presupposes a conceptual split of the action into its constituent parts, the activity and the state. The two aspects are each used to assert a constituent part of the action: the imperfective aspect asserts the activity, cf. (54), the perfective aspect asserts the state, cf. (53).

In my view the crucial difference between OR and MR aspect is that OR did not know a split of the action into its constituent parts. In OR an action could only be referred to in its totality.

This means that no verb form could be used to assert any single one of the two constituent parts of the action, as is the case in MR. In OR a verb could be used for assertion in three ways, cf. (60)-(61). 
(60) OR activity verbs (xodi-ti 'go, walk', tvori-ti 'create, glagola-ti 'talk') assertion

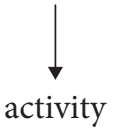

(61) OR state verbs (by-ti 'be, exist', leža-ti 'lie’) assertion

(62) OR action verbs (da-ti 'give', po-sŭla-ti 'send', pri-ja-ti 'receive')

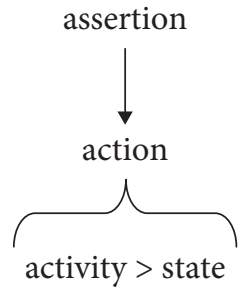

In (62) it is still indicated that an action - from a universal perceptual and conceptual point of view - consists of an activity and a state connected by telicity. However, the crucial point is that this distinction was not grammaticalised in OR: no verb form could be used to assert one - and only one - of the constituents.

What does this mean for the system of verbal derivation? As mentioned above, the basic system of verbal prefixation and suffixation, presented in (48) was the same in OR as in MR. The three types of MR aspect derivation, presented in (49)-(51), were all known to OR as well. There is, however, a remarkable statistical difference. The dominant and very frequently applied model of deriving aspect partners in MR, suffixation of prefixed verbs (e.g. MR u-govori-t' (pfv) > u-govar-iva-t' (ipfv) 'persuade'), was pretty rare in OR. ${ }^{68}$

In my view this is so because the aspectual distinction was not the same. In both OR and MR the perfective aspect was the marked member of the opposition and, thus, the one for which a meaning should be specified, while the imperfective aspect as the unmarked member of the opposition will be supposed to have a vague meaning, defined negatively in relation to the meaning of the marked member. In MR the perfective aspect has the meaning of asserting a new state (and thus a change of state)

68. I shall come back to the statistics below. 
(Durst-Andersen 1992: 100). This has been shown above for action verbs, but it is valid for perfective procedural (Aktionsarten) as well (Durst-Andersen 1992:175-76).

In $\mathrm{OR}$, on the other hand, the perfective aspect was used to denote an action. In other words the aspectual distinction was one of action (pfv)/non-action (ipfv).

The main consequences of this difference of aspectual meaning are the following. For state and activity verbs there will be no difference between OR and MR. They will be imperfective tantum and behave in a similar way in both languages. Even action verbs will often behave in the same way in the two languages. An action verb that is used to refer to a single action - which is the typical case of narratives presenting a series of events - will also appear in the same form in OR and MR. They will have slightly different meanings, but this will not have any consequences for the use in actual discourse. An OR perfective verb, referring to a single action, will have the meaning illustrated in (62), repeated below.

(62) OR perfective verb referring to a single action assertion

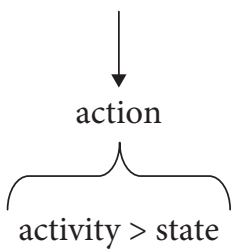

A MR perfective verb referring to a single action will have the meaning illustrated in (53), repeated below.

MR perfective verb referring to a single action presupposition assertion

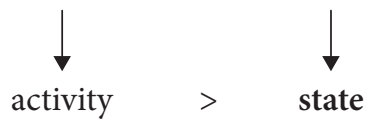

However, for the textual and pragmatic functions of the verbs, this difference of meaning does not really make any difference. In both cases the entire single action is referred to. This is why the use of aspectual forms in OR and MR looks so conspicuously similar, especially in the widespread genre of past tense narratives where actions are enumerated as events, one following the other.

The difference of meaning between OR and MR aspect appears clearly from a comparison of (62) and (53): in MR a presupposition is involved. To reveal this difference one has to turn to statistically more peripheral uses, in particular negated verb forms. As we have just seen, non-negated perfective verbs referring to single actions are used in the same way in OR and MR. This is not the case for negated perfective 
verbs. In connection with a MR perfective verb, a negation will only have the state as its scope, as illustrated in (55) repeated below.

$$
\begin{gathered}
\text { MR perfective verb: negation scope } \\
\text { negation } \\
\text { activity }>\quad \text { state }
\end{gathered}
$$

This is the background for the marked readings of negated perfective verbs in MR described above.

In connection with an OR perfective verb, a negation will have the entire action as its scope, cf. (63), which is the negated counterpart of (62).

(63) OR perfective verb: negation scope negation

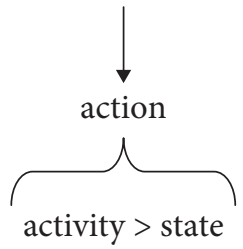

This is the background for the markedly different behaviour of negated perfective verbs in OR and MR. Let us, for the sake of illustration, have another look at the examples from the birch bark letters (58)-(59). On the background of the proposed interpretation of negated perfective verbs in OR in (63), the phrase ň prodai 'do not sell' in (58) should be interpreted as a neutral request not to let an action come true. As mentioned, this reading is strongly supported by the context. In (59), the two negated perfective present tense forms ne vosoleši 'you do not send' and ne ispraviť 'you do not do' are neutral statements about certain actions taking place (or rather, not taking place). None of these examples have the marked readings characteristic of the corresponding forms in MR.

The two aspectual systems can be described as paradigmatic oppositions, cf. (64) for OR and (65) for MR.

(64) OR: verbal aspect

Domain: $\mathrm{V}$

Frame: situation type

\begin{tabular}{ll}
\hline Expression & Content \\
\hline perfective verb & action \\
imperfective verb & non-action \\
\hline
\end{tabular}


(65) MR: verbal aspect

Domain: $\mathrm{V}$

Frame: change of state

\begin{tabular}{ll}
\hline Expression & Content \\
\hline perfective verb & change-of-state \\
imperfective verb & no change-of-state \\
\hline
\end{tabular}

Now, what we should try to pinpoint is the transition from (64) to (65). Theoretically, this may have involved several steps or a single reanalysis of paradigm (64) as paradigm (65). Further, the transition may have had different directions for different groups of speakers and for different regional and stylistic varieties of Russian. For our purposes, it is essential that the transition actually took place. In the following I shall assume that we have to do with a reanalysis which - as a precondition for the change in content indicated in (64)-(65) - also involved a grammaticalisation of the conceptual split of the action into its constituent parts: the activity and the state.

In order to trace the development and try to pinpoint the time of the reanalysis of paradigm (64) as paradigm (65), I shall analyse selected representative examples from two periods of Russian chronicle writing: (i) early chronicles from 11th-14th century, represented by the Primary Chronicle and the 1st Novgorod Chronicle, and (ii) the Piskarevskij Chronicle from the mid-17th century (1573-1645). I have chosen to operate with this relatively long distance in time between the two synchronic cuts of the presentation in order to avoid an unnecessarily complicated discussion of a number of details and problematic data. As was emphasised above, the examples should present negated perfective verb forms which in MR would have a marked reading.

(66)-(69) are examples from the early chronicles, representing the early synchronic cut.

(66) prid-i $k$ namŭ jako ne stvor-imŭ $t i \quad z l$-a (LL) come-IMP to us for not do.PFV-PRs.1PL you.DAT evil-GEN.SG 'Come to us, for we shall do you no harm'

(67) ǎšce $k$ vamŭ naš-i bež-at sěk-ite ix ili If to you our-PL fly-PRS.3PL cut-IMP they. ACC or věša-ite ili vaš- $i \quad k$ namŭ my že hang-IMP and-if your-PL to us we Particle

tako imŭ stvor-imŭ same they.DAT do-PRS.1PL

'If some of ours fly to you, cut them down or hang them! And if some of yours fly to us, we will do the same to them, 
da žl ne pol'st-jat promežju nami

for PART not be cunning.PFV-PRS.3PL among us

a s-ix ne vydad-imŭ (NIL)

but this-GEN.PL not hand over.PFV-PRS.1PL

in order that they will not be cunning among us. But these we are not going to hand over!'

(68) děti ne dospěite pogan-ymŭ poxvaly a svjat-ymŭ children not provide infidel-DAT.PL honour and holy-DAT.PL

cerkv-amŭ $i$ měst-u s-emu pustoty

church-DAT.PL and place-DAT.SG this-DAT.SG desolation

ne sŭstup-ite-sja bit-sja (NIL)

not resort to.PFV-IMP-REFL beat-REFL

'Children, do not give the infidels honour and the holy churches fight and this place desolation! Do not resort to fighting!'

(69) $i$ posla-ša novgorodc- $i$ posl-y

and send-AOR.3PL Novgorodian-NOM.PL envoy-ACC.PL

zov-ušč-e $\quad v$ Novŭgorod ... Luku Valfroméeva

call-PTCP.ACT-NOM.PL to Novgorod Luka Valfromeev

'And the Novgorodians sent envoys inviting Luka Valfromeev to Novgorod'

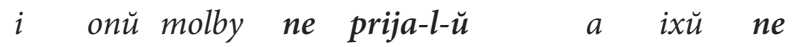

and he request not take.PFV-PST-M and them not

posluša-l a miru ne da-l-ŭ (NIL)

listen.PFV-PST and peace not give.PFV-PST-M

'and he did not accept the request, did not listen to them and did not offer them peace'

The verbs stvorimŭ in (66) and polstjat and vydadimŭ in (67) are negated perfective present tense forms. In the given contexts, they are readily interpreted as general negations of future events with no indication whatsoever that the action had been intended or planned (as would be the case with the corresponding MR forms). The negated perfective imperatives in (68) should be interpreted as a general instruction not to let the action pass - and not as a warning against something that is about to happen (the sense of the MR correspondent). Finally, the three negated perfective perfect forms in (69) convey that actions that should be expected to take place did not do so. This would require perfective past tense forms in both OR and MR.

Examples (66)-(69) all contain the aspect forms that should be predicted from the OR aspect system as specified above (paradigm (64)). They exhibit the same aspect use as the early birch bark letters, cf. (58)-(59). 
The following examples (70)-(73) from the Piskarevskij Chronicle represent the later synchronic cut.

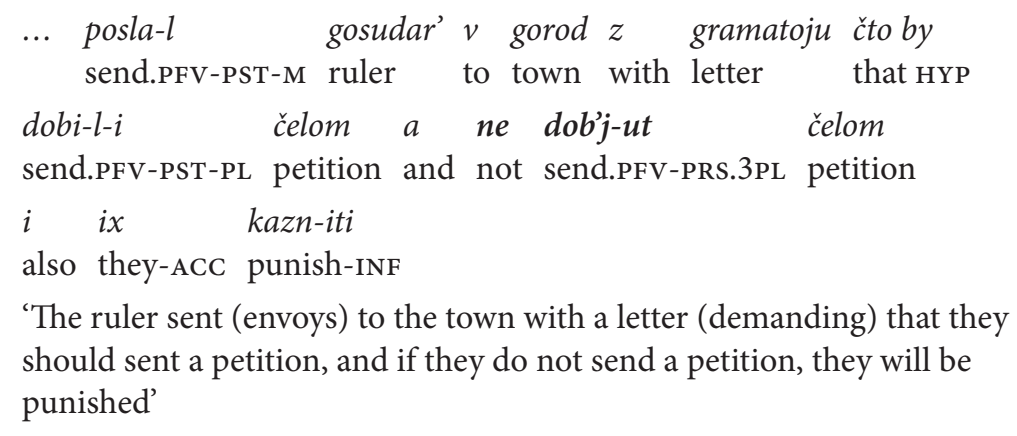

(71) $i$ velik-ogo knjazj-a ljudi s litovskimi ljud'mi and grand-GeN duke-GeN people with Lithuanian people bilisja, $i$ posadu žeč ne da-l-i fought and settlement-ACC burn not give.PFV-PST-PL

'And the grand duke's men fought with the Lithuanians and did not let them burn the settlement down'

(72) tobja darova-l bog rod-u naš-emu krepk-ago you.ACC give.IPFV-PST God family-DAT our-DAT ... strong-ACC straž-a ne ostav-i nas vo vremja skorb-i naš-ija guard-ACC not leave.PFV-IMP we.ACC at time sorrow-GEN our-GEN 'God gave you to our family as a strong guard, do not leave us at this time of our sorrow!'

(73) a k-omu otkaž-et tot vdrugorjad' ne and who-DAT reject-PRS.3sg that repeatedly not
bej čelom
send.IPFV-IMP petition
'and the one that he rejects should not send another petition (lit.:do not send)'

The negated perfective present tense form in (70) refers to a failure to perform an action that is expected to take place. It is the form that would be predicted by both the OR and MR aspect systems. Likewise, the negated perfective perfect in (71) ne dali 'did not give', conveying that a past action that was about to happen did not take place, conforms to both systems. It is, however, remarkable that in both cases we have negated perfective forms conveying the marked readings of the corresponding MR forms. In (72) we find a perfective imperative ne ostavi 'do not leave', and in (73) an imperfective imperative ne bej čelom 'do not send petition. The former would hardly be acceptable in MR since the context does not support the marked 'warning' reading, mentioned 
above. It resembles the use for negated perfective imperatives we have seen in earlier texts. The imperfective imperative in (73) conforms to both OR and MR.

In (70)-(73), representing the later synchronic cut, we find a use of aspect forms close to that of MR. The only deviation is the negated perfective imperatives in (72). As mentioned, this is probably the aspect form with the most marked reading in MR; it can only be used to issue a warning. This marked reading may have been subject to a late actualisation after the establishment of the MR aspect system (reanalysis of paradigm (64) as (65)) which consequently must have taken place some time between the two synchronic cuts, i.e. in the period from the 15 th through the 17 th century.

The question is now if we can get any closer in specifying the chronology of the reanalysis of paradigm (64) as paradigm (65) and, thus, the establishment of the specific kind of aspect system characteristic of MR. The analysis of negated perfective verbs narrowed down the time span to about 300 years, and it is not necessarily possible to get any closer. One must take into consideration that a reanalysis of a fundamental grammatical feature will need time to spread in the language community, and that it will be followed by an actualisation process where the logical consequences of the new system for aspect usage will be gradually implemented. Adding to all this the regional and stylistic differentiation and the fact that practically all Russian written texts were influenced by the Church Slavonic standard to a higher or lower degree at least until the 18th c., it is not surprising that many text sources are difficult to interpret. The two synchronic cuts of the present investigation have been chosen to test negated perfective forms, a test that does not seem to give any clear results for the chronicle texts of my corpus in between. ${ }^{69}$

In an attempt, after all, to get closer to the time of the reanalysis we can recall a characteristic feature of the MR aspect system: that any action verb (telecity verb) must be paired, cf. u-govorit' (pfv)/u-govar-iva-t' (ipfv) 'persuade. This means that when the MR aspect system was established, the derivation of imperfective partners from perfective action verbs became obligatory. As was illustrated above in (51), imperfective aspect partners are mainly derived by means of suffixation in MR. An investigation of the historical development of suffixation patterns, in particular the use of the very productive suffix -iva-/-ivaj-, could be a key to the history of aspect. In Table 2 I have sketched the development of verbal suffixation with special emphasis on -iva-/-ivaj- (based on Silina 1987).

69. E.g. the Moscow Chronicle Collection (Moskovskij letopisnyj svod) and the 2nd Novgorod Chronicle. 
Table 2. The development of verbal suffixation in Russian

Common Slavic (before 800)

Several suffixes, including -va-/-vaj-, -ova-/-ovaj-, indicating activity, iterativity, etc.

11 th $c$.

New suffix, -iva-/-ivaj-, initially purely iterative, later also indicating activity, etc.

Late 14th $c$.

Remarkable increase of the number of -iva-/-ivaj-derivatives, stylistically neutral.

18 th $c$.

Automatic derivation of imperfective verbs by means of -iva-/-ivaj.

The statistics supporting the conclusion about the remarkable increase of the number of -iva-/-ivaj-derivatives in the 14th century can be extracted from Silina (1987:198). Silina's statistics are based on the then unpublished card catalogue of the Old Russian Dictionary 11-14 c. (Avanesov 1988-), a catalogue containing a full collection of excerpts from all major texts from the given period), cf. Table 3.

Table 3. Use of the suffix -iva-/-ivaj-

\begin{tabular}{lccc}
\hline & Verb lexemes & First-time registered & Number of tokens \\
\hline 12 th c. & 11 & 11 & 14 \\
13 th c. & 23 & 22 & 32 \\
13 th-14th c. & 16 & 13 & 18 \\
14 th c. & 112 & 83 & 189 \\
$1400-1425$ & 63 & 41 & 106 \\
\hline
\end{tabular}

Unfortunately Silina does not provide information on the quantity of texts from the individual periods, but it is at least clear that the texts from the five periods in the material do not overlap. In other words, the subcorpus labelled "13th-14th c." contains text from the late 13th century and early 14 th century not included in the subcorpora labelled "13th c." and "14th c." Presumably resting on subcorpora of different sizes for the different periods, the figures in Table 3 are not directly comparable. On the other hand, Silina comments on the use of -iva-/-ivaj-in different registers. Till about 1300 -iva-/ -ivaj- was restricted to certain genres of secular literature; later it became common in all written texts. Not surprisingly, the suffix obtained an unmarked status at the time when it started to be used much more frequently.

It can be assumed that the sudden increase in number of -iva-/-ivaj- derivatives in the 14th century is caused by the fact that a reanalysis shaping the aspect system to its MR appearance, i.e. the reanalysis of paradigm (64) as paradigm (65), had been widely coined in the language community. As would be predicted, this was followed 
by massive derivation of aspect partners for action verbs lacking them, in particular by suffixing -iva-/-ivaj- to the stem of perfective action verbs to form imperfective aspect partners.

The evidence provided by the examination of the suffix -iva-/-ivaj-indicates that the reanalysis of paradigm (64) as paradigm (65) took place in the earlier part of the period that was tentatively specified above on the basis of the investigation of negated perfective verbs, i.e. around 1400 . This is conspicuously close to the time, specified in Section 2.3.2, of the reanalysis establishing animacy as a gender. In the concluding Section 4 I shall now consider the implications of this observation.

\section{Parallel grammaticalisation as a type of connecting grammaticalisation}

I shall now attempt to provide an overall interpretation of all the data discussed in this chapter in the light of the theory of connecting grammaticalisation.

As suggested in the conclusion of the previous section, the developments of aspect and animacy were roughly chronologically parallel. On this background it is relevant to enquire whether this parallelism has a semantic background. In other words, would it be possible to identify a common semantic distinction underlying both aspect and animacy?

As appears from the presentation above, the MR aspect system is based on a distinction between action on the one hand and activity-state on the other. It is peculiar to the MR aspect category that the action is perceived as consisting of its two logically constituent parts, the activity and the state, and that, in reference to single events, the two aspect forms are used to assert not the action as a whole but one or the other of its constituent parts, cf. (53)-(54). As we have seen, the activity/state distinction is reflected grammatically at two levels:

a. in lexicalisation: activity verbs vs state verbs.

b. in the aspect meaning: in reference to a single action the imperfective verb asserts the activity, while the perfective verb asserts the state.

We should now think of what a nominal correspondent of an activity or a state would be like. The activity corresponds, on the nominal side, to an individual qualified to carry out an activity. I shall refer to an individual of this kind as a potential actor. A state basically corresponds to an item that is not capable of carrying out any activity. These items make up the complement of the potential actors and can be referred to as not potential actors.

What has been grammaticalised in Russian as the category of animacy is exactly the distinction of potential actor/not potential-actor. There is thus a semantic parallel 
between aspect and animacy, and it is unlikely to be accidental. Rather the obvious connection between what is the most fundamental verbal and the most fundamental nominal category of MR should be seen as the result of a generalised semantic distinction activity/potential actor vs. state/not potential-actor penetrating both the lexicon and the dominant grammatical categories of the two major parts of speech, verbs and nouns.

It appears that the two changes investigated, those of animacy and aspect, are interconnected and can be considered not as two separate changes, but as one complex change scenario. A change scenario of this kind is what I have referred to as parallel grammaticalisation (Nørgård-Sørensen 2006).

If we compare the history of the changes investigated we find further evidence in favour of this idea: the development of aspect and the development of animacy exhibit certain similarities. These will be described in the following historical outline which will also summarise the results of the above investigations.

Common Slavic (before 800): There are several productive verbal prefixes and suffixes. New action verbs may be derived by prefixation; non-action verbs, that is verbs denoting state, activity, iterativity, etc., are either simple or derived by suffixation (Nørgård-Sørensen 1997a). It is important to bear in mind that the universal cognitive split of the action into its constituent parts, activity and state (Durst-Andersen 1992:59-63), was still not grammaticalised. The grammar treated the action as an indivisible whole. The aspectual opposition between perfective and imperfective verbs was, presumably already then, one of action vs. non-action.

As a result of regular sound changes the nominative and the accusative of mascu-

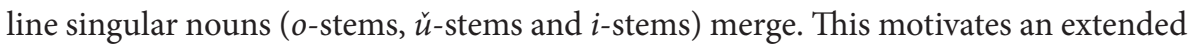
use of the genitive in the A2 slot and, for the domain of individual-denoting nouns, eventually a regrammation whereby the choice of A2 case, accusative or genitive, became an index of the animacy value of the noun, cf. paradigm (35).

Russian (11th c.): A new suffix:-iva-/-ivaj-appears as the result of a reinterpretation of the border between root and suffix in suffixed verbs derived from verbs with an - $i$ - as thematic vowel, for instance, poč $i$ - $t i$ 'rest' > poč $i$-va-ti, being resegmented into poč-iva-ti. In the beginning the -iva-/-ivaj-verbs seem to have been used exclusively as expressing iterativity, but later they obtained the broader function as a marker of non-action, at that time the meaning of the imperfective aspect. Being very productive, -iva-/-ivaj-began ousting other suffixes in this function.

In the same period and later, until about 1400, the genitive form spread as the A2 case of animate nouns. This was an adjustment of usage rules and apparently still not linked to the simultaneous development of the verbs.

Russian (14th c.): The formerly distinct plural declensions merged into one, and as a result the possibility of using the genitive in the A2 slot with animate nouns spread to all plural nouns. This was in itself also an adjustment of usage rules and did not involve any reanalysis, neither of case, nor of gender. 
We are here at a decisive turning point. The development described so far motivated the following two reanalyses which, from the point of view of parallel grammaticalisation, constituted one integral reanalysis.

First, aspect, which used to be a distinction of action vs. non-action, was reanalysed as a marker of change-of-state vs. no change-of-state, cf. the reanalysis of paradigm (64) as paradigm (65). This involved a conceptual reinterpretation of the action from an indivisible whole to a complex concept with two constituents, the activity and the state, linked by telicity. In other words, it markedly added to the grammatical prominence of the activity/state distinction.

Second, the genitive form of animate nouns, which had been used along with the historical accusative in the A2 slot, was reanalysed as the accusative proper of nouns in the 1st declension singular (formerly, $o$-stems) and in all plurals. This involved a spread of the animate/inanimate opposition to all nouns, i.e. the establishment of animacy as a gender distinction.

Both of these reanalyses can have started to spread in the language community in the late 14th century. This is supported by the evidence presented above. In the 15th century, the historical accusative of animate nouns disappeared from informal registers where the new accusative (identical to the genitive) became the only option, and already by the end of the 14th century we see a rapid increase in the number and occurrences of -iva-/-ivaj- derivatives in all registers.

If there is a difference in time - so that the two changes were consecutive rather than simultaneous - the data indicate that aspect was first reanalysed. It makes sense that a reanalysed aspect system would serve as part of the motivation for the coinage of animacy as a gender - in addition to the motivation provided by the merging of the plural declensions. However, the chronological information available at this point is not sufficient to confirm this hypothesis.

The two changes were a reshaping of the grammatical system and not just of the usage rules. The fact that the changes were first actualised in unmarked contexts (informal registers) confirms that we are dealing with internally motivated reanalyses (Andersen 2001b:33).

In view of the fact that the two reanalyses are motivated by a common semantic distinction (activity/potential actor vs. state/not potential-actor), it should not be considered accidental that they either coincide in time or that the one provides the motivation for the other. In both cases they can be seen as one integral reanalysis of major parts of the grammar, that is, as a case of parallel grammaticalisation. The reason why it took place at this particular time in history is that this was the point when the previous development of both verbal and nominal grammar had provided the motivating conditions: the reanalyses could be carried through without any drastic adjustment of usage. Only the more marked uses of verbal forms, e.g. the negated perfective forms considered above, were instantly modified. Further, the consequences of the reanalyses only became clear in the following actualisation process. 
This complex change scenario has even broader extensions, including also the shift of syntactic type from construction-based syntax in OR to a valency system in MR. I did not examine the syntactic data with a view to pinpoint the time of this change, but the chronology of the two other changes, in particular the reanalysis of aspect, gives a clue. With the conceptual split of the action in its logical constituents, activity and state, MR aspect implies that both the agent of the activity ( $p$-theme in Durst-Andersen 1992) and the carrier of the state ( $q$-theme) will be prominent. In an active sentence the $p$-theme will be realised as A1 (subject) while the $q$-theme will be realised as A2 (direct object) to form what is usually referred to as a transitive sentence. As a matter of fact, MR action verbs, i.e. the verbs that are realised as aspect pairs, are with very few exceptions transitive in this traditional sense. It appears that MR aspect and transitive syntax - which involves valency - are interdependent, and it should be assumed that the shift from OR construction-based syntax to MR valencybased syntax was also part of the complex change scenario together with the reanalysis of aspect and the establishment of animacy as a gender. The syntactic data considered support, though do not finally confirm this hypothesis.

In Chapter 4 the concept of connecting grammaticalisation was introduced with the purpose to capture the fact that two or more simple paradigms can be related in non-trivial ways, and that such relations are the result of historical formations. Chapters 6 and 7 contain studies exemplifying complex paradigms as a type of connecting grammaticalisation. In the present chapter the second type of connecting grammaticalisation, referred to as parallel grammaticalisation or parallel paradigms, has been investigated. I have shown that two clearly related distinctions of content, expressed by verbal aspect and nominal animacy, are not only complementary in the system of MR; they also exhibit clear parallels of historical development. Further, it appears that the shift from OR construction-based syntax to MR valency-based syntax was part of this complex development, offering yet another historical parallel to those of aspect and animacy.

The concluding theoretical point to be emphasised is that grammatical changes, be it grammations, regrammations or degrammations, do not proceed in closed environments separated from the rest of the structure. I have shown that fundamental changes in the noun, the verb and the syntax of Russian were closely interrelated, both logically and chronologically, in a pattern of parallel grammaticalisation and take this as an indication that language changes are generally connected to a much higher degree than has traditionally been acknowledged. 


\title{
Word order change as grammaticalisation
}

\author{
Paradigm structure and change in Scandinavian
}

\section{Lars Heltoft}

\section{Introduction}

Word order systems arise through grammation processes, and they change through regrammation processes (Andersen 2006a). Word order systems arise through the formation of paradigms, and they change through restructuring of paradigms. They disappear through the dissolution of their paradigms and through loss of productivity.

Since word order systems are complex sign systems, the relevant concept of reanalysis will be a content oriented one. Our view of reanalysis is found in Chapter 1-4 (see also Andersen 2001ac, 2006a). Changes at the expression side of word order systems will almost always involve semantic change as well, and two successive stages that look alike from the expression side may very well be semantically different. The change of Scandinavian verb second from Old to Modern (Mainland) Scandinavian will be studied as an example of such a change of content without any change of the expression system, and these changes would not be accessible under an approach based on reanalyses of syntactic deep or underlying structure, such as those proposed by Harris and Campbell (1995:51-52, 61-65). Nor will the discussions of parametrical setting (Lightfoot 2003) throw much light on these Scandinavian central changes, simply because the change from old to modern verb second is a semantic change of stable word order, not a change of syntactic hierarchy.

It is striking that a relatively recent book on semantic change (Traugott \& Dasher 2005) does not contain one single example of word order change, let alone of the content aspect of such changes. This is consistent with a perspective according to which semantics is really lexical semantics, and due to Traugott and Dasher's lexicalist understanding of constructions, these are included to some extent as well. Syntax - to the extent that they might recognise any purely compositional parts - is not saturated with semantics, it seems, nor is word order.

What is particularly interesting in the development of Scandinavian word order is the fact that some of the reanalyses involved are not reanalyses of syntactic constituents and hierarchy, but only of the codings of otherwise identical linear structure. 
And again, such content changes must be seen as the product of paradigm formation, resulting in new functional distinctions and new divisions of labour between the parts of the system.

I shall use the term topology (adj. topological) in two senses: namely as an overall term for the word order rules of a given language, thus "the topology of Old French"; and as a term for the systematic study of word order, for instance "Danish topological tradition".

\subsection{The principles of topological analysis}

Word order systems must be studied not as expression systems in isolation, but as paradigmatically organised sign systems. Word order patterns have content, and their content side is involved in the changes they undergo. As a matter of principle, we must assume that word order changes are reorganisations of topological paradigms. Thus, to study such changes we must synchronically identify the relevant input and output systems, i.e. identify older and younger paradigmatically organised word order systems. Therefore, studies of word order change in the sense of paradigmatic changes will involve a comparison between at least two synchronic systems, each representing a certain stage of development. In the present context, the development studied is the paradigmatic change of the word order patterns from Old Scandinavian verb second to Modern Mainland Scandinavian verb second. We shall need to study an intermediate stage, too, namely late Middle Danish where the forerunner of the modern socalled subordinate clause word order was formed.

In Chapter 2, Modern Danish word order served as an instance of a complex paradigmatic relationship between morphological mood and word order patterns. The imperative mood triggers its own word order pattern, a V1-pattern. The non-imperative mood triggers the modern verb second-pattern, including the choice between an empty and a filled-in initial position. Morphology and word order form complex paradigms. Similarly, although we must be able to precisely identify the topological part of the change, the historical development of verb second in Scandinavian cannot be approached as a topological phenomenon in isolation. Morphology and word order interact. Old Scandinavian mood included a productive distinction between an indicative mood and a subjunctive mood, and synchronically its verb second system must be understood as an instance of connecting grammaticalisation. The indicative mood defines one specific set of word order options, but subjunctive clauses are neutral in the sense that the semantic word order contrasts found in indicative clauses do not apply in subjunctive clauses.

The indicative defines a system much like the one found in the Old French verb second pattern. I shall compare these two systems for clarification; their later developments are radically different, and the Old French word order patterns are relevant mainly for synchronic comparison. 
As outlined in Chapter 2, word order must be studied on the preconditions that linear order need not and should not be bound up from the outset with syntactic hierarchies and relations, neither in terms of substantial assumptions, nor as a consequence of any formal apparatus. Changes of syntactic hierarchy are part of constructional syntax and do not belong here a priori, although there will of course be many empirical cases where the two levels intertwine. This view is a revised and updated position on the basis of the heritage from Danish topological tradition (Diderichsen 1941, 1966 [1943]), ${ }^{70}$ in which topology (word order analysis) presupposes syntax, but is carried out in principle on independent premises. Functional codings can use positions as their expression systems regardless of the syntactic material filling them.

A detailed example illustrating this point concerning coding will follow in Section 2.3, but at present I shall only give an example of the relative independence of topology from syntax. It does not follow from any set of preconditions or inherent assumptions about the syntactic model that a conjunction or a subjunction must be part of the topological system. It is possible to assume in principle that they can be external where topology is concerned. Example (1a) is a subordinate clause from Scanian Old Danish; from a topological point of view, subordinating conjunctions can - depending on the structure of the particular language - count either as position fillers, or they can be bracketed from the topological balance sheet, as in (1ab). In the latter case, main clauses (MCs) and subordinate clauses (SCs) have the same topology.

(1) a. vm thæet wil dylia arfu-ihan-s. at han-um døth-um.

if that will deny heir-NOM he-GeN at he-DAT dead-DAT

'If there is an heir after him who wants to contest that after his death'

(Scanic Ecclesiastical Law 8. GL 12, 23-24)

b. vm thoet wil dylia arfui hans at hanum døthum (SC) thæt wil dylia arfui hans at hanum døthum (MC)

The same holds for $w h$-constituents in general. The following is an example of embedded interrogatives of degree from Old Norwegian:

(2) Virð-um vér oc pa goðer brøðr hvesso appreciate-PRS.1PL we also then good brethren how mykin sigr os veit-ir craft-r great.ACC victory-ACC we.DAT yield-PRs.3sG power-NOM föst-u-nn-ar eða hvori-a ánauð vér fast-GEN-[DEF-GEN] or what-ACC distress-ACC we

70. For more recent, short international expositions, see Faarlund (1989), Herslund (2006). A theoretical discussion is found in Heltoft (1992). A comparison with Government and Binding Theory is Platzack (1985), with Minimalism Bjerre, Engels, Jørgensen \& Vikner (2008). 
$\begin{array}{lll}\text { toc-um } & \text { af } & \text { atgirn-inn- } i \\ \text { take.PST-1PL } & \text { from } & \text { desire-DAT-[DEF-DAT] }\end{array}$

'Let us appreciate at that time, too, good brethren, what a great victory the power of fast yields us, or what distress we had from the desire' Indrebø 74, 8-10 (some diplomataric peculiarities have been disregarded; the 'a' with u-metaphony is rendered as $\ddot{o}$ )

Syntactically, the $w h$-constituents are direct objects, but the wh-constituents contain a subjunctional element (in Scandinavian: $h v$-), and topologically they are bracketed. In other words, the wh-constituents do not count in the topological balance sheet. Bracketing the subjunction, the subordinate clauses in (3a) follow the same topological pattern as do the constructed main clauses (3b):

(3) a. (hvesso mykin sigr) os væitir craftr föstunnar (SC) (hværia ánauð) vér tocum af atgirninni (SC)

b. os væitir craftr föstunnar mykin sigr vér tocum ánauð af atgirninni

My analysis of these examples is not uncontroversial. Linguists working within the Chomskyan tradition are led by the framework itself to assume positional identitity between $\mathrm{C}^{0}$ and the finite verb. Working on Old Scandinavian material, they would claim that subjunctions and wh-constituents are in complementiser position and thus hold the same position as the finite verb in main clauses, see Holmberg \& Platzack (1995) and Vikner (1995). It is taken to follow that such wh-clauses are not verb second and that the subject (vér) and the indirect object (os 'us') in (3a) and (3b), respectively, are not in the same position. ${ }^{71}$

These are examples where other models, including all generative models, must struggle with both linearity and syntactic hierarchy at the same time as a consequence of their formal and theoretical points of departure. The disadvantage of these approaches is that the function of word order can never be studied per se, a basic need especially for those who focus on a description of the semantic functions and codings of word order systems.

71. Some linguists would take the indirect object in (3a) to be an instance of so-called stylistic fronting, a concept designed to distinguish such frontings from what they take to be topicalisations. Thus, this indirect object would not hold the same position as does the subject vér in (3b), which is in Spec [Comp]. This discussion is not the main issue here, and I shall just stress that from my point of view that stance will lead to the loss of an obvious topological generalisation. 


\subsection{Overview}

In the following study I present a scenario of verb second development in Scandinavian, Danish being the empirically studied representative. There will be three main sections, each treating one particular aspect of the Scandinavian change. I have given them the form of individual essays, hopefully also independently readable. A fourth section offers conclusions and perspectives.

Section 2 provides a survey of the paradigmatic systems forming the input and the output, respectively, of the change from Old Scandinavian verb second to Modern Scandinavian verb second. The question of the semantic difference between older and younger verb second will be raised, and many of the analyses offered will be different from those found in generative analyses of this subject. The modern outcome of these processes is a topological word order system where word order is in itself neutral with respect to the difference between main and subordinate clauses. It can be fruitfully compared to mood systems, and a final step is my claim that the modern system is best understood as a mood system.

Both systems - Old Scandinavian and Modern Mainland Scandinavian - are instances of connecting grammaticalisation, in the sense of synthetic paradigms, see Chapter 4.

In Section 3, the question of the rise of alternative, non verb second order is opened. Mainland Scandinavian develops a second clausal word order, normally termed the word order of subordinate clauses. The core of the new system is taken to be a functional identification of verb second order X V with complex subordinators. The constituents X V and subjunctions are partly identified where topology is concerned, and once more, the concept of connecting grammaticalisation is essential, this time in the shape of parallel grammaticalisation: an instance of the same content oppositions expressed through different expression systems, see again Chapter 4.

The so-called wedge position in Scandinavian, a special case of the verb second pattern, is often taken to be the point of departure for this innovation, but in the present analysis, the wedge is involved in the second part of a chain of reanalyses. Paradoxically, it would seem, these reanalyses lead to an increase in the frequency of OV-order during the 14th and the 15th centuries (cf. Delsing 1999); later, the OV order disappears through a reanalysis that makes the distinction between nuclear (valency bound) constituents and free constituents a topological one.

Section 4 is about the formation of wh-main clauses with SVO structure - from the 15th century onwards. This type of main clauses exemplified by: Hwre heligh han er som kanner thyn falskhet 'How holy he is who knoweth thy falsity', will mainly consist of mainly expressives(emotives). The claim will be that this type undergoes reanalyses similar to those affecting subordinate clauses, and this in turn was probably facilitated by its similarity to $w h$-subordinate clauses. This type, again, serves as the model for the later, 
very characteristic non verb second main clauses with an initial illocutionary particle, for example: gid 'wish' in Gid hun kommer hjem i tide 'I wish she comes home in time'.

Finally, Section 5 offers conclusions and perspectives. The development of verb second order in Mainland Scandinavian is interesting from the point of view that there is no change at the expression side. To grasp its development, one must approach it from the angle of content. Its meaning potential is restricted and reanalysed as a result of the new paradigmatic relations established.

The so-called subordinate clause order in Scandinavian is understood as the outcome of a number of processes in which already existing Scandinavian structure is reanalysed and organised into new paradigmatic relations. Given this analysis, no external influence need to be assumed, and I shall only sporadically mention the possibility of Low German influence.

\section{Verb second in Scandinavian - paradigms and changes in Danish}

\subsection{Verb second in Old Scandinavian}

By 'verb second' I simply understand a topological pattern that has the finite verb in second position. Nothing is presupposed with respect to possible syntactic hierarchies, symmetries or asymmetries, but it is a precondition that word order patterns are the expression systems of paradigms, and that word order differences convey meaning. Obviously, Old Scandinavian verb second did not manifest the same semantic oppositions as do the modern so-called Mainland Scandinavian languages: Danish, Norwegian, and Swedish. A stretch of text in the indicative mood like (4a) contains four main clauses all functioning in context as assertive speech acts, and within this frame there is a contrast between clauses (three in all), where the initial position is filled in, making the finite verb the second token, and one clause, møðer hon holdet, where the initial position is not filled in. The former order has been preserved in the modern languages, but with the relevant meaning the latter does not have. In the old languages this type of 'zero V' (for the terminology, see Section 2.2) word order was widespread; it is often taken to be a characteristic of narrative genres, but examples like (4ab) document its existence in non-narrative text as well: ${ }^{72}$

(4) a. LFasta megrir licamen. en hon feitir öndena.

fast makes.meagre the body, but it fattens the spirit

møðer hon holdet, en hon styrkir hiartat.

wears it the flesh, but it strengthens the heart

'It wears the flesh, but it strengthens the heart' (Indrebø 1931:74, 22-25)

72. Many examples in Icelandic sagas and chronicles, see Faarlund (2004) and Nygaard (1905). In The Old Norwegian Book of Homilies (Indrebø 1931) they abound as well. 
b. en guð sa verc poeirra ok iðran ok toc but God saw their work and effort and turned af poim ræiði sina ok fyrirforosc pæir aigi away from them wrath his and perished they not 'but God saw their work and effort and turned away from them his wrath, and so they did not perish' Indrebø 1931:73, 26-27

It will be clear already from the examples given that the central manifestation of the semantic system is the opposition between 'zero V' and ' $\mathrm{X} V$ ', the latter indicating a clause type where the first position is filled in by some constituent. The term 'verb second' is the standard term in expression based approaches and will be used here as well, a little misleading though this may be (Henning Andersen, p.c.), since 'verb second' ( = 'the finite verb in second position') is but a precondition for the semantic contrast to apply. The semantic function of 'the finite verb in second position' in Old Scandinavian is one of redundancy or indexical meaning, namely to point to the neighbouring contrast between 'zero' and ' $\mathrm{X}$.

My first major issue, then, is that any account of the development of Scandinavian word order must include the indicative zero $\mathrm{V}$ option and its disappereance in the modern languages. The modern languages retain only two main functions of the zero $\mathrm{V}$ order, namely question and conditional, see Section 2.2 below.

\subsection{Modern Danish verb second order and its simple paradigmatic organisation}

The second major issue is the development of a word order contrast to verb second order. We emphasised in Chapter 2 that word order patterns form paradigmatic oppositions in the sense of alternations between members of a limited set of complex signs. Thus, my aim is to present a scenario of the formation of the topological paradigms of Modern Mainland Scandinavian. The language considered is Danish.

The two major patterns of Modern Danish are the verb second pattern: XVS(V) O (5a), and the pattern IP (Illocutionary Particle)/Subjunction SVO (5b). In the latter pattern finite verb and perfect participle form a continuous constituent holding the same V position; in XVS(V)O a periphrastic verbal form will be discontinuous, each verbal form holding its own position.

73. I shall not be concerned with the - plausible - idea that in Modern Scandinavian DP and COMP are both anchoring positions/categories. This analysis cannot be carried out for Old Scandinavian, since there is no identifiable DP analogous to COMP. 
(5)

a. $\begin{array}{lllll}\mathrm{X} & \mathrm{V} & \mathrm{S} & \mathrm{V} & \mathrm{O}\end{array}$

Sin mor havde han besøgt (-) temmelig tit

His mother had he seen (-) rather often

'He had seen his mother rather often'

b. IP $\quad \mathrm{S}$ V

Gid han havde besøgt sin mor!

Particle 'wish' he had seen his mother

'I wish he had seen his mother!'

Their paradigmatic contrast is between XVSO: the assertive pattern, and IP SVO: the subjective-emotive pattern. The assertive main clause is the unmarked option, the subjective-emotive one the marked option, since the latter main clause can never express an assertive speech act.

In Modern Danish subordinate clauses we find the same contrast, this time as Subjunction XVSO vs. Subjunction SVO. This type of pattern is illustrated in examples (6)-(7). Notice the position of particles, sentence adverbials, and negation. These categories (in the order mentioned) precede the finite verb in Subjunction SVO-clauses (6), while in verb second patterns they follow the finite verb (7). The test is applied with the negation (ikke). ('>' = 'must precede')

(6) at folketingsmedlemmer ikke er bundet af andet end that MPs not are restrained by anything but deres samvittighed

their conscience

'that MPs are obliged by nothing but conscience'

(7) at folketingsmedlemmer er ikke bundet af andet end that MPs are not restrained by anything but

deres samvittighed

their conscience

'that MPs are obliged by nothing but conscience'

(6') Subjunction SVO: Negation $>$ Finite V > Non-finite V

$\left(7^{\prime}\right) \quad$ (Subjunction) XVSO: Finite V $>\ldots>$ Negation $>$ Non-finite V

The IP/Subjunction SVO-type is, in other words, a clause type with a contiguous and continuous verb phrase, whereas the VP of the verb second clause is discontinuous in the case of periphrastic verbal forms.

The IP/Subjunction SVO pattern is characterised by two main features:

1. The continuous finite verb phrase and its relative position to particles and sentence adverbials: Dialogic Particle $>$ Sentence Adverbial $>$ Negation $>$ VP

2. The fixed position for the subject: Subject $>$ Dialogic Particle $>$ Sentence Adverbial > VP 
The XVS (V) O-pattern opens up a second contrast, namely between what would in main clauses traditionally be labelled interrogative versus declarative sentences. In examples (8b)

(8)

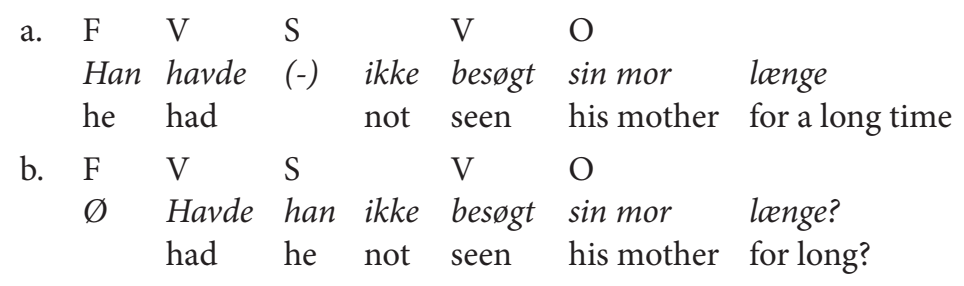

the 'emic' difference between interrogative and declarative potential is expressed by a combined syntagmatic and paradigmatic opposition, cf. Christensen (2007). The initial position X was labelled by Diderichsen (1946) F for 'fundamental field', cf. Dik's P1 (1989, 1997). Skårup (1975) speaks of la zone préverbale. The field F either holds a full constituent or is empty. Any material of propositional character may function as the initial constituent. The subject is the unmarked filler, but situational and cohesive adverbials are frequent. Objects are found as well, as shown in (5a). In clauses with a non-subject in F or an empty $\mathrm{F}$, the subject position $\mathrm{S}$ must hold the subject.

The content frame of the opposition (8a) vs. (8b) is reality value (German: Realitätswert), the opposition within this frame is Realis vs. Conditioned realis. ${ }^{74}$ It is found in main clauses and in subordinate clauses; for the latter, see Section 2.4-5.

\subsection{Verb second as subspecifications of the mood system}

The paradigmatic contrast 'zero V' vs. 'X V' as mentioned in (4) for Old Scandinavian and in (8) for Modern Danish depends on the choice of mood, in the sense that it applies on the precondition that the clause is in the indicative. Main clauses must be in the indicative for a coded contrast to apply between an empty initial position and a non-empty one. Subjunctive main clauses may have empty and non-empty initial positions without any word-order borne contrast. Examples (9)-(10) are for clarification.

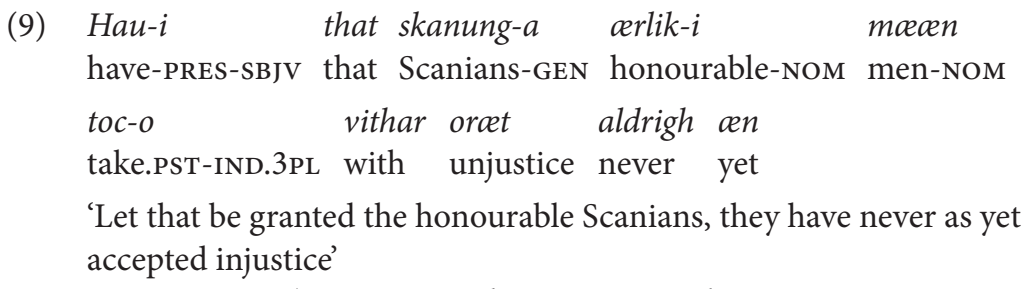

(Scanic around 1300. Marginal note in manuscript AM 37, 4, rendered in Dansk Litteraturhistorie 1)

74. Unfortunately named 'irrealis' by Givón, Palmer, Bybee and others; in the continental European tradition, irrealis means counterfactuality. 
(10) Thre-mma roett-i $j$ gien. tha hau-i bønd-ør This-DAT law-DAT in return, then have-sBJV peasants-NOM ia-t biscop- $i$ thrithiungs tindoe accept-PRF PTCP bishop-DAT a one third tithe af all-um sath sin-um of all-DAT seed-DAT REFL-DAT

'In return for these statutes, peasants should accept to give the bishop one third of all their seed as tithe. (Scanic Ecclesiastical Law 20. GL 18, 4-6)

The subjunctive main clause in (9) has an empty initial position and that in (10) a filled-in one ( $t$ ha 'then'). There is no systematic topological contrast; the functional differences are due to the polysemy of the subjunctive (cohortative vs. deontic meaning).

The indicative clause toco vithar orcet aldrigh on in (9), however, is an instance of what I shall call the cohesive function of the empty initial position, see (4). The empty position marks this clause as a direct continuation ('specification' or 'explanation') of the preceding clause. Since cohesion is also established by the inflection of the verb pointing to the subject referent, more convincing examples will be those with an explicit but inverted subject NP, see Section 2.4. below.

\subsection{Indicative contrasts: Old Danish verb second and Old French verb second}

Little has been said in analyses of Old Scandinavian languages about the obvious semantic differences compared with modern Mainland Scandinavian, see also Heltoft (2001). Andersson (1974) stresses the function of modern verb second as assertive illocutionary frame, and some generative grammarians - at the edge of what Chomskyan modular grammar will normally allow - acknowledge this coding (Holmberg \& Platzack 1995), but the difference between Old and Modern has not been spelled out in semantic terms, to my knowledge.

I shall include in the present study an obvious semantic parallel to Old Scandinavian, namely Old French verb second (see Buridant 2000 and Herslund 2006). For examples of Old French word order I rely on Buridant (2000). The following are examples of Old French as a 'langue à verbe second à létape TVX', since the initial position is not the subject position, but an open position. Objects can be initial topics in Old French, cf. (12).

Nostre empereres fut moult gentiz et fiers (S-V-O)
our emperor was very gracious and proud

$$
\begin{aligned}
& \text { Ceste avision vit li rois Mordrains en son dormant (O-V-S) } \\
& \text { This vision saw king Mordrains while sleeping }
\end{aligned}
$$


This declarative order alternates with so-called inversion, as illustrated in (13)-(15). Old French allows empty initial position, parallel at the level of expression to Mainland Scandinavian, old and modern. Quotations are from Buridant (2000); I construct systematic alternations (b.), parallels to which are easily found. Where questions are concerned, I quote the inverted clause forms and construct the non-inverted forms:
a. Sont vostre panel aborré? are your saddles bolstered?
b. Vostre panel sont aborré
your saddles are bolstered
a. Avez li vos son pere ne son frere tué. have him you his father or his brother killed? 'Have you killed (him) his father or his brother?'
b. Vos li avez son pere ou son frere tué.
'You have killed him his father or his brother'

Buridant $\$ 588$

Buridant $\$ 587$

Conditional readings and concessive readings are possible, too. I shall restrict myself to an example of the former.

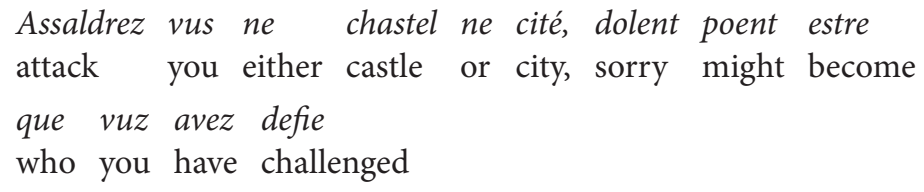

'If YOU attack either castle or city, those that you challenge will be sorry'

Buridant $\$ 524$

The point is that these are all instances of zero filling of the initial preverbal zone F. In the tradition of Danish topology, this can be accounted for in a word order template consisting of zones (fields) and positions. ${ }^{75}$ An Old French word order template is shown in (16); ${ }^{76}$ zero $=\varnothing$; only details relevant to the present analysis are included):

75. Zones (fields) hold complex constituents and may contain more than one position; positions hold only one constituent. F is actually a field in models of Scandinavian, but there is no need to specify these details in the present context.

76. Notice that atonic pronouns do not fill in a position in the Old French template. They glue to their (normally) verbal clitic basis, see Skårup (1975). An examples is $l i$ in (14a). 
(16) Old French word order template

\begin{tabular}{|c|c|c|c|}
\hline $\mathrm{F}$ & $\mathrm{V}$ & $S$ & Postverbal zone \\
\hline$\varnothing$ & Sont & vostre panel & aborré? \\
\hline Vostre panel & sont & & aborré \\
\hline$\varnothing$ & Avez li & vos & son pere ne son frere tué. \\
\hline Vos & li avez & $(-)$ & son pere ou son frere tué. \\
\hline$\varnothing$ & Assaldrez & vus & ne chastel ne cité \\
\hline
\end{tabular}

The Danish medieval word order system showed parallel cases of zero in verb second ${ }^{77}$ indicative patterns: (17) is a yes-no question, (18) a conditional.

(17) Vi-st $d u$ nogen herre $i$ werden som er megtigere end ieg? know-2sG you any lord in world-DEF who is mightier than I? 'Knowest thou of any lord in this world mightier than me?'

Christian Pedersen 1534265

(18) Vil-t $d w$ wide min slect, da er ieg en

Will.Prs-2sG 2sG know my kin, then be-PRs I a

konge søn

king's son

'Wilt thou know my kin, then: I am a king's son' Christian Pedersen 153473

In (19) I give a word order template of (17)-(18), adding a constructed declarative sentence:

(19) Word order template: Danish 1534

F V S Postverbal zone

$\varnothing \quad$ Vilt $\mathrm{dw}$ wide min slect

$\varnothing \quad$ Vist du nogen herre i werden som er megtigere end ieg?

Han ved (-) en herre i verden som er mægtigere end dig

'He knows a lord in this world mightier than you'

77. Examples with a subjunctive mood in conditional clauses are no counterargument to the general view that zero $\mathrm{F}$ depends on the indicative mood. This view will hold for main clauses. Examples like (i) have the subjunctive mood in indirect speech:

(i) 〈Roland swor om gud ath

'R swore by God that' $\rangle$

sade der nogen hiemme som bud finge, da sit-PAST.SUBj there someone athome who order have-PAST.subj then skulle han dø for hans eget swerd dyrendal. would he die from his (R.s) own sword D.

'If somebody should remain at home who had been summoned, then he would die from Roland's own sword Dyrendal'

Christian Pedersen 1534191 
In both languages, however, preverbal zones with zero filling were also found in declarative sentences (with an assertive illocutionary frame). Danish philological tradition and stylistic tradition speak of 'narrative inversion', a feature unknown to the modern language. Example (20) is for Old French, (21) for Middle Danish:

(20) Yra yvers, si revenra estez will pass winter likewise will come back summer 'Winter will pass, likewise summer return'

Buridant $₫ 643$

(21) Ieg tror paa den samme gud, $d w$ troer, I believe in the same God thou believest (in)

oc wil ieg lade mig døbe

and will I let me christen

'I believe in the same God as you do, and (therefore) I will let myself be christened'

Christian Pedersen 1534119

In (22)-(23) I give the word order templates for Old French and Middle Danish:

(22) Old French

$\begin{array}{llll}\text { F } & \text { V } & \text { S } & \text { Postverbal zone } \\ \varnothing & \text { Yra } & \text { yvers, } & \\ \text { si } & \text { revenra } & \text { estez } & \end{array}$

(23) Middle Danish

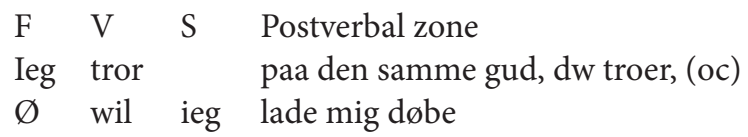

Notice that such examples are normally taken to be stylistically marked, cf. the traditional term 'narrative inversion'. However, the zero $\mathrm{V}$ order is widespread in Old Scandinavian, also outside the popular narrative, see (4ab). There is no space in the present context for a detailed documentation of the development, but it is beyond doubt that the indicative zero declarative is among the fundamental characteristics of Old Scandinavian word order.

Turning now to the semantics of these patterns, we find that the modern opposition of realis vs. conditioned realis will neither match Old French nor Middle Danish. Verb second with a zero VF is found also in declarative sentences, cf. (21), and the old opposition was clearly not a modal one.

Since clauses are complex signs, word order alternations cannot be between single items in paradigmatic relation to each other, but must be between complex signs bearing a systematic semantic opposition. Buridant offers an overall semantic characterisation of what he calls verb-subject order (l'ordre Verbe-Sujet) in Old French, namely that it marks the clause as open towards another clausal sequence, or consequence 
('ouvert sur une (con)séquence attendue'), a characterisation of such clauses as textually marked in a wider sense, as contextually conditioned. I suggest that both Old French and and Old Scandinavian word order (as represented here by Middle Danish) should be analysed as systems of cohesion. Example (21) must be interpreted as the speaker's reason for converting to Christianity, and I shall add (24) for clarity:

(24) Da wende de strax Ianemundsz lig omkring oc waar Then turned they immediately J.s body around and was hans høgre arm sønder slagen oc baade his right arm broken to pieces and both øgen laage vden paa hans kindben. eyes lay on his heek bone

'Then they immediately turned Janemund's body around, and his right arm was broken and both eyes lay on his cheekbone'

Christian Pedersen 1534125

Example (24) marks a specification of the implicit question, i.e. what they (the warriors) saw when they turned the dead body of Janemund around. Only one occurrence of 'zero $V$ ' is necessary to mark a stretch of text as cohesive: The following main clause has the unmarked form ' $\mathrm{X} V$ ', but is nevertheless part of the specification. The common paradigm is Table 1 :

Table 1. Cohesive word order in Old Scandinavian

Domain: positions [F ] V2 S

Frame: clausal cohesion

\begin{tabular}{lllll}
\hline \multicolumn{4}{c}{ Expression } & Content \\
\hline option 1 & $\mathrm{X}$ & $\mathrm{V}$ & $\mathrm{S}$ & unmarked \\
option 2 & $\varnothing$ & $\mathrm{V}$ & $\mathrm{S}$ & calling for another clause \\
\hline
\end{tabular}

Option 2 is the marked but still polysemous option. The content variants of option 2 in Table 1 are cohesive functions well known to traditional grammar, here with an explicit common denominator:

A. Question X calling for an answer Y.

B. Conditional: protasis X calling for its apodosis Y.

C1. Old French: Preceding narrative speech act - pointing to subsequent narrative speech act.

C2. Middle Danish ('connective inversion'): subsequent speech act X points back to preceding speech act $\mathrm{Y}$, normally to mark $\mathrm{X}$ as a specification of $\mathrm{Y}$.

The declarative pattern (option 1) is the unmarked option, pointing to no specific contextual conditions; the inverted order (option 2) is the marked term, instructing the 
receiver to find a second clause or stretch of text in general for the first clause to form a couplet with.

The cohesive verb second system applies to indicative main clauses, whereas the subjunctive allows empty initial positions without any obvious coded contrast. This point was briefly mentioned at the beginning of this Section, cf. (9)-(10). It is therefore, in fact, a case of connecting grammaticalisation, of the mood paradigm and the word order option X V vs. zero V.

In the following Sections 2.5 and 2.6, an exposition is offered of the reanalyses and new paradigm formations characteristic of Danish verb second and Mainland Scandinavian verb second in general. Section 2.5 describes the reinterpretation of the cohesive paradigm. Section 2.6 is an exposition of the complex system of main and subordinate clauses and their word order system characteristic of the modern language.

For ease of exposition I speak of them as the internal and the external reanalysis to mood. The internal change is a change of the semantic coding inside the verb second clause frame of the contrast ' $\mathrm{X} V$ ' vs. 'zero V'; the external change places verb second in paradigmatic contrast to the IP/Subjunction SVO clause type.

The actualisation processes can only be touched on sporadically. Both processes take place in post-Reformation times, between 1550 and 1750 .

\subsection{The internal reanalysis of verb second clauses as mood}

Following Andersen (2001ab, 2006a), I shall view grammaticalisation processes whether grammation, regrammation or degrammation - as complex processes consisting of reanalyses and subsequent actualisation processes. Reanalysis is basically a semantic phenomenon, and actualisation processes - which show themselves at the level of expression or in changes of distribution in usage - are our source when localising them. What is reanalysed here is the frame of the paradigm, from clausal cohesion to reality (Realität), leading to the obsolescence of one major usage variant, namely the narrative inversion labelled C2.

Stage 1: [= Frame 1: clausal cohesion, variants A, B, and C2].

Reanalysis 1, of frame 1 as 2 [= Frame: reality ('mood') by innovative speech groups].

Stage 2: [= coexisting frames 1,2$]$.

Actualisation process by which narrative inversion (variant C2) loses frequency and disappears, since it is not passed on by speakers of the frame 2 variant.

Stage 3 [= Frame 2, variants A and B]. 
Of the three main cohesive variants, $\mathrm{C}$ is marginalised and disappears; the expressions of $\mathrm{A}$ and $\mathrm{B}$ continue - reinterpreted as a modal opposition.

The loss of one sense out of three is equal to a reduction of polysemy, or rather, it narrows down the semantic scope of the word order pattern and reduces the number of possible syntactic manifestations. Note that this reinterpretation of the pattern zero V (option 1) will also imply a reinterpretation of its opposite, the X V (option 2) pattern. This pattern is now unmarked realis, instead of the unmarked opposite to a marked cohesive option. Thus, the interrogative and the conditional functions have been the basis for a reinterpretation of the frame (the conceptual zone) of the paradigm, implying that the opposition found is now within the domain of reality value, and this distinction is a straightforward distinction of mood.

French and Danish both lose the zero declarative option: Middle French to lose verb second, Danish to recast verb second as a mood paradigm. Where the paradigm of the late Middle Ages was similar to the Old French one, in modern times it is like Table 2:

Table 2. Word order as mood in Modern Danish: reality value

Domain: positions F V2 S

Frame: Reality value

\begin{tabular}{lllll}
\hline & \multicolumn{2}{l}{ Expression } & Content \\
\hline option 1 & $\mathrm{X}$ & $\mathrm{V}$ & $\mathrm{S}$ & realis \\
option 2 & $\varnothing$ & $\mathrm{V}$ & $\mathrm{S}$ & conditioned realis \\
\hline
\end{tabular}

The variant $\mathrm{C}$ was the only obstacle to an interpretation of the paradigm as a distinction of mood; its disappearance may be taken as an indication that such a reanalysis has in fact taken place. Danish (and the other mainland Scandinavian languages Norwegian and Swedish) preserve verb second, but restrict its semantics to assertive potential, "declarative function". Here verb second is integrated into a new hyperparadigm connecting word order and syntactic hierarchy (main clauses vs. subordinate clauses).

Note that this is not a bleaching process, but rather the opposite: one of semantic reconceptualisation and specification. Compare the simplified model above to the model of semantic bleaching as described by, for instance, Heine (2003:592). The bleaching model $(\mathrm{AB}>\mathrm{B})$ is about the loss of obligatory semantic features and is thus an abstraction process. The process above is essentially one that leads to a reduction of polysemy and it is therefore by no means a bleaching process. Rather, it reduces polysemy by redefining the frame, a process that adds new features to the system as a result of paradigm formation and is therefore a clear case of specification. 
Grammaticalisation in the sense of word order regrammation leads to the formation of obligatory paradigmatic oppositions, but it does not presuppose any bleaching process as a sine qua non.

\section{Loss of cohesive meaning in Middle Danish verb second}

\section{Middle Danish cohesive variants}

A. Speech act couplet (question calls for answer)

B. Conditional couplet (protasis calls for apodosis)

C. Narrative couplet (declarative sentence ${ }^{\mathrm{a}}$ calls for declarative sentence ${ }^{\mathrm{b}}$ )

$\mathrm{A}$ and $\mathrm{B}$ function as Questions and Conditionals and are as such interpretable as oppositions within a reality value frame.

\section{Modern Danish cohesive meaning}

$\mathrm{A}$ and $\mathrm{B}$ continue, reinterpreted as variants of conditioned realis as opposed to realis.

C abolished

2.6 The external reanalysis as mood: Illocutionary frame as a combination of mood and syntactic hierarchy

This section describes the fate and state of verb second in the modern language. A number of intermediate processes between 1300 and 1700 are dealt with in Sections 3 and 4 .

In the Old Scandinavian languages, the verb second patterns - $\mathrm{XV}(\mathrm{S})(\mathrm{V}) \mathrm{O}$ vs. $\varnothing \mathrm{V}(\mathrm{S})(\mathrm{V}) \mathrm{O}$ - were the only ${ }^{78}$ word order patterns. From the sixteenth century onwards this pattern develops a paradigmatic relation to a new pattern, the IP/Subjunction SVO pattern. The verb second pattern is reanalysed semantically to specify mood and illocutionary frame, see (25)-(26). XV(S)(V)O becomes the pattern normally used in main clauses to mark assertive illocutionary frame. However, such reinterpretations do not take place in isolation but through regrammation. I discuss later why regrammation and not grammation is the right term, and I shall claim that it is a regrammation process uniting several already existing paradigms into one more complex type. Verb second's alternative in main clauses is the more marked emotive-subjective main clause pattern IP SVO.

78. Generative grammarians will disagree, since they take a set of subordinate clauses to fall outside V2. This problem is not an issue in the present context, since the Old Scandinavian main clause paradigm XV vs. $\emptyset \mathrm{V}$ will be differently coded from the modern V2 anyway. 
The IP/Subjunction SVO pattern is characterised by firm SV order: the subject will always precede the finite verb, and there is no subject position after the finite verb. The object $\mathrm{O}$ is taken to be a representative of a variable ranging over all nuclear (valency bound) constituents except for the subject. That is: $\mathrm{O}$ is convenient shorthand for all types of objects, bound adverbials and predicative complements. Within the main clause system this opposition has acquired its paradigmatic status as an opposition between abstract frames of illocutionary interpretation, as the example below:
(25) Hvem der havde veret til stede! who there had been present 'Wish I had been present'

This is the IP/Subjunction SVO pattern. S is represented by the deictic or situative filler der, hvem is an interrogative pronoun in complementiser position, and the finite $\mathrm{V}$ is not verb second. Note that verb second will count as an $h v($ 'wh')-question only:
(26) Hvem havde der varet tilstede? Who had there been present? 'Who had been present?'

We shall insist that grammaticalisation processes - innovations or regrammations - must always be seen as changes at the content level. This is, for one thing, a necessary precondition - itself derived as a corollary from the nature of language as a sign system but secondly, it is a precondition for any study of linguistic change as complementary processes that we develop tools that will allow us to compare systems across differences of organisation: word order and types of affixal structure (inflexional, agglutinating or polysynthetic). The opposition at the expression level is given in (27):

(27) V2 XVS(V)O (Traditional Danish topology: Fvsa)

Neutral SV(V)O (Traditional Danish topology: ksav)

The SVO pattern is neutral since its order has no specific content function but is open to all interpretations, whereas verb second carries assertive potential. Examples of verb second vs. IP/Subjunction SVO in Modern Danish, main clauses (28-29) and subordinate clauses (30-31):

(28) Main clause XVSO

han kan ikke beslutte sig

he can not make up his mind

'He cannot make up his mind'

(29) Main clause SVO

at han ikke kan beslutte sig!

that he not can make up his mind

'Annoying that he cannot make up his mind' 
(30) Subordinate clause XVSO

(det er klart) at han kan ikke beslutte sig it is obvious that he can not make up his mind

'It is obvious that he cannot make up his mind'

(31) Subordinate clause SVO

(det er morkeligt) at han ikke kan beslutte sig

it is strange that he not can make up his mind

'It is strange that he cannot make up his mind'

The Subjunction SVO (31) and Subjunction XVSO (30) patterns are not synonymous. A key difference is illustrated in (32), the capital test of the semantics of verb second in the modern Scandinavian languages. Verb second in subordinate clauses is frequently found but not in contexts that demand a presupposing or factive complement clause, such as with emotive predicates (morkeligt 'strange'). The verb second pattern is coded as informative (to convey assertive potential), whereas the SVO pattern is the neutral option.

(32) Subordinate clause V2

* det er moerkeligt at han kan ikke beslutte sig

'It is strange that he cannot make up his mind'

The semantics of the modern topological system is rendered in Table 3 and note here the hyperparadigmatic character of this paradigm. XVSO vs. IP/Subjunction SVO is just one parameter, the second parameter being the function of the clause in the syntactic hierarchy as a main clause or a subordinate clause. Clauses are complex signs.

To facilitate the exposition, I shall first render this paradigm in a classical way, matching $2 \times 2$ dimensions at the expression level with 4 content elements or functions.

Table 3. Word order as mood in Modern Danish: assertive word order and neutral word order

\begin{tabular}{lll}
\hline & Main clause & Subordinate clause \\
\hline V2 & assertive illocutionary frame & assertive potential \\
& han kan ikke beslutte sig & $\begin{array}{l}\text { (det er klart) at han kan ikke } \\
\text { beslutte sig }\end{array}$ \\
& & neutral \\
neutral & subjective illocutionary frame & (det er mærkeligt) at han ikke kan \\
pattern & at han ikke kan beslutte sig! & \\
& & \\
\hline
\end{tabular}

The SVO pattern is the neutral option in the sense that this word order pattern does not in itself convey any specific coded sense. What determines the function of the SVO pattern is the choice of particle or complementiser and the position of the clause in the syntactic hierarchy.

The claim that this word order paradigm should be regarded as a mood system can be substantiated through a brief comparison with the coding of inflexional mood 
in the Romance languages. The indicative is normally taken to be the unmarked term, the subjunctive the marked one, but Hooper (1975) has launched the idea that the markedness relation is really - as I would render it - the reverse, at least for Romance, an idea later expanded for French by Danish romanist Hanne Korzen (1998). The indicative is coded as realis or 'informative', and the subjunctive occurs whenever the conditions for the indicative are not fulfilled. Italian gives a very clear picture of a set of oppositions that roughly equals the Danish topological system.

Table 4. Mood in Italian

\begin{tabular}{|c|c|c|}
\hline & Main clause & Subordinate clause \\
\hline indicative & $\begin{array}{l}\text { nessun dorme } \\
\text { 'nobody is sleeping' }\end{array}$ & $\begin{array}{l}\text { è chiaro che nessun dorme } \\
\text { 'it is clear that nobody is sleeping' }\end{array}$ \\
\hline subjunctive & $\begin{array}{l}\text { nessun dorma } \\
\text { 'no-one may sleep' }\end{array}$ & $\begin{array}{l}\text { è strano che nessun dorma } \\
\text { 'it is strange that nobody is asleep' }\end{array}$ \\
\hline
\end{tabular}

Personally, I would have no objections to generalising the terms indicative vs. subjunctive to also comprise topological mood. Others may prefer to reserve these traditional terms for inflexional systems, in which case I would suggest that we speak of this type of topological mood as declarative vs. neutral mood.

Following the graphics of paradigms elsewhere in this book, the complex paradigm for modern clausal word order will be:

Table 5. Mood as word order. The Modern Danish paradigm

Domain: clausal word order

Frame: illocution

\begin{tabular}{lllll}
\hline expression & content & & expression & content \\
\hline MC, V2 & assertive illocutionary frame & & SC, V2 & assertive potential \\
MC, non V2 & subjective illocutionary frame & & SC, non V2 & neutral \\
\hline
\end{tabular}

It is clear that the verb second pattern has changed semantically from being a quite unmarked pattern occurring in all default functions to a pattern that basically expresses assertive meaning, and this blocks a number of functions that were possible in the old language. Verb second in presupposing subordinate clauses was one major instance, and another one the fact that verb second can no longer occur in subjunctional conditional clauses, see further (38) below. Such reanalyses add features to the sign reinterpreted and are therefore specification processes. At the same time, the verb second clause acquires these functions when integrated in the paradigm in Table 5. Regrammation processes can redefine originally unmarked or default members as semantically delimited members of new paradigms. 
Gregersen and Pedersen $(1997,2000)$ offer a major contribution to the study of the actualisation process of the subordinate clause contrast. They document dramatic reductions in the number of verb second subordinate clauses from the 16 th to the 18 th century, from percentages as high as 60-90 during the 16th century to 20-30 by the end of the 17 th century, only to drop to 1 by the end of the 19 th century. ${ }^{79}$ More interestingly for my purpose, they also document the reduction of subordinate contexts to mainly at 'that' clauses and causal clauses. Verb second after a conditional subjunction is still found in Brochmand (1638), but not in Syv (1663). It is rare for the 18th century and not found at all in the 19th century.

The loss of narrative inversion, at a rough guess, is parallel in time. It was fully available to Christian Pedersen (early 16th century), and it is found in Leonora Christina and Johan Brunsmand (late 1680s). Holberg (1739) still preserves the option, but it is next to extinct in Malling (1777). ${ }^{80}$

\subsection{Conclusion of Section 2}

Danish and Mainland Scandinavian in general develop from a verb second system of a cohesive type (similar to the one found in Old French) to a verb second system that encodes mood, paradigmatically and semantically roughly similar to the inflexional mood systems of modern French, Italian and Spanish. Two major reanalyses lie behind these processes: one dismantles the cohesive system by reinterpreting the paradigm XV vs. $\varnothing \mathrm{V}$ as a contrast of mood - a case of regrammation. The other one is also a case of regrammation, that is: formation of new word order paradigms from old ones. The modally reinterpreted XVSO structure forms a new paradigm of mood with the relatively late SVO clause structure. Again, this structural word order change is describable in terms of classical grammatical oppositions - but certainly not in terms of morphological attrition processes and clines.

79. This result is due to the choice of genres studied for the late 19th century, namely academic prose. Had they taken in data from fiction and informal styles, they would no doubt have found other frequencies. Embedded verb second is quite normal in informal genres and in impressionist prose imitating the spoken language. Judging the linguistic potential as a whole, the embedded verb second clause is always structurally possible, but of course, its reinterpretation to a declarative mood makes it the marked type of subordinate clause, resulting in lower frequency.

80. Documenting the decline of connective inversion in details is beyond the scope of the present account. I have checked random samples of narrative prose by Holberg (Heltehistorier 1739 [Plutarch-style historical portraits]) and Malling (Store og gode Handlinger 1777 [Deeds of heroism and valour by subjects of the Danish kíng]), approx. 100 pages of each, finding 4,5\% of connective inversion in Holberg (49 connective inversions out of 1078 main clauses), and around $0.2 \%$ in Malling (4 findings out of 1350). 
In Sections 3 and 4, I shall offer a suggestion concerning the original grammations that form the basis for this major regrammation, namely the formation of marked cohesive subordinate clauses and of emotive main clauses.

Above all, this organisation of verb second order in a new paradigmatic setting is a major example of connecting grammaticalisation, in the sense that a number of simple (or relatively simple) innovations gain ground and regrammate through the connection of simple paradigms into one complex paradigm or hyperparadigm (Christensen 2007). The modern word order systems of the Mainland Scandinavian languages are characterised above all by this hyperparadigmatic structure. They connect syntactic hierarchy with word order to define a reinvented or reshaped semantic domain.

\section{The rise of SVO order in Scandinavian from Old Scandinavian $\mathrm{OV}$ order in non-finite VPs}

The Mainland Scandinavian languages all develop an alternative clause type to the verb second order, examples of which were given in Section 2.6. These two clause patterns, verb second (XVSO) and SVO, both occur in main clauses and in subordinate clauses, and by the beginning of the 18th century they form a paradigm in Danish (see Tables 2 and 3-5) that mark a typological swing away from cohesive word order towards word order as a system of mood and illocutionary frame.

In the first mood paradigm, existing word order patterns were reanalysed as an opposition within the domain of Realis. In the second modal paradigm, verb second order was reorganised paradigmatically in opposition to the relatively recent IP/Subjunction SVO order, the so-called subordinate clause order. These changes were complete by the second half of the 18th century.

In Sections 3 and 4 the development of the SVO patterns will be dealt with, specified as Subjunction SVO for the subordinate clause (Section 3) and Illocutionary Particle (IP) SVO for the (emotive) main clause (Section 4). Section 3 will describe a set of grammation and regrammation processes consisting of two major steps between three phases.

\section{Stage A. Old Scandinavian V2 $\rightarrow$}

Stage B. (from around 1300) Old Scandinavian V2 + subordinate clause non V2 $\rightarrow$ Stage C. (1500-1700) Valency bound constituents reorganised: subjects become obligatory and fixed to characteristic positions, and VO order is generalised; in other words: categorical sentence structure is introduced (Sasse 1987; Heltoft 2003).

The first step $(\mathrm{A} \rightarrow \mathrm{B})$ is the reanalysis described in Section 2.4-5: a positional identification of the cohesive elements of main clauses (XV) with the positions for 
subjunction of subordinate clauses. The result of this reanalysis is two subordinate clause types instead of one: a verb second subordinate clause type and a non verb second clause type, different from the modern SVO type.

To lay the ground for this analysis, we need to spell out some central features of the content (Section 3.1) and expression (Section 3.2) of the verb second word order system. Finally, we need a sketch of the information structural functions of Old Scandinavian word order (Section 3.3).

The Subjunction SVO pattern is illustrated in example (33), the verb second pattern in subordinate clauses in (34), both repeated for convenience from Section 2, (6)-(7). Note the position of particles, sentence adverbials, and negation. These categories (in the order mentioned) precede the finite verb in Subjunction SVO clauses (33), while in verb second-patterns they follow the finite verb (34). The test is applied with the negation (ikke). ('>' = 'must precede').

at folketingsmedlemmer ikke er bundet af andet end
that MPs not are restrained by anything but
deres samvittighed
their conscience

'that MPs are obliged by nothing but conscience'

(34) at folketingsmedlemmer er ikke bundet af andet end that MPs are not restrained by anything but

deres samvittighed

their conscience

'that MPs are obliged by nothing but conscience'

The finite and non-finite verb of the verb second clause form a discontinuous constituent, visible in the case of a periphrastic verbal form (34). The Subjunction SVO type, on the other hand, is a clause type with an always continuous verb phrase. The SVO patterns gain their present position by the late 17th century, but to my knowledge, no scenario of the sets of reanalyses leading up to the present situation has been offered anywhere. A brief sketch in Danish has been given in Heltoft (2005).

The new clause pattern is characterised by two main features:

1. The continuous finite verb phrase and its relative position to particles and sentence adverbials: Dialogic Particles $>$ Sentence Adverbials $>$ Negation $>$ VP.

2. The fixed position for the subject: Subject $>$ Dialogic Particles $>$ Sentence Adverbials $>$ Negation $>$ VP.

Old Scandinavian subjects did not have a fixed topology, see below. The traditional way of describing the change to Modern Scandinavian is to say that the subject becomes obligatory and acquires a characteristic position, in subordinate clauses even a fixed 
one. This change is not enough to even describe the rise of the SVO pattern, since what we really need to cope with are the reanalyses leading to the firm sequence Particles $>$ Sentence Adverbials $>$ VP and the continuous VP. In the present exposition, I shall claim that subordinate clause word order arises as a result of connecting grammaticalisation, that is: of paradigm formations that combine syntactic and topological distinctions in new ways.

In relation to non-finite verbs, Old Scandinavian could have both OV and $\mathrm{VO}^{81}$ order. This is, of course, well known from traditional expositions (Diderichsen 1941; Karker 1991; Pedersen 1993) and from generative discussions as well (Rögnvaldsson 1996; Delsing 1999). Examples of OV are:

En vm vigia scal. tha sculu bøndoer biscop thre noetor
But if consecrate shall, then must peasants bishop three nights
føtha. oc capalan-um half marc gifua.
feed and chaplains-DAT half mark-ACC give
'But if one is to consecrate a church, then the peasants must give lodgings to
the bishop for three nights and give the chaplains a half mark'
the bishop for three nights and give the chaplains a half mark'

(Scanic Ecclesiastical Law 2. GL 10, 18-20)

An example of VO:

(36) (= (10), where morphological glossing is given)

Thomma retti $\mathrm{j}$ gien. tha haui bøndør iat biscopi

This law in return, then have peasants accepted bishop

thrithiungs tindoe af allum sath sinum

a one third tithe of all seed theirs

'In return for these statutes, peasants should accept to give the bishop one

third of all their seed as tithe. (Scanic Ecclesiastical Law 20, GL 18, 4-6)

OV order - once the unmarked Germanic order - has been restricted to the positional field of the non-finite verb. Verb second is the unmarked position for the finite verb, in fact the only possible position.

\subsection{The meaning of Old Scandinavian verb second}

Old Scandinavian word order was verb second, implying that the position for the finite verb would always precede the positions for sentence adverbials and negations. At this stage there was no word order difference between main clauses and subordinate clauses. (37ab) are subordinate clause examples from Old Icelandic, clearly showing verb second topology. The finite verb precedes negation.

81. Or, in more general terms: XV or VX, since the order rules apply to any type of constituent, nuclear (valency bound) or free, and not just to objects. 
(37)

a. nu moeli ek pat um, at pú verðir now say I that about(it) that you become hvers nídingr, everybody's knave

'Now I shall say about it, that you will be a knave to everybody' ef pú hefnir eigi Ásbjarn-ar if you revenge not Asbjørn-GEN 'If you do not take revenge for Asbjørn' Nygaard 1905:372

b. svá at guð banni eigi sál peira himinríki á dómsdegi so that God forbid not soul their heaven on Domesday 'so that God will nor forbid their soul (admission to) heaven on Domesday'

Nygaard 1905:372

These subordinate clause types (conditional and consecutive) are fully compatible with the verb second order. In the modern language, however, subordinate clauses of these semantic classes would not allow this order, but demand the order Negation > Finite V, that is: the SVO-pattern. In Old Scandinavian verb second may coexist with semantically rich subjunctions, for example conditional, concessive and final subjunctions. This again indicates that a change must have taken place in the semantics of verb second, from an older, unmarked type of verb second, to a semantically more specific modern type. Examples (38ab) from Old Scanian Danish document the old type; see further Section 3.2.

a. $v m$ thoet wil dylia arfu-i han-s. at han-um døth-um. if that will deny heir-NOM he-GEN at he-DAT dead-DAT 'if there is an heir after him who wants to contest that after his death'

(Scanic Ecclesiastical Law 8. GL 12, 23-24)

b. *hvis det vil en arving benoegte (Modern Danish) if that will an heir contest

(38b) is impossible in the modern standard language, and maintaining the subject's position from (38a) would not help: ${ }^{\star}$ hvis det vil benoegte en arving. Such subordinate clauses must follow the SVO pattern, and there is no open position in front of the finite verb. In the old language, any type of constituent may squeeze in between the subjunction and the finite verb, in the case of (38a) a pronominal object.

\subsection{Positional analysis}

Old Scandinavian topology had only one position for the finite verb, and since the language is verb second, only one position precedes the finite verb.

Like in our analysis of Old French, the subjunction is topologically irrelevant and as such bracketed from the topological pattern. 
Examples of what tradition calls the 'wedge' position in relative clauses will belong to this pattern, for instance (39a). Example (39b) shows the same phenomenon in a consecutive at 'that'-clause.:

$$
\begin{aligned}
& \text { a. vtan vfritha man oer-i thoen or skip hafuir } \\
& \text { unless outlawed man be-PRS.SBJv he that ship has } \\
& \text { thoer brutit. } \\
& \text { there broken } \\
& \text { 'unless it should be an outlaw that has wrecked his ship there' }
\end{aligned}
$$

(Scanic Law 165. GL 103, 4)

b. ..swa myok spialloet at oy thol-e guths reet at... so heavily damaged that not admit-PRs.sBjv God's law that 〈'unless it (the church) should become〉 so heavily damaged that God's law cannot tolerate that $\langle$ it remains unconsecrated'〉

(Scanic Ecclesiastical Law 1. GL 10, 15-16)

The wedge does not distinguish different positions for NPs, adverbials and predicatives. There is just one position X: Example (39a) has a predicative complement in $\mathrm{X}$ ( $v$ fritha man) in the matrix subordinate clause, and an object in $\mathrm{X}$ in the embedded subordinate clause (skip). Example (39b) has an X filled by negation, and from Old Norwegian I have already quoted (40) $[=(2)]$ with a pronominal indirect object in X.

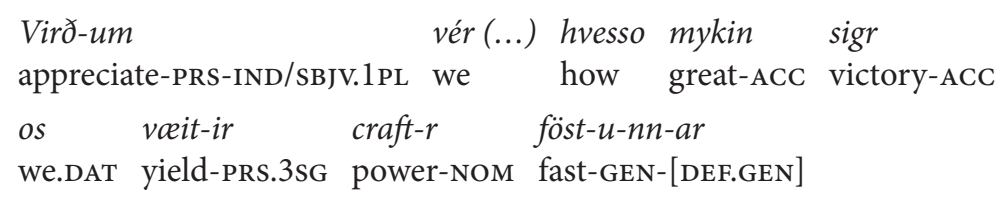

'Let us appreciate (...) what a great victory the power of fast yields us'

Indrebø 1931:74, 8-10

Thus, the word order of the initial part of Old Scandinavian is:

(subjunction) - X (open position) - V2 - negation

I claimed in Section 2 that the function of the open position is not primarily topicalisation but another textual contrast, expressed by the contrast between a filled and unmarked initial position and a marked and empty initial position, see Table 7. I therefore call the general position $\mathrm{X}$.

This contrast applies to main clauses - roughly - and in subjunctional subordinate clauses the initial position $\mathrm{X}$ is normally filled in by default. Remember again that the subjunction does not count in the topological balance sheet, and see the following examples, selected from those mentioned above, illustrating the topological 
similarity between main and subordinate clauses and the topological irrelevance of the subjunction..$^{82}$

Table 6. Old Scandinavian word order - expression system

\begin{tabular}{|c|c|c|c|c|}
\hline & Subjunction & $\mathrm{X}$ & $\mathrm{V} 2$ & Unanalysed \\
\hline$(35)$ & & tha & sculu & bøndær biscop thre nætær føtha \\
\hline$(37 a)$ & & $\mathrm{nu}$ & mæli & ek pat um. at... \\
\hline$(37 a)$ & ef & pú & hefnir & eigi Ásbjarnar \\
\hline$(37 b)$ & svá at & guð & banni & eigi sál peira himinríki \\
\hline$(38 \mathrm{a})$ & vm & thæt & wil & dylia arfui hans \\
\hline$(39 a)$ & vtan & vfritha man & æri & thæn ær... \\
\hline$(40)$ & hvesso mykin sigr & os & væitir & craftr föstunnar \\
\hline$(39 a)$ & ær & skip & hafuir & thær brutit \\
\hline
\end{tabular}

\subsection{Iconic focus}

In Old Scandinavian the word order rules did not code differences between subject and objects, nor between types of objects, which is a striking contrast to the modern Mainland Scandinavian languages. Word order signalled the function of constituents as focused or backgrounded, cf. Christoffersen (1993), Pedersen (1993), Heltoft (1995), and in detail Heltoft (2003). I offer a brief summary of this analysis.

Positions after a non-finite verb are unmarked with respect to information status, in the sense that constituents in these positions may be interpreted as focused or non-focused, depending on the context. By contrast, the positions preceding the non-finite verb trigger a choice between background positions and focus positions. This is a kind of iconicity in word order: ${ }^{83}$ constituents preceding a focus operator (typically the negation) escape from its scope, and as such they cannot be focus constituents. A constituent immediately to the right of a focus operator is marked as

82. The generativist distinction between a position $\mathrm{I}^{0}$ (inflexion) and a position $\mathrm{C}^{0}$ for complementisers has no parallel in this model, since there are no topological criteria and arguments that would support the relevance of $\mathrm{I}^{0}$.

83. This relation bears resemblance to Givón's principle of proximity (1991:80), part of which runs: 'Functional operators will be placed closest, temporally or spatially at the code level 〈i.e. at the expression level, $\mathrm{LH}$, to the conceptual unit to which they are most relevant". In the Peircean sense we are dealing with a diagrammatic relation, probably a diagram based on analogy, but this issue is not central to the line of argument. See Engberg-Pedersen (1996). 
a focused constituent. In what follows, backgrounded constituents are underscored; focused constituents are in bold face.

a. Julianus gat thon harm oy loenger thol-d Julianus could this scorn not longer bear-PRF PTCP 'Julianus could no longer bear this scorn'.

(Legend of St. Christina. GL 285, 25-26; Western Danish app. 1300)

b. Oc alla the dela them cumber jmoelle skal eig and all the disagreements them come between must not annar stath del-a-s on a huskarla stefna. other place decide-INF-PAss than at housemen's meeting 'And none of the strifes that come between them may be settled elsewhere than at a household's meeting.'

(Canute's household statutes. GL 118, 13-15; Scanic Danish 1430)

c. Theet oer for bothoet af loekoer.

It is for bidden by doctors,

at man scal oei børn oc oei gamloe latoe bloth that one must not children and not old people bleed for the $\langle$ rre $\rangle$ kranklek.

for their disease.

'It is a doctors' prohibition that one must not bleed children or old people for their disease'.

(Harpestreng 93, 17-18; Western Danish 1300)

When there is no focus operator, there is no explicit signal for the background-focus contrast, but note that a constituent with a semantically inherent focus (for instance: universal quantifiers) will very often have OV order:

$\begin{array}{llll}\text { Paw-i-n } & \text { hawir all-um cristn-um mann-um } \\ \text { pope-NOM-[DEF.NOM] has } & \text { all-DAT Christian-DAT men-DAT } \\ \text { forbuthit iernbiwrth. } & & & \end{array}$

forbidden ordeal by fire-ACC

'The pope has forbidden all Christian men the ordeal by fire'

(DgL II, Scanic Law Add XII, 781-82; Scanic Danish 1430, text dating back to 1215)

Examples with backgrounded pronouns are special cases of the backgrounding rule. ${ }^{84}$

84. They are not instances of preposed unstressed pronouns, in contrast to the modern situation, see Chapter 2, Section 5. 
(43) on wilt thu mic thoet oei sighee ac scal giuce thit kiøt undoe but will you me that not tell, I shall give your flesh vicious diur at oetce animals to eat

'But if you will not tell me this, I shall give your flesh to predators to eat'.

(Legend of St. Christina. GL 284, 10-12; Western Danish app. 1300)

(44) han swarathe. thoet oer nw nogot boetra: he answered. it is now somewhat better

jac høre thøm buldra oc roba.

I hear them bang and shout

oc iac seer thøm thaa ey.

and I see them yet not

'He answered: I am somewhat better now. I hear them banging and shouting, and yet I do not see them'

(SjT 23; Scanic Danish, app. 1425)

In (45) a locative pronoun carries the focus. Such focused pronouns may precede the non-finite verb and, furthermore, they would in all probability carry stress.

(45) Ma thonnoe athree oi thoerce finn-ce-s,

Can this vein not there find-InF-PAss

tha scal hun hittoes nithoer a armoen til handoen

then must it be find down on the arm towards the hand

'If this vein cannot be found there, then it must be found downwards in the arm towards the hand' (Harpestreng 94, 18-19; Western Danish, app. 1300)

Note the positional non-prominence of the subject. Example (46a) shows postfield position of the subject, (46b) shows focus position. Subjects in Old Scandinavian have no specific position but can occur in all three fields: initial position, prefield background, prefield focus, and postfield, depending on the textual role of the subject. From the vantage point that topology is a sign system, it makes no sense to generate them in one position and hence derive the alternatives.
a. Mik hafv-a
hvlpit
Me have-PRS.PL help-PRF PTCP your holy prayers
b. Thrennoe steen ma oi eld skath-oe
This stone can not fire damage-INF-ACT
'This stone cannot be damaged by fire'

thina hoelgho bønir

'Your holy prayers have helped me' (SjT 23; Scanic Danish app. 1425)

(Harpestreng 191, 13-14; Western Danish 1300)
c. Æn forbiuth-i-s thet tha skal thet
but forbid-PRS.SBJV-PASS it then must it
$<$ livestock for export>


ey konung oc ey hans embusman gewe not king and not his representative give orlogh burt at føra $i$ thet aar permission away to carry in that year

'But should it be forbidden, then must neither the king nor his representative give permission to export it in that year'

(Manuscript E donatione variorum 136, $4^{0}$ 83r CCD IV., Scanic Danish 1430)

The following Table 7 will show the iconic positions. The coded field is called the prefield, in contrast to the unmarked postfield. Clauses without negation or another focus operator are in principle ambiguous, and (42) is an example. Such examples are analysed here according to their focus structure, as a generalisation from the secure examples.

Note the positional flexibility of the subject, illustrated by examples (41a), (45) and (46abc), highlighted in Table 8. We cannot treat this part of the change in details, but the medieval subject rules are very different from the modern situation, and the subject is not yet restricted to thematic positions but may occur both in the postfield (46a) and in focus position (46bc). In the modern language, the subject is restricted to X position and to subject position ( 1st background position), as in (41a) and (45) (Heltoft 2001, 2003), see Table 8.

Table 7. Iconic focus

\begin{tabular}{|c|c|c|c|c|c|c|c|}
\hline & \multirow[t]{2}{*}{$\mathrm{X}$} & \multirow[t]{2}{*}{$\mathrm{V} 2$} & \multicolumn{3}{|c|}{ Prefield } & \multirow[t]{2}{*}{$\mathrm{V}$} & \multirow[t]{2}{*}{ Postfield } \\
\hline & & & Background & Neg. & Focus & & \\
\hline (41a) & Julianus & gat & thæn harm & æy & længær & thold & \\
\hline$(41 b)$ & alla the dela.. & skal & & eig & annar stath & delas & \\
\hline$(42)$ & pawin & hawir & & & $\begin{array}{l}\text { allum } \\
\text { cristnum } \\
\text { mannum }\end{array}$ & forbuthit & iernbiwrth \\
\hline (44) oc & iac & seer & thøm thaa & ey & & & \\
\hline (45) & & $\mathrm{ma}$ & thænnæ athræ & æi & thæræ & finnæs & \\
\hline (41c) at & man & scal & & $\begin{array}{l}\text { æi } \\
\text { æi }\end{array}$ & $\begin{array}{l}\text { børn (oc) } \\
\text { gamlæ }\end{array}$ & latæ & athræ bloth \\
\hline (46b) & thænnæ steen & $\mathrm{ma}$ & & æi & eld & skathæ & \\
\hline$(46 a)$ & mik & hafva & & & & hvlpit & $\begin{array}{l}\text { thina helga } \\
\text { bønir }\end{array}$ \\
\hline$(46 c)$ & tha & skal & thet & $\begin{array}{l}\text { ey } \\
\text { ey }\end{array}$ & $\begin{array}{l}\text { konung oc } \\
\text { hans } \\
\text { embusman }\end{array}$ & gewe & $\begin{array}{l}\text { orlogh burt } \\
\text { at føra }\end{array}$ \\
\hline
\end{tabular}


Table 8. Subject positions (S)

\begin{tabular}{|c|c|c|c|c|c|c|c|}
\hline & & \multirow[t]{2}{*}{ V2 } & \multicolumn{3}{|c|}{ Prefield } & \multirow[t]{2}{*}{ V } & \multirow[t]{2}{*}{ Postfield } \\
\hline & & & Background & $\mathrm{Neg}$ & Focus & & \\
\hline (41a) & Julianus (S) & gat & thæn harm & æy & længær & thold & \\
\hline (45) & & $\mathrm{ma}$ & $\begin{array}{l}\text { thoennoe } \\
\text { athree (S) }\end{array}$ & æi & thæræ & finnæs & \\
\hline (46b) & $\begin{array}{l}\text { thænnæ } \\
\text { steen }\end{array}$ & $\mathrm{ma}$ & & æi & eld (S) & skathæ & \\
\hline$(46 a)$ & mik & hafva & & & & hvlpit & $\begin{array}{l}\text { thina helga } \\
\text { bønir (S) }\end{array}$ \\
\hline (46c) & tha & skal & thet & $\begin{array}{l}\text { ey } \\
\text { oc ey }\end{array}$ & $\begin{array}{l}\text { konung (S) } \\
\text { hans em- } \\
\text { busman (S) }\end{array}$ & gewe & $\begin{array}{l}\text { orlogh burt } \\
\text { at føra }\end{array}$ \\
\hline
\end{tabular}

\subsection{Positional reanalysis of cohesive elements}

The early 14th century sees a topological innovation to the effect that OV order is now found before the finite verb in subordinate clauses. In traditional terms, the initial wedge position $\mathrm{X}$ is reinterpreted as a prefield between subjunction and finite verb, that is:

$$
\begin{array}{rlr}
\text { Sub } & \text { X } & \text { V } \\
\rightarrow \text { Sub Prefield } & \text { V }
\end{array}
$$

I suggest that this is only the second half of two reanalyses. What is at stake is also a case of functional and thereafter topological identification of the initial positions of the two types of clauses.

Some examples contrasting old and new will be useful. Examples (47abcd) show the topological innovation; (47ab) have SOV, (47c) has S - PP (Predicative Complement) - V, and (47d) is a subject relative clause: Subjunction - O - Locative Adverb - V.

a. LIomfruan kioerdhe for fathir oc modhir

Maid-DEF complained to father and mother

at hon ey finge lifvat.

that she not get-PST.SBjv live-PRF PTCP

vtan hon thæn swennen fing-e.

unless she that lad get.PAST-SBJV

'The maid complained before her father and mother that she was not able to live unless she had this lad'. 
b. the (..) cerce saa gladee at the hans onlodoe see at... they are so happy that they his face see that... 'They are so happy that they see his face that...'

(Luc 72r; Western Danish app. 1450)

c. forti tochvar man (for tochuorion) the at skrefft because in spite of they at confession hauce vercet tha voree the aldree $i$ thon have been then be.PST-SBJv they never in the hw at... mood that...

'because in spite of the fact that they have been to confession, then they would never be in the mood that.. $\quad$ (Luc 70v; Western Danish 1450)

d. thi cest thw then førstoe som naden therefore be.PRS-2sG thou the first that mercy hoss hanum hawer fwnnet with him have-PRs.3sG found 'Therefore, thou art the first one to find mercy with him' (Prayers II 153; Western Danish 16th century)

The innovative order generalises iconic order (the prefield) to the topological space between the subjunction and the finite verb. Iconic focus is documented in the following negated examples:
a. the syndher (...) ther
ey the sins (...) that not suitable is about to
syce owenbarligh
tell in public
'those sins that are not suitable for public mention'

(Luc 57r; Western Danish 1450)

b. at the aldree samon vildoe kommoe forree on vors that they never together would come before than our herre ængæl bøt tøm thet Lord's angel bade them it 'that they would never come together until the Lord's angel bade them'

(Luc 85; Western Danish 1450)

Clause (48a) is a subjectless relative clause having an adjectival predicative complement in focus position. At this stage, there is still no rule to the effect that the subject is the obligatory first prefield constituent. Even in these innovative subordinate clauses, examples can be found with a non-subject in the first prefield position: 
(49) A, kicere frwe, I haffwe nw woell kloedh mik Oh, dear lady, you have now well dressed me hwicketh ether gud skall lønoe which you.oBL God will reward 'Oh, dear lady, you have dressed me well now, for which God will reward you' (ML 406, 21-22; Western Danish 1480)

The subject is certainly very often the first background constituent, but in principle the subject can occur in all fields of the clause, and within the limits of the prefield it can occur both as background and as focus, see (46abc) and cf. Nygaard (1905:356-360), Heltoft $(1995,2001)$.

\subsection{Functional motivation}

This innovation can probably be seen as the result of identification of the functions of $\mathrm{X}$ in verb second order and of the subordinating conjunctions. Where the first stage was stably identifying $\mathrm{X}$ both in main clauses and subordinate clauses, the new reinterpretation identifies $\mathrm{X}+$ verb second with the function of subjunctions. Both are structural categories or configurations that express the cohesive value of the clause.

In the following Tables, $\mathrm{X} / \varnothing$ is shorthand for the cohesive contrast between a filled in X position and an empty one, see Section 2.4. Original topological relations prevail (Subjunction is bracketed, that is: outside the topological balance sheet):

Table 9. Medieval verb second

\begin{tabular}{llllll}
\hline & $\mathrm{X} / \varnothing$ & Vfinite & Prefield & Vnon-finite & Postfield \\
\hline Subjunction & $\mathrm{X}$ & Vfinite & Prefield & Vnon-finite & Postfield \\
\hline
\end{tabular}

$\rightarrow$ Innovative subordinate clause order (Subjunction is integrated topologically):

Table 10a. Verb second main clause and reanalysed non verb second subordinate clause

\begin{tabular}{l|l|llll}
\hline $\mathrm{X} / \varnothing$ & Vfinite & Prefield & Vnon-finite & Postfield & Vnon-finite \\
\hline \multicolumn{2}{c}{ Subjunction } & Prefield & $\begin{array}{l}\text { Vfinite } \\
\text { V non-finite }\end{array}$ & Postfield & Vnon-finite \\
\hline
\end{tabular}

This functional reinterpretation makes sense under the precondition that verb second is analysed as a cohesive system, as suggested by Buridant for Old French, 
see Section 2. Subjunctions are evidently a cohesive category, but there is no way to make sense of this topological identification if the issue is approached from the angle of expression syntax. Note that we cannot claim any modal interpretation of the relation for this stage. Mood and modal functions proper are still centuries ahead as grammaticalised in word order paradigms alone.

Old Scandinavian subordinators were often original prepositional constructions, for instance from Scanian Danish: num thes at except pron-GEN that 'except that'; fore thy at for pron-DAT that 'because'; af thy at for pron-DAT that 'for the reason that'; til thoes at to pron-GEN that 'until', 'to the purpose that' etc. Others consisted of a cohesive adverb + at 'that', for instance: tho at 'although', swa at 'so that'. Given the presupposition that they have already at this stage been reanalysed as double subordinators, there is a possible semantic analysis of them that might clarify their relation to verb second clauses.

We need to compare the sign functions of verb second clauses to those of the complementiser in the subordinate clause. As stated in Section 2 above (Table 1), the central symbolic contrast in verb second clauses is manifested by the opposition between 'zero $\mathrm{V}$ ' and 'XV'; here the position of the indicative finite verb in the second position is but a precondition for this semantic contrast to apply. The semantic function of 'the finite indicative verb in second position' is an indexical one: this very verb form in this position points to the neighbouring symbolic contrast, indicated by an arrow ' $\leftarrow$ '.

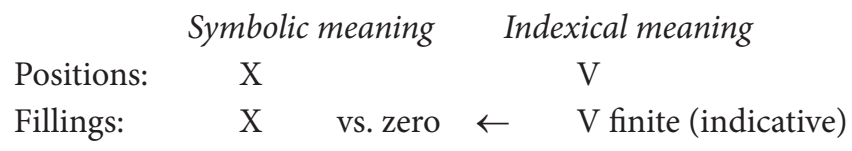

I suggest that the subjunctional complex could be analysed in a similar way, the PP being the symbolic part, of course. The subjunction at 'that' has no symbolic function in such contexts, but again an indexical one of pointing to its governing context (the PP).

$\begin{array}{lcc} & \text { Symbolic meaning } & \text { Indexical meaning } \\ \text { Positions: } & 1 & 2 \\ \text { Fillings: } & \text { PP } & \leftarrow \quad \text { at 'that' }\end{array}$

Thus, the mechanism that identifies subjunctions and the fillers of the two initial positions in verb second ( $\mathrm{X}$ and $\mathrm{V}$ ) is an identification of the semantics of positions across word categories.

$\begin{array}{lccc} & \text { Symbolic meaning } & \text { Indexical meaning } \\ \text { Positions: } & 1 & 2 \\ \text { Fillings: } & \mathrm{X} \text { vs. zero } & \leftarrow & \text { V finite (indicative) } \\ \text { Fillings: } & \mathrm{PP} & \leftarrow & a^{\text {'that' }}\end{array}$


I do not claim that $\mathrm{V}$ and at are members of the same syntactic category, but that they have been interpreted as topologically equivalent due to their common semantic function: indexical pointing to the cohesive element ${ }^{85}$.

Contrary to the analysis of verb second in generative grammar (where the finite verb goes to $\mathrm{C}^{0}$, for Platzack and his followers also in Old Scandinavian), I draw the conclusion that the rise of non verb second order is relatively late and secondary (Tables 11ab), and in particular that in this new clause type single subjunctions should primarily be regarded as fillers of the first position, the main cohesive position. Constituents filling this position are treated alike, not because they belong to the same syntactic category, but because they are semantically similar. As I have claimed elsewhere (Heltoft 1992, 2005), any theory must allow such direct mappings between positions (expression) and meaning (content), not necessarily referring to similarities of syntactic structure. Word order is organised in paradigms, in principle different from constructional ones, although complex paradigms do of course occur (See Chapter 4).

Compare this analysis to the moves of Harris and Campbell (1995:287-289) where they render traditional (and plausible) views of how complement dass 'that'clauses were formed in German. The complementiser dass is a reinterpretation of pronominal ^bat, Gothic pat-a, Norse pat, Old High German das, occurring originally as the head of a pronominal constitituent of the main clause, then reinterpreted as the subjunction of a subordinate clause. This process changes its category and its hierarchical position. Since it is no longer a part of the first clause, its topological properties have changed as well. In such cases of reanalysis of constituency, topology and syntax remain intertwined.

In the present case, however, a roughly similar process has already taken place, changing explicative cataphoric constructions into double subordinators like num thoes at 'unless' and swa at 'so that'. The next step, however, identifies X/zero V and the double conjunction positionally, on functional semantic grounds, not on the basis of syntactic reinterpretation.

Generative grammarians will object that $\mathrm{X}$ position is a position for topics and hence for maximal projections, ${ }^{86}$ and that subjunctions cannot be topics. My point is simply that $\mathrm{X}$ position is not a position coded for topics (constituents referring to

85. For a comparable analysis of the German weak adjective declension as indexical, see Haberland \& Heltoft (2008).

86. That is: for full or maximal constituents, not for heads or modifiers alone. Those are supposed to be cases of so-called stylistic fronting, differing from topicalisation and landing its material in I-Spec, not in C-Spec (see for example Holmberg \& Platzack 1995:115-123). Again, whatever status $\mathrm{I}^{0}$ may be given, it is certainly not a topologically motivated position different from the position for verb second. 
entities) but for cohesive relations of another kind (2.4), and that $\mathrm{X}$ is open to full constituents, to heads alone, and to modifiers alone. Again, we need to make the analysis of $\mathrm{X}$ a purely empirical one, that is: to identify the coded relation between expression and content.

The subjunction at deserves special mention, since it is polysemous in the old language and may occur as the single subordinator in all its senses. In cases where it is the sole (indexical) subordinator, as in (41c) and (47a), it points to the matrix clause, or better: to the governing verb determining the status of the subordinate clause. It can also convey a final or consecutive sense (like classical Italian che 'that', German daß 'that'), and in these latter senses I suggest it should be analysed along the same lines as other single subjunctions. Again, in its indexical sense I treat it as an ordinary subjunction, since (a) it is in paradigmatic opposition to interrogative um 'if, whether', and since (b) its indexicality is extraclausal, pointing to the predicate of the matrix clause. No definite topological argument can be given.

The finite verb will form a contiguous constituent with the non-finite verb, probably aided by a second reanalyses of the topological system. $\mathrm{X}$ is reanalysed from a simple position to a prefield with only one constituent:

$\begin{array}{rll}\quad \text { Sub } & \text { X } & \text { V } \\ \text { Sub } & \text { Prefield } & \text { V }\end{array}$

This again paves the way for more than one constituent, like in (50) ${ }^{87}$

(50) tha the vpa mor-it como. saghdhothe som... when they upon sea-DeF came, said those who... 'when they had put to sea, said those who...' $\quad$ SjT GL 330, 33-34

Accordingly, table 10a can be revised as 10b. The details of the analysis follow in table $10 \mathrm{c}$, the result in $10 \mathrm{~d}$. Note the principled generalisation from maximally filled examples to reduced examples, see Chapter 2, Section 4.1-2.

87. Another trend of purely syntactic analysis of change is the generative one, represented by Lightfoot (2003), for the Scandinavian development particularly by Holmberg \& Platzack (1995). Discussion develops along the possible positions for finite verbs: $\mathrm{V}^{0}, \mathrm{I}^{0}$, or $\mathrm{C}^{0}$. Change is analysed in terms of changing parameter settings, this again in terms of cues for parameters. I cannot go into much detail, especially because my view of the relation between constituency and linear ordering is radically different. There is no way in my model that anything similar to $\mathrm{I}^{0}$ could be a part of the description of Danish sentences, since there is no possible trace of any raising to such a category/position. It is not relevant to Danish topology. 
Table 10b. Verb second main clause and reanalysed non verb second

\begin{tabular}{llllll}
\hline $\begin{array}{l}\mathrm{X} / \varnothing \\
\text { (cohesive) }\end{array}$ & $\begin{array}{l}\text { Vfinite } \\
\text { (indexical) }\end{array}$ & Prefield & Vnon-finite & Postfield & V non-finite \\
\hline $\begin{array}{l}\text { Subjunction } \\
\text { (cohesive) }\end{array}$ & $\begin{array}{l}\text { Subjunction } \\
\text { (indexical) }\end{array}$ & Prefield & $\begin{array}{l}\text { Vfinite } \\
\text { Vnon-finite }\end{array}$ & Postfield & Vnon-finite \\
\hline
\end{tabular}

Table 10c. Subjunctional structure

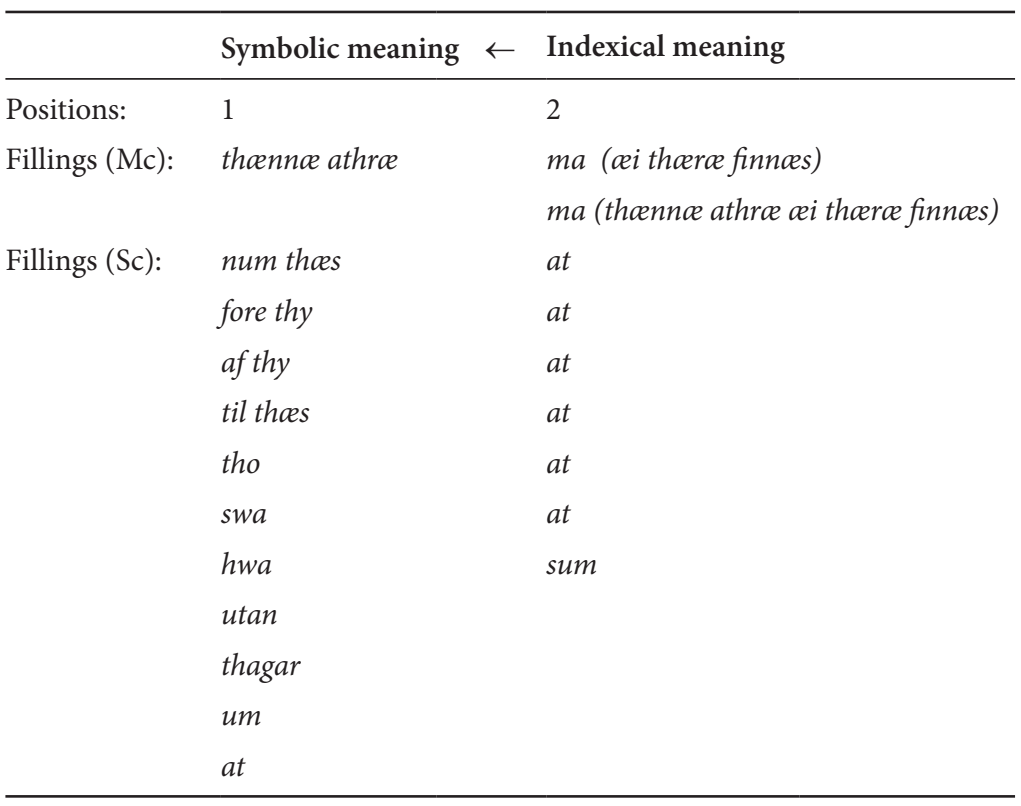

The logic behind the topological analysis is exactly the same as presented in my introduction Section 1.1 where in (3) the clause hvesso mykin sigr os voeitir craftr föstunnar 'what a great victory the power of fast yields us' is analysed as (hvesso mykin sigr) os veitir craftr föstunnar, that is: with a bracketed initial subjunctional. Although a syntactic object, it also contains a lexicalised subjunctional element and can therefore on semantic grounds be treated topologically along with syntactic subjunctions like $u m$ 'if'. 88

88. Similar analyses apply to relative constructions with an initial $h w a+s u m$, as in
(i) hvat sum man brytoer at vatha. oc oy moeth
Whatever that man breaks without his will and not
wilia. tha (...)
willfully, then..

'Whatever violation a man commits by accident and not willfully, then...' 
Table 10d. Reanalysed non verb second subordinate clause: details

\begin{tabular}{llllll}
\hline $\mathbf{1}$ & $\mathbf{2}$ & Prefield & $\mathrm{V}$ & Postfield & Vnon-finite \\
\hline Cohesive PP & at & & & & \\
Cohesive adverb & at & & & & \\
$h w$-pronoun & sum & & & & \\
single Subjunction & - & & & & \\
\hline
\end{tabular}

To clarify the importance of this step in the sequence of reanalyses involved, I shall set up the topological structure of the modern language for comparison, differing mainly in the fact the the first prefield is now restricted to Subjects-Particles-Free adverbials and Focus operators. No valency bound constituents go there, except for the subject. The point is that nevertheless, the initial identification of XV and subjunction has been maintained, of course, no longer inside a frame of cohesion, but inside a new frame of mood.

Table 11. Modern Danish topology. Some positions have been omitted and the change of the second non-finite field to a field for predicative complements is irrelevant here

\begin{tabular}{lllll}
\hline $\mathrm{X} / \varnothing \quad$ Vfinite & Subjects Particles etc. & Vnon-finite & Objects & Predicatives \\
\hline Subjunction & Subjects Particles etc. & Vfinite Vnon-finite & Objects & Predicatives \\
\hline
\end{tabular}

Thus, this reinterpretation must be seen as initiated from the content level, and its result is a change of the paradigmatic organisation of word order. There is now a marked alternative in subordinate clauses to the normal verb second order. The new paradigm is Table 12.

At the first stage, illustrated by the 12th century Scanic Ecclesiastical Law, the hwa/hwat sum is bracketed; after the reanalysis the $h w$-wh'constituent is the cohesive constituent, sum the indexical one. Umambiguous reanalysed relative $h w$-clauses may be scarce in the Danish material, but an example is (ii), with the subject and an adverbial preceding the finite verb:

(ii) cellevo iosephs brødhir the voro til honum comne, eleven Joseph's brothers they were to him come-PL.

af hwilkit som konungin oc hans hoerskap migit gloeddos of which that king-DEF and his court much rejoice-PRET.PL 'Eleven brothers of Joseph's had come to him, which was a great joy to the king and his court.'

SjT 51, 22-23

I venture to claim a division of labour between the two subjunctions at and sum, so that the former points to predicates and predications, the latter to NPs. 
Table 12. Connecting cohesion

Domain: functional positions preceding the prefield

Frame: clausal cohesion

\begin{tabular}{lll}
\hline & Expression & Content \\
\hline option 1 & $\mathrm{X} / \varnothing \quad \mathrm{V}$ & $\begin{array}{l}\text { 'unmarked' vs. 'demanding another clause to form a couplet } \\
\text { with' }\end{array}$ \\
option 2 & Subjunction & lexically specified relation to other clause \\
\hline
\end{tabular}

Table 12 is a neat illustration of an instance of a paradigm connecting a syntacticolexical option to a topological system. But the analysis can be taken one step further, namely to a purely topological paradigm attached to the paradigm in Table 12, and both must be selected. Position and subjunctions are parallel in the sense that their content articulations are similar. Not only are they instantiations of clausal cohesion, but they have a parallel coding of their positions: a 'symbolic' position precedes an 'indexical' position, see Tables 13 and 10b. Table 13 illustrates a case of parallel grammaticalisation in the sense defined in Chapter 4.

Table 13. Parallel cohesion

Domain: functional positions preceding the Prefield

Frame: clausal cohesion

\begin{tabular}{lll}
\hline & Expression & Content \\
\hline option 1 & X preceding V & $\begin{array}{l}\text { 'symbolic cohesion' preceding 'indexical } \\
\text { cohesion' }\end{array}$ \\
option 2 & Sub1 preceding Sub2 & $\begin{array}{l}\text { 'symbolic cohesion' preceding 'indexical } \\
\text { cohesion' }\end{array}$ \\
\hline
\end{tabular}

Strictly speaking, the formation of these cohesive paradigms is a case of regrammation, since it unites two already existing simple paradigms into a new complex paradigmatic structure. One original paradigm is constructional: subjunction vs. zero (no subjunction); the other one is topological: X V vs. zero V (cf. Table 9).

The resulting connecting paradigm is shown in Tables 12-13. I find it satisfactory that this major innovation in Scandinavian topology can be interpreted as a connection of already existing options within an already relevant frame of interpretation. Cohesion is far more important in understanding the older Scandinavian languages than is normally held.

One final point about the positional identification of X V and Sub1 Sub2: In Danish - but not in Swedish - the double subjunctional structure has been generalised for all dialects and for the spoken standard language to optionally occur nowadays also with subjunctions where it did not originally occur, for instance $h v$-('wh-') constituents and the interrogative subjunction om 'if, whether', and above all, to the second position of subjective IP SVO main clauses. 
a. Her vil nogen måske spørge, hvorfor at Here will someone maybe ask why that jeg fortceller jer om alt det. I tell you about all this.

'Here somebody might ask why I am telling you about all this'

Korpus DK

b. Jeg kan ikke huske hvad at sygdommen hedder,

I can not remember what that the disease is called

hvor at de far det store hul $i$ siden.

where that they get the big hole in their sides.

'I don't remember what the disease is called where they get the big hole in their sides.'

Google

(52) Gid at ens favorithold altid vandt....

Wish that one's favourite team always won.

'Wish that one's favourite team would always win'.

Google

Its function is not that of an extraclausal subjunction but of an indexical marker, and of course no longer to a cohesive symbolic element, but to the illocutionary operator of IP SVO main clauses (52), and in subordinate Subjunction SVO clauses (51ab) to the initial subjunction, not as a cohesive element, but as the general functional frame indicator of such clauses. In its modern shape, it has been adapted to the function of the clausal topological system as indicator of illocutionary frame and mood.

\section{Frame indicator $\leftarrow$ Indexical meaning \\ (IP or subjunction)}

$\begin{array}{lll}\text { Positions: } & \mathrm{X} & \mathrm{V} \\ \text { Fillings: } & \text { X vs. zero } & \leftarrow \quad \text { V finite } \\ \text { Fillings: } & \text { IP/Subj } & \leftarrow \quad \text { at 'that' }\end{array}$

I pointed above to the differences and similarities between my tables and the analyses of finite $\mathrm{V}$ and Comp in the generative account of verb second (originally by den Besten for Dutch). Generative linguists (Platzack 1985; Bjerre, Engels, Jørgensen \& Vikner 2008) have indeed stressed the possibility of transferring the substance of the V/Comp analysis to Danish topological tradition, in the sense that they claim that the generative analysis equals the topological one with respect to descriptive adequacy and exceeds it by far with respect to explanatory power. My point in the present context, however, is actually that upon closer examination, both the Old Scandinavian data and Danish topological tradition and its methodology will call for a different analysis of Scandinavian topology. In general, my aim is to do (part of) what the generative linguists do not do, 
namely to analyse the word order systems as grammatical systems (paradigms) in their own right to see what scenarios of reanalyses this may pave the way for.

\subsection{Adverbials as false friends}

Free adjuncts, for instance $(53 \mathrm{a}-\mathrm{c})$, occur in clauses that might be superficially analysed as examples of the modern subordinate clause SAdvVO order. Such adverbials are simply special cases of a much wider rule and certainly not examples of modern adverbial topology. ${ }^{89}$ They do not count as instances of the modern reanalysis, but they are certainly possible starting points for future reanalyses.

a. thet barn ther hun thaa fødho

the child that she then bore

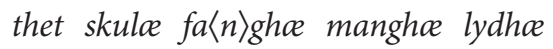

it was to have many defects

'The child she gave birth to then, that was to have many defects'.

(Luc 56v; Western Danish 1450)

b. see nw huilkon thu nw oest

Look now whom you now art

'Now look what kind of person you are now'.

(Luc 82v; Western Danish 1450)

c. at hon ey finge lifvat.

that she not get.PST-SBJV live-PRF PTCP

Pronouns occur as well in the 'new' prefield. Note again that such pronouns are cases of backgrounded constituents, not clitics.

Sicetoe er ormoe ther tøm oder bodoe bag oc force
Sixth are snakes that them eat both back and front
Relative Obj V
'the sixth is snakes that eat them from both ends'

(Luc 66v; Western Danish 1450)

89. Larsson (1931) and Skautrup (1968 [1947]) mistakenly count such tokens as first instances of modern Subj SAVO order, and their views lead Pedersen and Gregersen (2000) to state that the S(ubordinate) C(lause) W(ord) O(order) must have been initiated during the 14 th century, probably in its beginning. What we find from 1300 onwards is not modern SCWO, but its structurally different forerunner. 
The iconic information system has now been generalised and OV order is expanding. ${ }^{90}$

This alternative, marked clause pattern is one predecessor of the modern nonverb second pattern, traditionally labelled subordinate clause word order. Its transformation to the modern situation is a relatively simple matter, given the present analysis. See Section 3.7.

\subsection{The loss of OV (XV)}

The modern language has lost OV completely where valency bound constituents are concerned: all primary objects (indirect and direct), predicative complements and all valency bound PPs must be in the postfield (except, of course, for the alternative initial position):
a. vtan hon
thon swennen finge $(=47 \mathrm{a})$
b. hvis ikke hun fik den fyr (Modern) if not she had this lad the 'Unless she had this lad'

This reanalysis applies to all types of sentences and is part of a restructuring of Danish clausal structure to NP VP structure, see Section 3.7.1. The verb second parallel to (55a) is simply hun fik den fyr or even clearer: hun vil have den fyr 'she wants to have this lad', never: ${ }^{\star}$ hun vil den fyr have. Only free adverbial adjuncts retain the possibility of preceding the non-finite verb. In the modern language such adverbials can still occur preverbally in a focus position. See further Heltoft (2003). Verb second instances have the focus position next to the non-finite verb:

Hvorfor kan vi ikke $i$ vores egen baggård
Why can we not in our own backyard

leve op tilde krav, vi stiller $i$ den 3. verden?

match the demands we impose upon the Third World?

'Why can't we in our own backyard match the demands we impose upon the Third World?

Berl 28061998

In SVO clauses the focus position precedes the finite verb:

90. Diderichsen (unpublished note) says that OV frequency is increasing during the 14th century. Similarly for Swedish by Delsing (1999). This disturbing fact finds its explanation in this new clause type. 
(57)

Det er et udvalg der kun sjoeldent benytte-s.

This is a committee that only seldom use-PRS-PASs

'This is a committee only seldom in use'

Berl 28061998117

For modern instances of free adjuncts preceding negation, see Heltoft $(2003,2005)$.

\subsubsection{Reanalysis to VO-structure}

The central point of this analysis is that it offers an explanation of the 'lowering' of the finite verb and the odd positions of particles, sentence adverbial and focus operators in the SVO clause - 'explain' in the sense of offering a frame of understanding that makes use only of topological rules (fields) and constituents already necessary in the description of Old Scandinavian, and of reanalyses that are already necessary. There is no reanalysis that directly affects the position of these categories, but the whole point is that given the positional reanalysis of the relationship between complementiser and verb second, the peculiarities of the SVO clause follow automatically. An overview of this three-step change will be useful:
A. $\mathrm{OSc} \mathrm{V} 2 \rightarrow$
B. (1300) OSc V2 + subordinate clause non V2 $\rightarrow$
C. (1500-1700) Reorganisation of valency bound constituents.

The first step is the reanalysis described in $2.4-2.5$, namely the positional identification of the cohesive elements of main clauses (X V) with the subjunction of subordinate clauses. The result of this reanalysis is two subordinate clause types instead of one:

\begin{tabular}{|c|c|c|c|}
\hline V2 Mc: & & X V & Backgrounc \\
\hline $\mathrm{V} 2 \mathrm{Sc}$ & Subjunction & X V & Background \\
\hline Jon V2 Sc: & & Subjunction & Background \\
\hline
\end{tabular}

This reanalysis manifests itself through an identification of former $\mathrm{X}$ with the background positions of verb second clauses. In clauses like (39), the position X can be understood as a special case of background or focus filling, with just one constituent where more were possible (Subj $=$ Subjunction):

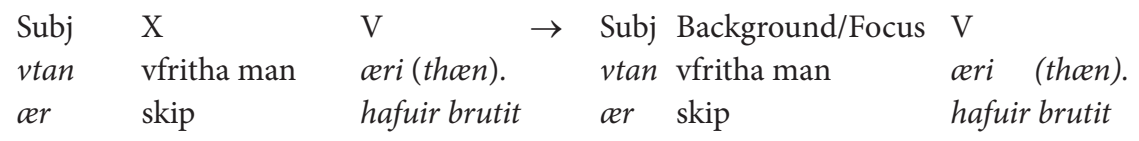

The second step is the identification of the first background position with the position for the subject. This reanalysis applies everywhere, to main clauses and to subordinate clause types alike. It leads to the obsolescence of examples like (46bc) and (49), later also of (38a) and (46a). 
Tables 14. ABC. Sentence frames of the three main stages

A. OSc V2:

\begin{tabular}{|l|l|l|l|l|l|l|}
\hline X & V & $\begin{array}{l}\text { backgrounded: } \\
\text { valency bound + } \\
\text { adjuncts }\end{array}$ & neg & $\begin{array}{l}\text { focused: } \\
\text { valency bound }+ \\
\text { adjuncts }\end{array}$ & V & $\begin{array}{l}\text { postfield: } \\
\text { valency bound + } \\
\text { adjuncts }\end{array}$ \\
\hline
\end{tabular}

B. OSc V2 + Subordinate Clause

\begin{tabular}{|l|l|l|l|l|l|l|}
\hline X & V & $\begin{array}{l}\text { backgrounded: } \\
\text { valency bound }+ \\
\text { adjuncts }\end{array}$ & neg & $\begin{array}{l}\text { focused: } \\
\text { valency bound }+ \\
\text { adjuncts }\end{array}$ & V & $\begin{array}{l}\text { postfield: } \\
\text { valency bound }+ \\
\text { adjuncts }\end{array}$ \\
\hline
\end{tabular}

\begin{tabular}{|l|l|c|l|c|l|}
\hline subjunction & $\begin{array}{l}\text { backgrounded: } \\
\text { valency bound }+ \\
\text { adjuncts }\end{array}$ & neg & $\begin{array}{l}\text { focused: } \\
\text { valency bound }+ \\
\text { adjuncts }\end{array}$ & V & $\begin{array}{l}\text { postfield: } \\
\text { valency bound }+ \\
\text { adjuncts }\end{array}$ \\
\hline
\end{tabular}

C. Modern situation

\begin{tabular}{|c|c|l|l|l|l|l|}
\hline $\mathrm{X}$ & $\mathrm{V}$ & $\begin{array}{l}\text { non-focus } \\
\text { subject > pronouns }> \\
\text { adjuncts }\end{array}$ & neg & focused: & Vdjuncts & $\begin{array}{l}\text { postfield: } \\
\text { non-subjects }+ \\
\text { adjuncts }\end{array}$ \\
\hline
\end{tabular}

\begin{tabular}{|l|l|c|l|c|l|}
\hline subjunction & $\begin{array}{l}\text { non-focus } \\
\text { subject }>\text { adjuncts }\end{array}$ & neg & $\begin{array}{l}\text { focused: } \\
\text { adjuncts }\end{array}$ & V & $\begin{array}{l}\text { postfield: } \\
\text { non-subjects + adjuncts }\end{array}$ \\
\hline
\end{tabular}

The third step relegates all valency bound constituents but the subject to the postfield, or to postverbal position, the result of which is the generalisation of the classical notion of subject - predicate structure to Danish syntax. Subject position is now typically backgrounded and to get a subject out of background function requires 'much effort' in the sense of additional constructions or operators.

I do not take for granted that NP VP structure is part of universal grammar, and that such a bipartition must therefore also lie behind Old Scandinavian syntax. The Old Scandinavian positional rules for the subject are very different from those for the modern subject, and the point is that subject - predicate structure is a historically specific development peculiar to a number of Western European languages, but not to older Indo European languages, and probably not as widespread as is often taken for granted. See Heltoft (2001a) for a more detailed exposition of the codings and development of the subject. 


\subsubsection{Details of the reanalysis to $\mathrm{VO}$}

The process sketched above as step 3 can in fact be split up into two further steps, both of which confirm the relevance of information structure as the semantic distinctions that undergo reanalyses.

After the fixation of the subject, VP reorganisation first affects complex constituents but not anaphoric object pronouns and locative adverbs, which were still found in the prefield, or better: a position for anaphoric pronominal constituents. This stage is found in the literature of the Reformation in Peder Palladius' Visitatsbog, a text where $\mathrm{OV}$ is scarce except for pronouns. The pronominal rule is presumably optional:

(58) sielff haffde hand giort det, oc sielff maatte hand det haffue Himself had he done it, and himself must he it have 'He had done it himself, and he himself must suffer it'

(Palladius 90, 35 - 91,1)

This pronominal background rule is found active up to the late 17th century, but it is not characteristic of the 18th century.
a. Der
ieg ded sagde, groed hun
meere en[d] som før
When I that said cried she more than before
'When I said that, she cried more than before'

(Leonora 56)

b. ...bleff min kiere Husbonde anfectet nat oc dag, was my dear husband attacked night and day saa ingen kand det troe eller tenke.. so nobody can it believe or imagine

'My dear husband had fits night and day, to an extent that nobody could believe or imagine'

(Brunsmand 118)

In conclusion, this part of the process has a transitional stage where only complex valency bound constituents are relegated to the postfield. Later, even this rule disappeared by reinterpretation of unstressed pronouns as clitics (with a full topological function). This late clitic rule ran counter to the occurrence of pronouns in the background position, as shown in (58)-(59) where the pronoun precedes its governing verb. In the modern language, only orders like (60ab) are possible.

(60) a. Da jeg sagde det, groed hun mere end før when I said it, cried she more than before Sub Subject Finite V Pron.Obj.

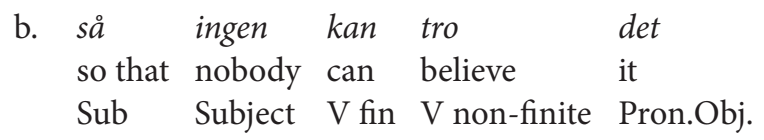


An overview of the topological rules for pronouns is given in Tables $15 \mathrm{C} 1$ \& C2.

Tables 15. C1 \& C2. Change of pronominal topology

C1. 17th century

\begin{tabular}{|c|c|c|c|c|c|c|}
\hline & & non-focus & & focused: & & postfield: \\
\hline $\mathrm{X}$ & $\mathrm{V}$ & $\begin{array}{l}\text { subject }> \\
\text { pronouns }> \\
\text { adjuncts }\end{array}$ & neg & adjuncts & V & $\begin{array}{l}\text { Complex } \\
\text { non-subjects } \\
+ \text { adjuncts }\end{array}$ \\
\hline
\end{tabular}

\begin{tabular}{|c|c|c|c|c|c|}
\hline & non-focus & & focused: & & postfield: \\
\hline subjunction & $\begin{array}{l}\text { subject }> \\
\text { pronouns > } \\
\text { adjuncts }\end{array}$ & neg & adjuncts & V & $\begin{array}{l}\text { Complex } \\
\text { non-subjects } \\
+ \text { adjuncts }\end{array}$ \\
\hline
\end{tabular}

C2. Modern situation

\begin{tabular}{|l|l|l|l|l|l|l|}
\hline X & V & $\begin{array}{l}\text { non-focus } \\
\text { subject }> \\
\text { pronouns }> \\
\text { adjuncts }\end{array}$ & neg & adjuncts & V & $\begin{array}{l}\text { focused: } \\
\text { non-subjects } \\
\text { + adjuncts }\end{array}$ \\
\hline \multicolumn{1}{|l|}{ subjunction } & $\begin{array}{l}\text { non-focus } \\
\text { subject + } \\
\text { adjuncts }\end{array}$ & neg & adjuncts & V & $\begin{array}{l}\text { postfield: } \\
\text { valency } \\
\text { bound } \\
\text { + adjuncts }\end{array}$ \\
\hline
\end{tabular}

\section{The origin of subjective main clauses}

As described in Section 2, Modern Danish SVO is used in main clauses to code a subjective (emotive) illocutionary frame. In the present section, I shall suggest that the predecessor of this type is a late medieval split between subjective emotive verb second clauses and a marked type, in origin possibly subordinate clauses in main clause use, later interpreted as a main clause pattern. I find it a plausible hypothesis that there is a separate origin for this type of clause, and that these two types were later connected with the reanalysed verb second order to form the modern paradigm, see Section 2.

Due to the character of manuscript tradition in Denmark, genres that would be expected to contain emotive main clauses are scarce (narrative prose text, legends, and oratories). Most of the early examples I have been able to track are from the early 15th century, but this is probably only accidental. In the Norse tradition, the type has probably been overlooked by grammarians and philologists, since neither Nygaard (1905) nor Faarlund (2004) seem to mention it. 


\title{
4.1 Emotive verb second main clauses and their replacement
}

In all probability, emotive main clauses were originally just a special case of verb second:

(61) hwat en stor oc moektoghir gudh oer bell! what a great and mighty god is Bell!

'What a great and mighty god Bell is!' (SjT 22; Scanic Danish. app. 1425)

Sentences like (61) are impossible in the modern language, and this pattern is today very restricted with respect to emotive reading, occurring only in clauses with a fronted $h v$ - ('wh-') degree adverbial (62a); example (62b), however, is no longer interpretable as an emotive, but only as a wh-question. Only the SVO-pattern is possible, cf. (62c).
a. Hvor er den dreng sød!
how is that boy sweet!
'How sweet that boy is'
b. ${ }^{\star}$ Hvor sød er den dreng!
c. Hvor sød den dreng dog er! How sweet that boy Particle is

Emotive main clauses could, however, follow the alternative pattern exemplified in (63ab). The oldest example known to me is (61a), from an early 14th century manuscript. (63b) is from the late 15 th century.

\author{
a. ceya hurce glath oek wrth-ce \\ Eia, how happy I become.PRS-SBJv. $1 \mathrm{sG}^{91}$ \\ thoer oek theek fang-ce \\ when I you have.PRS-SBJv.1sG \\ oc hurce sceligh oek wrth-oe \\ and how blessed I become.PrS-SBJv.1sG \\ thoer oek thoek se \\ when I you see.PRS-SBJv/IND.1sG
}

'Eia, how happy I may be when I have you, and how blessed I may be when I see you' (Harpestreng p. LXXIII; Western Danish around 1300)

91. The form wrthe is probably to be read as worthe, the present subjunctive. The past indicative worth is sometimes written wrth in the $\mathrm{K} 48$, and the formally possible past subjunctive wurthoe is less probable due to the clear present forms fangee and se. The question is not important for the topological analysis. 
b. O hwre vndherligh oc gudh thoeckeligh oc orligh $\mathrm{O}$ how wonderful and to God pleasant and famous mønster thu bygdhe! temples thou built!

Their topology is probably identical to verb second clauses with a subjunction. It remains unclear, however, if this type was actually restricted to instances with the subject in X position. All examples known to me have the subject in X. Example (64) is a completely parallel subordinate clause, with emotive function and similar syntactic structure: The $h v$ - 'wh-' clause is the direct object.

(64) See nw, hwicken løen oc tack hwn giffwer tik Look now, what payment and thanks she gives you ighen for thyn otmyghe thienesthe! back for your humble service (ML 420; Western Danish)

Their status as presumed verb second is shown in Table 16:

Table 16. Emotive verb second, MCs and SC

\begin{tabular}{lllll}
\hline & Subjunction & X & V & Background \\
\hline$(61)$ & & hwat en stor oc & ær & bell! \\
& & mæktoghir gudh & bygdhe! & \\
$(63 b)$ & O hwre... ærligh mønster & thu & giffwer & tik \\
\hline
\end{tabular}

And their status as variants is confirmed by coordinations like (65):

(65) O liiff, fulth meth snare! Hwre manghe thu snoerer $i$ wordhen! O body, full of latches! How many you latch in this world Hwre manghe lidhe hoelfwetes pyne with tik! How many suffer the torments of Hell with you! Hwre heligh han er som konner thyn falskhet... How holy he is that knows your falsity

(ML 102, 15; Western Danish 1480)

The plain verb second type soldiers on into the 16th century:

(66) O huilken sorge oc drøffuelse var $\mathrm{O}$ what sorrow and lament was thenne valsignede eenfødde søns moder vdil this blessed only begotten son's mother in! 
Example (67) is versified drama, but would nevertheless seem to count as a continuation of verb second structure.

(67) $O$ herre, hwilcken en vnderlig ting

Oh Lord, what a wonderful thing

Motte mand see $i$ then ring!

could one see in this ring

(Comedies 67, Dorothea Komedie; Western Danish 1530)

If the subjective main clause variant (63ab) is actually verb second with a (bracketed) initial subjunction, we would expect it to undergo the process reinterpreting the $h v$ constituent as the topological equivalent of $\mathrm{X} \mathrm{V}$ and hence the wedge position as a full prefield (see Section 3.4). Examples are again scarce, but an adverbial in prefield position is found in (68):

(68) O hurce manghoe thare thu tha vth giø-st

Oh how many tears you then shed.PsT-2sG

'Oh how many tears you shed then'

(Prayers I, 280; Western Danish, app. 1500)

I have found this alternation between verb second order and SVO in emotive main clauses throughout the 16th century, but we may restrict ourselves to a few prose examples:

(69) Huilche onde naboer vaare de (Verb Second)

What vicious neighbours were they

'What vicious neighbours they were!'

(Palladius 105, 22-23 1543)

(70) ah huad det er got at vandre om dagen, da støder oh what it is good to wander during daytime,

en sig icke (SVO)

then stumbles one REFL. not

'Oh how good it is to wander during the day, one does not stumble, then'

(Palladius 87, 7-8)

The emergence of a marked expression for emotive main clauses indicates the formation of a new word order paradigm. The change of this expression structure to main clause function means that the $h v$-constituent is no longer a subordinating conjunction but an illocutionary frame indicator. Or, rather: the function of the $h v$-constituent is specified through its hierarchical position. This is the first step towards the integration of hierarchical syntax and word order in a complex paradigm: 
Table 17. Emotive clauses

Domain: functional positions preceding the Prefield

Frame: emotivity

\begin{tabular}{lll}
\hline & Expression & Content \\
\hline option 1 & $h v$-constituent, in non V2 MCs & emotive illocutionary frame \\
& $h v$-constituent in all other patterns, & non-emotivity \\
option 2 & MC or SC & \\
\hline
\end{tabular}

Since this paradigm is formed parallel to the paradigm in Table 13, it is no wonder that they are partly alike. But note that while the paradigm for lexical cohesion was marked by the lexical status of the conjunction, lexical status is irrelevant in the present context since the parameters are word order and hierarchy, not lexical coding as one particular word class (subjunctions). Note, too, that the relation of markedness has been turned round to the effect that the MC, not the SC, is now the marked term.

The importance of this paradigm, as we shall see, lies in the fact that its markedness structure is in fact preserved when it is later integrated into the complex paradigm for modern Danish word order, see Section 5.1. and Chapter 2, Table 2.

\subsection{SVO main clauses and illocutionary particles}

In the 16th century, we find examples of other subjective main clauses, formed with emotive or dubitative particles. An early innovative formation of such a particle is sikken 'see what', 'what', from se hvikken 'see what' (hvikken from hvilken, again from hwilk-), see Heltoft $(2006,2007)$. This particle combines with both orders; (71a) is IP SVO, and (71b) shows both, IP SVO and verb second:

a. Sicken en inzel $^{92}$ ieg vil eder giffwe,

See what a thing I will you give

om $i$ kunne eders $k o(n) s t$ bedriffwe.

if you can your art perform

(Comedies 28; Den utro Hustru 1530)

b. Du kand icke vere saa hellig, som Nathan din Prest vil haffue dig 'You cannot be so holy as Nathan your priest wants you to be'

92. Finzel has been taken to mean 'reward', but probably without good parallels. My interpretation is substantiated in Heltoft (2007). A vulgar pun is undoubtedly intended. 
see huad det er en deylig quinde. (SVO)

Look, what it is an attractive woman

Sicke smucke huide been haffuer hun. (V2)

Look what beautiful white legs has she

'Look what an attractive woman she is, look what beautiful white legs she has'

(NH Sermon 123; 1565)

Assuming general verb second order, (71a) and (71b) would relate as in Table 15:

Table 18. Competing verb second and SVO in emotive MCs

\begin{tabular}{llllll}
\hline & Subjunction & X & V & Background & \\
\hline (71b) & & $\begin{array}{l}\text { Sicke smucke } \\
\text { huide been }\end{array}$ & haffuer & hun! & \\
(71a) & Sicken en finzel & ieg & vil & eder & giffwe \\
\hline
\end{tabular}

Assuming, however, that modern SVO order has now split out from the original verb second, the relation is as shown in Table $19 \mathrm{AB}$ :

Table 19AB. Reinterpretation of emotive MCs

A. Verb second:

\begin{tabular}{llllll}
\hline & X & V & Subject & $\begin{array}{l}\text { Free } \\
\text { advb. }\end{array}$ & V etc. \\
\hline$(61)$ & hwat en stor oc mæktoghir gudh & $æ r$ & bell! & & \\
$(69)$ & Huilche onde naboer & vaare & de! & & \\
$(71 b)$ & Sicke smucke huide been & haffuer & hun! & & \\
\hline
\end{tabular}

B. Verb second emotives reinterpreted to SVO:

\begin{tabular}{lllll}
\hline & $\begin{array}{l}\text { Subjunction/ Illocutionary } \\
\text { marker }\end{array}$ & Subject & Free adv. & V etc. \\
\hline (63b) & O hwre... ærligh monster & thu & & bygdhe! \\
$(68)$ & huræ manghæ thare & thu & tha & vth giøst! \\
$(71 b)$ & huad & det & & er en deylig quinde \\
$(71 \mathrm{a})$ & sicken en finzel & ieg & & vil eder giffwe \\
\hline
\end{tabular}

One objection might be a claim that we are just dealing with subordinate clauses in main clause use, and that this function is generally possible, cf. in English: If he was just more considerate! When we met for the first time! German: Daß du dies gewagt hast! 'That you dared do this'. This situation is found in examples like. 
(72) Herre gud at der er slig forstand

Good Lord that there is such wit

$i$ en quinde $v d j$ en land.

in a woman in a country

'Good Lord that such wit is found in a country woman'

(Randers, vol. 1, 82; Nabals Comcedia, 1600)

But note, and this will be developed further, that paradigmatisation is different from embedding or subordination. Contrasts of hierarchical syntactic relations are not by themselves a paradigmatic relation; we can claim that they are part of paradigms if we can tie them up with stable content differences and stable expression differences. Many languages allow main clause usage of subordinate clauses, given that an illocutionary interpretation can be found for the subjunction.
a. If she was just here next to me! ('wish')
b. Daß ich nicht lache! (final use of daß: 'I hope I won't laugh')
c. Naar jeg toenker paa den Aften! ('when I think of that night')

Such instances are constructional paradigms using syntactic hierarchy as the expression variable, see also Boye and Harder (2007). Some languages like Scandinavian, and above all Danish, add word order to such constructional hierarchies and, moreover, develop special particles to mark such main clauses. Sikke is one such subjective particle, mon (dubitative) and gid ('I wish') two others. Forerunners showing the basis of reinterpretation are for instance:

(74) mon iek wore bethree on alle myne foedhreno? EPIST.MODAL I be better than all my forefathers?

'Should I be better than all my ancestors?'(ML 129, 6; Western Danish 1480)
a. Mawolskee
at iek offthe thigdhe
sandhet
May (well) happen that I often kept silent truth
$i$ mith hioerthe.
in my heart
'Maybe I often concealed truth in my heart'

(ML 124,11; Western Danish 1480)

b. Mawcelske thu giorthe thet forthy at han skall May (well) happen you did it because he shall together meth thik regnerce with you reign

'Maybe you did it because he shall reign together with you' (ML 165, 15; Western Danish1480)

Some examples of gid 'wish', including one of its possible early forerunners, a version of the particle formed from the imperative form of the verb give 'give'. 
(76)

a. Giff Fanden besatt-e
wish (the) devil occupy-PRs-sBjv him
'May the devil take hold of him'

(Leonora 118, 12; 1670-1685)

b. Gii der fa-er en Dioffwel $i$ ier

wish there rush-PRS.IND a devil into you

'Wish a devil occupies you'

(Leonora 153, 18; 1670-1685)

(77) Gid I faae en U-lykke,

Wish you have.PRS-PL an accident

hvilke Skriver-Karle I ere!

what clerks you are!

'May you have an accident, what clerks you are!'

(Holberg: Den Stundesløse. Værker 6. 325)

Grammaticalisation processes have their origin in semantic innovation. In Old Scandinavian appeals to God could be formed freely in subjunctive clauses, with a well known division of labour between the present subjunctive (in hypothetical wishes) and the past subjunctive (in counterfactual wishes). An example of the counterfactual wish from Old Norwegian is.

(78) Geef-e guð sunr Mario at loken

giv.PST.SBJV-SBJV god son of Mary that ended

voer-e bin afe

be.PST.SBJV-SBjv your life-time

'Wish that God son of Mary would give that your life-time was brought

to an end'

(Indrebø 1931: 152, 18-19)

Similar examples are found in later Danish up to around 1500. Documented from the beginning of the 16th century, we find examples in Danish that transcend the semantic opposition of the hypothetically possible and the counterfactual. Peder Palladius - Lutheran bishop and supervisor of the correct faith - can create imagined but counterfactual worlds using the present subjunctive. The condemned members of a parish cry out from hell, reproaching their vicar for their ill-fate:

$O$ huilchen sogneprost haffuer $d u$ veret oß, $\mathrm{O}$ what a vicar have you been to us, du haffuer veret os en dieffuel, och iche sogneprost (...). you have been to us a devil and no vicar.

gud giffu-e-t

God giv.PRS-SBJV=PRON-N

at $d u$ haffde voret en hugorm under en gioerde... that you had been a viper underneath a stonewall..

(Palladius. 5, 82) 
This content change is a symptom showing that what was a regularly formed syntactic construction with a regular use of the subjunctive, has now taken one step towards lexicalisation. The syntagm gud giffu-e-t no longer just means 'may God give it', but its meaning has been extended to include a more general optative function also, 'wish by God' or just 'wish'. This takes place through dissolution in this syntagm of the paradigmatic contrast between the present and the past subjunctive, and later we also see sentences with an initial plain subjunctive with no mention of God: give + clause, or givet + clause.

'Bleaching' as used in grammaticalisation theory (e.g. Sweetser 1988; Heine \& Kuteva 2002; Heine 2003) would not adequately describe the present process. A better way of looking at this phenomenon is to view it as an instance of increasing polysemy followed by reanalysis and split. The original meaning 'may God give it that' has, of course, never been lost, since the expression remains in the modern language with this very meaning. In examples like (79) the newly coined meanings 'wish by God' and 'wish' are discernible within the limits of the expression Gud givet as possible variants of a polysemous sign.

Cases like the present one give rise to the suspicion that at least in some cases 'bleaching' is but a reference to an epiphenomenon that can be accurately described in other terms, in the present case an increase of polysemy. By reanalysis the more abstract sense 'wish' finds its own expression through unification of the syntagm, and this split leaves the original meaning of Gud give at behind as the only one possible in the modern language.

$$
\text { (Gud) giv-e-t > givet [gi·wəð] }>\text { gi-ed [gi·əð] }>\text { gid [gið/gi?ð/gið? }{ }^{93}
$$

So far it might seem that there is no obvious disagreement with the American functional school of grammaticalisation. But the formation of gid cannot be seen as the development of a single item or 'gram', and the strategies generally adopted and described by Hopper and Traugott and by Joan Bybee (Bybee, Perkins \& Pagliuca 1994) will fail. This description calls for the notion of paradigm formation since it is part of a larger converging set of changes. The novel lexical formation gid has its analogues: two 16th century contemporary ones, mon (dubitative interrogative particle, a reinterpreted modal verb), sikke (from se hvikken 'see what a'), later bare ('if only', from adjective bar 'bare, naked'), and a latecomer from around 1900 set 'what if' (about negative outcome, from imperative sat 'suppose'). These particles arise from very different morphological material, but they are all furnished with the function of subjective or expressive main clause marking:

93. Or, possibly, the final expression comes from a competing imperative: (Gud) giv-ed [gi?eð] > gid, but the line of argument holds no matter which interpretation is the valid one. 
$(81)$
a. Gid han var en hugorm!
'wish he were a viper'
b. Mon han er en hugorm? 'could he be a viper?'
c. Bare han var en hugorm! 'if only he were a viper'
d. Soet han var en hugorm! 'suppose he was a viper'
e. Sikke en hugorm han var!
'What a viper he was!'

These subjective main clauses contrast with the simple verb second patterns:
a. Han var en hugorm (declarative)
He was a viper
b. Var han en hugorm? (interrogative)
Was he a viper?

Clauses containing these illocutionary particles adjust to models already there, namely to emotive main clause uses of clauses with a normally subordinating complementiser. And with the rise of the category of particles, the subjective function acquires 'emic' status in that the particles provide this type of main clause with morphology of its own and mark it as a subjective main clause type. Moreover, they grammaticalise with the word order patterns already available to form a complex word order pattern, and the particles hold the position of complementisers, yet they are not subjunctions and do not occur in subordinate clauses.

\section{Conclusions and perspectives}

In this final section, a number of issues will be highlighted and conclusions drawn from the analysis.

- An overview of the main developments of word order will be given, emphasising the paradigmatic organisation of the word order systems. (5.1.)

- An alternative view of reanalysis will be considered, especially the syntactically based views of Harris and Campbell (1995) and Harris (2003). (5.2)

- No other traditions have presented a paradigmatic view of word order and of constructions as a basis for expositions of syntactic change. It will be useful to point out the characteristics of such paradigmatic changes in comparison to the features normally taken to be characteristic of grammaticalisation processes in the narrower 'cline' sense. (5.3) 
- Finally, a conclusion will be drawn with respect to the need for a paradigmatic, content based theory of grammaticalisation, in particular the need for complex paradigms and thus for connecting grammaticalisation. (5.4).

\subsection{A brief overview of the topological changes from old scandinavian to Modern Mainland Scandinavian}

An overview of the scenarios presented in Chapters 1-3 will be useful. For each reanalysis I repeat the semantic part, namely the frame reanalysed or resulting from it. And for each reanalysis I emphasise which parts of structure are affected: linear expression, syntactic hierarchy and/or paradigmatic content.

The starting point is OSc verb second, characteristic of both main clauses and subordinate clauses (A1). Subordinate clauses with a subjunction develop an alternative analysis, increasing the number and range of preverbal constituents to also comprise positions preceding the finite verb. The semantic frame of this new paradigm is clausal cohesion. The innovation is a marked subordinate clause type with a new hierarchical syntax and new ordering (B1).

A1. OSc V2 (tha sculu bøndoer biscop thre noeter føtha (35)) $\rightarrow$

B1. (1300) OSc V2 + subordinate clause non V2 (vtan hon thæen swennen finge (47a))

Emotive main clauses were from the beginning plain verb second clauses(A2), but develop a non verb second variant, and further, this type undergoes an extension parallel to the development B1. This change is probably also in part a case of analogic extension, but the result is grammation of a new paradigm. Semantic frame: emotivity. The result is a marked main clause structure with a new hierarchical syntax and new ordering (B2).

A2. Emotive V2 MCs (hwat en stor oc moektoghir gudh or bell!) $\rightarrow$

B2. (14th century) Emotive V2 MCs + Emotive Non V2 MCs (O hurce manghe thare thu tha $v$ th giøst!)

From 1500 onwards VO is generalised and subjects become obligatory with a fixed position $(\mathrm{C})$. Constituents are reorganised, to the effect that all valency bound nonsubjects go to the postfield. The semantics behind this change is the formation of categorical clause structure, the classical subject - predicate dichotomy, with its expression system NP VP.

C. (1500 onwards) OV is generally lost, VO generalised.

Rise of the modern neutral subordinate clause: the output of B1 + C.

Emotive non verb second (B2) generalises through formation of many parallels, esp. with an illocutionary particle. A subjective main clause type has been formed, in contrast to verb second (D). The semantic frame is emotivity. A lexical category of illocutionary particles provides alternative fillers of the $h v$-position. 
D. Formation of further emotive sentence types along the pattern B2 (16th century onwards, for instance: Gid I faae en U-lykke (77) )

In the 16th and 17th centuries verb second was still possible in a large number and types of subordinate clauses. The disappearance of most types of subordinate verb second clauses by the mid 18th century allows us to hypothesise that the reanalysis of verb second at the level of content takes place in the second half of the 17th century. It was reanalysed to manifest assertive frame or assertive potential and integrated with non-verb second to form a complex paradigm. By the end of the 17th century we find the integration of the emotive paradigm and the cohesive paradigm into one complex paradigm. Verb second is reanalysed at the level of content to manifest assertive frame or assertive potential and is integrated with non- to form a complex paradigm. No changes occur at the expression level of syntax and word order.

The cohesive paradigm X V vs. zero V was still active in the 16th and 17th centuries, but is also reanalysed as mood, and the frame is reality value (E).

E. Internal reanalysis of V2 (A) as Mood (late 17th or early 18th century): Loss of connective inversion during the 18th century, clauses with and initial finite verb can no longer be declarative.

F. External reanalysis as mood (late 17th century). Verb second is assertive mood, paradigmatised with $\mathrm{D}$ and with neutral subordinate clauses (see Table 5). Loss of most types of subordinate verb second during the period mid 17 th to mid 18 th century.

The result $\mathrm{F}$ of the regrammation processes is repeated here, Table 20:

Table 20 (= Table 5). Mood as word order. The Modern Danish paradigm

Domain: clausal word order

\begin{tabular}{lllll}
\cline { 5 - 5 } \multicolumn{2}{c}{ Frame: illocution } & & \multicolumn{2}{c}{ Frame: assertivity } \\
\cline { 1 - 1 } expression & content & & expression & content \\
\hline MC, V2 & assertive illocutionary frame & & SC, V2 & assertive potential \\
MC, non V2 & subjective illocutionary frame & & SC, non V2 & neutral \\
\hline
\end{tabular}

\subsection{Harris and Campbell: A non-semantic concept of syntactic reanalysis}

My claim about the change of Scandinavian verb second from Old to Modern (Mainland) Scandinavian is that it is a change of content without any change of the verb second expression system. The two major changes $\mathrm{E}$ and $\mathrm{F}$ above can be viewed as content reanalyses and regrammation of paradigms; there is no rebracketing, but only paradigmatical reorganisation. It establishes novel relations to the new subordinate clause type and to the new emotive main clause type, and these two include 
reorganisations at the level of constructional syntax. Verb second's content changes are at the level of paradigmatic organisation only, and such changes would not be accessible through an approach based on reanalyses of syntactic deep or underlying structure, like the ones proposed by Harris and Campbell (1995:51-52, 61-65), and by Harris (2003).

Other parts of the scenario consist of constructional changes, especially the reorganisation of Mainland Scandinavian as an obligatory subject language (language with a categorical subject, see Sasse 1987), in combination with the obligatory VX order of their VPs.

Harris and Campbell (1995) differentiate between five aspects of syntax: constituency, hierarchical structure, category labels, grammatical relations and cohesion, of which the first four are repeated in Harris (2003:532). Thus, the dominant view in American linguistics that syntax is an autonomous, non-semantic component is also visible in these works, but none of these aspects of syntax will furnish us with the distinctions we need.

Harris and Campbell present convincing examples of reanalyses affecting constituency and hierarchy, for instance the reanalyses leading to the German final infinitival construction illustrated in (83), rendered with its modern bracketing in (83a), with its older one in (83b):
a. Er ging heraus [um Wasser zu holen]
b. Er ging heraus, um Wasser [zu holen]

They mention that semantic change is also involved. The preposition um loses local meaning and marks the infinitival construction, but this is not their main point since they illustrate syntactic rebracketing. From the point of view of the present book, however, semantics is in principle always involved, and I would suggest that um should be analysed as the marker of finality, taken over, in fact, from the infinitival marker $z u$, originally a local preposition, in (83b) still interpretable as a marker of finality, but nowadays just the simple infinitival marker. Altogether a nice illustration that syntactic reanalysis will combine with semantic change.

Note, however, that the question of reanalysis and the question of regrammation must be kept apart, and I suspect that the present example is not a case of regrammation but a case of recategorisation to already existing grammatical structure, the model of which is (84):

Er ist herausgegangen [statt Wasser zu holen]

'He has gone out, instead of fetching water'

Grammaticalisation will include paradigmatic change, which the present example (83) would seem not to be. 
Semantics is not mentioned in Harris and Campbell's examples of category reanalysis, but must definitely lie behind in some sense, also according to them. An example is Chinese bă, an object marker that was originally a transitive verb 'take hold of', later reanalysed (Harris \& Campbell 1995:63). Whether or not they take this particle to have content or not, the change will surely be a semantic one.

Grammatical relations are exemplified as the loss of oblique subjects (methinks $>I$ think), a change that establishes - according to them - isomorphy between underlying and surface subjects, where the 'impersonal' constructions had formerly been surface object for underlying subjects. It is not clear whether this type of reanalysis will count for Harris and Campbell as an example of semantic change. I would just stress that to count as a case of degrammation it must contain dissolution of paradigmatic structure, an opposition between impersonal constructions and transitive ones. ${ }^{94}$ If just a case of surface structure assimilation, this process has another name in tradition already, namely analogy: the assimilation of expression systems by extension.

Cohesion in their sense is not cohesion in the textual sense applied elsewhere in my text, but rather boundedness, as employed by C. Lehmann (1985).

Next, word order typology is made the basis of the discussion of word order. Constructions can be changed in two ways; one is called harmony (or disharmony) by reanalysis, the other one harmony by extension (in fact, as the examples show, analogy, always an extension process that copies models). Behind their considerations lie the typologies of word order as put forth by Greenberg, Dryer and Hawkins. Headmodifier/modifier-head orders are copied throughout systems, through reanalysis or extension. In short: word order changes are studied as processes that generalise typological universals across a language, or, as they emphasise: disharmony may also arise through reanalyses that run counter to the levelling of the type. Harmony is shown in (85)-(87) (from Harris \& Campbell 1995:213), on the basis of older German alternations between Gen N and N Gen:
a. de-s
König-s Schloss
DEFART-GEN king-GEN palace
b. das
Schloss de-s
König-s
DEFART.NOM palace DEFART-GEN king-GEN

94. Discussing the question of 'oblique subjects' is far beyond the scope of the present text. From our stance, however, the idea that case forms are just expression phenomena (surface restrictions) is out of the question. 'Oblique subjects' certainly share subject properties in some languages, including the Old Germanic languages, but for the picture to be complete a semantic analysis of the function of the oblique cases will also be needed. 
This forms the model for a reanalysis of Ns to adpositions, and an extension from postposition to preposition:
a. des Königs wegen
b. wegen des Königs
a. an des Königs statt
b. statt des Königs

Of these, the older ones (86a, 87a) are now obsolete; the ones formed by extension (86b, 87b) are standard. ${ }^{95}$ The essence of this model is that syntactic reanalysis can lead to a basis for extension. And if extension copies new orders, a rule of word order has been extended to contexts where it did not originally apply.

There is no discussion of the meaning of word order systems, and in short, changes of word order systems are treated as products of reanalysis of underlying structure, and as extension. In Section 3, however, I have suggested that reanalysis can work from the content side, that is, it can take word order paradigms and their content as a starting point. Old Scandinavian subordinators were often original prepositional constructions (num thoes at 'except pron-G that', fore thy at 'for pron-DAT that', 'because'), and I have suggested that these double subjunctions should be understood as consisting of a symbolic part (Prep $+\mathrm{NP}$ ) and an indexical part pointing to its neighbouring original PP. Thus, the mechanism of reanalysis that equals subjunctions and the two initial positions in verb second ( $\mathrm{X}$ and $\mathrm{V}$ ) does so as an identification of the semantics of the positions involved regardless of the differences between the syntactic categories.

\subsection{The need for a content based approach}

It is well known that word order can express semantic systems different from case functions, namely illocutionary frame and modality, and again, relations of cohesion. In Hallidayan terms, all three main metafunctions can be expressed by word order: the experiential function (compare 'case'), the interpersonal function (mood and illocutionary frame) and the textual function (cohesion). But we have seen that the determination of exactly what is coded in word order in specific languages and stages of their development is not a straightforward matter. Old Scandinavian codes clausal cohesion, not illocutionary frame, whereas Modern Mainland Scandinavian does code illocutionary frame. Old Scandinavian does not code topicality either, if this notion is to mean something different from 'first token', but rather it codes background-focus structure. The modern language has largely limited this function where word order is concerned.

95. An example of the disharmonic model is Sanskrit antarā 'in the inner part of something', a case form of a noun reanalysed as a preposition instead of the typologically normal postposition, but good examples are scarce in this part of their exposition. 
We have also seen that grammaticalised word order systems, although they do, of course, combine with syntactic hierarchy, cannot in principle be reduced to hierarchical syntax, since they always code content and semantic similarities may cut across differences of syntactic hierarchy, as claimed in my analysis of the marked subordinate clause type, see change B1 above (5.1). Word order systems can even code content by way of order alone, without hierarchy. An example is Danish free adverbials in focus position, compared to the normal position for such adverbs. It is not convincing, either, that the distinction in Romance between Adjs in pre $\mathrm{N}$ position and Adjs in post $\mathrm{N}$ position should be bound up with differences in syntactic hierarchy.

To describe word order systems synchronically, we need to look at their paradigmatic structure. To describe the input and output of word order change, we need to compare paradigmatic systems from two or more synchronic stages.

Grammaticalisation processes of word order do not, of course, share the characteristics of the cline model. Self-evidently, there is no direct counterpart to the attrition processes of morphological development, since word order differences presuppose welldistinguishable constituents to hold positions, but do not - differences of order as they are - contain substance that can undergo tear and wear.

The idea that bleaching is always involved in grammaticalisation is a consequence of the word to affix cline. Our view of morphological grammaticalisation does not presuppose continuous bleaching, ${ }^{96}$ nor can we say about the semantics of word order grammaticalisation that bleaching processes are a necessary part. On the contrary, we have found in the study of Scandinavian (the loss of indicative zero $\mathrm{V}$ and the change to mood) that regrammation processes of semantic specification play a central part in reanalysis, in the sense that some semantic variants may be reanalysed, other variants lost, and polysemy thereby reduced.

Of course generalisation processes occur as well. In the development of Danish word order the sequence $S>$ Particle $>$ Adverbial $>$ Negation $>$ Finite V turns into the neutral pattern with no markedness articulation in itself. Such clauses get their semantic specification from lexical information (illocutionary particles and subjunctions) and from hierarchical status as main clause or subordinate clause.

Harris and Campbell (1995) present many interesting views and examples of syntactic change, but they have little to say about word order as grammaticalisation. Extensive reference is made to works on word order typology, for instance typological harmony (W.P. Lehmann 1974; Hawkins 1983); they refer to Givón's hypothesis (1979) of the unidirectionality of word order change (SOV > VSO > SVO), and to a predecessor like Vennemann (1974), and they stress the unlikeliness

96. See Heltoft $(1996,2006)$ for an example of regrammation: the content changes of the Danish morphological passive, a case of reduction where polysemy is concerned. 
of unidirectionality to apply to word order change. Throughout, word order is addressed in the sense of expression patterns, reflecting the idea of a central nonsemantic syntax. What I would stress, on the contrary, is the need for further investigations of word order coding across languages to make explicit what categories word order manifests and how this may play a role with respect to the direction of changes.

In Mainland Scandinavian, there is no loss of mood on the whole, but there is a loss of the inflexional opposition between indicative and subjunctive, and there is a redesign of the main topological paradigmatic system from cohesive word order to modal word order. And word order develops case functions as well, since subjects and objects now hold characteristic positions.

The functions of the subject cannot be dealt with in detail here (for my position, see Heltoft 2001, 2003), but even though Mainland Scandinavian develops a categorical subject structure (NP VP prototypically expressing subject argument + rheme (predicate)), this pattern remains subordinate to the function of the modal subject. Modern Mainland Scandinavian clauses must always contain at least a subject marker for the inversion of the illocutionary system to work. The subject argument can go elsewhere in the clause, or even be absent, but in such cases there has to be a subject marker (or 'dummy subject', as some schools have it) to secure the necessary function of the illocutionary subject of the illocutionary frame system.

Compare below the functional change of the topological systems from cohesion to mood and case:

Table 21. Functional shifts from Old Sc. to Modern Mainland Sc.

\begin{tabular}{lccc}
\hline Old Scandinavian & Morphological & Topological & Constructional \\
\hline Cohesive system & 97 & $\mathrm{X}$ & \\
Mood system & $\mathrm{X}$ & & \\
Case system & $\mathrm{X}$ & & $\mathrm{X}$ \\
\hline
\end{tabular}

\begin{tabular}{lccc}
\hline Modern Danish & Morphological & Topological & Constructional \\
\hline Cohesive system & $\mathrm{X}$ & 98 & $\mathrm{X}$ \\
Mood system & & $\mathrm{X}$ & $\mathrm{X}$ \\
Case system & 99 & $\mathrm{X}$ & $\mathrm{X}$ \\
\hline
\end{tabular}

All reanalyses of word order systems must have semantic correlates, and word order systems can be reanalysed from the semantic level (content level) only, that is: 
without changes of the expression system. The major examples are the reanalyses of verb second as mood.

Or word order systems can be reanalysed at the topological level only, without the direct involvement of syntactic relations. The topological reanalysis of subjunctions was the main example. In itself, its output was simply a new relationship between positions and meaning.

As expected, such purely positional reanalyses can form part of chains of reanalyses, again demonstrated by the topological reanalysis of subjunctions, which led to syntactico-semantic reanalysis as well, namely the interpretation of $\mathrm{X}$ as the first prefield.

Traugott and Dasher (2005) focus on lexical change in their search for regularity in semantic change, and consequently subjectification processes play a major role. The process of turning verb second into a mood system can certainly be viewed as a process of subjectification as well, on the precondition that a precise distinction must be observed between the functional potential of the stages and the coded borderlines of the systems. The Old Scandinavian cohesion system did not code mood and illocutionary force, but since the cohesive system included questions and conditionals as possible variants, this system could also indirectly point to these functions. In the modern system, however, both mood and illocutionary force are coded options, and if we consider these functions to be more speaker-oriented, at the level of coding we can certainly speak of the change from old to modern verb second as a process of subjectification. However, definiteness systems and focus systems are also intersubjectively functioning subsystems in the sense that they enable the speaker to signal his view of the status of referents and the status of certain bits of information in relation to the state of knowledge of the listener. These systems code different perspectives on the Speaker-Receiver relationship, and both are intersubjective systems. In many systems of adverbials and particles across languages, the cohesive functions between utterances and the modal functions are inextricably intervowen.

The point, then, is not to discuss what genuine subjectification is but to study the relations and connexions between mood, illocution, and cohesion.

97. The definite article of Old Scandinavian is treated as typologically marginal, since it is not obligatory and since its indefinite counterpart has not yet been formed.

98. The medieval topological cohesive system is replaced by a morphological cohesive system (definiteness) and a cohesive constructional system (thetic sentences, cleft sentences).

99. The medieval morphological case system is replaced by a topological and constructional case system. 
Detailed investigations of functional shifts may lead to functional typologies of grammar and of grammatical change. For an original and thought-provoking model of grammatical structure and semantic change, see Durst-Andersen (2011), who includes the importance of tense and aspect systems, a necessary extension not included here, since my main objective is the claim that grammaticalisation must be described in terms of paradigmatic structure, simple and complex, across the traditional modular borders of morphology, syntax and semantics, including semantics everywhere in the analysis of different expression systems: morphology, topology and constructional syntax.

\subsection{The need for complex paradigms and connecting grammaticalisation}

Simple paradigms or oppositions can unite and form complex paradigms, and we have defined such processes as connecting grammaticalisation, see Chapter 4. Complex paradigms, again, are to be kept strictly apart from chains of grammaticalisation, which are sequences leading from one stage to another, irrespective of the difference between simple and complex paradigmatic structure.

The final conclusion of this Chapter, then, is that all processes studied in detail in Sections 3-4 do in fact constitute necessary parts of a case of connecting processes of regrammation:
A. Regrammation of verb second as mood (Section 2)
B. Formation of a subordinate clause type with a specific word order system (Section 3)
C. Subject fixation (Section 3)
D. Generalisation of VO order for valency bound constituents (Section 3)
E. Formation of emotive main clause (Section 4)
F. Formation of emotive main clause along the lines of the subordinate clause type (B) (Section 4)
G. Formation of subjective illocutionary particles (Section 4)
$(\mathrm{B}-\mathrm{G}) \rightarrow \mathrm{H}$. The second reanalysis as mood (Section 2 )

Items B - G are all constitutive formation processes, the endpoint of which is the formation of the complex paradigm, the result of the so-called second analysis as mood (Section 2). All subparts are in themselves processes of paradigm formation (including $\mathrm{C}$ and $\mathrm{D}$, although I have not spelt out these in detail as paradigm formation since this would mean we must include an extra article on categorical and thetic clause structure). By themselves, they are cases of paradigm formation, and together they form a novel complex paradigm. Only through detailed descriptions of structure can we capture the input and output of these processes. 


\section{Sources}

Berl = Berlingske Tidende. Danish daily newspaper.

Brunsmand = Johan Brunsmand. Køge Huskors. Ed. by Anders Bæksted. København: Ejnar Munksgaard 1953.

Canute's statutes for the household (= Vederloven). Text from GL.

CCD = Corpus Codicum Danicorum Medii Ævi. I-X. Redigendum curavit Johannes Brøndum-

Nielsen. Copenhagen: Ejnar Munksgaard. 1960-1973.

Christian Pedersen = Karl Magnus' Krønike, text by Christian Pedersen 1534. Ed. Poul Lindegård Hjorth.

Comedies $=$ Tre Skolekomedier fra tiden omkring 1530. Ed. by Leif Stedstrup. Copenhagen: C.A. Reitzel.

DgL = Danmarks gamle Landskabslove. Eds. Johs. Brøndum Nielsen et al. Copenhagen 1933.

$\mathrm{GL}=$ Gammeldansk loesebog. Eds. Nelly Uldaler and Gerd Wellejus. København 1968.

Harpestreng = Harpestrong. Gamle danske Urtebøger, Stenbøger og Kogebøger. Udgivne for

Universitets-Jubilæets danske Samfund ved Marius Kristensen. København 1908-1920.

Hjorth, Poul Lindegård 1960. Karl Magnus' Krønike. Copenhagen: J. H. Schultz Forlag.

Holberg 1739 = Ludvig Holbergs Helte=Historier, Volume 2. Ed. by F. L. Liebenberg, 1-112.

Copenhagen 1868 (First Edition 1739).

Indrebø = Gamal norsk Homiliebog. Ed. by Gustav Indrebø. Oslo 1931.

Inf = Information. Danish daily newspaper.

Legend of St. Christina. Text from GL.

Leonora = Leonora Christina Grevinde Ulfeldt's "Jammers-Minde". Ed. S. Birket Smith. 3rd edition.

Copenhagen: Gyldendal 1885.

Luc $=$ Lucidarius. A Danish Teacher's Manual from the Mid-Fifteenth Century (COD. AM 76, $\left.8^{0}\right)$.

Ed. S. Kroon et al. Lund: Lund University Press 1993.

Malling 1777 = Store and gode Handlinger af Danske, Norske og Holstenere, samlede ved Ove Malling. Ed. by Erik Hansen. Det Danske Sprog- og Litteraturselskab, 19-131. Copenhagen: Gyldendal 1992. (First Edition 1777).

ML = Mariager Legendehåndskrift. Ed. by Gunnar Knudsen, for Samfund til Udgivelse af gammel nordiak Litteratur. Copenhagen 1917-1930.

NH Sermon = Humanitas christiana. Mindetaler over Herluf Trolle af Niels Hemmingsen og Christian Machabous. Ed. by F. J Billeskov Jansen. Copenhagen: C.A. Reitzel 1990.

Palladius = Visitatsbog. Peder Palladius: Danske Skrifter V. Ed by Lis Jacobsen. UniversitetsJubilæets danske Samfund. Copenhagen 1925.

Prayers = Middelalderens danske Bønnebøger I-V ed. by Karl Martin Nielsen. Copenhagen: Gyldendalske Boghandel/Nordisk Forlag.

Randers = Randershåndskriftet. En samling skolekomedier fra ca. 1600 ed. by Leif Stedstrup. Copenhagen: C.A. Reitzel. 2001.

Scanic Ecclesiastical Law. Text from GL.

Scanic Law. Text from GL.

SjT = Sjoelens Trøst (Consolatio animae). Ed. for Universitets-Jubilæets danske Samfund by Niels Nielsen. Copenhagen: Schulz.

Van Hoecke, Willy. éd. "La Rectorique de Marc Tulles Cyceron". La traduction par Jean d’Antioche (1982) du "De Inventione" de Cicéron et de la "Rhetorica ad Herennium" éditée d'après le manuscript unique. 



\title{
CHAPTER 7
}

\section{Scenarios of grammatical change in Romance languages ${ }^{*}$}

\author{
Lene Schøsler
}

\section{Introduction}

The aim of this chapter is to provide further evidence that important changes of grammar should not be investigated as isolated changes. Instead, they should be studied as connected changes of grammar, as the different parts of grammar interplay. Two different types of connection should be distinguished: firstly, changes may form chains in the sense that one is presupposed by the other, so that the first is a (non-causal) presupposition for the second to take place. This chapter will provide cases of this type, but they are not the focus of the chapter. Secondly, changes may be connected in the sense that they create or modify paradigmatically organised parts of grammar and form parallel or complex paradigms. In order to illustrate this, I will include in my investigation several grammatical elements that have not traditionally been considered to be combined. I have chosen to illustrate the connecting grammaticalisation processes as defined in Chapter 4 by means of three studies of scenarios of change that are related to non subject argument marking and to instructions for identification of referents, with special focus on French. The changes to be studied took place over some 2000 years, from Latin to the modern Romance languages. Compared to Latin, we find a larger variety of grammatical subsystems in modern Romance languages, e.g. cross-reference, extensive use of prepositions, word order, constructions, and - as in Latin - morphology and lexical selectional restrictions. The large number of grammatical subsystems in Romance languages compared to Classical Latin will

* The theoretical framework of this chapter has been developed in collaboration between the authors. The view that constructions are paradigmatically organised lies behind Hansen and Heltoft (2011) and is expressed in Christensen (2007). I want to thank also the following colleagues who have read and commented previous versions of this chapter: Henning Andersen, Ulrich Detges, Martin Maiden, Rosanna Sornicola, Roger Wright. All shortcomings are, of course, mine. 
be discussed in this chapter with focus on the role of constructions as defined in Chapter 3, since this phenomenon is not normally included in the discussion of how arguments are marked and referents identified in Latin and Romance languages. It is my hypothesis that the reorganisations of the case system following the period of Classical Latin had an impact on the organisation of sentences, among other things, in such a way that special valency patterns became linked to a special content. In the cases to be studied, case, case roles, referentiality, and patterns become connected, resulting in the creation of a number of paradigmatically organised constructions. I will test the hypothesis concerning the connecting grammaticalisation processes by investigating a number of grammatical subsystems concerning non subject argument marking and instructions for referent identification in Romance languages. My presentation is based on the following assumptions:

- Argument marking and instructions for referent identification should be described in terms of reorganisation of paradigmatic structures, or more precisely as creation and modifications of paradigms.

- If more than one grammatical paradigm (morphological, topological or constructional) are organised together in paradigms that have a common semantic frame (see Chapters 3 and 4), then they form complex paradigms, i.e. they form a case of connecting grammaticalisation.

Changes in the marking of arguments and in instructions for the identification of referents take the form of reorganisations inside a paradigm and/or between paradigms. In this chapter I intend to illustrate both types. Examples concern the marking of the second and the third argument (A2 and A3) in Romance languages.

In the following subsections of this introduction, I will provide the necessary information on the topic and on my methodology. Chapters 2, 3 and 4 have already provided illustrations of paradigmatic reorganisation and division of labour between paradigms.

\subsection{The development of the case system}

In Latin, case undoubtedly contributed to the identification of arguments, without being absolutely "necessary". Although it was probably not the main function of the nominal morphology to identify arguments, ${ }^{100}$ case was a marker on nouns pointing

100. Examining his Classical Latin corpus, Pinkster finds (1990:62) "that the marking of the syntactic and semantic function by means of a case is really necessary in less than $5-10 \%$ of instances." Detges (2009) claims that in Old French, case is not "useful". In Schøsler (2008) it is proposed that an important function of the declension system is to mark the constituents of a noun phrase by means of concord, as Latin is a non-configurative language (the term proposed in Andersen (2008:29) for this function is phrase-internal indexing). It is in fact one of 
to their function as arguments in the sentence. Instead of asking whether case was more or less superfluous, I propose in the following to explore the role of case and its relation to other parts of grammar.

\subsection{From Latin to the Romance languages}

The Classical Latin declension system was reduced, compared to the Indo-European declension system, and several oppositions had merged in some of the paradigms (e.g. the opposition between the dative and the ablative). Specific case oppositions merge due to the replacement of the distinction of quantity (short vs. long vowels) by the opposition of quality (high vs. low vowels) and the subsequent fusion of vowels, and due to the disappearance of final $-m .{ }^{101}$ In spite of this the case system is stable, and serious case confusion is not found in the texts before the end of the 2 nd century. Especially from the 3 rd century onwards, the genitive and the dative are confused, in form as well as in function, implying an extension of the original functions of these cases. From the 4th and 5th century onwards, the system is reduced to two- or three-case systems that differ to some extent between the regions. This reduction is general, in spite of the variations found, whereas the subsequent elimination of case is not. Between the 6th and the 9th centuries, nominal (with the exception of pronominal) case disappears completely in most regions, while case is preserved in Romanian, Rheto-Romance and Gallo-Romance dialects. In geographical terms, three zones can be distinguished: a central-southern zone with early disappearance of nominal case: Africa, Southern and Central Italy, and Spain; a north-western zone retaining the distinction between the nominative and oblique cases (still partially found in Rheto-Romance dialects); and an eastern zone with preservation of a two-case system opposing the nominativeaccusative form to the genitive-dative form (still existing in Romanian). ${ }^{102}$

the typical - and for a modern reader one of the most difficult - features of written Latin that the noun phrase can appear discontinuously through a sentence. The use of discontinuous nominal NPs is extensive from Early Latin (e.g. Plautus) to Renaissance and Humanist Latin (e.g. Petrarch, Erasmus, Calvin), and its frequency is related to text type, genre and style. See Schøsler and Skovgaard-Hansen (2007) for an extensive study of discontinuous NPs in selected passages from more than twenty Latin texts.

101. Examples of merger caused by the disappearance of phonetic distinctions are the opposition between the nominative of the first declension with a short $a$, the accusative with a short $a$ followed in writing by $m$, which disappeared, and the ablative with a long $a$, e.g. nom.sg. mensa, acc.sg. mensam, abl.sg. mensā; in the third declension, merger of es and is, accusative plural and genitive singular, respectively, e.g. montis, montes, and the merger of accusative singular with ablative singular: montem - monte. See further examples e.g. in Penny (2002:116-117).

102. For an excellent short account of the development from Latin to Romance languages, and balanced analyses of interacting factors, see Herman (1998), (2000) and Maiden (2000). 
Probably alongside the disintegration of the Latin case system, all the ancestors of Modern Romance languages gradually adopted a continuous noun phrase, which is a prerequisite for the existence of grammatically (rather than pragmatically) motivated word order rules. It has been proposed that the basic order of Latin was SOV, whereas most modern Romance languages have the order SVO. These generalisations have been much debated, and none of the languages are "pure" examples of these types. Even so, it is generally accepted that Latin word order does not provide information about argument structure; it is more likely that Latin word order expressed pragmatic distinctions. I shall return briefly to word order in Section 2 and in the Conclusion (Section 5).

In the course of the gradual disintegration of the nominal case system in Late Latin, important changes took place. According to the traditional account of the development from Latin to the Romance languages, case was replaced by prepositions and by word order rules, the latter especially relevant for French. The traditional positions have been shown to be incorrect (see references in Schøsler 2008), especially because of chronological inconsistencies. As I see it, traditional accounts of these changes have, wrongly, linked two synchronic analyses in an alleged causal relation. Let me consider, as an illustration, declension and word order. The first traditional claim runs like this: The main function of the Latin case system is to identify arguments. The second claim is: word order is used to identify the arguments in, e.g. Modern French. The alleged causal link is that the loss of the first caused the appearance of the second.

Both accounts sketched above are incorrect for factual reasons, but this line of thinking needs to be discussed further before it can be rejected. The underlying assumption is that important functions in grammar, such as the marking of arguments and instructions for the identification of referents, depend on fragile markers that may deteriorate and vanish, leaving behind them a defective grammar in search of new markers. I do not agree with this view; on the contrary, I find it more plausible to think that important functions are marked by various, connected, grammatical subsystems, and that these may gain or lose importance during the history of the language. Illustrative cases supporting this view are found in the previous chapters. My hypothesis concerning the changes of grammatical subsystems for marking arguments and identifying referents is that these can be described as major shifts in argument marking, or, in Henning Andersen's terms (Andersen 2008:29), shifts in case-role indexing, as these

A fine discussion of different approaches to the many problems related to the development of the declension system is found in Sornicola (2007) Section 3. A speculative presentation of the development of case and constructions in Proto-Romance is found in Dardel (2001). 
markers point to specific case roles. ${ }^{103}$ I believe that with respect to case-role indexing, the Romance languages preserve, increase and innovate compared to Latin:

1. they preserve the marking of arguments and identification of referents by means of case, since case never completely disappeared in Romance languages; case is still present in all languages, especially in the pronominal system;

2. they increase the use of specialised constructions, and they increase marking and identification of arguments by grammaticalising and extending the use of prepositions;

3. they innovate by introducing cross-reference and by introducing word order rules.

The grammatical subsystems mentioned in 1. to 3. are found in all Romance languages. They are organised in paradigms, some of which are simple, others complex. Their relative importance depends on language-specific conditions that should be studied for each language. In the following sections I will go into detail with a few exemplifications only. The common denominator of the examples to be studied is that they illustrate changes of paradigmatically organised constructions that are connected to other expression systems. I will elaborate on constructions in the following subsection. In Section 2, I will investigate the intricate complex of connected changes in the Romance languages with relation to the marking of the third and the second argument (case, prepositions, cross-reference and the lexical distinction \pm animate). This is my most complex change scenario. In Section 3, I will follow the scenario of the creation of a construction paradigm with the dative as second argument in French (involving case and the lexical distinction \pm animate). This is a clear illustration of connecting grammaticalisation. Thus, in Sections 2 and 3 I analyse reorganisations inside and between paradigms. In Section 4, I will focus on successive constructional changes in French linked to the alternation between an expressed and an unexpressed second argument (involving the lexical distinction \pm animate), i.e. on reorganisations inside a paradigm. Thus, this chapter addresses not only broad and complex questions concerning argument marking, but also specific and detailed ones. The sections will also show the increasing importance of the distinction \pm animate (or \pm human) in all Romance languages. This distinction is related to the observation that animate arguments are prototypical subjects, but also frequent non-subject arguments. The changes will be studied

103. The term case role is used for argument marking and for subspecification of certain arguments, such as patient, recipient, experiencer, etc. 
as scenarios of innovation, and I will propose plausible diachronic correspondences between interdependent synchronic stages separated in time. ${ }^{104}$

\subsection{Constructions}

The progressive merger of the different oblique forms and, in many geographical areas, the merger of the nominative and the oblique forms, led to a situation with reduced formal distinction between the three arguments subject, direct object and indirect object, labelled here first, second, and third argument (A1, A2, A3). I will show that Latin constructions are part of the paradigmatic organisation of argument marking. An example is the marking of A3 in cases like mitto litteras Romam/ad Romam, Herennio/ ad Herennium ('I send letters to Rome/to Herennius'), with paradigmatically organised alternation possibilities between the accusative form (Romam, Herennium) indicating the goal of the transfer ( \pm the preposition $a d$ ), the goal being a location or a person, and the dative form (Herennio) indicating the recipient, to be discussed in detail in Section 2 of this chapter. During the period from Latin to the modern Romance languages we find an interesting increase in the number of constructions, a point that has not yet been investigated by Romance historical linguists. Before exploring the development of paradigmatically organised constructions during the last two thousand years, I will provide further motivation for the constructionist view already presented in Chapter 3, as opposed to a lexicalist view (Section 1.3.1), and specify the differences between my view and those presented by other constructionists (Section 1.3.2).

\subsubsection{Lexicalist account or constructionist account?}

Within a functionalist approach to grammar, there are at least two possible ways of describing the organisation of sentences: a lexicalist account, based on the valency patterns of the verbs, or a constructionist account, as proposed here. The traditional account is lexicalist, implying that the combinatory possibilities of a given verb are part of its lexical description. According to this account the semantic representation of a lexical item determines the syntactic environment in which the item occurs. General projection principles from lexicon to syntax will normally be formulated, as well as general constraints on syntactic well-formedness, see e.g. Taylor (1998: 189), referring inter alia to the lexicalist accounts by Levin and Rappaport Hovav (see, e.g., Levin 2003 and Levin \& Rappaport Hovav 2005). A strict lexicalist approach implies that quantitative and qualitative differences should be accounted for by means of different lexical entries. In other

104. I am, of course, aware that the analyses of synchronic stages are only partly comparable, because there is only written evidence in Latin and in the old periods of Romance languages, whereas I will draw upon both written and oral evidence in recent periods. 
words, a traditional lexicalist presentation of the alternating constructions discussed in Chapter 3 would result in a description of different verbs.

A strict lexicalist approach has at least the following two disadvantages: first, it leads to a counterintuitive proliferation of homographs or to uncontrollable polysemy; ${ }^{105}$ secondly, and more importantly, it makes it difficult to uncover interesting similarities of patterns, such as those presented in Chapter 3, e.g. that Danish brainstorme may construe like skyde, and it makes it difficult to describe these interesting similarities in a more general way, rather than mere resemblances between individual lexical units. As convincingly argued by Stefanowitsch and Gries (2003:236), no significant associations between syntactic structures and specific verbs should be expected if these structures served as meaningless templates waiting for the insertion of lexical material. I am convinced that a more abstract level of the organisation of sentences than the lexical level is needed, i.e. the constructional level of syntax.

\subsubsection{Definitions of constructions}

Constructions have been defined as symbolic combinations of a syntactic element and a semantic component organised in grammar in a taxonomic hierarchy. Put differently, "a construction is any linguistic expression, no matter how concrete or abstract, that is directly associated with a particular meaning or function, and whose form or meaning cannot be compositionally derived." (Stefanowitsch and Gries (2003:212), see also Goldberg (1995) and Croft (2001:60)). Construction Grammar (CG) holds morphemes, words, idioms, and grammatical categories to be constructions. Per definition, as correctly pointed out by Noël (2006:9), grammaticalisation, as a change from lexical to grammatical, is not an issue in CG. I do not share the general CG view, and I do not find it useful to extend the term construction to simple or complex words (labelled atomic and complex constructions, respectively, by Croft and Cruse (2004:255)). I believe that if used too extensively, the term construction will lose its explanatory power. Instead, I will propose a narrow definition of constructions, which implies that I am not a constructionalist in the general CG-sense. I find the term construction superfluous or even misleading at the level of morphemes, words and idioms. As explained above, I find it useful to distinguish between the level of the individual lexical verb (labelled substantive

105. The constructionist approach has been formulated directly in opposition to strict lexicalist approaches. Goldberg (1995) rightly devotes important parts of her study to rejecting the multiplication of lexical entries found in the lexicalist approaches. She convincingly argues against the lexicalists (represented by Levin and Rappaport Hovav and Pustejovsky), even when they try to avoid these problems, see e.g. her Chapter 7. This line of argumentation from constructionalists against lexicalists appears to have convinced some lexicalists, see e.g. Levin and Rappaport Hovav (2005). 
constructions by Croft and Cruse) and the level of grammar, corresponding to the level of sentences in CG, and I will use the term construction only in the latter sense as defined in Chapter 3, summarised here for convenience:

- A construction is a complex sign with an internal syntax and a semantic coding

- Its grammatical status is defined by its position in a paradigm (one or more)

- Like in morphology and in topology, a constructional paradigm has both a domain and a frame

- The domain of a constructional paradigm is the syntagmatic context in which the paradigmatic relations between two or more constructions apply

- The frame is the common semantic denominator for the paradigm (its conceptual zone, 'Begriffszone' in Hjelmslev's sense)

- Its language-specific expression is linked to a language-specific content.

Goldberg (1995) expressed the view that simple clause constructions encode basic experiences of humans, especially those with dynamic events, such as someone transferring something to someone else, someone causing something to move or change state, someone experiencing something, something moving, etc. It is probably uncontroversial to propose the existence of a universal cognitive level, but the cognitive level should be distinct from the level of constructional content. Our view on constructions differs from that of Goldberg's, because we believe that constructions link together language-specific expressions of a content that is not universal, but language-specific, as shown in Chapter 3. Constructions can be transferred to verbs in such a way that these verbs acquire a new meaning in addition to their basic lexical meaning, if they adopt this construction. In other words: constructions have a specific content that is transmissible or inherited, as exemplified in Chapter 3. In the following, I will briefly discuss how constructions come into existence and how they are accepted by verbs. I will also consider the relation between different constructions in order to clarify the differences between our conception of constructions and the general constructionist way of seeing things.

Let me first consider the acquisition of constructions. According to Goldberg (1998:209), constructions are "abstractions over the particular semantics of learned instances with particular verbs". The high frequency of particular verbs in particular constructions allows children to note a correlation between the meaning of a particular verb and the construction itself. More explicitely stated by Tomasello (2003: 8):

Human beings use their linguistic symbols together in patterned ways, and these patterns, known as linguistic constructions, take on meanings of their own deriving partly from the meanings of the individual symbols but, over time, at least partly from the pattern itself.

I agree with Noël's interpretation of Tomasello's statement as a description of the emergence of constructions in a language. I will talk about grammaticalisation of a 
construction when referring to the emergence of a construction, implying that it has achieved a grammatical status instead of a lexical (i.e. valency) status.

Verbs may adopt a construction that they did not have before. This is only possible if the verb is semantically compatible with the meaning of the construction. This is convincingly illustrated by Stefanowitsch \& Gries (2003) and Gries \& Stefanowitsch (2004) in their corpus investigations of different constructions, e.g. of English ditransitive structures, and by Hummel (2004) in his study of Romance meteorological verbs, which are found with an astonishing variety of patterns and with a systematic change of meaning linked to the change of patterns.

As I see it, verbs are normally used with their specific valency patterns, but when used in a different pattern, they acquire the meaning conveyed by this pattern. This has been illustrated in Chapter 3 e.g. by means of the Danish verb kommentere 'to comment. We have interpreted cases like these as arguments in favour of the view that the pattern has acquired a meaning of its own, irrespective of the individual verb that instantiates it. In other words, it has become a construction.

When do we know whether a syntactic string is indeed a construction? We have stated in our definition that a construction must be a member of a paradigm, i.e. that there is a formal opposition between at least two members belonging to the same semantic frame. This urges me to discuss the relation between constructions. I will mention two types of relations, alternating ones and opposed ones. The Danish examples cited in Chapter 3 (skyde, knoekke etc.) are alternating constructions. It is superfluous to try to determine which is more basic than the other; what is interesting about alternations, is to determine their individual content, including the aspectual or informational specificities of each member of the alternation pair. Alternating constructions have been described in Chapter 3 as members of a paradigm, because the choice between one of two (or more) expressions implies the choice of a specific content. The nature of the semantic relation between the constructions is an onomasiologic one: the members of the paradigm share a common meaning (i.e. they have a common semantic frame). Constructions that are not alternations are opposed to other constructions in a more abstract way; for example the direct transitive construction as opposed to the ditransitive one. If no paradigmatic relation is found, it is not a construction. This is a new and "strong" definition of constructions, presented in Chapter 3, to be illustrated in this chapter.

\subsubsection{Views on how constructions come into existence and how they may change} Frequency is crucial for the acquisition of constructions according to Goldberg (1998: 209). In the following, I want to take a closer look not only at how constructions come into existence, but also on diachronic aspects of constructions. In their analysis of conversational English, Thompson and Hopper (2001) mention two aspects that are relevant for my topic, i.e. the relation between the expression and the 
content of constructions, to which they refer with the term schemas, and the question about their origin. However, the authors do not seem to distinguish the two aspects. It seems that frequency is put forward as an argument for the creation of the link between expression and content, not only with respect to acquisition, but probably also with respect to changes over lifetime. ${ }^{106}$ Frequency is undoubtedly important for the acquisition of constructions by children, but it is a weak argument for the origin of constructions, since it does nothing more than raise another question: why are some schemas (or constructions) more frequent than others in the first place? Moreover, it is not clear whether frequency is to be conceived in terms of types or of tokens; apparently both are relevant, but are not always clearly distinguished. The point that constructions are the result of a historical development - a view which is only implicit in the quotation from Thompson and Hopper (2001:47) - is explicitly taken up by Tomasello (1998: xviii):

All constructions, whether composed of one word or of many words in specific orders with specific markers and intonations, and at whatever level of abstraction, derive from recurrent events or types of events, with respect to which the people of a culture have recurrent communicative goals. Because they are formed this way historically, they exhibit prototypical structure just like other cognitive categories and schemas. Thus in English, the basic transitive construction has as its prototype utterances such as He broke the vase in which an animate actor does something to cause a change of state in an undergoer (Hopper \& Thompson 1980). But the construction over historical time has been extended to other, less prototypical situations in which the 'force dynamics' are not so clear or are only metaphorical, as in, for example, John entered the room and The car cost $\$ 400$. In German ... the transitive construction has stayed much closer to the prototype.

Tomasello only touches on the fact that, in general, constructions are the result of diachronic processes. We have seen above that scholars refer more or less explicitly to a historical process (Goldberg (1995), Tomasello (1998: xviii), Thompson \& Hopper (2001), Croft (2001), and Croft and Cruse (2004)). However, such processes

106. "[T]he sense of a verb or predicate is related to the lexico-grammatical schemas that it can occur in and argument structure can be seen as essentially a subset of these schemas" (Thompson \& Hopper 2001:48) - and further: “... predicate 'meanings' can only be understood as including a vast range of semantic and pragmatic associations regarding the sorts of activities, states, and participants that can invoke their use ... these 'meanings' are actually generalizations from many repetitions of hearing predicates used in association with certain types of human events and situations over the course of a person's lifetime. What appears to be a fixed 'structure' is actually a set of schemas, some more 'entrenched' (Bybee 1985, 1998; Langacker 1987) than others, arising out of many repetitions in daily conversational interactions." (Thompson \& Hopper 2001:47). 
have hardly been explicitly investigated by CG-scholars as already pointed out by Noël (2007), although this could legitimately be expected. To my knowledge, only a small number of scholars working in the framework of grammaticalisation have proposed combining CG and historical linguistics, so this is a fairly recent field of research. Radical Construction Grammar (RCG), in contrast to the CG of Goldberg or Fillmore, Kay and O'Connor, is designed in such a way that it can account for diachronic changes, see Traugott 2008a:223-4. In her 2007 and 2008 papers, Traugott exemplifies Croft's model in an interesting way. However, as already stated, we have preferred a "strong" version of CG, which differs from "standard" CG, especially by proposing a paradigmatic organisation as a prerequisite for constructions. The existence of a constructional paradigmatic relation depends on the presence of an opposition between complex signs. As said above (Section 1.3.2), paradigmatically organised constructions share a syntagmatic domain and belong to a common semantic frame. Thus, constructions - being members of paradigms - will have a systematic relationship between content and expression, to be studied through applications of the commutation test. A paradigmatic ordering of constructions has the advantage - among others - that it permits the separation of the different types of constructions that have been proposed in CG (Traugott 2008b): constructs, micro-constructions, meso-constructions, and macro-constructions. Compared to our model, these types correspond more or less to three steps of our analysis, as the tokens (constructs) are realisations in the usage of valency patterns, labelled micro-constructions or substantive constructions, which instantiate (schematic) constructions in the CG terminology. The latter have a syntagmatic context in which the paradigmatic relations between two or more (schematic) constructions are organised, and this syntagmatic context we have labelled the domain of a constructional paradigm. ${ }^{107}$ Put differently, we distinguish between usage (parole) and structure (langue); paradigmatically organised constructions belong to the level of structure.

Now, if our purpose is to combine a constructionalist approach and a grammaticalisation approach, it should be explained in which sense constructions are integrated into grammar, and more specifically in which sense the grammaticalisation process "entails a semantic change towards a more grammatical meaning", as Noël (2006:11) puts it. Indeed, if grammaticalisation processes are described according to the traditional cline (see Chapter 1), constructions are not easily included. In contrast, our view on grammaticalisation as presented in the previous chapters permits the integration

107. In contrast to our model, "standard" CG treats all linguistic elements: morphemes, words, and clauses as constructions, and studies individually these entities. Moreover, according to "standard" CG, these linguistic elements are supposed to be stored in the lexicon, they are not part of a grammar. 
of constructions into the grammar and the specification of their "grammaticalised" meaning.

How can we proceed in order to uncover the emergence and, possibly, the reorganisations of paradigmatically organised constructions? I believe that the only way to do this is by means of successive synchronic investigations. I do not agree with the view presented in Sornicola $(2007: 12)$ that a diachronic investigation based on synchronic analyses implies that diacrony is subordinated to synchrony. On the contrary, I find it difficult to imagine diachronic analyses without systematic synchronic ones: we cannot provide the historical perspective without adequate "photographs" of the past. From a variational point of view, synchronic variation or gradience is an important and valid link to diachrony. These perspectives shed light on each other, without distorsion of methodology.

\subsection{Conclusion of Section 1}

In Chapter 3 we proposed a scenario for the creation of constructions as part of the grammar, in a series of reanalyses, and in the following three sections I intend to provide detailed analyses of the emergence and reorganisations of different constructions. The common denominator of these analyses is that they concern constructions with a second argument (A2), firstly opposed to the third argument, secondly the oppositions of case marking of the second argument, thirdly oppositions of expressed and non expressed second arguments. In this way I hope to contribute to the further development of the constructionist approach. Moreover, there have been only few, and exclusively synchronic, constructionist studies of Romance languages; the following sections are intended to fill this gap. In sum, the aim of the following is threefold: to propose scenarios of change from Latin to Romance languages with special focus on the emergence and change of constructions, to show that these changes should be analysed as cases of connected grammaticalisation, and to contribute to further theorising on constructions and on grammaticalisation.

\section{An illustration of connecting grammaticalisation processes: The marking of the second and the third argument}

This section is intended to present a number of intricate, combined changes of nonsubject arguments in Romance languages. The common denominators of these changes are: constructions and paradigmaticity. More precisely, I will study the regrammaticalisation of the markers of the second argument (A2) and the markers of the third argument (A3), and the identification of their referents. This section will focus 
on the development from Latin to Modern Romance languages and is based on the following principles:

- in order to understand the development from Latin to Modern Romance languages, one must investigate whether the marking of A2 and A3 is integrated in the organisation of constructions;

- the marking of A2 and A3 must be considered, not in isolation, but in their interaction with other parts of grammar;

- we must proceed by means of successive synchronic investigations in order to uncover the different structures; the result of the synchronic investigations should take the form of stages, i.e. of interdependent steps;

- we must distinguish two different types of relation between changes: firstly, changes may form chains in the sense that one is presupposed by the other, so that the first is a (non-causal) presupposition for the second to take place. Secondly, changes may be connected in the sense that they create or modify paradigmatically organised parts of grammar and form complex paradigms. This section will illustrate both types, but the focus will be on the second type.

I intend to show that one cannot fully understand the reorganisations of the marking of complementation with respect to A3 and A2 that have taken place during the period from Latin to the Modern Romance languages without taking into account at least three changes that will be discussed in this section. These are related in the two ways distinguished above. The phenomena will be discussed in chronological order of appearance: the development of the markers of the third argument (A3, Section 2.1) $)^{108}$ and the development of the markers of the second argument (A2, Section 2.2). The third change concerns the development of cross-reference, i.e. the representation of the argument by means of clitic pronouns (Section 2.3) providing additional marking of arguments or cross-clausal indexing (see Andersen 2008:29). It is my claim that these changes are best described as modifications of paradigms with the same semantic frame, cf. Chapter 3 . The modification of the paradigms will be described in a number of stages from one to four. The distinction between the stages is based on the paradigmatic status and structure of A3.

108. For the sake of clarity I shall focus on each development separately. A different construction with the dative as A2 will be studied in Section 3 of this chapter. 
2.1 The development of the dative as marker of the third argument in Romance languages

\subsubsection{Latin, stage 1}

Latin had a number of trivalent patterns (see e.g. Happ 1976). ${ }^{109}$ In the following, a particular focus will be on verbs of transfer.

A typical pattern in Latin for trivalent verbs of transfer was that A2 took the form of the accusative and A3 the dative case. Examples are dare 'to give', see (1a); and adimere 'to take away'. The dative of A3 is preserved in passive constructions, see (1b):

(1)
a. fili-a
$d a-t$
mihi
coron-as
daughter-NOM give-PRS.3SG me.DAT crown-ACC
'[his] daughter gives me the crowns'

(Plautus, Aulularia vv.23-25 (Christol 1998a: 482))
b. quid Amphitruon-i a Telebo-is
what-NOM Amphitryon-DAT by Teleboians-ABL
datum est
give-PTCP be-PRs.3sg

'what has been given to Amphitryon by the Teleboians'

(Plautus, Amphitruo, v.418 (Christol 1998a:482))

However, we also find verbs of transfer with an accusative-ablative pattern: afficere aliquem aliqua re 'grace someone (accusative) with something (ablative)'. Sometimes the same lexical verb displays the two patterns; e.g. the verb donare, see examples (1cd), quoted from Pinkster (1990:50, examples (28)-(29)):

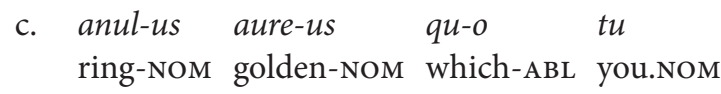

ist-um in contion-e dona-v-isti

he-ACC during meeting-ABL endow-PRF-2sG

'the gold ring with which you endowed him during the meeting'

(Cicero Ver. 3.185)

d. Gabini-us, cu-i regn-a omni-a

Gabinius-NOM who.DAT kingdom-ACC all-ACC

Syr-orum ... dona-ra-s

Syrian-GEN give-PST.PRF-2SG

'Gabinius, to whom you had given all the kingdoms of the Syrians'

(Cicero Dom. 124)

109. As defined in Section 1 of this chapter, the term pattern designates the (lexical) level of valency. It is opposed to the construction level. 
We find comparable constructions with the verb circumdare; see the constructed examples (1ef) (quoted from Van Hoecke 1996:29) where the direct object in the accusative form denotes either the wall (1e) or the city (1f):
e. circumdare mur-um urb-i
put around wall-ACC city-DAT
'to put a wall around the city'
f. circumdare urb-em mur-o
put around city-ACC wall-ABL
'to surround the city with a wall'

The traditional account is that the dative should not be seen as a semantically delimited case; see Van Hoecke (1996: 18): "Investigations of the uses of the dative ... lead to the conclusion that in Latin the dative is not really a "dative", a casus dandi, indicating attribution." On the one hand, the dative is one of several ways to indicate the recipient, and on the other hand, the dative has many other functions. According to the statistical study of Latin texts by Pinkster, the dative had the function of A2 almost as frequently as it had the function of A3. As Pinkster finds no clear syntactic motivation for the case distribution of arguments, he suggests that semantic and pragmatic differences are involved. A similar opinion is found in Van Hoecke (1996:32) and Christol (1998b:755). However, our conception of how grammar is organised motivates me to undertake a closer inspection of alternating patterns in Latin in order to look for content distinctions which are linked to expression distinctions, i.e. examples of constructions.

Latin verbs of transfer expressing A3 in the dative are also found with an alternative prepositional pattern, with the prepositions in or ad governing the accusative. ${ }^{110}$ Examples include adferre 'to bring', distribuere 'to distribute', mittere 'to send', offerre 'to offer', and tradere 'to hand over'. There has been much discussion as to the origin of the prepositional pattern, which probably began with the concrete locative use. Thus the prepositional pattern started with verbs indicating a concrete movement of transfer to a person or to a location (e.g. adferre, mittere), see Christol (1998a: 481 ff.) for an analysis of the reinterpretation from concrete to abstract transfer. In Classical Latin, the variation is seen as one between a concrete (prepositional) vs. abstract (dative) transfer (Théoret 1982:42), or between an inanimate (prepositional) vs. animate (dative) argument. However, as pointed out by Théoret, these two tendencies often interact. According to Théoret $(1982: 58,62)$ these distributions are just tendencies, not clear patterns. Both are found with nouns and with pronouns. With pronouns, there seems

110. Examples are already found in Plautus (Selig 1991:198); see further examples in Christol (1998a:482). Théoret has studied 28 verbs of this type in Cicero. He found 337 occurrences with the dative and 325 with the prepositional construction (Théoret 1982:41). 
to be a tendency towards the use of the dative when referring to animates and use of the prepositional pattern when referring to inanimates. Théoret's examples are quoted as (2ab). An often quoted example from Cicero is $(2 \mathrm{c}) .{ }^{111}$
a. responde-b-o
ad $e-a q u-a e$
$\operatorname{dix}[\mathrm{k}-\mathrm{s}]-i s t i$
answer-FUT-1SG to these-ACC.PL that-ACC.PL say-PRF-2SG

'I will answer to the things that you have said' (Cicero, Pro Plancio 58)

b. qu-ae magnitudo

what-NOM.sG abundance-NOM.SG

obseruanti-ae tot tant-isque benefici-is

observance-GEN.SG so many so great-DAT.PL=and favour-DAT.PL

respondere poterit

respond be able-FUT.3sG

'which abundance of observance will be able to respond to so many and so great favours'

(Cicero Post red. in senatu, 24)

c. scrip-s-i etiam ad Camill-um

write-PRF-1sg also to Camillus-ACC

'I have also written to Camillus'

(Cicero, ad Atticum V,8)

I believe that the unclear tendencies described by Théoret probably reflect ongoing reorganisations having as result a paradigmatic structure; this is presented in Table 1 and illustrated with the verb mitto 'I send' in the constructed examples ( $2 \mathrm{~d}-\mathrm{g})$ :
d. mitt-o
litter-as
Rom-am
send-PRs.1sg letter-ACC.PL Rome-ACC.PL
'I send letters to Rome'
e. mitt-o litter-as ad Rom-am
send-PRS.1SG letter-ACC.PL to Rome-ACC.SG
'I send letters to Rome'
f. mitt-o litter-as Herenni-o
send-PRs.1sg letter-ACC.PL Herennius-DAT.SG
'I send letters to Herennius'
g. mitt-o litter-as ad Herenni-um
send-PRs.1sG letter-ACC.PL to Herennius-ACC.SG
'I send letters to Herennius'

I interpret this situation in the following way: in Classical Latin we find variation with trivalent verbs of transfer between a dative and a prepositional pattern, the former

111. If not otherwise indicated, Latin examples are quoted from electronic Latin sources and from Lewis \& Short (1879), see Sources at the end of this chapter. 
being the original unmarked one, and the latter coming into use mostly in order to express concrete transfer towards a goal or abstract transfer with inanimate arguments (Théoret 1982:56). Thus, we see e.g. mitto combine with an accusative or with the preposition $a d+$ accusative when it indicates the goal of the transfer, for example (ad) Romam (2de). However, a person can be seen as a place, hence the pattern ad Herennium $(2 \mathrm{~g})$, where the person is seen as the goal of transfer. In Classical Latin the relation of markedness is such that the dative form (Herennio) is the default option, i.e. the unmarked option; the prepositional pattern (ad Herennium) is the marked one. This relation of markedness is to change at stage 2 of the development in such a way that the prepositional form becomes the unmarked one. In connection with this change, the local prepositional use is reanalysed. The result of this reanalysis is the interpretation of the prepositional pattern (exemplified here by ad Herennium) as non-local, i.e. as an equivalent to the dative Herennio.

Table 1 presents the structure of transfer illustrated by mitto $(2 \mathrm{~d}-\mathrm{g})$ in the form of constructions organised as a paradigm, because the alternation of expression between the dative, the accusative, and the prepositional form is linked to a predictable change of content. The content is, however, clearly related. These alternative possibilities should be seen as the first step from a purely morphologically structured paradigm, based on the distinctions of case, towards the organisation of the paradigms that we will find in the next stages of the development, where case and construction (here a PP-construction) collaborate and express the same content or semantic frame: that of transfer of an item to a recipient.

Table 1. The paradigmatic structure of transfer illustrated by $(2 \mathrm{~d}-\mathrm{g})$

Domain: V A2 [A3]

Frame: transfer of $\mathrm{A} 2$ to $\mathrm{A} 3$

\begin{tabular}{ll}
\hline Expression of A3 & Content of A3 \\
\hline dative form of NP & recipient \\
$(a d+)$ accusative form of NP & goal \\
\hline
\end{tabular}

The paradigm presented in Table 1, with A3 expressed by a dative (2f), an accusative (2d), or a PP (2e og $2 \mathrm{~g}$ ), represents just one of several ways of expressing the relation between three arguments. In order to illustrate the different trivalent patterns of Latin, I will compare the pattern of verbs of transfer to two other patterns exemplified by verbs of jurisdiction and verbs of communication. Verbs of jurisdiction include verbs like accuso 'I accuse', condemno 'I sentence', absolvo 'I acquit', arguo 'I prove', typically governing the genitive (the accusation) and the accusative (the person concerned), see example (3a). Verbs of communication include verbs governing two accusatives, the person addressed and the topic, such 
as verbs meaning 'I teach' (doceo), 'I ask' (rogo, oro, imploro, quaero), 'I demand' (flagito, posco), etc.; see example (3b). I have shown that verbs of transfer exemplified by mitto are paradigmatically organised. The two other types do not show similar alternations of expression linked to a predictable change of content. In other words, they are instantiations of lexically determined valency patterns, not constructions in my sense of the term.
a. accusare aliqu-em
ambit-us
accuse someone-ACC canvassing for office-GEN
'to accuse someone of canvassing for office'
b. te hoc beneficium rog-o
you.ACC this-ACC.sG favour-ACC.SG ask-PRs.1sG
'I ask you this favour'

(Cicero, Clu. 41)

(Plautus Merc 3,1, 17)

In Table 2 the pattern of verbs of transfer, e.g. mitto, is compared to the typical trivalent patterns of verbs of jurisdiction and verbs of communication, e.g. accuso and rogo. These are opposed to each other by means of their individual expressions of A2 and of A3 linked to their individual content. Thus, they display three different organisation possibilities of the relation between three arguments. Of course, Latin had more trivalent patterns than these, but for the sake of simplicity, I just present these three types. They are opposed to mono- and divalent patterns, which, for the sake of brevity, I will not present here, as the point is to provide the necessary information before moving on to study the mitto type in detail.

The dative is normally taken to mark the third argument with verbs of transfer (type 1 of Table 2). As for the other types of trivalent verbs, it is not evident which argument should be labelled A2 or A3, respectively. The distribution chosen here is based on the following reasoning: first, accusative is normally taken to be the default-form of A2; secondly, the argument that corresponds to the subject of a passive construction should be labelled A2. The semantic labels in Table 2 and in the following ones should be interpreted in a very broad sense: A1: agent, A2: transferred item/person concerned/person addressed, A3 recipient-goal/term of accusation/topic. By the term topic, I simply refer to what is communicated by A1 to A2.

It should be noted that the three patterns illustrated in Table 2 are instantiated by different verbs classes (verbs of transfer, of jurisdiction, of communication). We have seen above that verbs of transfer are especially interesting, as they are paradigmatically organised (see Table 1). In the following subsections I will focus on the subsequent changes of this paradigm, which is going to spread to other verb classes; later, it becomes the default three-argument construction of most Romance languages. 
Table 2. Classical Latin. Three trivalent valency patterns

\begin{tabular}{llllll}
\hline 1: verbs of transfer & 2: verbs of jurisdiction & \multicolumn{2}{l}{ 3: verbs of communication } \\
\hline Expression & Content & Expression & Content & Expression & Content \\
\hline A1: NOM & A1: agent & A1: NOM & A1: agent & A1: NOM & A1: agent \\
A2: ACC & A2: transferred item & A2: ACC & $\begin{array}{l}\text { A2: person } \\
\text { concerned }\end{array}$ & A2: ACC & A2: person \\
A3: DAT/PP & A3: recipient/goal & A3: GEN & $\begin{array}{l}\text { A3: term of } \\
\text { accusation }\end{array}$ & A3: ACC & A3: topic \\
\hline
\end{tabular}

\subsubsection{Late Latin and Early Romance languages, ${ }^{112}$ stage 2}

The development from stage 1 to stage 2 is marked by two changes in the paradigmatic organisation of the constructions: change in the status and change in the internal structure of the paradigm. I use the term status to refer to the generalisation of the construction illustrated in Table 1 by mitto, to other verbs classes. In Late Latin, we find a general increase in the use of prepositional constructions: $a d+$ NP spreads from verbs of transfer such as mitto to verbs of communication such as rogo. The use of the preposition ad + accusative in A3, corresponding to the former dative of NPs as expression of $\mathrm{A} 3$, subsequently spreads in all ${ }^{113}$ Romance languages. There has been much discussion concerning how we should understand the process of the reanalysis of the PP as opposed to the dative form. In my view, the reanalysis should be interpreted as a metaphoric locative, ${ }^{114}$ as proposed for mitto above, see examples (2c) and (2g).

In all Romance languages, with the exception of Modern Standard Romanian, which no longer has this construction, we find prototypical trivalent verbs organised, like the verbs of transfer, with the recipient marked by means of a form of $a d+\mathrm{NP}$ and/or a dative form of the personal pronoun. I mentioned above that the Latin verb of transfer donare did not originally follow this pattern: with this verb the recipient was originally in the accusative case and the object transferred was in the ablative case (see 1c). Later, the pattern of dare was extended to donare, and dare tended to vanish

112. I accept the argumentation concerning the "fragmentation" and the periodisation of Latin and Early Romance expressed in the different works by Wright (e.g. 1982, 1995, 2004, 2006b).

113. According to Densusianu (1938:144) the prepositional construction also spreads to Romanian, since there are traces of $a d+\mathrm{NP}$ in the earliest texts - and still in colloquial Romanian - see below.

114. See e.g. Selig (1991), Jacob (1991), and especially Detges (2001) for different, but plausible, scenarios. 
in the Northern areas. ${ }^{115}$ In the default pattern of transfer, A3 is expressed by means of the local form of the Latin preposition $a d+\mathrm{NP}$, or by a dative form of the personal pronoun. Thus we must assume that a semantic identity between $a d+\mathrm{NP}$ and a dative pronoun already existed in Early Romance (see Table 3a). This implies that the original equivalence between $a d+$ accusative NP and $a d+$ the accusative form of a pronoun, e.g. ad illum, has been reanalysed into equivalence between $a d+$ accusative NP and the dative form of a pronoun. ${ }^{116}$ It follows that the PP ad Herennium of the constructed sentence dono litteras ad Herennium ('I give the letters to Herennius') has the function of recipient, just like the dative form illi of the sentence illi dono litteras ('I give him the letters'). Thus, the shift from stage 1 to stage 2 in Early Romance implies three changes: first, the paradigm in Table 1 is reanalysed as the prototypical three-argument construction with $\mathrm{A} 3$ as the recipient/beneficiary, i.e. the status of this construction is no longer restricted to just one type of lexical verbs, e.g. mitto. Secondly, the PP is reanalysed as being the semantic equivalent of a pronominal dative. Thirdly, the internal structure of the opposition has undergone a shift of markedness: the dative case is no longer the unmarked expression of A3, because $a d+$ accusative NP has become the unmarked form. This point connects closely with Wright (2004) and Banniard (2004) who defend the view that changes crucially depend on a central period of markedness reversal, and markedness in states of variation depends on paradigmatic comparisons. Interestingly, each of the two expressions of A3 are not linked to a specific content, as was the case in Table 1. The expression of A3 depends on the constituent type: if a pronoun, it takes the dative form, if a NP, it takes the preposition $a d+$ accusative form. Thus, this is not a paradigmatic opposition. What we see here is a reorganisation of a grammatical structure with loss of the opposition found in the transfer pattern. In other words, it is a case of degrammation. However, at a higher level of analysis, this pattern has a paradigmatic opposition to other patterns, to be exemplified in Section 2.1.4, Table 4a.

Table 3a. The default trivalent pattern. Verbs of transfer and additional types of verbs, stage 2: Early Romance languages

\begin{tabular}{llll}
\hline Expression of A2 & Content of A2 & Expression of A3 & Content of A3 \\
\hline \multirow{2}{*}{ accusative form } & affected entity/ patient & $\begin{array}{l}a d+\text { accusative NP } \\
\text { dative form of } \\
\text { personal pronoun }\end{array}$ & recipient / beneficiary \\
\hline
\end{tabular}

115. I want to thank Michèle Fruyt for information on the verb donare. See also Christol (1998a:498) and Christol (1998b:753-767) for useful comments.

116. The dative forms of the personal pronoun are e.g. illi, the analogical form ${ }^{*} i l l u i$, or the original genitive form, illorum being later used as dative. 
In Old French and in Old Occitan we find many instances of A3 expressed by an NP referring to a human without the preposition $a d$, which suggests, for that area at least, the existence of a slightly more complex system (see Table $3 b$ ) than the one presented in Table 3a. As illustrated in the following examples, we find the use of the oblique form (OBL) referring to a human without a preposition mo senhor in (3c, Occi$\tan$ ), instead of a prepositional construction, a touz in (3d, Old French). The latter is occasionally accompanied by a dative pronoun (leur), which clearly shows the equivalence between the PP and the dative form of the pronoun.

\section{c. Lo somne comtei mo senhor the dream-obl.sg tell-PST.1Sg my-OBL.SG lord-obL. SG} 'I told the dream to my lord'

(Jensen 1990:31)

d. Lors leur ${ }_{1} \quad f u$ penitance baillie a touz $z_{1}$ ensamble then they-DAT.PL was penitence given to all-OBL.PL together 'then all of them received penitence'

(Dits Uv. 428)

Later, the non-prepositional construction is marginalised, and it disappears. It is probably the trace of an earlier distribution, with A3 marked differently according to the distinction \pm human.

Table $3 \mathrm{~b}$. The default trivalent pattern. Verbs of transfer and additional types of verbs, stage 2: Early Romance languages

\begin{tabular}{|c|c|c|c|}
\hline Expression of A2 & Content of A2 & Expression of A3 & Content of A3 \\
\hline & & $\begin{array}{l}a d+\text { NP in the oblique } \\
\text { form }\end{array}$ & \\
\hline \multirow[t]{2}{*}{ accusative form } & $\begin{array}{l}\text { affected entity / } \\
\text { patient }\end{array}$ & $\begin{array}{l}\text { NP in the oblique form, } \\
\text { referring to a human } \\
\text { referent }\end{array}$ & recipient /beneficiary \\
\hline & & $\begin{array}{l}\text { dative form of } \\
\text { personal pronoun }\end{array}$ & \\
\hline
\end{tabular}

It should be noted that there was absolutely no merger of the two arguments A2 and $\mathrm{A} 3$, as appears clearly from the use of pronouns in the function of A3: these are always found in the dative form in spite of the possible identical (oblique) nominal expression of A2 and A3. This is a striking difference with respect to Spanish and to Engadine: as we will see below in subsection 2.2, these languages tend not to differentiate $\mathrm{A} 2$ and $\mathrm{A} 3$, and present a different, complex paradigmatic structure.

\subsubsection{Early Romance languages, stage 2}

In Early Romance verbs of transfer were not opposed to the two Latin trivalent patterns presented in Table 2, neither of which survived, but to newly coined 
patterns; for example, to a differently organised ${ }^{117}$ trivalent pattern with the meaning 'to provide somebody with something', labelled type 2 in Table 4a, and to different divalent patterns. I have chosen to exemplify the divalent patterns by only one type: prototypical action verbs, such as the Romance equivalents of occido 'I kill', opprimo 'I overpower', perdo 'I lose', etc. There are many more patterns than these three. Below, I just intend to show the existence of different patterns without discussing the paradigmatic relation between them, as my focus is still on the default trivalent pattern illustrated by (3e). Just as we saw in Tables 3ab, there is no paradigmatic opposition in the marking of A3, but two bound variants: a dative form of the pronoun or a PP. Later, this pattern will undergo important modifications, most spectacularly in Peninsular Spanish, see Section 2.2. The examples quoted below are Modern Standard Italian $(3 e-3 g)$, which adequately represents modern and previous periods on this point:

e. do delle lettere a Paolo
give-PRs.1sG PARTITIVE=DET letters to Paolo
gli do $\quad$ delle

\subsubsection{Later periods, stages 2 and 3}

During the Middle Ages two important changes take place: first the spreading of a prepositional marking of A2, secondly the split of the personal pronouns into two series: stressed vs. unstressed, later free vs. bound (clitic), and the subsequent use of

117. The default trivalent pattern illustrated in example (3e) obviously has an information structure that differs from that of (3f), but the information structure is not relevant here. 
Table 4a. Early Romance Languages, stage 2, a selection of trivalent and divalent patterns illustrated by Modern Standard Italian examples

Trivalent patterns type 1 (example $3 \mathrm{e})$

\begin{tabular}{llll}
\hline \multirow{2}{*}{ verb + A1 } & A2 & \multicolumn{2}{c}{ A3 } \\
\cline { 3 - 4 } & & Expression of A3 & Content of A3 \\
\hline do verb + agent 'I give' & $\begin{array}{l}\text { delle lettere transferred } \\
\text { item 'letters' }\end{array}$ & $\begin{array}{l}\text { a Paolo prep + NP 'to Paul' } \\
\text { = recipient / } \\
\text { beneficiary }\end{array}$ \\
\hline
\end{tabular}

Trivalent patterns type 2 (example $3 f)$

\begin{tabular}{llll}
\hline verb + A1 & A2 & \multicolumn{2}{c}{ Preposition Argument (PP) } \\
\cline { 3 - 4 } & & Expression of PP & Content of PP \\
\hline $\begin{array}{l}\text { ho ricoperto verb + } \\
\text { agent 'I have covered' }\end{array}$ & $\begin{array}{l}\text { Maria, 'Mary', 'hecipient } \\
\text { 'Maryer }\end{array}$ & $\begin{array}{l}\text { di gioelli prep + NP } \\
\text { 'with jewels' }\end{array}$ & $\begin{array}{l}\text { = transferred } \\
\text { item }\end{array}$ \\
\hline
\end{tabular}

Divalent pattern type 1 , action verbs (example $3 g$ )

\begin{tabular}{ll}
\hline verb $+\mathrm{A} 1$ & $\mathrm{~A} 2$ \\
\hline $\begin{array}{l}\text { uccido verb + agent } \\
\text { 'I kill' }\end{array}$ & $\begin{array}{l}\text { Paolo, lo patient } \\
\text { 'Paul', 'him' }\end{array}$ \\
\hline
\end{tabular}

these clitics for cross-indexing. ${ }^{118}$ As these changes modify the paradigmatic opposition in several Romance languages, I need to introduce them briefly here. They will be exemplified below and discussed in more detail in Sections 2.2 and 2.3.

Romance languages develop differently with respect to the marking of A2 and A3 in the default trivalent pattern presented in Table $3 \mathrm{a}$ above. We need to distinguish between three areas of development: French-Occitan and Standard Italian, see Table $4 \mathrm{~b}$ below and examples in (4); Peninsular Romance ${ }^{119}$ and several Italian dialects, see Table 5 and examples in (5); and Romanian, see Table 6 and examples in (6). French-Occitan and Standard Italian are characterised by the fact that A2 is distinguished from A3, because the latter takes the form of a PP introduced by a form of ad ( $\grave{a} \mathrm{Luc}$, ai poveri)

118. I do not imply any causal relation between the two changes. Latin pronouns were probably pronounced differently in stressed and in unstressed contexts, but they are written in the same way, unlike Romance pronouns.

119. Following Penny (2002) I use the term Peninsular Romance when I refer in general to the Romance varieties of the Iberian Peninsula. 
and the corresponding pronouns are in the dative case (lui, gli, loro), ${ }^{120}$ see (4a-b), whereas A2 is an NP and the pronouns are in the accusative form, see (4cd) (examples quoted from Detges 2001:241). Table 4b shows the French and Italian default trivalent pattern, which is identical to that of the early Romance languages presented in Table 3a. Just as we saw in Tables 3ab, there is no paradigmatic opposition in the marking of A3, just two bound variants: a dative form of the pronoun or a P. ${ }^{121}$ The term "accusative" is short for the "direct object form".

(4) a. French

Marie a consacré beaucoup de temps à Luc

Mary has spent much of time on Luc

'Mary has spent much time on Luc'

elle lui a consacré beaucoup de temps

she he-DAT.SG has spent much of time

'She has spent much time on him'

b. Italian

$\mathrm{Ha}$ dedicato tutta la sua vita ai poveri

has devoted they-Dat.PL entire his life to the poor

'He has devoted his entire life to the poor'

gli ha dedicato/ ha dedicato loro tutta la suavita

they-DAT.PL has devoted his entire life

'He has devoted his entire life to them'

c. French

Marie voit Luc

'Mary sees Luc'

elle le voit

she he-ACC.sg sees

'she sees him'

d. Italian

Maria vede il bambino

'Mary sees the child'

lo vede

he-ACC.SG sees

'She sees him'

120. Standard Italian uses gli not only in the singular, but also in the plural (instead of the more formal form loro).

121. The preposition of the PP has been glossed with the best possible English approximation. 
Table $4 \mathrm{~b}$. The default trivalent pattern in French and Standard Italian, stage 2 , examples $(4 a-d)$

\begin{tabular}{llll}
\hline Expression of A2 & Content of A2 & Expression of A3 & Content of A3 \\
\hline accusative form & $\begin{array}{l}\text { affected entity / } \\
\text { patient }\end{array}$ & $\begin{array}{l}a+\text { accusative NP } \\
\text { dative form of pers. pronoun }\end{array}$ & recipient / beneficiary \\
\hline
\end{tabular}

Peninsular Romance and Italian dialects differ from the situation in FrenchOccitan and Standard Italian, as both A2 and A3 NPs are found introduced by a form of the preposition $a d$. This urges me to consider more closely the relation between the default trivalent pattern and divalent patterns in these Romance varieties. I will do this in Sections 2.2 and 2.3. Table 5 presents the construction possibilities of Peninsular Romance and Italian dialects illustrated by Castillan; it corresponds to a further stage of development in these languages: stage 3. As already stated, the shift from stage 2 to stage 3 depends on changes in the status and the internal structure of the paradigm of A3. At stage 3 the former nominal expression of A3, PP ad + NP, is no longer exclusively the marker of A3, but may also be that of an animate referent of A2. However, at stage 3, the third person nonreflexive personal pronouns referring to $\mathrm{A} 3$ and $\mathrm{A} 2$, respectively, still take different forms, as accusative pronouns (la) refer to A2 (5a) and dative pronouns (le) refer to A3 (5b) (from Detges 2001:242). The default trivalent pattern with a non-human referent of A2 is illustrated in (5c). The non-human A2 is not relevant for this table. At a subsequent stage, stage 4, pronouns referring to A3 and A2 may take the same form; see below, Sections 2.2-2.3.

\section{Castillan}
a. A María la espera su madre for Mary she-ACC.sG wait her mother 'Mary's mother is waiting for her' For Mary she-DAT.sG wait a surprise 'A surprise is waiting for Mary'
b. A María le espera una sorpresa
c. ¿Le das el libro a mi hermana? she-DAT.SG give the book to my sister 'Will you give the book to my sister?'

Compared to the previous, much simpler, structures presented above, we here find a complex paradigm, as the following parameters are involved: case (accusative:dative), role of hierarchy (A2 or A3), role of arguments (A2: patient or beneficiary). I will return to the case roles of the dative below. 
Table 5. Divalent and default trivalent patterns organised paradigmatically. The paradigm of (mainly human) A2 and A3 in Peninsular Romance and Italian dialects, illustrated by Castillan, stage 3, examples (5a-c)

Domain: V [A2] (A3)

Frame: role of animate $\mathrm{A} 2$

\begin{tabular}{|c|c|c|c|}
\hline Expression of A2 & Content of A2 & Expression of A3 & Content of A3 \\
\hline$a+\mathrm{NP}$, accusative & patient & \multirow{3}{*}{$\begin{array}{l}a+\mathrm{NP} \text { dative form } \\
\text { of pers. pronoun }\end{array}$} & \multirow{3}{*}{ recipient } \\
\hline form of pers. pronoun & & & \\
\hline $\begin{array}{l}a+\mathrm{NP} \text {, dative form } \\
\text { of pers. pronoun }\end{array}$ & beneficiary & & \\
\hline
\end{tabular}

Romanian differs from the Western areas on two counts: this language usually introduces the human A2 by the preposition pe, from Latin per; and in the modern standard language A3 is not introduced by the preposition $a d$. Instead, we find a dative-genitive form, opposed to the nominative-accusative form, as Romanian preserves case in the determiner, as seen in (6a) quoted from Christol (1998a:484) and (6b). In colloquial speech, however, we may find the preposition la probably from Latin illac ad, see example (6c). I said above that the change from stage 2 to stage 3 was linked to the extension of the expression of the nominal form of A3 $(a(d)+\mathrm{NP})$ to A2. Accordingly, this change has not taken place in Romanian, where the form of A3 is distinct from that of A2. Table 6 presents stage 2 of Romanian. There is no paradigmatic opposition in the marking of A3. But there is a paradigmatic opposition between human and non-human referents of A2, not indicated in Table 6, which includes only human A2. The opposition is between a PP introduced by pe (6a) with a human referent, or the nominative/accusative form with a non-human referent (6b). We will return to this opposition below.

\section{Romanian}

(6) a. copil-ul (subject function)

child-DEF.NOM/ACC.SG

pe copil (object function)

on child-ACC.SG

copil-u-lui (dative/genitive function)

child-u-DEF. DAT/GEN.SG

b. $i$-am

dat

he.DAT.SG-have.PRs.1sG give-PRF PTCP

cărți-le copil-u-lui

books-DEF.ACC child-u-DEF.DAT/GEN.SG

'I have given the books to the child' 


$$
\begin{array}{lll}
\text { c. Am cărți-le la copil } & \text { dat } \\
\text { have.PRs.1sg give-PRF PTCP book-F.PL to child } \\
\text { 'I have given the books to [the] child' }
\end{array}
$$

Table 6. Default trivalent and divalent patterns with +human A2 in Romanian, stage 2 , examples $(6 a-c)$

\begin{tabular}{llll}
\hline Expression of A2 & Content of A2 & Expression of A3 & Content of A3 \\
\hline $\begin{array}{l}\text { pe + NP / NP in the nom/acc } \\
\begin{array}{l}\text { form accusative form } \\
\text { of pers. pronoun }\end{array}\end{array}$ & patient & $\begin{array}{l}\text { of pers. pron. } \\
\text { (marked diastratic/ } \\
\text { diatopic variant) }\end{array}$ & $\begin{array}{l}\text { recipient / } \\
\text { beneficiary }\end{array}$ \\
\hline
\end{tabular}

Summing up: in this section I have focused on the diachronic development of the marking of A3 from Latin to Modern Romance languages through three stages in some of the languages, stages characterised by three different structures including an A3. We have seen that in Latin (stage 1) there were different ways of marking A3, one of them, found with verbs of transfer, by means of a dative (the unmarked form) or a PP introduced by ad (the marked form). The latter form has developed into the standard Romance way of expressing A3. This development is best described as a grammaticalisation of a construction according to the definitions provided in Chapter 3 . The criteria for identifying stages 2 and 3 of the development are the status and the internal structure of the paradigm of A3. At stage 2, the paradigm has spread to additional types of verbs, and the internal structure is modified in such a way that $a d+\mathrm{NP}$ has generalised and no longer alternates with a dative form of the NP. The personal pronouns are in the dative form. In other words, we have a change of markedness, as the PP form is no longer the marked form. At stage 3, found in Peninsular Romance and in Italian dialects, the paradigm is further modified, as $a d+\mathrm{NP}$ has also become the marking of a human A2. This change will be explored in the following section.

\subsection{The development of the second argument in Romance languages}

All varieties of Romance languages, with the exception of Standard Italian, Standard French and varieties of Rhaeto-Romance, have at least to some extent developed a prepositional marking of A2. It is grammaticalised in Spanish, Catalan, Portuguese, Galician, and Romanian, and found in South-Western French varieties (e.g. in Gascon). Use of prepositional A2 at the French Court in the 16th and 17th centuries was stigmatised as "Gasconism". A frequently quoted example comes from Molière: comment tu me traites à moi, avec cette hauteur 'how you treat me A me, with this arrogance. Prepositional A2 is found in colloquial speech in Brussels, in different varieties of Romansch, 
especially in Engadine and Münstertal, in Southern and Central Italian varieties (in Sicily, Calabria, Apulia, Abruzzi; in Lazio, Elba, Corsica), and in Sardinia.

In what follows, my focus will be on changes of the marking of A2 in Romanian and especially in Peninsular Spanish, as these changes result in the creation of interesting constructions with a special A2 subparadigm. As mentioned above, Romanian marks A2 by means of the preposition pe from Latin per. All other Romance languages use $a$ from Latin $a d$ or a combination of this preposition and another element (Gascon ena, enda, end $<$ in $+a d$, Catalan $a n<a+e n$ etc.). Prepositional marking of A2 did not exist in Latin; it is an innovation of Romance languages. Although it is found in almost all Romance varieties, it should probably be considered a polygenetic creation, since it is found early in some areas (especially in Spain), but later in other areas: in Engadine from the 16th century, in Romanian (language attested only from the 16th century) not before 1581. According to Densusianu (1938:376 ff.) the use of pe in the early texts does not yet correspond to that of Modern Romanian. Illustrations of prepositional A2 from the different Romance languages, quoted from Bossong 1998a: $224 \mathrm{ff}$., are provided in (7). In Portuguese, Catalan, Sardinian, Romanian, and in Languedoc, we find clitics representing the prepositional A2 referring to an entity with the feature +definite, +human (examples 7a-c, 7e, 7h). ${ }^{122}$ This phenomenon (=cross-reference) will be taken up in Section 2.3.

(7) a. Portuguese:

$\begin{array}{ll}\text { vejo-te } & a t i \\ \text { see-PRs.1sG-you.ACC.2sG } & \text { to you.2sG } \\ \text { 'I see you' } & \end{array}$

b. Catalan:

a tu no $t^{\prime}$ havia vist

at you.2SG not 2.SG.ACC have-PST.1SG see-PST PTCP

'I didn't see you'

c. Sardinian:

ti bio a ttibe

you.2sG-ACC see-PRs.1sg at you.2sG

'I see you'

d. Calabrese $^{123}$

tu canusc- $i$ mali $a-i$ fimmini

you.NOM.2sG know.PRS-2sG bad of-DEF.PL women 'you, you don't know women'

122. It should be noted that in these examples, the clitics are obligatory and the PP optional.

123. See Rohlfs $₫ 632$ and Maiden (2003:264) for further examples of human prepositional A2s in Southern Italian variants, Sicily, and Sardinian. Examples are also found in Northern Italian variants. 
e. Romanian:

te văd pe tine

you.2sG.ACC see-PRs.1sg to you.2sG

'I see you'

f. Lower Engadine

Andrea cuerna a Niculin cu seis tschop

André cover-PRs.3sg at Nicolas with his jacket

'André covers Nicolas with his jacket'

g. Languedoc

va-u ajudar a l'ome

go-PRS.1sG help to DEF-M.SG=man

'I will help my husband'

h. Languedoc:

a ièu me compren pas

of 1sG 1sG.ACC understand-PRs.3sg not

'He does not understand me'

\subsubsection{From Latin to Romance}

The use of the prepositional marking of A2 apparently originated with verbs that expressed relations between humans, or between humans and saints, God, etc. It probably started as a way of marking attention and respect, as seen in early Portuguese, Castilian and Catalan texts, see the examples $(8 \mathrm{a}-\mathrm{c}):^{124}$

(8) a. Old Castilian (marker of respect, Poema de Mio Cid (ca. 1200)

A vos llama por señor

of you.2PL call-PRs.3sg for Master

'he calls you his Master'

b. Portuguese (16th century, marker of respect)

aprouve a Deus levar a el-Rei vosso padre a àquele celestial assento que se dà aos católicos e critianíssimos principes

please to God lift up at the-King your father to-this heavenly position that is given to the Catholic and most Christian princes

'May it please God to lift the King your father to the heavenly position prepared for Catholic and very Christian princes'

124. Examples (8ab) are quoted from Detges (2001:285), (8c) from Bossong (1998a:223-225). According to Bossong, Mozarabic examples of prepositional object are already found in the 11th-12th centuries. Precise references of the examples quoted are not available. A detailed diachronic study of the Spanish changes is found in Company Company (2006). Interestingly, a similar shift of markedness of respect is found in the actualisation of the relative pronoun who in English, as shown by Bergs and Stein (2001). 


\section{c. Old Sicilian:}

$\begin{array}{llll}\text { vid-iti vuy } & a \text { sanctu } & \text { Petru } \\ \text { see-PRs.2PL } & \text { you.NOM.2PL at saint } & \text { Peter } \\ \text { 'you see Saint Peter' } & & & \end{array}$

The use of prepositional marking spread from such marked contexts to others; for example, to contexts of reciprocity, comparison, contrastivity, i.e. generally contexts of focus. The constituents governed by the preposition are: firstly personal pronouns, then proper names, nouns indicating family relations, definite nouns referring to individual humans, and later to animals. The spread thus conforms to the well-known implicational referential hierarchy ${ }^{125}$ reproduced below in (8d), implying that the preposition is first introduced before nouns referring to individual definite humans [+deix, +propr, +pers, +hum], and only later (if at all) to non-individual, non-human indefinite entities [-deix, -propr, -pers, -hum; +anim, +discr, +concr]. The Romance languages differ, however, with respect to the spread of prepositional marking. It is interesting to observe that this hierarchy does not seem to have been important in Classical Latin, whereas it has become relevant for all Romance languages, and not only with respect to this specific point of grammar. I will return to this point later.

d. Referential hierarchy:

$$
[+ \text { deix }]>[+ \text { propr }]>[+ \text { pers }]>[+ \text { hum }]>[+ \text { anim }]>[+ \text { discr }]>[+ \text { concr }]
$$

At the outset, A2 without a preposition was the most frequent; later, the use of the preposition generalised. In other words, we see a shift of markedness. In Peninsular Spanish, Romanian, and Southern Italian dialects the prepositional marking has generalised furthest, in that the preposition tends to take an NP referring to individual humans. Spanish has extended the prepositional marking from definite human referents to indefinite human referents and to animals, see examples (9ab), but not to inanimate referents, see $(9 \mathrm{c}) .{ }^{126}$
a. no quis-e not want.PST-1SG decapitate to my dog favourite 'I did not want to kill my favourite dog'
b. mord-i-ó elperro al gato
bite-PST-3SG ART.M.3SG dog to-DEF.M.SG cat 'the dog bit the cat'

degollar a mi perro favorito

125. A more complex hierarchy especially designed for Spanish is found in Company Company (2006:436). Here, the author combines two hierarchies, one of animacy and one of definiteness.

126. As pointed out by García (1993:39 ff.), the diffusion of $a$ as marker of A2 should be interpreted as a "focus-worthiness of the overwhelmingly human referent". See also Delbecque (1998:396 and 1999). 

c. el
hombre beb-e
$\varnothing$ la
cerveza
DEF.M.SG man drink-PRS.3sG
DEF.F.SG beer
'the man drinks the beer'

Castilian influence may have favoured the spread of the prepositional object in Portuguese between 1560 and 1640. After this period, its use declined, and in Modern Portuguese the use of prepositional objects is regressing and only obligatory with personal pronouns, see examples (7a) above and, in contrast, (9d), without any preposition introducing a human A2.

In Modern Catalan, as in Portuguese, the prepositional object was original. However, after the first Congress of the Catalan language in 1908, its normative grammar banned this use as a Castilianism, with the result that the use of prepositional A2 is regressing. Standard Catalan without a preposition introducing a human referent of A2 is exemplified in (9e). As in Portuguese, it is only obligatory with personal pronouns.
e. he
encontrat
$\varnothing$ el
teu germà
have-PRS.1SG meet-PST PTCP DEF.M.SG your brother
'I met your brother'

Peninsular Spanish and Romanian have generalised prepositional A2 referring to humans to such a degree that it has grammaticalised as a construction, and that we can establish a subparadigm of A2. The paradigm has two members: human referents are marked by means of a preposition, and non-human referents are not marked. It should be recalled that the feature human here implies the feature +individuated. Examples $(10 \mathrm{a}-\mathrm{g})$ illustrate this paradigm presented in Table 7. In Romanian, the use of pe with a human referent of A2, (10a): pe fratele meu 'my brother' is opposed to the non-prepositional form of A2 with a non-human referent, (10bc): Cuțitul 'the knife', and fân 'hay'. I reiterate that in Romanian A2 is distinct from the A3, which takes the genitive-dative form: calului 'the horse' (10c), as shown in Section 2.1.4., examples quoted in (6).

(10) a. l-am văzut pe fratele meu

$\begin{array}{lll}l- & \text { văzut } & p e \\ \text { he-ACC.SG have-PRS.1sG } & \text { see-PST PTCP at } \\ \text { frate-le } \quad m e u & \\ \text { brother-DEF.M.SG mine } & \\ \text { 'I have seen my brother' } & \end{array}$


b. Mi-am pierdut cuțitul

Mi- am pierdut cuțit-ul

me.DAT.SG have.PRs.1sg lose-PST PTCP knife-DEF.NOM/ACC.SG

'I have lost my knife'

c. Dă fân calului

Dă fân cal-u-lui

give hay horse-u-DEF.DAT/GEN.SG

'give hay to the horse' ${ }^{127}$

In Spanish, the use of $a$ with a human A2, (10d): a Fernando 'Fernando' is opposed to the non-prepositional form of A2 with a non-human referent, (10ef): el libro 'the book'. The combination of an A2 with non-human referent and an A3 is shown in (10f), with cross-reference between the dative pronoun le and A3 a mi hermana 'to my sister'. With a human referent of A2, only A3 normally is a PP $a$, as exemplified in (10g): Envié el soldado al rey, rather than Envié al soldado al rey. Examples combining a PP A2 and a PP A3 are, however, found, see below (11de).

d. ¿puedes ir a buscar a Fernando esta tarde? can-PRs.2sG go to fetch to Fernando this evening 'Can you fetch Fernando this evening?'

e. ¿puedes ir a buscar el libro esta tarde? can-PRS.2sG go to fetch DEF book this evening 'Can you fetch the book this evening?'

f. ¿Le das el libro a mi hermana? (= $5 \mathrm{c}$ above $)$ she.DAT.SG give the book A my sister 'Will you give the book to my sister?'

g. Envi-é el soldado al rey send-PST.1sG DEF soldier to.DEF king 'I sent the soldier to the King'

127. The Romanian examples are quoted from Bourciez (1967:590-592). I am greatly obliged to Martin Maiden for having had the patience to discuss my Romanian examples with me on several occasions. 
Table 7. The subparadigm of A2 in Modern Peninsular Spanish and Romanian, stage $3,{ }^{128}$ examples $(10 \mathrm{a}-\mathrm{g})$

Domain: V [A2]

Frame: Referentiality of A2

\begin{tabular}{lll}
\hline Expression & Content & \\
\hline a/pe + NP & affected person/patient & human referent \\
$\mathrm{NP}$ & & non-human referent \\
\hline
\end{tabular}

\subsubsection{Potential merger of the second and the third argument, stages 3 to 4}

In all Romance languages which mark A2 and A3 by means of a form of Latin $a d$, there is a potential risk of merger of A2 and A3. In Portuguese, however, the formal opposition between the accusative and the dative functions in third-person pronouns persists, see examples (11a-c) (examples from Berlinck 1996:121-22).
a. Maria não ama ao Pedro
Mary not love-PRs.3sg to-DEF.M.sG Peter
'Mary does not love Peter'
b. Maria não o
ama
Mary not he-ACC.3sg love-PRs.3sg
'Mary does not love him'
c. ${ }^{*}$ Maria não the ama
Mary not he-DAT.3sg love-PRs.3sg

Moreover, the dative is frequently expressed here by means of the preposition para, in stead of $a$, thus preserving the formal distinction of the two functions.

Spanish has developed differently. At the outset the distinction between A2 and A3 was preserved. In Old Spanish, for example, there was no general merger of A3 and prepositional A2 as the latter was mainly found with pronouns and proper names. Later, as the use of $a+\mathrm{NP}$ in Spanish spread, and as the third-person masculine dative pronouns tended to spread to the accusative functions, i.e. the so-called leísmophenomenon, the distinction between $\mathrm{A} 2$ and $\mathrm{A} 3$ tended to vanish. In constructions that combine an A2 and an A3 that both refer to humans, we may find both of them marked by $a$, as seen in (11de):
d. ¡Allí se
daría orden
de llevar
there CLIT-REFLEX would be given order to bring

128. In Section 2.1.4. I characterised the passage from stage 2 to stage 3 as a change of the status and of the internal structure in such a way that $a d+$ NP has generalised and has become the marker of both $\mathrm{A} 2$ and $\mathrm{A} 3$. In Table $8 \mathrm{I}$ present the paradigm of $\mathrm{A} 2$ and $\mathrm{A} 3$. 
a Dorotea a sus padres! ${ }^{129}$

to Dorotea to her parents

'There the order would be given to bring Dorotea to her parents'

e. Los traidores entregaron

the traitors handed

a los presos a-l enemigo

to DEF.M.PL prisoners of=DEF.M.SG enemy

'The traitors handed the prisoners over to the enemy'

These examples illustrate a change from stage 3 to stage 4 with human referents. The change was marked by the spreading of $a+\mathrm{NP}$ to new contexts, A2 and A3 (di- and three-argument constructions), and both are equivalent to a dative personal pronoun; see the paradigm in Table 8. According to Delbecque and Lamiroy (1996:88) we here witness a "remodelling of grammatical relations", different from the original accusative/dative opposition, with $a+\mathrm{NP} /$ dative pronoun as an indicator of a "more salient, active participant" than NP/accusative pronoun. Put differently, the opposition between the two members of the paradigm would depend on the feature \pm salient. I accept this analysis, but not the labelling of the feature, since the feature \pm salient, which is not easily identified, can be derived from the feature \pm human of the referent. In Delbecque (1998:397-398), cases of A2 with and without $a$ have been analysed, and the opposition is presented in a way that permits me to interpret it as a paradigmatic opposition. Whether the opposition is best described in terms of \pm salient or in terms of \pm human of the referent, it should be clear that an important change has taken place, and that the choice between the two expressions no longer corresponds to the choice between an affected person/patient (i.e. content of A2 at stage 3) and recipient/beneficiary (i.e. content of A3 at stage 3). Thus, in Spanish compared to Latin, the changes of the dative have profoundly modified the expression of transitivity.

The successive modfications of A3 and A2 marking studied until now lead us to stage 4: a paradigm in Peninsular Spanish that is essentially different from those of Latin and of other Romance varieties. As shown in Chapter 4, this paradigm is a complex paradigm. Complex paradigms are paradigms connecting simple paradigms

129. Example (11d) is from Don Quijote. Examples (11de) are quoted from Delbecque and Lamiroy (1996). It has not been possible to identify the precise references of the examples. In the important study by Company Company (2006:655 ff.), it is shown that the combination of two human arguments in the functions of A2 and A3 is rather infrequent, and that in such combinations A2 is found both without and with the preposition $a$, whereas A3 is always introduced by the preposition $a$. An example with two human arguments is: el Rey Sol presentó a su hijo a los Grandes de España, 'The Sun-King presented his son to the noblemen from Spain' (Company Company 2006: 655). 
to form more complex packages of paradigms since e.g. the morphological parts, the construction parts and cross-reference (to be studied in next subsection) are interdependent. Thus, we have witnessed a reshaping of the paradigm. The synthetic character of the paradigm (stage 4) in Table 8 and its difference to the paradigm (stage 3 ) in Table 7 lie in the fact that referentiality ( $₫$ human referent) in Table 8 is bound up with syntactic hierarchy (A2/A3) in such a way that we have a non-human case system opposed to a human case system.

Table 8. Default three and two-argument constructions. The paradigm of $a+\mathrm{NP}$ in Peninsular Spanish. Stage 4

Domain: V [non subject arguments]

Frame: Referentiality

\section{Expression}

A2/A3: $a+$ NP or dative form of pron

A2: NP or accusative form of pron

\section{Content}

human referent

non-human referent

I said above that cross-reference is relevant for the marking of arguments. Romance languages behave differently as to how far they express the relation between nominal arguments by means of cross-reference. This urges me to investigate in the following subsection the development of personal pronouns with respect to cross-reference and with respect to their referential potential.

\subsection{The development of the personal pronouns: Cross-reference phenomena}

The development of the personal pronouns in Romance languages is so complicated that I will restrict myself mainly to the marking of non subject arguments, to their referential potential and to cross-reference. I will claim that in some Romance varieties, cross-reference has developed into a discontinuous marking of argument functions. This means that cross-reference in these varieties can be interpreted as partly equivalent to the syntactic function of Latin case marking, as these pronouns point, as indexes, to nominal arguments and mark their syntactic functions. On the other hand, personal pronouns have acquired different referential potential in the Romance languages. This implies for some of the Romance languages that the paradigmatic structure is modified; see Section 2.3.3. This is why I need to discuss cross-reference in some detail in this section.

Cross-reference probably started as the routine use of an originally expressive repetition of an argument by means of a personal pronoun. Formally, an NP is dislocated to the right or to the left and pleonastically repeated by means of the pronoun. These 
constructions were rare in Latin texts, but probably existed as expressive devices in spoken Latin.

\subsubsection{The development of cross-reference in Romance languages}

The use of a clitic to represent A2 and A3 is known in all Romance languages, and is found as an expressive device from the early texts. It is, however, only fully grammaticalised in Romanian (12a-b) and in Spanish with anteposed arguments (12c-e), especially in the function of A3, to such an extent that it can be analysed as a discontinuous marking of arguments with human referents. The other Romance languages display different stages of the routine use of cross-reference.

In his interesting analysis of the use of clitics, Detges stresses the importance of pragmatic factors for the use of cross-reference (2001:313), a view which is confirmed by the actualisation process in colloquial Spanish, as we find cross-reference in the 1st and 2nd person pronouns before the 3rd person pronoun - as shown for different varieties of Spanish (Bascuñán 2006a-b). In the 16th century it was more widespread in Castilian than in Catalan and in Portuguese.

Romanian has generalised cross-references (to human referents); see (12a-b): ${ }^{130}$
a. $i-$
am
dat
him.DAT.sG have.PRs.1sg give.PST PTCP
cărți-le
copil-u-lui
book-DEF.F.PL child-u-DEF.DAT.SG
'I have given the books to the child'
b. te văd pe tine
you.sG see-PRs.1sG to you.ACC.SG
'I see you, you'

I repeat that cross-reference is not obligatory when the argument is not dislocated, see (12cd), but it is habitual in Spanish (12e); see Rotaetxe (1998:416-417). In Peninsular Romance dislocation is always accompanied by cross-reference, see $(12 \mathrm{~g})$.

Spanish

c. Juan le ha dado
Juan he.DAT.SG have-PRs.3sg give.PST PRTC
el libro a María
DEF.M.SG book to Maria
'Juan has given the book to Maria'

130. Example (12a) is quoted from Christol (1998a:484), (12b) from Bossong (1998a:234), (12d, 12f-h,1 2m) are quoted from Bossong (1998a:224). Examples (12i-m) are quoted from (Detges 2001:289). 

d. ¿has visto a mi hermano? have-PRS.2SG see.PST PRTC to my brother 'have you seen my brother?'
e. $t e$
ve-o
you.ACC.SG see-PRS.1sg to you.2sG
a tí
'I see you, you'
Portuguese
f. vejo -te $\quad$ a $t i$
see-PRS.1sG you.ACC.SG to you.2sG
'I see you, you'
Catalan
g. a tu no $t^{\prime}$ hav-ia vist
to you.2sg not you.ACC.SG have-PST.1SG see.PST PRTC
'You, I did not see you'

In many other Romance varieties we find exactly the same pattern, as seen in examples (12h-m):

\section{Sardinian}
h. ti bio a ttibe
you.ACC.SG see-PRS.1sG to you.2sG
'I see you, you'

Sicilian

i. non vi pòzzu pavari a ttutti

not you.ACC.PL can-PRs.1sg pay to all

'You, I cannot pay you all'

\section{Corsican}

j. a Salbadòre un lu cunòsc-u

to Salvatore not he.ACC.sg know-PRs.1sg

'Salvatore, I don't know him'

Romantsch Grischun

k. giavüsch chia'l ans mantega

hope-PRS.1SG that he we.ACC.1PL preserve-PRs.3sG

a nus touts in buna sandet

to we.1PL all in good health

'I hope that he will preserve us all in good health'

\section{Gascon}

1. ad quéro damo nou la counechipas

to this lady not she.ACC.SG know-PRs.1sg not

'This lady, I don't know her' 


\section{Languedoc}
m. a ièu
me
compren
pas
to me.1sG me.ACc.1sg understand-PRs.3sg not
'Me, he does not understand me'

Standard French and Standard Italian differ from the Romance varieties quoted in (12) by not having generalised cross-reference. Italian is special as cross-reference was frequent until the 15th century; see (13a):

\section{a. Iscriverrogli \\ una lettera a Matteo, e dirogli...}

write-FUT.1sG-he.DAT a letter to Matteo, and tell-FUt.1sG-he.DAT 'I'll write Matteo a letter, and I'll tell him ...'

(Maiden 2003: 198)

During the sixteenth century left dislocation began to recede from literary texts. According to Maiden (2003: 198), this was apparently due to the influence of prescriptive grammarians. Right dislocation was restricted to the texts closest in character to the spoken language, already from the fourteenth century; accordingly, there is no cross-reference in Standard Italian (13b):

\section{b. do una lettera a Marco \\ 'I give a letter to Marco'}

(Maiden 2003: 100)

However, in Colloquial Italian, cross-reference is frequent; see Maiden (2003: 198), who states that "the syntactic function of dislocated nouns other than subjects is usually indicated within the clause by a clitic pronoun, acting as a kind of syntactic trace of the dislocated element (Il gatto, l'ho visto or l'ho visto, il gatto 'I've seen the cat')." This may, according to Maiden (2003:259) "be interpretable as a tendency towards obligatory clitic signalling of objects - a tendency already observable in a number of Italo-Romance dialects (Neapolitan, Abruzzese, Tuscan, Piedmontese (Berruto 1983:46)), and which has become obligatory in certain Romance varieties, such as Romanian."

In older periods of French, cross-reference was never as general as in Italian. In Modern Colloquial French, however, the situation resembles that of colloquial Italian with respect to the frequency of the phenomenon; see examples $(14 \mathrm{a}-\mathrm{c})$ quoted from Gadet $(2003: 47,51)$ and (14d) from Riegel et al. (1999:427):

a. les mômes ${ }_{1}$ qui pleurent tout le temps, je les the children who cry all the time, I them-ACC.PL égorgerais volontiers

kill-COND.1sG happily

'I would like to kill the children that are crying all the time' 
b. mes parents ${ }_{1}$ je $m^{\prime}$ en fous

my parents I me.ACC.SG of-them care-PRs.1sG

'I don't care about what my parents think'

c. Jacqueline, sa mère, la bonne, elle

J. her mother the maid she.NOM.sG

$\mathrm{la}_{2} \quad l u i_{3} \quad$ refile

she.ACC.SG she.DAT.SG pass on-PRS.3sG

'Jacqueline passes on her maid to her mother'

d. Moi, ma femme, ses robes, elles

$\mathrm{Me}$ my wife her clothes they.NOM.F.3PL

me coûtent une fortune

me.OBL.1.SG cost-PRS.3.PL a fortune

'my wife's clothes cost me a fortune'

Dislocation and pronominal clusters preceding the finite verb, as seen in (14c), have been much discussed in the literature and have led to repeated claims that Modern French is in the process of a second change of language type. First it changed from a traditional Indo-European synthetic type of language towards a more analytical type of language, and now further towards an isolating or polysynthetic type (see e.g. Hjelmslev 1963:91). This claim is relevant for all the Romance languages with extensive use of cross-reference and will be discussed further below. The examples presented above show cross-reference to A2 and A3 with human referents, but it need not be so. Italian and French use cross-reference also with non-human referents. I have not discussed examples of cross-reference of A1, as the focus has been on A2 and A3. However, examples like (14c) Jacqueline ... elle, and (14d) Moi, ma femme, ses robes, elles ... exist to a certain extent in all Romance languages, but an important difference in French-Occitan, Rhaeto-Romance varieties and Gallo-Italian should be noted: in these varieties the pronominal subject is an obligatory clitic, in contrast to the other Romance varieties. Before discussing the possible typological change of Romance languages and their subsequent paradigm implications, I will need to have a closer look at the development of Romance clitics and their referential potential.

\subsubsection{The development of Romance clitics. Discussion concerning a possible typological shift due to the generalised use of clitics}

Latin had personal pronouns for the first and second persons. For the third person, Latin used different demonstrative pronouns; of these especially ille provided the pronouns of the third person in Romance languages. Except in the function of A1, or when governed by a preposition, these pronouns had lost their stress. All Romance languages have developed two series of pronouns: stressed and unstressed or atonic forms; the former are usually longer than the latter, which are almost always reduced 
to monosyllables. The atonic forms became cliticised, typically to the verb, in a series of five possible steps, ${ }^{131}$ of which most Romance languages have arrived at the fourth. The five steps are: 1 , loss of accentuation, 2 , adjacency to a host, 3 , adjacency to one particular host: the verb, 4, fixation of position before or after the host, 5, fusion. At step 5 , the clitic turns into an inflectional affix. As step 5 is particularly relevant for my topic, I will concentrate in the following on the much debated question of whether any of the Romance languages have reached this step, where the clitic turns into a proper inflectional affix. It is sometimes argued that this is the case both for the languages with obligatory subject pronouns and for the languages with obligatory cross-reference of A2 or A3. For Modern French, see e.g. Trask (1996:118) and Lambrecht (1981), who refers to the subject clitics of French as agreement markers and to the pronominal clusters preceding the finite verbs as 'morphologized affixes'. In other words, these authors believe that we here witness a typological shift. I will briefly discuss this position in the following, as it is relevant for the paradigmatic organisation.

Latin is a typical Indo-European inflectional language and the Romance languages have partly preserved this type, especially in the conjugation of verbs. The clitics of Romance that could be analysed as affixes mainly have the characteristics of (sometimes discontinuous) portmanteau morphs, combining several features such as person, number, case and gender, so they are not strictly speaking agglutinating affixes, although they clearly permit segmentation; see e.g. the often quoted example (15a) from Tesnière (1976: 175):

$$
\begin{aligned}
& \text { a. il la lui } \quad \text { a donnée, } \\
& \text { he.NOM.SG it.ACC.F.SG he.DAT.sG has given } \\
& \text { à Jean, son père, sa moto } \\
& \text { to Jean, his father, his motorcycle } \\
& \text { 'Jean's father has given his motorcycle to him' }
\end{aligned}
$$

Examples with reduction of some of these features, e.g. il for both the masculine and the feminine, as in (15b) are found. They are already seen in 17th-century French, especially in women's usage. These forms were criticised by the Remarqueurs ${ }^{132}$ who stated that they should be avoided in writing (Ayres-Bennett 2004:38, 162).

131. See Bossong (1998c:769-787) for an interesting account of the Romance clitics, which conforms to the classical cline of grammaticalisation. When two clitics combine, special rules of concatenation may occur, which are not relevant for our topic. The positioning of the clitics and their respective order has changed from medieval to modern times; for Italian, see Maiden (2003: 166 ff.), for French, see Riegel et al. (1999), and for Spanish, see Penny (2002:132 ff.). A general introduction to Romance clitics is Wanner (1987).

132. The Remarqueurs were contemporary grammarians commenting on the French language and proposing specific rules. 


\section{b. Ma femme il est venu ${ }^{133}$ my wife 3sg has come-3sg \\ 'My wife has come'}

Gadet (2003: 108) cites a very unusual variation in subject clitics from advanced French with partial neutralisation of case, number ([ $[\varepsilon],[\varepsilon l],[a])$ and gender ([il]), see (15c). However, as we do not find general neutralisation of these features in subject clitics, these are not strictly speaking agglutinative structures, but rather polysynthetic ones.

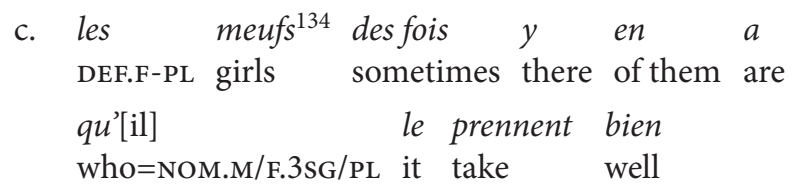

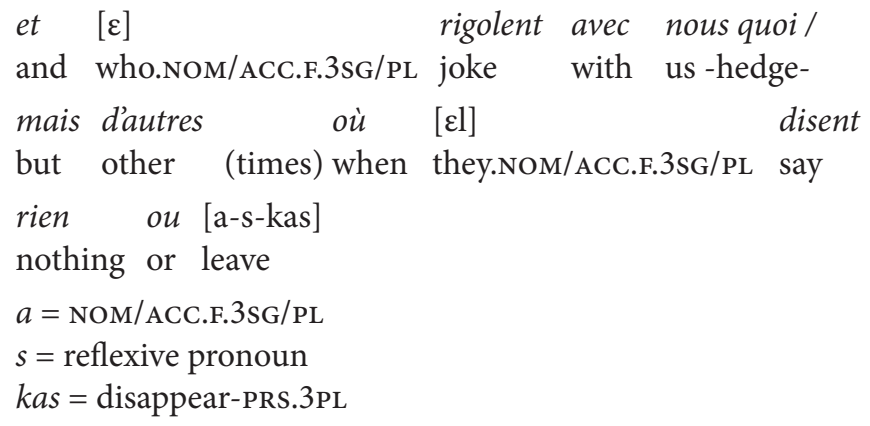

'Sometimes girls accept jokes and laugh with us, other times they say nothing or leave'.

The discussion concerning how to analyse French clitics is not recent; it was very lively in the 1920s and has continued ever since. Tesnière claimed for example that the subject clitics in French are directly comparable to the Latin verbal affixes of person and number (Tesnière 1976:139), see also Lyons (1990:25). The idea that Romance clitics might be agreement markers was originally inspired by comparisons with polysynthetic languages with verb forms including affixes whose features correspond to the arguments of the verb. Later, this analysis was extended to other Romance languages and to the object clitics of Spanish, Portuguese and Romanian, which were analysed as instances of "object-conjugation".

In addition to the typological importance of the generalisation of cross-reference, it should be noted that in advanced French cross-reference also has important implications for word order and intonation. In standard French the basic word order is S-V,

133. Note that the clitic il displays number and case-marking, but not gender-marking.

134. The form meuf is 'verlan', i.e. a colloquial variant of French with inversion of letters or syllables, here inversion of the form [famə], written femme. 
but in advanced French the word order is considered to be verb initial (Lambrecht 1981, 2004 \& Jacob 1990:126-127). The examples quoted in (15) are currently analysed as instances of left or right dislocation of an NP, so that the sentence is analysed as starting with the verb preceded by its clitics: (15a) clitics + a donnée, (15b) clitic + est venu, (15d) clitics + aime. In some cases the intonation, and not the order of the NPs, contributes to the clarification of the cross-reference; see example (15d), which is remarkably different from Standard French. It should be noted that both Marie and Nicole can be left or right dislocated or split - one to the left, one to the right (Gadet 1990). The slash indicates a pause, and the presence or absence of a pause before elle provides two different interpretations of the sentence. The presence of a pause (15d) indicates that the subject precedes the object, and the absence of a pause ( $\left.15 d^{\prime}\right)$ that the object precedes the subject.

\section{d. Marie/Nicole/elle l'aime pas = standard: Marie n'aime pas Nicole \\ 'Mary doesn't like Nicole' \\ d'. Marie/Nicole elle l'aime pas \\ = standard: Nicole n'aime pas Marie \\ 'Nicole doesn't like Mary'}

Let me now sum up the development of the clitics used for cross-reference of A2 and A3. I have shown that clitic representation of a nominal A2 or A3 next to the verb is commonly used in all varieties of Romance languages. There are, however, noteworthy differences concerning the frequency and the functions of cross-reference. In most varieties cross-reference is frequent, but optional. In Standard Romanian and Standard Spanish, however, cross-reference has become frequent with A2 and A3 referring to human referents to the point that the clitics can be considered as parts of a discontinuous marking of the arguments or cross-clausal indexes. In other varieties, mainly colloquial ones, we find clear tendencies towards generalised crossreference. However, I believe that clitics cannot (yet?) be considered to be proper agglutinating affixes.

\subsubsection{The distinction \pm human in clitics, stage 3 for French, Italian (and Catalan)}

We cannot describe properly the paradigmatic organisation of argument marking until we have discussed the features \pm human with relation to the reference of the personal pronouns, a phenomenon which is also connected to the cliticization of the locative forms (e.g. $y<$ Latin $i b i$ ). The cliticization of these forms is found in Italian, French, Occitan, Catalan and Aragonese (Bossong 1998c: 785). In these languages, the originally adverbial forms are integrated in different ways into the 
atonic paradigm, thus providing the possibility of a differentiation of pronouns that depends on the feature \pm human of the referent. In Modern French this distinction determines the choice between lui and $y$ in examples (16ab), quoted from Detges (2001:241):

a. Marie a consacré beaucoup de temps à Luc Mary has spent much of time to Luc 'Mary has spent much time on Luc' elle lui (=à Luc) a consacré beaucoup de temps she him.DAT has spent much of time 'She has spent much time on him'

b. Marie a consacré beaucoup de temps à ce boulot Mary has dedicated much of time to this job 'Mary has spent much time on this job' elle $y$ (= à ce boulot) a consacré beaucoup de temps she it.DAT has spent much of time 'She has spent much time on it'

In Catalan the feature \pm human determines the choice between the forms, in examples (16cd) between els and $h i$ :

c. Als meus fills, els dedico molt de temps A my children, they.Dat I spend much of time 'I spend much time on my children'

d. A la ciència, hi dedico molt de temps A research it.DAT I spend much of time 'I spend much time on research'

In Italian the feature \pm human determines the choice between gli/loro and $c i(16 \mathrm{ef})$ :

e. Ha dedicato tutta la sua vita ai poveri has devoted entire DEF his life to-the poor 'He has devoted his entire life to the poor'

$\mathrm{e}^{\prime}$. gli ${ }^{135}$ ha dedicato tutta la sua vita they.DAT has devoted entire DEF his life 'He has devoted his entire life to them'

135. As mentioned previously, Standard Italian uses Dative gli not only in the singular, but also in the plural (instead of the more formal form loro). These have different positions with respect to the verb: gli ha dedicato/ ha dedicato loro tutta la sua vita. The former is illustrated in $\left(16 \mathrm{e}^{\prime}\right)$. 


\section{f. Ha dedicato tutta la sua vita alla scienza has devoted entire DEF his life to-the science 'He has devoted his entire life to science' \\ $\mathrm{f}^{\prime}$. ci ha dedicato tutta la sua vita it.DAT has devoted entire DEF his life 'He has devoted his entire life to it'}

The distinction is not relevant for Spanish, Portuguese or Romanian pronouns.

The specificity of the development of clitics in standard Italian, French-Occitan and in Catalan, previously united with Occitan, shows the importance of the feature \pm human of referents of A3 in the languages which generally do not mark this distinction in A2 by means of a preposition. In the following, I will illustrate the development of the pronominal paradigm of A3 by means of French. It motivates me to establish a subsequent stage for the whole area, not only for French. I will label this stage 2', as it follows stage 2 in these languages, but is not identical to stage 3 in other Romance areas.

In older periods of French, until the 18th century, the feature \pm human was not yet important for the organisation of the pronominal paradigms, neither for the indefinite, the interrogative nor the personal pronouns. The introduction of this distinction modified the pronominal paradigms of the post-classical period and is relevant for Modern French; see e.g. Fournier (1998: Section 2, especially $\$ 278)$, Seguin (1972: 102 ff.), Riegel et al. (19995: $₫ 5.2 .2)$, Grevisse (1986: $\$ 653$ ). Thus, still in Classical French, the forms $y$, lui, leur, and à lui are found alternating in the function of A3. The grammarians of Classical French (the Remarqueurs) condemned this use, and tried to insist that $y$ should refer only to non-humans and lui to humans, and that à lui should be banned as a form of A3. These recommendations correspond more or less to the situation of Modern Standard French; see Table 9. In spite of the norms, $y$ can be found referring to entities with the feature +human. In advanced French, we find extended use of cross-reference with all arguments, as illustrated above (examples quoted in (15)), and we find a general remodelling of paradigms according to the distinction \pm human of referents, in some cases to the distinction \pm individuated, as we will see later in Section 4. Above, I have defined the change from one stage to the other as a change in the status and the structure of A3. I will locate the change from stage 2 to stage 2' between Classical and Modern Standard French, i.e. the reanalysis resulting in the creation of the subparadigm presented in Table 9, where the distribution of pronouns referring to $\grave{a}+\mathrm{NP}$ is reanalysed in such a way as to depend on the semantic features of the referent.

In Romance varieties with extensive cross-reference, this device has turned into an additional marker of the relation between arguments, and as such it can be compared to the declension system of Latin, which I have analysed as a marker on nouns 
pointing to their function as arguments in the sentence (see Section 1). In advanced French as in many Modern Romance varieties, clitics point to the arguments by means of agreement, indicating the function of these arguments in the sentence and providing additional information on the features \pm human of the referent. As such, they become parts of complex paradigmatic structures of argument marking.

Table 9. The subparadigm of A3 of Modern Standard French, stage 2', examples (16ab); also relevant for Standard Italian and Catalan examples (16c-f)

Domain: V [A3]

Frame: referentiality

\begin{tabular}{ll}
\hline Expression & Content \\
\hline$\grave{a}+\mathrm{NP} /$ lui $/(y)$ & human referent \\
$\grave{a}+\mathrm{NP} / y$ & non-human referent \\
\hline
\end{tabular}

\subsection{Conclusion of Section 2}

In this section I have described the development from Latin to Modern Romance languages in terms of changes in the paradigmatic organisation of constructions. Let me briefly recapitulate the stages that I have uncovered.

- The prepositional marking of A3 was introduced by means of the preposition $a d+$ accusative. This was stage 1 .

- The use of $a d$ as marker of the recipient generalised and the PP was no longer the marked nominal form of the A3-paradigm. This was stage 2 .

- From this point, the Romance languages developed in partly different directions. I have distinguished between languages without prepositional A2 and languages with prepositional marking of an A2, which implies a modification of the relation between A2 and A3 (stage 3). In French, Italian and Catalan the features thuman showed its increased importance, as this distinction became relevant for the pronominal forms of A3 (stage 2'). In Spanish the change went a step further towards the partial merger of A2 and A3 (stage 4).

- Finally, cross-reference by means of clitic pronouns was introduced providing additional marking of arguments by cross-clausal indexing.

These changes imply that argument markers have accumulated from Latin to Modern Romance languages, ${ }^{136}$ forming paradigmatically organised constructions,

136. The expression "accumulated marking" should not be interpreted teleologically; languages simply differ with respect to e.g. the explicitness of argument marking. Accumulated 
simple or complex; in other words, we find a collaboration between grammatical subsystems. The marking of A3 and A2 and the identification of their referents are done by means of paradigmatically organised constructions, by means of case in pronouns, cross-reference, and, in advanced French, intonation. In other words, we have witnessed major shifts in argument marking, i.e. in case-role indexing. I consider such a collaboration between grammaticalised devices an instance of connecting grammaticalisation.

I have presented the development of the marking of A2 and A3 from Latin to Modern Romance languages in terms of successive structures or paradigms. The different stages were established on the criteria of the status and the structure of the marking of A3. The paradigms have the same domain (V A2 (A3)) and the same semantic frame: semantic role (patient, recipient, beneficiary ...) and status of the referent as + or - human. Some of these paradigms are simple, others are complex and synthetic, because they involve more than one opposition.

At each of the four stages, the paradigmatically organised constructions have reached a further step in the process of grammaticalisation, in the sense that their applicability has been extended: from few verbs to many concerning the A3marking, the spreading of the prepositional marking of A2, the spreading of crossreference, etc.

This section has supported the claim that we need to consider the marking of arguments, not in isolation, but in its interaction with other parts of the grammar, and that we must proceed by means of successive synchronic investigations in order to uncover the difference of structures. The synchronic analyses have made it possible to uncover the four stages of change which constitute chains of grammaticalisation.

\section{Formation of construction paradigms: The dative as second argument in French}

The preceding section presented the interaction of several grammaticalised categories, organised in complex paradigms and constructions, in a number of Romance languages studied over a long period. The following two sections focus on only one case

markers are morphological and constructional: prepositional arguments, cross-references etc. Topological markers (i.e. word order rules) are not relevant for the distinction between nominal A2 and A3 in Romance languages, which differ in this respect from other languages such as English and Danish, where nominal, non-prepositional, A3 must precede A2. See Bossong (1998c: 783) for examples of triple marking of syntactic functions. 
each, studied in just one language, French, in order to describe in detail the processes of formation of constructions. In the present section I will show the formation of the two-argument experiencer-constructions in French, e.g. le chocolat lui plait lit. 'chocolate pleases him' and il lui plairait de partir 'he would like to leave.' The section is intended to demonstrate the usefulness of constructions in our precise definition of the term and to illustrate the following claims:

- the two-argument experiencer-constructions in French constitute a continuation and a specialisation of classical Latin tendencies;

- the dative in classical Latin was widely used in a number of different case roles;

- from Latin to Modern French we witness a number of changes of the function of the dative in the case roles experiencer and recipient;

- these changes are the result of reanalyses that are best described as instances of regrammation and reparadigmatisation.

I will first provide a brief overview of the development of divalent dative patterns, ${ }^{137}$ focusing on four periods: (1) Latin, (2) Old and Middle French, (3) French of the Renaissance and Classical French, (4) Modern French, see list of electronic and written sources at the end of this chapter. Secondly, I will investigate the changes in detail, I will propose a scenario for the development, and I will show how verbs are excluded from and included in these constructions.

\subsection{Latin}

My presentation of the divalent dative patterns in Latin is based on Happ (1976), Pinkster (1990) and Van Hoecke (1976). In Latin many verbs govern the dative. In Section 2, I referred to the statistical study by Pinkster, who stated that the dative had the function of the second argument (A2) almost as frequently as it had the function of the third argument (A3). I quoted Christol (1998b:755), Van Hoecke (1996:32) and Pinkster, who found no clear motivation for the case distribution of arguments. Similar opinions are found in Blake (1994:144-145, 157) and Palmer (1954:295). However, there are interesting distributional patterns that could be analysed as constructions. I will examine these below.

137. As previously mentioned, the term divalent (and mono- or trivalent) is used at the lexical level of valency, whereas the term two-argument- (and one-argument- or threeargument-) is used at the construction level. When using the former term here, I want to indicate that not all divalent patterns with dative A2 develop into constructions - according to our definition of the term. 
Latin divalent verbs governing the dative are mainly found in impersonal patterns. Some verbs are found with both personal and impersonal patterns, with important differences of meaning between the two, which suggests that these may be cases of paradigmatic opposition, i.e. of constructions. The verb contingo illustrates my point. There is a personal construction with contingo, meaning 'I meet, I oppose', and a mainly impersonal construction, contingit, meaning 'it happens. The personal construction has a first argument (A1) which refers to an entity with the features +concrete. It has an A2, referring to an entity with the features \pm human in the dative or in the accusative case. The dative is used with a locative meaning, the accusative has both an allative and a locative meaning; see examples (17ab), both from Caesar, both indicating closeness of location of A1 and A2. The mainly impersonal construction differs from the personal one in three respects: it is found only in the 3rd person sg., A1 is impersonal, represented for example by an infinitive construction or an expression of occurrences happening (labelled -concrete, + predicational in Table 10), and A2, exclusively in the dative, indicates the person concerned or experiencer; see $(17 \mathrm{~cd})$.

a. ...ut radic-es mont-is ex utr-a-que part-e so that feet-NOM mountain-GEN from both-ABL side-ABL rip-ae flumin-is conting-ant bank-DAT river-GEN reach-PRS.SBJV.3PL

'so that the feet of the mountain are adjacent to the riverbank from both sides'

(Caesar BG 1,38)

b. Helv-i, qu-i fin-es

Helvi-NOM who-NOM borders-ACC

Arvern-orum conting-unt

Arverni-GEN reach-PRS.IND.3PL

'The Helvi, who border upon the territory of the Arverni'

(Caesar BG 7,7)

$\begin{array}{lll}\text { c. non cu- } i \text {-vis homin- } i \text { conting-it } & \text { adire Corinthum } \\ \text { not anyone.DAT man-DAT happen-PRs.3sg to go Corinth }\end{array}$

'It is not everybody's lot to go to Corinth' (Horace Ep. 1,17,36)

d. ... quod ist- $i$ contig-it un- $i$

which-NOM he-DAT happen-PST.3sg alone-DAT

'Which happened to him alone'

(Cicero, de Or.2,56,228)

The point here is that the function of the dative as an experiencer results from its being part of a construction and the construction is part of a complex paradigmatic opposition. The paradigm of the two-argument constructions illustrated by contingo is presented in Table 10. 
Table 10. Paradigm of the two-argument construction illustrated by contingo (Latin), examples $(17 \mathrm{a}-\mathrm{d})$

Domain: V A1 A2

Frame: abstract relation between $\mathrm{A} 1$ and $\mathrm{A} 2$

\begin{tabular}{|c|c|c|c|}
\hline Expression of A1 & Content of A1 & Expression of A2 & Content of A2 \\
\hline $\begin{array}{l}\text { NP in the nominative } \\
\text { (personal) }\end{array}$ & $\begin{array}{l}\text { A1 has a referent with } \\
\text { the features: non- } \\
\text { human +concrete } \\
\text {-predicational }\end{array}$ & $\begin{array}{l}\text { NP in the accusative } \\
\text { or dative }\end{array}$ & $\begin{array}{l}\text { A2 has a referent with } \\
\text { the feature non-human; } \\
\text { semantic role: patient }\end{array}$ \\
\hline $\begin{array}{l}\text { infinitive, neuter } \\
\text { pronoun or abstract } \\
\text { NP in the nominative } \\
\text { (impersonal) }\end{array}$ & $\begin{array}{l}\text { A1 has a referent with } \\
\text { the features non- } \\
\text { human, non-concrete, } \\
\text { +predicational }\end{array}$ & $\mathrm{NP}$ in the dative & $\begin{array}{l}\text { A2 has a referent with } \\
\text { the feature +human; } \\
\text { semantic role: } \\
\text { experiencer }\end{array}$ \\
\hline
\end{tabular}

The opposition between the two constructions is not only found with this verb. A series of verbs are found in personal constructions governing the dative, such as verbs denoting confidence or their antonyms: fido, diffido; verbs meaning help: 'I favour, I spare': faveo, parco, assideo ('I assist'); verbs meaning 'I oppose': adversor, obsto, occurro, resisto; verbs meaning 'I please' or their antonyms: placeo, invideo, displiceo; verbs meaning presence/absence: sum (est mihi lit. it is for me, i.e. 'I have'), desum, resto; verbs meaning 'I obey': obtempero, cedo, pareo, and the verb praesum 'I command. These verbs do not form a clearly delimited semantic group, although they include many psych-verbs, neither can any common feature be identified concerning the choice of the dative or the accusative case of A2, which mainly takes the function of a patient. But the construction as a whole is opposed to the mainly impersonal construction, always in the 3rd person sg., with an experiencer-A2 in the dative. A series of verbs instantiate this construction: verbs meaning importance: interest 'it is important'; verbs indicating psychological reactions: placet ( $p$. mihi lit. to me it is pleasant, i.e. 'I am pleased'), piget ( $p$. mihi lit. to me it is boring, i.e. 'I am bored') pudet ( $p$. mihi lit. to me it is shaming, i.e. 'I am ashamed'), paenitet ( $p$. mihi lit. to me it is regrettable, i.e. 'I regret'); verbs meaning 'to be allowed': licet; verbs meaning 'to seem': videtur. (Some verbs are found with both the personal and the impersonal construction, e.g. placeo. I shall return to the verb 'to please' - which is often taken as the model of psych-verbs - in the following subsections). The mainly impersonal type is highly marked as it is found only in the 3rd person singular, the constituents of A1 and A2 are very restricted, and the content of the construction is to indicate that a person (i.e. an experiencer) is affected by some, mainly psychological, process, frequently represented by a sentential A1. Table 10 presented the paradigmatic opposition between the two constructions illustrated by contingo. If we compare this paradigm to the threeargument one identified for Latin in Section 2, Table 1, illustrated by mitto 'I send', and 
to Table 3a we clearly see that the difference of content of the dative argument depends on its hieararchical position in the construction: if $\mathrm{A} 3$, it is a recipient, if $\mathrm{A} 2$, it is an experiencer. Combining these paradigms, we obtain the overview of a few two- and three-argument constructions shown in Table 11. Note that this paradigm is only valid for a small selection of verbs (see the list above).

Table 11. Paradigm for two- and three-argument constructions in (Late) Latin

Domain: V A1 A2 (A3)

Frame: abstract relation between $\mathrm{A} 1, \mathrm{~A} 2$, and $\mathrm{A} 3$

\begin{tabular}{|c|c|c|c|c|c|}
\hline \multicolumn{2}{|r|}{ A1 } & \multicolumn{2}{|r|}{ A2 } & \multicolumn{2}{|c|}{$\mathrm{A} 3^{138}$} \\
\hline Expression & Content & Expression & Content & Expression & Content \\
\hline $\begin{array}{l}\text { verbal } \\
\text { inflection or } \\
\text { NP in the } \\
\text { nominative } \\
\text { (personal) }\end{array}$ & $\begin{array}{l}\text { A1 has a } \\
\text { referent with } \\
\text { the features: } \\
\text { non-human } \\
\text { +concrete } \\
\text {-predicational }\end{array}$ & $\begin{array}{l}\text { NP in the } \\
\text { accusative } \\
\text { NP in the } \\
\text { dative }\end{array}$ & $\begin{array}{l}\text { A2 has a } \\
\text { referent with } \\
\text { the features } \\
\text { non-human; } \\
\text { semantic role: } \\
\text { patient }\end{array}$ & $\begin{array}{l}\text { dative form } \\
\text { /PP: ad }+ \\
\text { accusative }\end{array}$ & $\begin{array}{l}\text { A3 has a } \\
\text { referent } \\
\text { with the } \\
\text { features } \\
\pm \text { human; } \\
\text { semantic } \\
\text { role: } \\
\text { recipient }\end{array}$ \\
\hline $\begin{array}{l}\text { verbal } \\
\text { inflection, } \\
\text { infinitive, } \\
\text { neuter } \\
\text { pronoun or } \\
\text { abstract NP in } \\
\text { the nominative }\end{array}$ & $\begin{array}{l}\text { A1 has a } \\
\text { referent with } \\
\text { the features: } \\
\text { non-human, } \\
\text { non-concrete, } \\
\text { +predicational }\end{array}$ & $\begin{array}{l}\text { NP in the } \\
\text { dative }\end{array}$ & $\begin{array}{l}\text { A2 has a } \\
\text { referent with } \\
\text { thefeatures } \\
\text { +human; } \\
\text { semantic role: } \\
\text { experiencer }\end{array}$ & & \\
\hline
\end{tabular}

In the following subsections I intend to show that the modifications of the twoargument constructions during the subsequent periods are the result of reanalyses that are best described as instances of regrammation and reparadigmatisation, resulting in the grammaticalisation of the two-argument construction of Table 10 for expressing the relation of experiencer with Modern French psych-verbs.

\subsection{Old and Middle French}

Old and Middle French display constructions similar to the ones found in Latin, in spite of several changes in the inventory of the constructions. Many verbs have no direct continuation in French, but several of those that continue have a choice between the accusative and the dative A2 during the period, as I will show in this subsection.

In Table 10 I illustrated the two-argument dative constructions by contingo, which, however, did not survive as a verb in French. I will illustrate the patterns of psych-verbs in Old and Middle French by means of the verb abelir 'to be agreeable', 
derived from the adjective bel 'beautiful', 'agreeable'. This verb was found in a personal pattern, with an A1 referring to an entity with the semantic features \pm human in the nominative case in texts preserving the declension system, and an A2 referring to an entity with the feature +human, indicating the experiencer, in the dative (or $\grave{a}+\mathrm{NP}$ ); see examples $(18 \mathrm{a}-\mathrm{b})$. The neuter or impersonal pattern was found only in the third person singular, with a neuter or a sentential A1 and an A2 having a referent with the feature thuman, indicating the experiencer in the dative (or $\grave{a}+\mathrm{NP}$ ); see examples $(18 \mathrm{c}-\mathrm{d})$. The sentential A1 was occasionally represented by a dummy pronoun $i l$.

a. Dames, ainz voir ne m'abelil Ladies, never certainly NEG me.ACC/DAT.1sG please-PST.IND.3sG/

Chevaliers nus que je veisse, /

Knight-NOM none-NOM that I see-PST.SBJv.1sG

.../Tant con fet Malianz de Liz

.../.. to.the.extent that do-Prs.IND.3sg Malianz de Liz

'Ladies, no Knight that I have seen ever pleased me so much as

Melianz de Liz did'

(Perceval 4970)

b. ...Et comanda à Deu celi/ and command-PST.3sg to God-obl she.F.3sg /

Cui se-s salu-z point nabeli

who.DAT his-NOM greeting-NOM NEG NEG=please-PST.3sG

'.. and commanded to God her, whom his greeting did not please'

(Perceval 764)

c. ...ce mabeli

this me.ACc/DAT please-PST.3sG

'it pleased me' (referring to the preceding text)

(Yvain 234)

d. A Percheval molt abeli /

To Perceval-oвL much please-Pst.3sg /

$\begin{array}{llll}\text { ce qu'il } & \text { vit } & \text { une } & \text { hache pendre } \\ \text { DEM COMP=he } & \text { see-PST.3sG } & \text { INDEF.F.SG axe hang }\end{array}$

'It pleased Perceval very much that he saw an axe hanging'

(Perceval ms. C, Nouveau Corpus d'Amsterdam)

Just as in Latin, we find an opposition between the personal and the impersonal pattern depending on the form of the verb and on the expression and content of A1. But we do not find a corresponding opposition between two realisations of A2 - accu-

138. The dative form of A3 presupposes a non dative form of A2. 
sative or dative. In Old and Middle French, A2 had similar expression and similar content in the two patterns: NP in the dative form (or introduced by the preposition a) - as did some of the comparable Latin psych-verbs, e.g. placeo, 'please' as mentioned above. Put differently: the paradigmatic opposition in Table 10, illustrated by contingo, is not found in Medieval French. This implies, as shown in Table 12, that there is no paradigmatic opposition between the personal and the impersonal patterns of psych-verbs in Old and Middle French:

Table 12. Patterns of the two-argument constructions illustrated by abelir (Old and Middle French), examples (18a-d)

\begin{tabular}{|c|c|c|c|}
\hline Expression of A1 & Content of A1 & Expression of A2 & Content of A2 \\
\hline $\begin{array}{l}\text { NP in the nominative } \\
\text { (personal) }\end{array}$ & $\begin{array}{l}\text { A1 has a referent with the } \\
\text { features } \pm \text { human }\end{array}$ & \multirow[t]{2}{*}{ dative or à $+\mathrm{NP}$} & \multirow{2}{*}{$\begin{array}{l}\text { A2 has a referent } \\
\text { with the features } \\
\text { +human; semantic } \\
\text { role: experiencer }\end{array}$} \\
\hline $\begin{array}{l}\text { demonstrative pronoun } \\
\text { (neuter), infinitive, } \\
\text { subordinate clause } \\
\text { (impersonal) }\end{array}$ & $\begin{array}{l}\text { A1 has a referent with the } \\
\text { features non-human, non- } \\
\text { concrete, + predicational }\end{array}$ & & \\
\hline
\end{tabular}

These patterns are found with a series of two-argument verbs; examples are verbs meaning 'to please'139 or their antonyms: agreer, atalenter (des)plaisir, ennoyer, loisir, nuisir, seoir; verbs meaning 'to deplore': peser, grever; verbs meaning 'to wait for', 'to expect': targier, demorer. Other verbs are only found with a dative in their impersonal constructions, e.g. verbs meaning 'to happen': avenir; verbs meaning 'to care about': chaloir; verbs meaning 'to remember': remembrer, sovenir, or are only found in personal constructions: verbs meaning 'to help': aider, assister, servir, (secourir acc./dat.); verbs meaning 'to instruct': endoctriner; verbs meaning 'to harm', 'to betray': faillir, forfaire, mesfaire. Other verbs that do not form a semantic group are mentir 'to lie', obéir 'to obey', ressembler 'to look like'. With verbs that only instantiated one of the construction possibilities, the dative A2 was associated with the role of experiencer, e.g. with the verb obeir.

The patterns in Table 12 are opposed to different di- and trivalent patterns presented in Table 13, where we find alternation in case marking (accusative or dative)

139. As suggested by Noël (2006:23-24), it might not have been without consequence for the emergence of this construction that Latin placere $>$ French plaire, which is the prototypical representative of this class of verbs, was consistently used with a dative in the entire period. Note that there is no "standard" spelling of Old French, the spelling adopted here is just one of several possible ones. 
and in functions (patient or experiencer) of A2. Example (18e) illustrates the default three-argument construction with a dative recipient. The default two-argument construction with an oblique patient is illustrated in (18f). The variation between the dative form of the patient (18g) and the accusative form of the patient (18h) is illustrated by the verb aidier 'to help' found in the same author, Chrétien de Troyes, without any clear difference of content between the two expressions of A2, just as we saw in Latin, with the personal construction of the verb contingo. The personal and the neutral or impersonal construction are exemplified in (18ab) and (18cd), respectively.

e. Encor ai ge .lx. de vozper-s /

still have.PRs.1sG I 40 of your.OBL.PL peer-OBL.PL/

a cui ge nai ne

to who.DAT.SG I NEG=have-PRs.1sG NEG COORD

promis ne doné [rien]

promise-PRF PTCP NEG COORD give-PRF PTCP

'I still have 40 of your peers to whom I have neither promised nor given [anything]'

(Charroi de Nîmes, ms. A2 v. 280-281)

f. Ne les osast veïr në esgarder

NEG they.ACC.PL dare-PST.SBJv.3SG see NEG look

'[he] dared neither see them nor look at them'

(Charroi de Nîmes, ms. C v. 1043)

g. Et la pucele li aïe/

and DET.sg maiden he.DAT.Sg help-PRs.3sg /

$\mathrm{Au}$ mialz qu'el set

at-DET.SG best COMPL she know-PRs.3sG

et quele puet

and COMPL she can-PRs.sG

'And the maiden helps him the best she can'

(Perceval 6716)

h. Et cort por aidier son seignor

and run-PRs.3sG for help his.oBL.SG master-OBL.SG

'And he runs off in order to help his master'

(Erec 4987)

My point here is that the divalent dative A2 pattern was not yet grammaticalised, since no precise content could be ascribed to the choice between the dative and the accusative form of A2 with verbs such as aider, assister, endoctriner, servir, and secourir. But with a specific series of verbs, such as abelir, we see the generalisation of the dative A2 in the role of experiencer in the two-argument impersonal pattern. 
Table 13. Overview of different di- and trivalent patterns in Old and Middle French, examples (18)

\begin{tabular}{lll}
\hline $\begin{array}{l}\text { A1: nominative } \\
\text { (pro)noun/null subject }(\varnothing) / \\
\text { subordinate clause }\end{array}$ & $\begin{array}{l}\text { A2: accusative form of (pro) } \\
\text { noun/PP introduced by } a / \\
\text { dative pronoun }\end{array}$ & $\begin{array}{l}\text { A3: PP introduced by } a / \text { dative } \\
\text { pronoun }\end{array}$ \\
$\begin{array}{l}\text { (18e) nominative pronoun: ge } \\
\text { accusative rien (patient) }\end{array}$ & $\begin{array}{l}\text { a+dative pronoun } a \text { cui } \\
\text { (recipient) }\end{array}$ \\
$\begin{array}{l}\text { esgarder/cort por aidier... } \\
\text { (18g) NP: la pucele aïe }\end{array}$ & $\begin{array}{l}\text { accusative les/son seignor } \\
\text { (patient) }\end{array}$ & dative li (patient) \\
$\begin{array}{l}\text { (18a) }(18 \mathrm{~d}) \mathrm{NP} / \text { subordinate } \\
\text { clause: Chevaliers nus abelit/ } \\
\text { abeli..ce que.. }\end{array}$ & $\begin{array}{l}\text { dative } \text { me (experiencer) } \\
\text { (experiencer) }\end{array}$ & \\
\hline
\end{tabular}

It should be mentioned here that a choice between the accusative and the dative form was also found with trivalent verbs, as convincingly shown in Lüdi (1978). Lüdi discusses the choice of case with verbs of communication concerning the expression of the addressee found in the accusative or in the dative form/PP introduced by $\dot{a}$. The author investigates whether this was a case of confusion of forms, a case of confusion of functions, or whether it corresponded to a difference in meaning. In certain dialects a few cases of confusion of the accusative/dative forms were found (Lüdi 1978:172), but as stated in Section 2, no genuine confusion of the functions of A2 and A3 was found in Old French (Lüdi 1978: 180, 181). Lüdi finds it impossible to assign any clear difference in meaning to the choice between the two case forms. In (19a) we find the default three-argument construction with the person who asks a favour (=Oliuier) as $\mathrm{A} 1$, the thing asked for (a subordinate clause) as A2, and the person of whom the favour is asked as A3 (au roy), represented by a PP equivalent to a dative form of the personal pronoun. Example (19b) does not follow this default construction, as the person asked $(=\mathrm{A} 3)$ is represented by an accusative form of the personal pronoun (la), and $\mathrm{A} 2$ by an infinitive clause (de demeurer). In the two-argument construction of (19c), without the expression of the A2, i.e. of a favour, we find the person addressed (in principle an A3, dieu) in the accusative form. According to Lüdi, the dative ( $\grave{a}$ $\mathrm{Dieu}$ ) and the accusative often alternate in sentences without an expressed A2 with no difference in meaning, as far as he can tell. In other words: this is not a construction because there is no paradigm. And there is no paradigm, because the choice between case forms does not correspond to a choice between two meanings.

140. In this and in the following tables we refer to the cases 'nominative', 'accusative' and 'dative', although many texts do not preserve the distinction between the first two cases. The term 'dative' is short for 'an NP or a PP introduced by the preposition à equivalent to the dative 
(19)

a. Oliuier requist au roy dangliterre

Olivier ask-PST.3sg to-DET.SG king of England

qui [=qu'il] luy baillast gens

that he he-DAT.SG give-PST.SBJv.3sg men

'Olivier asked the King of England to provide him with men'

(Lüdi 1978: 161)

b. Elle la pria tresinstamment

she she.ACC.SG ask-PST.3sg insistently

de demeurer en la court

to stay at DET.SG Court

'she implored her to stay at Court'

(Lüdi 1978:164)

c. Ainsi se lamentoit,

in this way he-REFL PRON complain-PST.IPFV.3SG

ainsi prioit dieu

in this way ask-PST.IPFv.3sg God-obL.sG

le noble Pierre

DET.SG noble-obL.sg Pierre

'in this way the noble Pierre complained, and prayed to God'

(Lüdi 1978: 164)

In order to analyse the function of the dative in di- and trivalent patterns, let me briefly turn to Herslund (1980), which, as far as I am aware, is the only study devoted entirely to the use of the dative in Old French. Like the author's dissertation on the dative in Modern French (1988), it is a purely synchronic study. Herslund (1980) defines the use of the dative in Old French as designating the argument having the role of the recipient, represented by $\mathrm{Z}$ in the three-argument construction: $\mathrm{X}$ gives $\mathrm{Y}$ to $\mathrm{Z}$. The dative in the two-argument construction is explained by the existence of an underlying object. Accordingly, the verb 'to help', aider, supposedly has an underlying structure identical to that of the three-argument one that can be paraphrased as 'X gives help to Z' (1980:51). However, the author does not explain why secorre, a synonym of aider, which is allegedly followed by the accusative, does not have the same underlying structure, nor does he explain why aider no longer has this structure in Modern French. In Old French, however, secorre was followed both by the accusative and by the dative, although apparently not in Herslund's data. Should we then understand that this verb can be paraphrased as 'to provide help' only in the examples with

form of the personal pronoun'. In the glosses, оBL for oblique is the designation for the form of an NP which does not have a subject function. 
the dative? It appears from the analysis proposed by the author for aider and similar divalent verbs that the definition of the dative A2 as an underlying A3 is partly semantically motivated, in terms of a semantic decomposition of the lexeme into basic components, and partly formally motivated. I do not believe that Herslund's analyses provide an adequate description of the constructions found in Old French, nor do they offer the prerequisites for an interpretation of the changes that have occurred with these verbs.

In general, the period between 1300 and 1600 has been poorly described. There is, however, some information on the two-argument construction in Goyens (2000, 2001) and Troberg (2006), see also Roberge \& Troberg (2006). The studies by Goyens permit me to consider more closely the development of a number of divalent verbs governing the dative and the accusative. I have grouped the information presented in her articles in Table 14. None of the verbs in Table 14 show a straightforward development from Latin to Modern French. In several cases the Latin etymon had two construction possibilities. We have already seen that the Old and Middle French periods present extensive variation, which in most cases did not stop before the normative postclassical period. It is presumed in this table that no semantic change of the verbs influenced the development. For the sake of simplicity I preserve the case labels 'accusative' and 'dative' through the periods, although these cases are only found in the personal pronouns in French after the Old French period.

It appears from Table 14 that both the accusative and the dative were extensively used in the function of A2 until the 17th century when such verbs decide on only one case, which is generally the one used in Modern Standard French. This is also the conclusion of the statistical study by Troberg (2006) who has investigated the alternation of the accusative and the dative in a series of verbs. ${ }^{141}$ According to her, the period of transition was between 1500 and 1700. After 1700, the parallel use of the accusative and the dative was exceptional, and the modern pattern was in place. I suggest that this was due to two partly overlapping factors: the normative tendency of Classical French, especially after 1700, and - more interestingly for my topic - the structural internal motivations for the reanalysis of the two-argument dative patterns, which grammaticalised.

In this subsection we have seen that Old and Middle French showed alternation between the dative and the accusative with psych-verbs and with a number of other verbs, such as verbs of communication. The two-argument patterns with the dative A2 continued the classical Latin patterns: an impersonal and a personal one. The impersonal pattern had the dative form of A2 with the role of an experiencer, like the impersonal use of contingit in Table 10. The personal pattern displayed case

141. The verbs examined by Troberg include: aider, applaudir, assister, commander, congratuler, contrarier, contredire, ennuyer, épargner, éviter, favoriser, insulter, prier, servir, secourir, soigner, administrer (=servir), empêcher (=gêner), voir (=veiller), persuader, requérir. 
Table 14. The development of the case marking of the etyma of a series of French verbs

\begin{tabular}{|c|c|c|c|c|c|c|}
\hline Verbs & Latin & $\begin{array}{l}\text { Old } \\
\text { French }\end{array}$ & $\begin{array}{l}\text { Middle } \\
\text { French }\end{array}$ & 16th c. & 17 th $\mathrm{c}$. & $\begin{array}{l}\text { Modern } \\
\text { French }\end{array}$ \\
\hline $\begin{array}{l}\text { déroger }<\text { derogare 'take } \\
\text { away' }\end{array}$ & $\begin{array}{l}\text { accus } \\
\text { dative }\end{array}$ & $\begin{array}{l}\text { accus } \\
\text { dative }\end{array}$ & $\begin{array}{l}\text { (accus) } \\
\text { dative }\end{array}$ & $\begin{array}{l}\text { (accus) } \\
\text { dative }\end{array}$ & dative & dative \\
\hline faillir < fallere 'deceive' & accus & $\begin{array}{l}\text { accus } \\
\text { dative }\end{array}$ & $\begin{array}{l}\text { accus } \\
\text { dative }\end{array}$ & $\begin{array}{l}\text { accus } \\
\text { dative }\end{array}$ & $\begin{array}{l}\text { accus } \\
\text { dative }\end{array}$ & dative \\
\hline mentir < mentiri 'lie' & $\begin{array}{l}\text { accus } \\
---\end{array}$ & $\begin{array}{l}\text { accus } \\
\text { dative }\end{array}$ & $\begin{array}{l}\text { accus } \\
---\end{array}$ & accus & dative & dative \\
\hline obéir < oboedire 'obey' & dative & $\begin{array}{l}\text { accus } \\
\text { dative }\end{array}$ & $\begin{array}{l}\text { accus } \\
\text { dative }\end{array}$ & $\begin{array}{l}\text { accus } \\
---\end{array}$ & dative & dative \\
\hline $\begin{array}{l}\text { ressembler }<\text { re+similare } \\
\text { 'I am alike' }\end{array}$ & $\begin{array}{l}\text { accus } \\
\text { dative }\end{array}$ & $\begin{array}{l}\text { accus } \\
\text { dative }\end{array}$ & $\begin{array}{l}\text { accus } \\
\text { dative }\end{array}$ & $\begin{array}{l}\text { accus } \\
\text { dative }\end{array}$ & $\begin{array}{l}\text { accus } \\
\text { dative }\end{array}$ & dative \\
\hline $\begin{array}{l}\text { contredire < contra + } \\
\text { dicere 'say' }\end{array}$ & dative & $\begin{array}{l}\text { accus } \\
\text { dative }\end{array}$ & $\begin{array}{l}\text { accus } \\
\text { dative }\end{array}$ & $\begin{array}{l}\text { accus } \\
\text { dative }\end{array}$ & $\begin{array}{l}\text { accus } \\
\text { (dative) }\end{array}$ & accus \\
\hline $\begin{array}{l}\text { empêcher <impedicare } \\
<\text { impedire 'hinder' }\end{array}$ & $\begin{array}{l}\text { accus } \\
\text { dative }\end{array}$ & $\begin{array}{l}\text { accus } \\
\text { dative }\end{array}$ & $\begin{array}{l}\text { accus } \\
\text { dative }\end{array}$ & $\begin{array}{l}\text { accus } \\
---\end{array}$ & $\begin{array}{l}\text { accus } \\
\text { dative }\end{array}$ & accus \\
\hline $\begin{array}{l}\text { prévenir }{ }^{142}<\text { praevenire } \\
\text { 'anticipate' }\end{array}$ & accus & --- & $\begin{array}{l}\text { accus } \\
\text { dative }\end{array}$ & $\begin{array}{l}\text { accus } \\
\text { dative }\end{array}$ & accus & accus \\
\hline $\begin{array}{l}\text { supplier < supplicare } \\
\text { 'make petition to' }\end{array}$ & $\begin{array}{l}\text { accus } \\
\text { dative }\end{array}$ & dative & $\begin{array}{l}\text { accus } \\
\text { dative }\end{array}$ & $\begin{array}{l}\text { (accus) } \\
\text { dative }\end{array}$ & dative & accus \\
\hline
\end{tabular}

alternation. In the following period, we will see the first signs of the emergence of a genuine construction following the model of impersonal contingit. This emergence is accompanied by the exclusion of deviant verbs from this pattern. I will exemplify the process of exclusion with the verb aider 'to help', which originally mainly governed the dative, but which in Modern Standard French is exclusively followed by the accusative. I will focus on the period 1500-1799 (Renaissance and Classical French), since Table 14 and Troberg's data clearly show that this was the relevant period of change. This period will permit us to study the steps of the change in detail, i.e. the actualisation processes which follow the reanalysis.

\subsection{The development of the verb aider from 1500-1799}

The verb aider has been studied in FRANTEXT in a corpus of three different registers: a selection of novels (see examples (20a-h)), a corpus of private letters, and a selection of sermons, essays and scientific texts. ${ }^{143}$ The corpus of the 16 th century does not have

142. Prévenir is a loan introduced in the 15 th century.

143. I want to thank Xavier Lepetit for having compiled the corpus. The compilation was made in 2007. 
a single example of aider followed by the accusative form. Typical examples from the corpus of novels are quoted in (20ab).

(20) a. mais il ne se faisoit point de mal: Dieu lui aidoit tousjours.

'but he did not make much effort. God always helped him (dative)'.

(B. Des Périers: Les Nouvelles récréations et joyeux devis 1. (1558: 517) Nouvelle LXXVII, Du bon yvrogne Janicot et de Jannette sa femme)

b. Ajoustant pour conclusion que s'il vouloit tenir cela secret et leur aider de son conseil...

'He concluded by adding that if he would keep this secret and help them (dative) with his advice.'

(P. Boaistuau: Histoires tragiques (1559: 180). Sommaire de la sixième

histoire)

In the 17th century we witness increasing variation between the constructions. One author (J.-P. Camus) exclusively used the accusative construction (20c); all the other authors showed variation between the dative $\mathrm{e}^{144}$ - which is predominant $(20 \mathrm{~d})$, as it is found in $67.5 \%$ of the examples - and the accusative, as in (20e), in $32.5 \%$. No clear pattern of distribution can be identified.

c. 〈Quand elle vit l'object de sa vie, soudain elle ressuscita, et comme elle le vit empesché à faire secourir Glaphire, son amour, enfant de la complaisance, $\rangle$ [cela] la porta aussi tost à l'aider en ces devoirs

'... [this] motivated her to help her with her duties'.

(J.-P. Camus: Palombe ou la Femme honnorable (1625:119) Livre (2)

d. Les bergeres ... peurent encores aider à la nymphe à prendre sa robe 'The shepherdesses... could help the nymph to take her clothes ...' (Honoré d'Urfé: L' Astrée (1631:556) Livre 10)

e. Merindor et Periandre aidoient Dorinde à descendre; 'Merindor and Periandre helped Dorinde to step down'. (Honoré d’Urfé: L’ Astrée (1627:487) Livre (9)

The 18th century offers extensive variation with every author, with a predominance of the accusative construction, found in $72.2 \%$ of the examples. The dative construction is found in $27.8 \%$; the accusative is especially frequent with animates, as in (20f);

144. All ambiguous forms have been excluded from this investigation. A few examples of $y$ are found, corresponding to $\grave{a}+$ NP. They have also been excluded. 
$\grave{a}+\mathrm{NP}$ persists, especially with inanimates, see $(20 \mathrm{~g}-\mathrm{h})$. Pronouns are exclusively found in the accusative.

f. ... peut-être aussi elle vouloit aider Schézaddin, ...' and possibly she wanted to help Schézaddin,..'

(Crébillon fils: Ah quel conte! (1751:144) Livre 1, partie 2, chapitre 11)

g. Peut-elle aider encore à l'illusion ... ? 'can she still help (=support) the illusion ...?'

(Crébillon fils: Ah quel conte! (1751:26) Livre 1, partie 1, chapitre 3)

h. Mais vous savez combien le coeur aide à la mémoire, il ne lui échappe rien.

'But you know how much the heart helps memory, nothing gets lost.' (L' Abbé Prévost: Nouvelles lettres angloises ou Histoire du chevalier Grandisson (1755: 18) Lettre 59)

In the second corpus, the collections of private letters in FRANTEXT, the development is comparable: in the 17th century we find aider followed by the accusative in $25 \%$ of the cases, and in the 18 th century in $74 \%$ of the cases. In the 18 th century all personal pronouns are in the accusative form and no animate nouns are found with the preposition $\dot{a}$. From the 19th century the accusative is generalised in Standard French. However, the construction with $a$ followed by an inanimate noun is occasionally found in the 19th century (20i). The dative and the corresponding construction with $\grave{a}+\mathrm{NP}$ is, however, still found in dialectal and in francophone varieties, for example in the dialect of Languedoc and in Modern Canadian French, see $(20 \mathrm{j}) .{ }^{145}$

i. Il enveloppe un côté de l'estomac, et aide à la digestion par sa chaleur 'it covers one side of his stomach and helps the digestion by its heat' (Marivaux: Le Paysan Parvenu, quoted by Troberg (2006))

j. J'aide à Marie à faire la vaisseille - Je lui aide à faire la vaisselle, 'I help to Mary to wash the dishes' - 'I help her (dative form of the pronoun) to wash the dishes'.

In the third corpus (sermons, essays, and scientific texts), the development proceeds more slowly, and a higher degree of individual variation among authors is found, see (20kl). In this high register of texts we do not see the spreading of the accusative according to the hierarchy found in the previous corpora. I interpret the strong variation found here as an effect of style. It is noteworthy that Vaugelas $(1647,2000: 479)$

145. France Martineau (University of Ottawa) has kindly provided these examples. 
recommends the use of the accusative form instead of the dative/prepositional form with verbs expressing help, such as servir and assister.

k. Vous lui devez vingt pistoles qui sauveroient la vie à sa femme malade, ou qui lui aideroient à marier sa fille;

'You owe him 20 pistols, which could save the life of his sick wife, or which could help him (dative form of the pronoun) to marry his daughter'

(Charles-François-Nicolas Le Maître de Claville: Traité du vrai mérite de l'homme (1736:294) Chapitre (5)

1. L'astronomie, qui lui avoit servi à découvrir ces riches pays, lui aida aussi à s'y établir.

'Astronomy, which had helped him (dative form of the pronoun) to discover these rich countries also helped him (dative form of the pronoun) to settle there.'

(Charles Rollin: Histoire ancienne des Égyptiens (1738:642) Tome (6)

The process of change found with aider is interesting for at least the following reasons:

- the verb is in the process of adopting the default construction of transitivity (A2 having the function of patient is found in the accusative form) from the start of the 17 th century, i.e. shortly before the period of strong normative pressure on the language;

- the change started in the pronouns, then spread to nouns, animate nouns before inanimate nouns, in the lower registers. This process of development is in accordance with the referential hierarchy reproduced in Section 2.2 (8d) and with the spreading process predicted by Andersen's actualisation theory for internally motivated changes (see the discussion of Andersen 2001abc in Chapter 1);

- the change is found in relatively plain style, novels and private letters, so it should be considered to be a change starting in unmarked contexts, i.e. from below, with no influence from the Remarqueurs. The change proceeds more slowly in high style, and here it does not follow the referential hierarchy. I interpret this as the result of a more elaborate, less spontaneous style.

I believe that two important changes took place during the period from Latin to Old and Middle French. Firstly, the dative A2 was reanalysed as experiencer in the divalent pattern, and the paradigm in Table 10 was generalised to divalent psych-verbs; secondly, as correctly observed by Noël (2006:19), the accusative A2 was generalised as the default two-argument construction. The correctness of my analysis is confirmed by the transfer of aider and its synonyms, as well as that of other verbs that did not really fit into the two-argument dative pattern, from the experiencer-pattern to the default pattern because their A2 had the form, but not the content (=the case role experiencer) of the two-argument dative pattern. 


\subsection{Modern French, standard and advanced}

In Modern French, the two-argument dative construction of psych-verbs is represented in a relatively transparent paradigm, opposed to the default two-argument construction; see Table 15. As in the preceding periods, there is both a personal and an impersonal construction, with a number of verbs instantiating both. The verb forms display the differences we have seen previously; the expression and the content of A1 show the opposition between a personal and a sentential argument represented by a neutral pronoun, most frequently the dummy $i$. With a few exceptions, the dative $\mathrm{A} 2$ has become restricted to the case role of the experiencer, and new verbs adopt this paradigm, which shows its productivity. I will illustrate the experiencer construction in Modern French with the verb plaire 'to please'. The verb is found both in the personal (21a) and in the impersonal (21b) construction. The default direct object construction is illustrated by the verbs chanter 'sing' and prendre 'take' $(21 \mathrm{~cd})$ :

(21) a. Luc/ le chocolat/la musique classique plaît à Marie

'Luc/ chocolate/ classical music pleases Mary'

b. Faites ce qu'il lui plaira

'Do what pleases him'

c. Luc chante la chanson

'Luc sings the song'

d. Luc prend le livre

'Luc takes the book'

Table 15. Paradigm of the two-argument dative constructions in Modern French, illustrated by the verbs plaire 'to please', chanter 'to sing' and prendre 'to take', examples (21a-d)

Domain: V A1 [A2]

Frame: the function of A2

\begin{tabular}{ll|l|l}
\hline Expression of A1 & Content of A1 & \multicolumn{1}{|l}{ Expression of A2 } & Content of A2 \\
\hline NP (personal) & $\begin{array}{l}\text { A1 has a referent with the } \\
\text { feature } \pm \text { human; } \\
\text { semantic role: agent }\end{array}$ & $\begin{array}{l}\text { direct object } \\
\text { (pronoun in the } \\
\text { accusative) }\end{array}$ & $\begin{array}{l}\text { A2 has a referent with } \\
\text { the feature } \\
\pm \text { human; semantic } \\
\text { role: patient }\end{array}$ \\
\hline NP (personal) & $\begin{array}{l}\text { A1 has a referent with the } \\
\text { feature } \pm \text { human }\end{array}$ & $\begin{array}{l}\text { pronoun in the } \\
\text { dative/a }+ \text { NP }\end{array}$ & $\begin{array}{l}\text { A2 has a referent with } \\
\text { the feature +human; } \\
\text { semantic role: } \\
\text { experiencer }\end{array}$ \\
\hline $\begin{array}{l}\text { dummy subject } \\
\text { (impersonal) }\end{array}$ & $\begin{array}{l}\text { A1 has a referent with the } \\
\text { features: non-human, non- } \\
\text { concrete, +predicational }\end{array}$ & & \\
\hline
\end{tabular}

A series of verbs instantiate both experiencer-constructions, for example verbs meaning that the subject is or is not suitable for the experiencer, such as agréer, aller, convenir, profiter, servir, suffire; synonyms or antonyms of plaire: déplaire, nuire, peser, 
répugner; verbs meaning that something happens to somebody: advenir, apparaître, arriver, échapper, parvenir, revenir, survenir; verbs indicating belonging or lacking, such as falloir, manquer, importer, incomber, appartenir. Other verbs show only the personal construction; e.g. moral predicates: (dés)obéir, être fidèle, loyal; verbs of intransitive communication: mentir, sourire; new verbs: téléphoner, causer ('to talk'); verbs meaning equivalence: ressembler, succéder; survivre. In Standard and Advanced French new verbs have joined this construction, especially two types expressing that something is happening to an experiencer: (1) verbs (frequently verbs of movement) + a particle representing an activity most often harmful to the referent of $\mathrm{A} 2$, il lui court après 'he is following her', ils lui tirent dessus 'they are shooting at him', l'évidence lui est tombée dessus 'he was taken aback by the evidence, and (2) expressions meaning that A1 is suitable for or appreciated by A2: ça (lui) parle, ça (lui) dit. ${ }^{146}$ Interestingly, verbs are found both in the experiencer-construction and in the default direct object construction, with a clear difference of meaning, just like contingere in classical Latin (see Table 10). Examples are e.g. chanter, see (21c and 21e) and prendre, see (21d and 21f) and newly coined constructions with dire, tomber etc. Presented in this way, what is normally interpreted as single isolated instances of verbal polysemy, reveals itself as regular constructional differences.
e. cela lui chante
'this pleases him'
f. qu'est-ce qui lui prend?
'what comes over him'

Most of the verbs listed above fit nicely into the paradigm presented in Table 15, and their dative A2 represents the experiencer. Two deviant cases are found: verbs of intransitive communication and verbs meaning equivalence. The dative found with verbs of intransitive communication might be influenced by verbs of transitive communication with the default three-argument construction, i.e. their dative argument is in fact an A3, which will normally take the form of a dative with verbs of communication. ${ }^{147}$ Thus, we find (22a) by analogy with (22b):
a. Marie téléphone à Luc (qu'il faut partir)
'Mary telephones to Luc (telling him to leave)'
b. Marie dit à Luc qu'il faut partir
'Mary tells Luc to leave'

146. These examples of Advanced French are discussed in Krötsch and Oesterreicher (2002:118).

147. It is only with these few verbs that I accept an explanation of the phenomenon close to the one proposed by Herslund (1980) for all divalent verbs with a dative A2. 
The second type, including ressembler, succéder, survivre (see 22c), is not easily accounted for; they might be cases of fossilisation.

\section{c. Marie ressemble à sa mère - elle lui ressemble \\ 'Mary looks like her mother' - 'she looks like her'}

Let me now describe the paradigmatic relation of the paradigm presented in Table 15 to other psych-constructions. According to Koch (2001) we find two main kinds of expression involving a stimulus, labelled $\mathrm{O}$, creating an impression on an experiencer, labelled E. Verbs such as plaire, déplaire, répugner represent what can be called 'the perspective of O', implying that $\mathrm{O}$ is coded as A1. Other verbs meaning appreciation or the lack of it, such as adorer, aimer, apprécier, détester, represent what can be called 'the perspective of E', implying that E, the experiencer, is coded as A1. Below I present five different constructions that express the relationship between $\mathrm{O}$ and $\mathrm{E}$ from these two perspectives. The default direct object construction (labelled (c) accusative construction in Table 1) can express both perspectives: that of the stimulus (23a) and that of the experiencer (23b). A reflexive prepositional construction can also express the perspective of $E$ (23c). This construction is an alternative to that of (23a), used with the same verbs. Some of the verbs instantiating the personal dative construction of Table 15, here illustrated by (23d), are also found in a prepositional construction expressing the perspective of $\mathrm{E}$, as in (23e).
a. Pierre l'amuse
'Peter amuses him'
b. Pierre aime le chocolat
'Peter likes chocolate'
c. Il s'amuse de Pierre
'He is amused by Peter'
d. L'argent lui manque
money him lacks
'He is short of money'
e. Il manque d'argent
He lacks PREP money
'He is short of money'

When considered more closely, it appears that the divalent dative construction has grammaticalised as the only unequivocal construction expressing a stimulus-experiencer relation considered from the perspective of O. Table 16 illustrates how a selection of verbs and constructions differ with respect to the two perspectives.

In other words, the divalent experiencer dative pattern (labelled (a) in Table 16) has grammaticalised into a very specific construction. It was found already in classical Latin with a few verbs (illustrated by contingit, see Table 10), and we have followed its 
specialisation from Old to Modern French. It is a construction conforming to our definition: a complex sign with internal syntax (the two-argument dative construction) and with a paradigmatic relation to other complex signs belonging to a common grammatical domain. Its expression (V A1 dative-A2) is linked to a content, which is to express the O-E-relation considered from the perspective of the stimulus. It has a paradigmatic relation to the four ways of expressing the O-E-relation shown in Table 16 (b-e). These have a different expression and the relation is partly seen from a different perspective. Most importantly, constructions (b)-(e) also express other relations than the O-E relation, that is, unlike (a) they do not have a specific content. This paradigm is not a simple paradigm, but a hyperparadigm (see Chapter 4), because three parameters interplay: construction, case and syntactic hierarchy. The case role of A2 depends on its case form: if accusative, it is a patient, if dative, it is an experiencer. The content of the dative depends on the syntactic hierarchy: if A2, it is an experiencer, if A3, it is a recipient (see the specifications of A3 in Table 12, which applies to Modern French as well).

Table 16. Overview of five different ways to express an O-E relation in Modern French

$$
\mathrm{O}=\mathrm{A} 1
$$

(a)

dative $\mathrm{A} 2$ (b)

accusative A2

$$
\mathrm{E}=\mathrm{A} 1
$$
(c)
(d)
(e)

accusative A2 prepositional A2 reflexive verb and

\begin{tabular}{|c|c|c|c|c|}
\hline $\begin{array}{l}\text { l'argent lui } \\
\text { manque }\end{array}$ & Pierre l'amuse & $\begin{array}{l}\text { Pierre aime le } \\
\text { chocolat }\end{array}$ & $\begin{array}{l}\text { Il manque } \\
\text { d'argent }\end{array}$ & Il s'amuse de Pierre \\
\hline $\begin{array}{l}\text { agréer, aller, } \\
\text { appartenir, arriver, } \\
\text { bénéficier, chanter, } \\
\text { convenir, coûter, }\end{array}$ & $\begin{array}{l}\text { agacer, amuser, } \\
\text { effrayer, étonner, } \\
\text { fâcher, indigner, } \\
\text { préoccuper, etc. }\end{array}$ & $\begin{array}{l}\text { aimer, adorer, } \\
\text { apprécier, } \\
\text { détester, etc. }\end{array}$ & $\begin{array}{l}\text { bénéficier de, } \\
\text { manquer de, } \\
\text { profiter de, etc. }\end{array}$ & $\begin{array}{l}\text { agacer, amuser, } \\
\text { effrayer, étonner, } \\
\text { fâcher, indigner, } \\
\text { préoccuper, etc. }\end{array}$ \\
\hline
\end{tabular}
prepositional A2

déplaire, échapper,

échoir, importer,

incomber, manquer,

mentir, messoir,

nuire, obéir,

parvenir, peser,

plaire, prendre,

profiter, répugner,

ressembler, réussir,

revenir, seoir,

sourire, tarder

newly coined

expressions:

ça (lui) parle, ça

(lui) dit;

il lui court apres, ils lui tirent dessus,

l'evidence lui est

tombée dessus 
In many languages we find changes in the expression of the O-E-relation. Verbs expressing the O-perspective often shift to the E-perspective. This shift is also referred to as "the acquisition of subjecthood". It is illustrated, for example, by the development in Germanic. In Gothic, the experiencer for 'please' galeikan was in the dative, as in Modern German: mir gefallen diese Damen. This was the first stage. In the second stage of the development, experiencers (still) took the oblique form, but acquired subject behavioural properties. For example, in Early Middle English, the experiencers were still in the oblique form, but examples are also found with a null argument ( $\varnothing=$ experiencer) coordinated to an A1: Arthur ${ }_{i}$ loked on the sword and $\varnothing_{i}$ liked it passynge well (Malory: Morte d'Arthur, ca. 1470). At the third stage, experiencers took the form of subjects and had the behaviour of subjects: I liked the sword. These are cases of verbs shifting from one construction to another, not of the disappearance of a construction with a specific perspective. Thus, following Croft's terminology, the development of English is not a case of unidirectional change from oblique experiencer to subject experiencer, as new oblique experiencer constructions arose in English at a period when the old oblique experiencer constructions had become wholly subject experiencers. ${ }^{148}$

In French, things seem to have developed differently, as there are series of different constructions expressing the relation between $\mathrm{O}$ and $\mathrm{E}$, but only one construction that has grammaticalised as the expression of the E-perspective.

\subsection{Conclusion of Section 3}

The aim of this section has been to show the emergence and grammaticalisation of constructions, and the case illustrating this was the two-argument dative construction in French that corresponds to the construction instantiated e.g. by contingit in Classical Latin. I have shown that from the outset the divalent dative pattern was not linked to one specific content. During the 16th and the 17th centuries the pattern was instantiated by a number of verbs sharing more or less clearly comparable features, representing not any type of relation between two entities but more specifically the relation between an A1 referring to an entity with the features \pm human having an impact on an experiencer (i.e. psych-verbs). After a series of reorganisations, a specialised construction emerged.

We saw in Chapter 3 that deviant verbs may be ejected from a construction with a specific semantic frame. This is what has happened in French. We have seen the entire group of verbs meaning 'to help, ${ }^{149}$ illustrated above by the verb aider, shift from

148. See also Koch (2001) for an interesting and detailed study of changes of perspective in different languages.

149. The group comprises: aider, assister, servir, secourir, and soigner. 
the dative construction to the default direct object-construction with accusative A2. Other deviating verbs ${ }^{150}$ have shifted as well. Having lost a large number of its members, the two-argument dative construction might have fossilised, but this did not happen. On the contrary, we find that new verbs have joined it recently (e.g. ça (lui) parle, ça (lui) dit, 'this pleases him'; il lui court après 'he is after her'; ils lui tirent dessus 'they are shooting at him'; lévidence lui est tombée dessus 'he was taken aback by the evidence'). Thus it is too simple to claim, as does Geisler (1988), that Modern French has a strong tendency towards the default direct object-construction. This claim is in fact inconsistent with the development and the productivity of the two-argument dative constructions. On the other hand, the specialisation of dative A2-constructions presupposes the generalisation of the default direct object-construction, so these changes are certainly interconnected.

I have illustrated the shift of construction from the two-argument dative to the default direct object-construction with the verb aider, and my conclusion was that in relatively plain style the change started with animate nouns. I propose that this is due to two factors: firstly, after the grammaticalisation of the two-argument dative construction, the opposition between this construction and the default direct object-construction was conditioned by the type of the non-subject entity. If it was an experiencer, it should take the form of the dative; if it was not an experiencer but a patient, it should take the accusative form. So the change should be expected to start with animates in the role of patients. And this is what happened. Secondly, spreading of (internal) changes has been shown by Andersen (2001b) to follow a referential hierarchy like the one presented in Section 2.2, (8d). As there is no reason to believe that this change had an external cause, but rather an internal one, one would expect it to start with pronouns before nouns and with animate nouns before inanimate nouns. This is exactly what happened in plain style, so the two factors motivating the course of the change should lead to the same actualisation process. Finally, we should expect this change to start in unmarked contexts, i.e. from below, and this is what happened.

Summing up: This section has shown the emergence of new constructions. I have identified this development by means of a number of synchronic analyses of successive stages. If the analysis proposed here is correct, the changes relating them imply modifications of paradigms as part of grammar. Thus, they are cases of regrammation. Finally, I have shown the interaction of construction, case and hierarchy, and thus we have not a simple, but a complex paradigmatic organisation.

In a Romance perspective it is interesting to observe that the original pattern with dative A2 is still found in a large range of verbs, e.g. verbs meaning 'help' in other

150. Other verbs shifting to the default transitive pattern are: commander, congratuler, contrarier, contredire, ennuyer, épargner, éviter, favoriser, insulter, offenser, persuader, requérir. 
Romance languages, such as in Spanish. This is probably related to the fact presented in Section 2 of this chapter, i.e. that Spanish has a different organisation of A2 and A3 markings than French, so the reorganisation possibilities studied here for French, leading to a specialised construction, were not available in Spanish.

\section{The importance of absence: Constructional alternation between expressed and unexpressed second argument}

This section is intended to illustrate that with constructions - just as in morphology - a zero form (the non-expression of an argument signalled below by means of [Ø]) may be member of a paradigm. I will study one specific phenomenon: the absence of the second argument (A2), and the focus will be exclusively on the development from Latin to French. The underlying principles are the following:

- $\quad$ in order to understand the development from Latin to Modern French, I will need to investigate whether the unexpressed A2 is part of the paradigmatic structure of a construction, and not just a case of contextual or stylistic ellipsis;

- $\quad$ in order to discover the different structures under investigation, it is necessary to proceed by means of successive synchronic steps;

- a paradigmatic analysis is necessary in order to discover the importance of the semantic hierarchy of referents in French;

- $\quad$ we need to study the non-expression of A2 not in isolation, but in interaction with other parts of grammar.

I will distinguish the following three types of non-expressed A2 in Modern Standard French and Advanced French:

- the non-expression of A2 implies that any member of the class of possible referents is intended, ${ }^{151}$ i.e. that the result of the absence of $\mathrm{A} 2$ is to focus on the state of affairs expressed by the verb, as in example (24a) below. Here, Pierre mange means that Peter is eating, without specification of what he is eating, and the process of eating is what is important - in contrast to the construction with an expressed A2: Pierre mange un poulet, where the eating of a specific item is focused upon. Additionally, the presence or absence of A2 has implications for aspect: Pierre mange indicates an activity, Pierre mange un poulet is neutral with respect to the opposition \pm telicity;

151. This type is also called "generic ellipsis”, see Schøsler (2000a: 116-117). 
- the non-expression of A2 is context dependent: ${ }^{152}$ there is a referent in the context which may or may not be explicitly mentioned, but which can be inferred, as in example (24b). The unexpressed A2 may be any member of the class of possible referents in the context; in example (24b) it is the door, only implicitly referred to in the preceding sentence;

- the non-expression of A2 is part of a subparadigm and it has a specific content, as in $(24 \mathrm{~cd})$. Here, the unexpressed A2 alternating with ça can only be understood as an argument referring to a referent with the features: -individuated, -animate, such as ce truc (Oui je connais [Ø] - Oui je connais ça). Reference to ce truc by means of le is problematic. If A2 is intended to refer to a referent with the feature +animate, such as ce type, the expression of A2 by means of the personal pronoun le would be required: Oui je le connais. With null expression or ça, the sentence is ungrammatical, if intended to refer to ce type. Thus, there exists for this third type in Modern French a paradigmatic relation between $l e$, zero, and ça, which will be discussed further in Section 4.5.
a. Pierre mange $[\varnothing]$ - Pierre mange un poulet
'Peter is eating' - 'Peter is eating a chicken'
b. On a sonné. Va ouvrir [Ø]!
Someone has rung [the door bell]. Go open [the door]
c. Tu connais ce truc? - Oui je connais [Ø] - Oui je connais ça-?Oui je le connais

'Do you know this thing? - Yes I do - Yes I know that - Yes I know it'

d. Tu connais ce type? - ${ }^{\star}$ Oui je connais $[\varnothing]-{ }^{\star}$ Oui je connais ça - Oui je le connais

'Do you know this guy? Yes I know - Yes I know that - Yes I know him'

The three cases of non-expression of A2 should not be confused with cases of argument reduction (the so-called ergative alternation) illustrated in Chapter 3 by the examples Peter knokkede grenen, 'Peter broke the branch' (transitive, ergative construction) and grenen knoekkede, 'the branch broke' (intransitive, inergative construction). The difference between argument reduction and an unexpressed A2 is that the former implies a change in the function of arguments: the patient in the transitive construction (la branche) acquires the subject function in the intransitive construction, as described

152. This type is also called "contextual" or "anaphoric ellipsis", see Schøsler (2000a: 116-117). Specific syntactic contexts may favour ellipses, e.g. series of questions and answers, sequences of verbs, contrastive uses, imperatives and infinitive constructions. Ellipses are also text type dependent. For more details, see Schøsler (1999b: Section 2). 
in Chapter 3. Nor should non-expression of A2 be confused with argument reduction by means of passivisation, as there is no change of voice here; and they should not be confused with cases of homophony, such as Pierre vole l'argent and loiseau vole, described in Chapter 3. Finally, they differ from the monovalent use of divalent verbs like craindre in Advanced French, e.g. ça craint, meaning that 'there is a problem' or 'something is bad', with a permutation of arguments. I intend to show below that the status of non-expression of A2 has changed from Latin to Modern French. The verbs studied are divalent, with the selectional features tanimate of referents for A1 and A2. The development of the lexicon makes it impossible to include in this section only Latin verbs which survive in French; I have also studied French equivalents to Latin verbs that do not survive.

I shall investigate unexpressed A2 in five periods: Latin (Pre-Classical, Classical and Late Latin, including Merovingian Latin), in Section 4.1; Old French (the earliest texts, 9th-11th centuries, and later Old French, 12th-13th centuries), in Section 4.2; Middle French (14th-15th centuries), in Section 4.3; Classical French (17th-18th centuries), in Section 4.4, and Modern French (standard and colloquial), in Section 4.5.

\subsection{Latin}

The expression of A2 has been studied with a large selection of verbs, in a series of electronic corpora, which are intended to cover a range of text types, genres and styles from the Pre-Classical to the Merovingian period. ${ }^{153}$ The result of this investigation can be summarised as follows:

- Latin has examples of generic (25a) and contextual (25b) ellipsis; in (25a) we do not know yet what we shall hear, in (25b) the unexpressed A2 refers to the person addressed;

- $\quad$ the frequency of non-expression of A2 depends on the individual lexical verb; ${ }^{154}$ some verbs tend to avoid ellipsis and others tend to favour it; verbs avoiding ellipsis include accipio, amo, perdo; verbs favouring ellipsis include adjuvo, audio, defendo, sequor;

153. The following subcorpora have been investigated: Pre-Classical: Plautus (3rd c. BC); Classical Latin: Caesar, Cicero, Apuleius (2nd c. AD); Post-Classical and Late Latine texts: legal texts: Digesta (1st-5th c.); texts following the norms of Classical Latin: Augustine (4th-5thc.), Boethius (5th-6thc); texts not imitating Classical Latin: Vulgate (4th c.); 200 pages of Merovingian Latin (8th-9thc.).

154. See also Joffre (1995). 
- the corpus permits me to establish only one tendency of ellipsis linked to text type: unexpressed A2s are relatively frequent in legal texts;

- the corpus permits me to detect hardly any chronological difference in the frequency of ellipsis, though there is an increased tendency towards fewer ellipses at the end of the period (in the Merovingian texts).
a. Nunc denique? verum tamen now in sum? truth however
petat; audiamus [Ø]
seek-PRS.SBJV.3sg hear-PRS.SBJV.1PL
'Now, let him look for the truth; let us hear [what he will tell]' (Cicero)
b. Quo sequar $[\varnothing]$ ? quo ducis nunc me?
where follow-FUT.1sG? where lead-PRs.2sg now me
'Where shall I follow [you]? where do you lead me now?'
(Plautus)

Clearly, my Latin corpus does not permit me to establish any paradigmatic opposition between expressed and unexpressed A2s.

\subsection{Old French}

The expression of A2 has been investigated in a series of corpora from the earliest texts to the end of the 13 th century. ${ }^{155}$ The results can be summarised in the following two points:

- all verbs tend to express their A2 overtly, especially if the arguments have the feature +human, as in examples (26) below;

- non-expression of other arguments, especially of A1, largely depends on the text type and on the conception ${ }^{156}$ of the text (written style versus oral style), as shown in Schøsler 1984: Chapter 4, 1988, 2002a, and Reenen \& Schøsler 2000. Thus legal texts are characterised by their overt expression of all arguments, whereas

155. Three subcorpora have been investigated: 1 . the earliest texts, from the 9 th to the 11 th c.: Les Serments de Strasbourg, La Prose de Sainte Eulalie, La Vie de Saint Léger, La Vie de Saint Alexis; 2. Le Charroi de Nîmes ms. A4 (a description of the electronic study of this ms. is found in Schøsler (1984) Chapter (2), a narrative text composed in the 12 th c.; 3. Jean d'Antioche, translation of De Inventione and Rhetorica ad Herennium (1282). All these texts have been examined in extenso. Marchello-Nizia (1995:110) mentions that A2 is obligatorily expressed, without statistic information.

156. Conception as defined by Söll and by Koch and Oesterreicher (2001). 
passages of (fictional) direct discourse, especially dialogues, have more ellipses. Specific syntactic contexts favour ellipses, e.g. series of questions and answers, sequences of verbs, etc.

The Old French case system distinguished in the masculine between nominative and oblique forms, but already in the earliest texts we find oblique forms instead of nominative forms. Like Latin and most Romance languages, Old French was a language with null subjects. Consequently, a transitive verb combining human referents of A1 and A2, like avoir 'to have', esgarder 'to see/look', and trover 'to find', with only one expressed argument, can in principle be an instantiation of two patterns: (S) VO or SV(O). In the texts, however, we normally find (S)VO and not SV(O); i.e. as a rule, A2 is expressed. I interpret the near obligatoriness of A2 as a means of facilitating the interpretation of the argument structure. In (26a), the unexpressed A1 of the verb is Eulalia; in (26b) it is Alexis. In (26b), la pulcela is an obvious candidate to be A1, but our knowledge concerning the overt expression of A2 provides us with the key to the correct analysis in both examples, which is VO. In (26c) Monseignor Gavain et son hoste has the function of A2, though formally, it could be A1.

$$
\begin{aligned}
& \text { ael auret corps, bellezour anima } \\
& \text { beautiful have-PST PRF.3sG body more beautiful soul } \\
& \text { '[She] had a beautiful body, and a more beautiful soul' }
\end{aligned}
$$

b. Cum veit le lit, esguarda la pulcela

when see-PRS.3sg the bed, look-PST.3Sg the maiden 'when [he] saw the bed, [he] looked at the maiden'

(Alexis: 56)
c. Monseignor Gavain et son hoste/ Ont a deus
Sire G and his guest / have-PRs.3PL by two
fenestres trové
windows found

'[They] found sire G and his guest by two windows' (Perceval 8294-5)

Even in a context that seems to facilitate the non expression of arguments, Old French tended to express them: in (26d), there is a coordination of arguments which one might have expected to be unexpressed (charrette ...l'), and in (26e) we find expressed arguments in a dialogue with a question and an answer. However, non-expression is exceptionally found in coordination, as in (26f):

d. Quant tu verras/Charrete et tu l'anconterras,/Fei croiz sor toi et te sovaigne/De Deu, que max ne t'an avaigne.

'When you see/the cart and you meet it/make a cross before you and remember God, in order that nothing bad should happen to you'. 
e. - Ce verroiz vos, fet il, par tans./- Jel verrai? - Voire.

'You will see that, he says, when it is time/- I shall see it?

- Yes'

(Lancelot ou le Chevalier de la Charrette vv. 500-501)

f. Que de la honte ne li chaut/Puis qu'Amors le comande et [Ø] vialt. 'He does not care about shame/since Love orders it and wants [it]'

(Lancelot ou le Chevalier de la Charrette v. 381)

There is only one context with regular non-expression of A2: in a series of two third person singular accusative and dative clitics, e.g. le $l i$, the accusative form is normally not expressed, see (26g):

g. (Et cil dit: «Or la me bailliez,/Et si nian dotez ja de rien, / Car je la remenrai molt bien/Tote heitiee et tote sainne.» /) Li rois [Ø] li baille et cil l'an mainne.

'The king gives [her] to him, and he takes her away with him' (Lancelot ou le Chevalier de la Charrette v.194-197)

This ellipsis of le/la/les is traditionally explained as the avoidance of haplology, which is not a convincing analysis. ${ }^{157}$ This type of ellipsis is still found in 17th century texts and in Colloquial French; see Section 4.4.

In sum, Old French differed from Latin with respect to A2, which tended to be expressed even in contexts favouring ellipsis. Thus, non-expression of A2 was infrequent and had no paradigmatic opposition to the expression of A2.

\subsection{Middle French}

The expression of A2 has been investigated in a series of Middle French texts, partly in electronic form. ${ }^{158}$ Even in contexts that are known to facilitate the non-expression of arguments, Middle French tended to express them: in (27a), there is the repetition of coordinated arguments which one might have expected to be unexpressed: le fist ... l'acolle et le baise et lui dist; in (27b) there is the expression of arguments in a

157. See e.g. Grevisse (1986:1009). See Arteaga (1998) for a minimalist analysis of "null objects" in Old French.

158. The Middle French corpus comprises the following electronic texts: Les Chroniques de Froissart, Les Mémoires de Commynes, Les quinze Joies de Mariages, Cleriadus (14 th-15th c.). The verbs in these large electronic texts have not all been investigated. Instead, we have studied the expression of A2 in a series of verbs, including those studied for Latin and those studied in the later periods. Two 16th century texts have also been studied: Rabelais: Pantaguel (1532) and the anonymous Discours merveilleux de la vie, actions et deportements de Catherine de Médicis, Royne-mère (1576). 
dialogue concerning words to be said or not to be said. In spite of this context, all the A2s are expressed. However, there are a few cases of non-expression of A2, as in (27c), in a context favouring ellipsis, i.e. with coordinated verbs. Cases of non-expression of generic $\mathrm{A} 2$ are also found.

a.

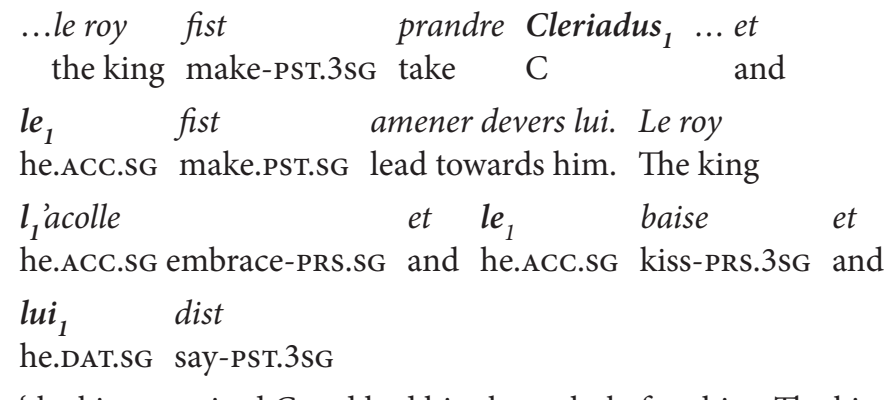

'the king required $\mathrm{C}$ and had him brought before him. The king embraces and kisses him and says to him ...'

(Cleriadus: 40)

b. (Mamie, fait il, dites moy pour quoy vous me dites telles parolles?

Par Dieu, fait elle, sire, il nest ja mestier) que je le vous dye, car c'est une chose, puis que je la vous avroye dite, vous nen feriez compte et il vous sembleroit que je le feisse pour autre chose.

Vrayement, fait il, vous le me direz.

Lors elle dit: Puis qu'il vous plest, je le vous diroy...

(Première Joye: 49-56)

'...that I should tell you [Ø], ${ }^{159}$ because it is [such] a matter, [that] when I would have told you [Ø], would not care about it, and it would seem to you that I would have done it for another reason. In fact, he answered, you should tell me [Ø]. Then she said: Because it pleases you, I will tell you $[\varnothing] \ldots$..'

c. ...oncques puis hyer a matin ... il ne beut [Ø]

never since yesterday morning he not drink-PST.3sG

ne ne mengea $[\varnothing]$ ne ne repousa

and not eat-PST.3sg and not rest-PST.3sg

'since yesterday morning he has not drunk, eaten or rested.'

We have seen that Middle French, like Old French, differed from Latin, as A2 tended to be expressed, even in contexts that might favour ellipsis. I have interpreted the near obligatoriness of A2 in Old and Middle French as a means of facilitating the identification of argument structure in a language with null subjects, with relatively free word

159. In the English translation the non expressed A2 is marked by []. 
order, and a nominal declension that in many dialects was in the process of degenerating after 1100. The infrequent cases of non-expressed A2 had no paradigmatic opposition to the expression of A2.

\subsection{Classical French}

The expression of A2 in Classical French has been investigated by consulting the socalled Remarqueurs and a number of texts ${ }^{160}$ from the electronic Frantext-corpus.

The Remarqueurs of Classical French did not discuss the expression of arguments in general. In the Remarques sur la langue françoise (1934/2000:33), however, Vaugelas criticised the omission of the pronominal object, labelled LE, pronom relatif oublié. ${ }^{161} \mathrm{He}$ mentions, but explicitly rejects, the frequent non-expression of le preceding a dative pronoun lui or leur in e.g. Amyot's writings, a usage which was the norm in older periods of French, as mentioned above. The contemporary grammarians commenting on Vaugelas (Ménage, Conrart, Patru, Corneille, Andry and Tallemant) all agree that non-expression of le preceding lui and leur is frequent, especially in speech, but they disagree in their evaluation of this ellipsis, whereas the grammar of the Academy clearly condemns non-expression (see comments in Streicher 1936: 61-63).

A series of divalent verbs which permit reference to arguments with the feature +animate in A1 and A2 (see the introduction to this section) have been studied for optionality of A2, as was done for the study of Medieval French. I find that non-expression of A2 is infrequent (only 38 cases out of a total of 1042 tokens), even in contexts identified previously as favouring ellipsis, e.g. (28a). If I find non-expression, it is mostly in contexts of repetition and with non-finite forms. The types of ellipsis are mainly those seen previously: anaphoric, as in example (28b), or generic, as in (28c):

(28) a. Repetition with expressed A2:

Je vous adore, je vous hays, je vous offense, je vous demande pardon;

'I adore you, I hate you, I offend you, I beg your pardon'

(La Princesse de Clèves 1678: 162)

160. The electronic corpus is composed of four novels: Jean-Pierre Camus: Palombe ou la Femme honnorable (1625), Mme de Lafayette: La Princesse de Clèves (1678), Voltaire: Candide, ou l'Optimisme (1759), and Denis Diderot: Jacques le Fataliste et son maître (1784).

161. I want to thank Wendy Ayres-Bennett for bringing this reference to my attention. See also Ayres-Bennett (2004:39). In colloquial French, we still find the non-expression of le before lui, leur, see Sandfeld (1928: \$13), Marchello-Nizia (1995:110, Note 113), and Kiesler (2005:259-261). 
b. Anaphoric:

on lui propose un jeu, une promenade, un spectacle: elle accepte [Ø]; 'she is proposed a play, a promenade, a spectacle: she accepts [it]'

(Jacques le Fataliste et son maître 1784:734)

c. Generic:

Je l'aimais comme on aime $[\varnothing]$ pour la première fois, avec idolatrie, avec emportement.

'I loved her as one loves [Ø] for the first time, with idolatry, with passion'

(Candide, ou l'Optimisme 1759:59)

However, a special use with a subset of verbs in Classical French should be mentioned. This concerns the frequent use of ellipsis instead of the expression of a specific referent with the feature +human found in a very specific context: the language of courtly love. Here we find a paradigmatic opposition of expression and content; non-expression of A2 refers to an entity with the feature +human, as in (28de), and expression of A2 by means of an NP or the pronouns le, la, les refers to an entity with the features thuman,+individuated:

d. à ce que je voy, mon frere, reprit Fulgent, vous aymez [Ø], et comme je le veux croire, vous aymez [Ø] en bon lieu, et honnestement, et à dessein d'espouser $[\varnothing]$;

'as far as I can see, dear brother, Fulgent continued, you love [somebody], and, I hope, you love [somebody] worthy, and you do it honourably, and with the intention to marry [her]',

(Palombe ou la Femme honnorable 1625:782)

e. Vous aimez [Ø], on ${ }^{162}$ vous aime; Vous n'aimez donc pas [Ø]? -jaime [Ø], et beaucoup;

'You love [her], she loves you; Then, don't you love [her] ? - I love [her], and very much'.

(Jacques le Fataliste et son maître 1784: 732)

The examples clearly show that these ellipses are essentially different from the ellipses illustrated by (24a): Pierre mange 'Peter is eating', the main difference being that in (24a) any member of the class of possible referents is intended, whereas in (28de) a very specific referent is intended. Moreover, the ellipsis has no aspectual consequence, thus, in (28d) ... à dessein d'espouser [Ø] is telic, just as à dessein d'espouser X. Consequently, for this subset of verbs, we find a paradigmatically organised construction,

162. The subject pronoun on refers to the non-expressed specific referent of the object ellipsis. 
presented in Table 17, which existed in this special text type during a limited period (17th and 18th centuries).

Table 17. Paradigmatic opposition of A2, see examples (28de)

Domain: V [A2]

Frame: referentiality

\begin{tabular}{ll}
\hline Expression of A2 & Content of A2 \\
\hline$l e$, la, les & \pm thuman, +individuated referent \\
$\varnothing$ & +human referent \\
\hline
\end{tabular}

Summing up: on the one hand, Classical French resembles the previous periods of French as it tends to express A2 even in contexts favouring ellipsis. On the other hand, it differs from the previous periods by its special use of ellipsis typical of the style of courtly love, found in a construction with a subset of verbs. The non-expressed argument ( $\varnothing$ in Table 17) has a specific content, corresponding to the feature +human of the referent, in contrast to an expressed argument (le, la, les), and should thus be seen as one of the members of a paradigm. Consequently, according to the definition of Chapter 3, this has become part of grammar: it is a construction.

\subsection{Modern Standard French and Colloquial French}

The expression of A2 has been examined in three subcorpora: 1. Modern Standard French: Le Monde 1994 (electronic corpus), 2. Modern Colloquial French (the electronic GARS-corpus), and 3. an informal conversational corpus. ${ }^{163}$

Modern French differs from the previous periods as we here find a paradigm of A2 with a new opposition in addition to the one introduced in the introduction to this section, i.e. not only le, but also zero and the demonstrative ça, see Table 18 . In the following I will discuss neither the generic ellipsis nor the contextual ellipsis mentioned in the introduction to this section; I will focus on the construction illustrated by means of the verb connaitre 'to know' in (24c), which conforms to the paradigmatic opposition of Table 18. I will briefly exemplify the paradigm in examples $(29 a-c)$, quoted from Akihiro (2004:120). On the one hand we have examples with

163. See the description of this corpus and different studies of it in Leth Andersen and Thomsen (2004). The subcorpora 2 and 3 have been studied in a different way from those of the preceding periods, as there were indications that the constructions were organised differently. Consequently, a number of verbs (some 200 transitive verbs with 250 different readings) have been studied in extenso in the two large electronic corpora. Examples quoted from these corpora are authentic unless explicitely stated. 
expressed A2: le referring to the person Roger Vaillant (29a), i.e. the referent of le has the feature +human, +individuated, or ça referring to an entity with the feature nonindividuated, ${ }^{164}$ +deictic, implying reference to the work of the author (29c). On the other hand we have zero, also referring to the work of the author (29b), and here the referent has the feature non-individuated. Note that there is the same expressed referent in the three examples: Roger Vaillant, but the interpretation of this proper name depends on the choice of construction, i.e. on the choice of expression of A2.
a. Roger Vaillant je ne le
connaissais
pas bien
RV I not him.ACC.SG know-PST IPFV.1sG not well
'I didn't know RV well'
b. Roger Vaillant je ne [Ø] connaissais pas bien
RV I not [Ø] know-PST IPFV.1sg not well
'I didn't know the work of RV well'
c. Roger Vaillant je ne connaissais pas bien ça
RV I not know-PST IPFV.1sG not well DEM.N
'I didn't know the work of RV well'

Table 18. Paradigmatic opposition of A2, see examples (29a-c)

Domain: V [A2]

Frame: referentiality

\begin{tabular}{ll}
\hline Expression of A2 & Content of A2 \\
\hline$l e$, la, les & \pm human, +individuated referent \\
$\varnothing$ & non-individuated referent \\
$c ̧ a$ & $\begin{array}{l}\text { non-individuated, +deictic } \\
\text { referent }\end{array}$ \\
\hline
\end{tabular}

The paradigm in Table 18 is found in my corpus with some 60 verbs, ${ }^{165}$ most of which are instantiated with a human referent of A1 and an A2 referring to a thuman entity. These verbs all have the particular feature illustrated by means of the verb connaitre - that the content (in terms of the feature \pm individuated of the referent) depends

164. Concerning the feature \pm individuated, see Riegel et al. (1999:199, 205). This feature is probably the result of a recategorisation of the opposition \pm human.

165. This group comprises: abandonner, abimer, aborder, accepter, accuser, admirer, adorer, aimer, amener, apercevoir, approuver, attendre, attraper, chercher, comprendre, connaître, convertir, critiquer, dédaigner, détester, détruire, échauffer, écouter, emmener, entendre, envoyer, éviter, juger, laver, louer (=réserver), maîtriser, montrer, observer, oublier, palper, panser, parachuter, paralyser, parodier, parquer, peigner, peindre, percer, peser, pétrir, piller, prendre, préparer, rejeter, rencontre, suivre, tasser, tâter, taxer, tenir, trahir, voir. 
on the expression of the A2. If the speaker wants to refer to the referent as non-individuated, A2 takes the form of ça, especially in colloquial French, as in (29c) and (29e), or the non-expression, found with the same speaker in (29d). Note that in (29de) the topic is the films by Woody Allen, not the person Woody Allen. In the latter case, we would need reference by means of the clitic le, as in (29f). Just as in the examples quoted above $(29 \mathrm{a}-\mathrm{c})$, the alternation between $l e / \varnothing / c ̧ a$ indicates how one and the same expression (Woody Allen) should be interpreted in terms of the features \pm individuated, \pm deictic.
d. moi je sais que Woody Allen jadore [Ø]
me I know that Woody Allen I-love
'I know that I love Woody Allen films'
e. Woody Allen jadore ça
Woody Allen I love that
'I love Woody Allen's stuff'
f. Woody Allen je l'adore
Woody Allen I him love
'I love Woody Allen'

Yaguello (1998) cites similar examples: Shakespeare, je connais [Ø] vs Shakespeare, je le connais, ('I know the works of Shakespeare' vs 'I know the person named Shakespeare') with similar conclusions; these are that non-expression of A2 has a specific content and should be included in the paradigm, opposed to ça, and to le, la, les. Many other scholars have failed to recognise this difference. ${ }^{166}$

It appears that the alternation between the anaphoric forms ça, le, la, les, and [Ø] was first mentioned by Frei (1979:301), who provided examples from other verbs than the type studied here, like (29g-h), quoted from Jacob (1990):

g. Les Marocaines, vous fumez [Ø]?

(= les Marocaines en général)

'Do you smoke Moroccan cigarettes?'

h. Les Marocaines vous les fumez?

(= ce paquet de Marocaines)

'Are you smoking (these) Moroccan cigarettes?'

Jacob (1990:145-147) discusses Frei's examples and proposes that the alternation between expressed and non-expressed A2 should be described primarily as an opposition between \pm individuated, rather than \pm human, as proposed by previous scholars.

166. Several scholars have not observed the systematicity of the alternation pattern; instead, they believe that there are no rules concerning optionality, or that each verb behaves differently. See Schøsler (2000a) for a presentation of different analyses of the non-expression of A2. 
I agree with Jacob's analysis. Just as we saw in the case of the construction of Classical French (Table 17), ellipsis has no aspectual consequence.

The paradigm presented in Table 18 is currently in the process of spreading from Colloquial to Standard French, and possibly also to more verbs. Besides the first group of some 60 verbs that I have identified, illustrated above by the verbs connaitre and aimer, there is individual variation as regards non-expression of A2. In my corpus I find two additional groups of verbs. Firstly, a group of 23 verbs, ${ }^{167}$ all of which are primarily found with animate referents of A1 and A2, includes convaincre 'to convince', épouser 'to marry', marier 'to marry', surprendre 'to surprise. With these verbs, expression or non-expression of A2 depends on the individual verb. A typical example of non-expression of A2 is found in (30a), quoted from Larjavaara (2000: 125):

\section{a. Le premier ministre a-t-il convaincu $[\varnothing]$ ?}

'Did the Prime Minister convince [his public]?'

Secondly, there is a group of 39 verbs, ${ }^{168}$ all of which are most frequently found with an inanimate referent of A2. Most of these verbs permit the non-expression of A2; very few, like perpétrer 'to continue', and parfaire 'to finish', need specific contexts for nonexpression of A2. Example (30b) illustrates the typical non-expression of A2 with this group of verbs, in a context favouring ellipsis, i.e. a repetition.

b. Visage d'une femme de pouvoir, ou de contre-pouvoir? Grandieux capte [Ø], cherche [Ø], il ne donne pas de réponses.

'... Grandieux catches, searches, he does not give any answer.'

(Larjavaara 2000: 128)

Let me sum up: in Modern French, especially Advanced French, the paradigm of A2 is reorganised and the distinction \pm individuated, \pm deictic is introduced. This newly established distinction is instantiated with a series of divalent verbs that combine with an A2 referring to an entity with the features thuman. This innovation is spreading from Advanced French to Standard, and it is spreading from the first group of verbs to other verbs. We cannot know yet whether it will spread to the verbs of group 2 (e.g. convaincre) or group 3 (e.g. perpétrer) with features of A2 that differ from those of the

167. This group comprises: accompagner, aider, appeler, convaincre, culpabiliser, décevoir, déranger, draguer, énerver, épouser, louer (=complimenter), marier, pacifier, passionner, peiner, persécuter, présenter, persuader, surprendre, tancer, taquiner, tarabuster, vaincre.

168. This group comprises: abjurer, abolir, abréger, accélérer, accorder (un piano), accoster, boire, bougonner, capter, conduire, chipoter, dédicacer, défendre (=interdire), jeter, manger, paginer, perpétuer, perpétrer, panacher, parachever, parafer, paraphraser, parfaire, pasteuriser, paver, pavoiser, paufiner, pêcher, pelleter, percuter, perfectionner, photocopier, ponctuer, tacher, taillader, tailler, tamiser, tapisser, tartiner. 
first group. There is not yet any clear tendency towards the adoption by these verbs of the paradigmatic opposition of Table 18. I believe that the development of Advanced French will indeed spread, and that to-day's Advanced French will turn into Standard French, since the development is a continuation of existing tendencies. It should indeed be noted that the distinction \pm individuated is found in other parts of the grammar. It is relevant for the paradigm of A3 in Advanced French (see Section 2.3.3) and it is relevant for determiners.

As illustrated in Wilmet (1998: $133 \mathrm{ff})$, count nouns can be conceived of as mass nouns if preceded by the partitive article. This implies that they lose the feature +individuated. Thus le/un flic means 'the/one copper', but flic can be disindividuated as $d u$ flic (Wilmet 1998: 134). The effect of disindividuation may be a change of grammatical gender, as in (31a) quoted from Wilmet (1998:135), where the proper names Claude ( $\mathrm{M}$ or F) and Mathilde (F) figure as mere examples of items to be kissed, when combined with the partitive article:

a. Mais non, mais non, elle n'est pas malheureuse, votre nièce, qui secoue ses larmes, qui embrasse du Claude et du Mathilde, tout ce qui se trouve à la portée de sa bouche, au hasard.

'No, no, she is not unhappy, your niece, who is spreading her tears, who is kissing a Claude and a Mathilde, everything that happens to be within the reach of her mouth.

This is a general rule for French, as illustrated in (31b), where a specification, e.g. de Jacques 'of Jacques' implies a +individuated meaning, consequently excluding the use of the non-individuating partitive article, as seen in (31c).

b. je bois le vin de Jacques/les vins de Jacques

'I am drinking Jacques' wine/wines' (+individuated)

c. *je bois du vin de Jacques

'I am drinking Jacques' wine'.

\subsection{Conclusion of Section 4}

The results of the investigation of the non-expression of A2 can be summarised in five points:

- The status of non-expression differs from period to period. In Latin it largely depended on the individual verb; in the early periods of French non-expression was avoided. In Classical French, with a subset of verbs, we see the emergence of a (schematic) construction based on the opposition between expression and nonexpression of A2 for specific purposes linked to the rules of courtly love. Finally, in Modern French, especially in Advanced French, expression and non-expression 
are opposed with a different content in a new construction instantiated with a large number of verbs.

- I have shown that the semantic opposition between expressed and non-expressed A2 differs between the periods of Classical French and Modern French: in spite of the same form (non-expression of A2), the content is completely different (+individuated $v s$-individuated).

- I have proposed that the tendency to obligatory expression of A2 in the earlier periods of French should be seen in connection with other parts of the grammar. French was a language with null subjects, with a relatively free word order, and its nominal declension system was in the process of breaking down in many areas after 1100. In such a situation, the non-expression of arguments with transitive verbs, especially with verbs combining two arguments referring to entities with the same semantic features, might have made it difficult to identify the argument structure. ${ }^{169} \mathrm{I}$ interpret the expression of A2 as a way of making argument structure more transparent, accompanied by major changes in case-role indexing. Non-expression of A2 acquired grammatical meaning only after French had developed into a language with obligatorily expressed subject. Thus, this development illustrates that changes should not be considered in isolation but in their interaction with other parts of the grammar. As changes occur, e.g. concerning the rules of the expression of arguments, this paves the way for new grammatical oppositions to be exploited, e.g. the non-expression of A2. Thus, this section has illustrated the phenomenon that I have labelled chains of grammaticalisations (Section 1), chains in the sense that one is presupposed by the other, so that the first (the quasi-obligatoriness of A1) is a (non-causal) presupposition for the second (the emergence of the paradigmatic opposition between \pm expression of A2) to take place.

- Moreover, I have found that the paradigmatic opposition \pm individuated is found not only in the pronominal paradigm of A2 but also elsewhere, e.g. in the paradigm of determiners. This constitutes a case of connecting grammaticalisation, of the type labelled parallel paradigmatic structures of grammar (Chapter 4), because the paradigms have the same semantic frame.

- I have put forward the hypothesis that the construction with non-expression of A2 presented in Table 18 is in the process of spreading; it is spreading from Colloquial to Standard French.

169. This is not intended to imply that languages cannot have relatively free word order and rudimentary declension. Later stages of medieval Danish were organised like that, see Chapter 6. It simply implies that early periods of French seem to have been organised differently. 
In this section I have shown that the study of a series of synchronic analyses helps us to make sense of the changes of the status of non-expression of A2 and to establish different paradigmatic relations. Previous studies of optionality of A2 have focused on Modern French and have hardly observed anything but fluctuation and freedom of syntax. Instead, I have shown that non-expression of A2 has grammaticalised as a construction.

\section{Conclusion}

In the preceding sections, I have proposed an entirely new description of important changes from Latin to Romance languages in terms of emergence and modifications of constructions. I believe I have provided plausible diachronic scenarios and coherent analyses of changes. Moreover, these changes have often been shown to be connected in different ways. In the following sections I will sum up my results on three points of interest, from the simpler to the more complex cases. Firstly, the creation of relatively simple paradigmatically organised constructions (Section 5.1); secondly, the creation and reorganisation of complex paradigms (Section 5.2); and thirdly, the implications of my study for the theory of language change (Section 5.3), in terms of chains of grammaticalisation and of parallel or connecting grammaticalisation processes.

\subsection{Simple paradigmatically organised constructions}

The changes discussed in the previous sections can be described as major shifts in argument marking, or, in Henning Andersen's terms (Andersen 2008:29) shifts in case-role indexing, as these markers point to specific case roles. In Latin, argument marking and instructions for identification of referents were mainly achieved by means of lexicon and morphology: nominal morphology, cases on pronouns, and A1-marking by means of verbal inflection. Marking of arguments and identification of referents in the Romance languages is more diverse: argument identification may be achieved by means of the lexicon, as in Latin, and the identification of A1 by means of the verbal inflection is still found in most Romance languages. The use of prepositions as markers of non-subject arguments is widespread; explicit subjects are obligatory in French, Rheto-Romance, Ladin, Friulan, and Gallo-Italian, and frequent, although optional, elsewhere. The use of clitic object pronouns, especially for cross-reference, is frequent. Fixing of word order is another way of marking arguments, most importantly in Modern Standard French. In sum, the marking of arguments in Romance languages has developed into a complex matter with a 
large variety of grammatical subsystems involving different levels of grammar, as we find morphological, syntactic, and word order marking. To these - more or less well-known devices - I have added paradigmatically organised constructions, which provide important models of interpretation for listeners. Constructions and their paradigmatic organisation have been the focus of the preceding sections. They are constructions, in accordance with our terminology, because they belong to the grammatical level of language, not to the lexical or valency level. I interpret the different grammatical subsystems listed above as case-role indexes which are organised in simple or complex paradigms, according to the terminology used in Christensen (2007).

Section 4 provided an example of the creation of a construction based on a simple paradigm with only two opposition members, found in a specific textype, related to the rules of courtly love of Classical French, with a limited number of verbs, see Table 17 reproduced below for convenience. This is a construction that permits speakers to exploit the non-expression of a second argument in order to obtain a specific content: the reference to a human entity. In Modern Standard and Colloquial French we witness the creation of another construction, based on another paradigm which is slightly more complex, as we here see three opposition members, see Table 18.

Table 17. (repeated for convenience). Paradigmatic opposition of A2

Domain: V [A2]

Frame: referentiality

\begin{tabular}{ll}
\hline Expression of A2 & Content of A2 \\
\hline le, la, les & \pm human, +individuated referent \\
$\varnothing$ & + human referent \\
\hline
\end{tabular}

Interestingly, my investigations have shown that the semantic opposition between expressed and non-expressed A2 differs between the periods of Classical French and Modern French: in spite of the same form (non-expression of A2) the content is completely different (+individuated vs non-individuated). I want to stress that such changes can be uncovered only by means of synchronic successive investigations of paradigmatic organised constructions.

\subsection{Creation and reorganisation of complex paradigms}

Complex paradigmatic structures are characterised by the interaction of different formal oppositions. As such, they are not easily described nor presented in Tables. 
Here, I will sum up two important cases: the comparatively simpler case, which is the creation of the dative A2 paradigm in French, and the most difficult and complicated case concerning the reorganisation of the non-subject argument paradigm in Peninsular Spanish.

\subsubsection{The creation of the dative A2 paradigm in French}

Section 3 showed the emergence and grammaticalisation of the two-argument dative construction in French. From the outset, this was just one possible construction instantiated e.g. by contingit in Classical Latin, and the divalent dative pattern was not linked to one specific content. During the period of Classic French (the 16th and the 17th centuries), the pattern was instantiated by a number of verbs sharing more or less clearly comparable features, representing not any type of relation between two entities but more specifically the relation between an A1 referring to an entity with the features thuman having an impact on an experiencer (i.e. psych-verbs). After a series of reorganisations, a specialised construction emerged. The complex paradigm of this construction is presented in Table 15 (repeated for convenience). The experiencer construction in Modern French is illustrated with the verb plaire 'to please', which is found both in the personal and in the impersonal construction. The default direct object construction is illustrated by the verbs chanter 'sing' and prendre 'take'. I reproduce below the examples (21a-d) from Section 3 as (31a-d):
a. Luc/ le chocolat/ la musique classique plaît à Marie
'Luc/ chocolate/ classical music pleases Mary'
b. Faites ce qu'il lui plaira
'Do what pleases him'
c. Luc chante la chanson
'Luc sings the song'
d. Luc prend le livre
'Luc takes the book'

The paradigm is complex, because the following formal oppositions interplay:

- the case of A2 (if accusative, it has the role of a patient; if dative, it has the role of an experiencer)

- the construction (two argument construction, opposed to one- and three argument constructions)

- $\quad$ subspecification of A1 (if A1 is a dummy subject, it refers indexically to an infinitive or a subordinate clause) 
Table 15. (reproduced for convenience). Paradigm of the two-argument dative constructions in Modern French, illustrated by the verbs plaire 'to please', chanter 'to sing' and prendre 'to take'

Domain: V A1 [A2]

Frame: the function of A2

\begin{tabular}{ll|l|l}
\hline Expression of A1 & Content of A1 & \multicolumn{1}{l}{ Expression of A2 } & Content of A2 \\
\hline NP (personal) & $\begin{array}{l}\text { A1 has a referent with the } \\
\text { features } \pm \text { human; } \\
\text { semantic role: agent }\end{array}$ & $\begin{array}{l}\text { direct object } \\
\text { (pronoun in the } \\
\text { accusative) }\end{array}$ & $\begin{array}{l}\text { A2 has a referent with } \\
\text { the feature } \pm \text { human; } \\
\text { semantic role: patient }\end{array}$ \\
\hline NP (personal) & $\begin{array}{l}\text { A1 has a referent with the } \\
\text { feature } \pm \text { human }\end{array}$ & $\begin{array}{l}\text { pronoun in the } \\
\text { dative / } a+\text { NP }\end{array}$ & $\begin{array}{l}\text { A2 has a referent with } \\
\text { the feature +human; } \\
\text { semantic role: } \\
\text { experiencer }\end{array}$ \\
\hline $\begin{array}{l}\text { dummy subject } \\
\text { (impersonal) }\end{array}$ & $\begin{array}{l}\text { A1 has a referent with the } \\
\text { features: non-human, } \\
\text { non-concrete, +predicational }\end{array}$ & & \\
\hline
\end{tabular}

\subsubsection{Reorganisation of the non-subject argument paradigm in Peninsular Spanish}

In Section 2, I described the development from Latin to Modern Romance languages in terms of changes in the paradigmatic organisation of non-subject arguments in four stages. Firstly, the prepositional marking of A3 was introduced by means of the preposition $a d+$ accusative. This was stage 1 . Secondly, the use of $a d$ as marker of the recipient generalised and the $\mathrm{PP}$ was no longer the marked nominal form of the A3 paradigm. This was stage 2 . Thirdly, Romance languages developed in partly different directions. Here, Spanish is a special case, as it has a prepositional marking of an A2 by means of the preposition $a$, which implies a modification of the relation between A2 and A3 (stage 3). The change has gone a step further towards the merger of A2 and A3 (stage 4). Finally, cross-reference by means of clitic pronouns was introduced, providing additional marking of arguments by cross-clausal indexing. The paradigm of Modern Peninsular Spanish with leismo is complex, because the following formal oppositions interplay:

- $\quad$ the nature of the referent: \pm human

- the case of the argument: accusative or dative

- syntactic hierarchy: A2 or A3

- the construction (two argument construction, opposed to three argument constructions; NP governed by the preposition $a$ )

- cross-reference

Put differently: if the argument has a non-human referent, it is normally an A2. If it has a human referent, it is an A2 or an A3. If it is an NP, it is an A2 with a non-human 
referent, or an A2 in a three argument construction (with a non-human or a human referent). ${ }^{170}$ If it is a PP introduced by $a$, it is either a human A2 or a (human) A3. As a consequence of the paradigmatic reorganisations related to the leismo-phenomenon, the personal pronouns no longer distinguish an A2 from an A3, but they provide additional markings of arguments, especially with dislocated nominal arguments. In Table 8 repeated below, I proposed a (simplified) paradigm for Modern Peninsular Spanish non-subject arguments. The synthetic character of the paradigm lies in the fact that referentiality ( \pm human referent) in Table 8 is bound up with syntactic hierarchy (A2/A3) in such a way that we have a non-human case system opposed to a human case system.

Table 8. (repeated for convenience): Default three and two-argument constructions. The paradigm of a + NP in Peninsular Spanish. Stage 4

Domain: V [non-subject arguments]

Frame: Referentiality

\begin{tabular}{ll}
\hline Expression & Content \\
\hline A2 / A3: $a+$ NP or dative form of pron & human referent \\
A2: NP or accusative form of pron & non-human referent
\end{tabular}

\subsection{Implications for the theory of language change}

\subsubsection{Theoretical implications: Chains of grammaticalisation and connecting grammaticalisation}

In Section 1 I proposed that important changes of grammar should not be investigated as isolated changes. Instead, they should be studied as connected changes of grammar, as the different parts of grammar interplay. I introduced the distinction between (a) changes that form chains in the sense that one is presupposed by the other, and (b) changes that are connected in the sense that they create or modify paradigmatically organised parts of grammar and form complex paradigms. Section 4 provided a clear example of chains, as non-expression of A2 acquired grammatical meaning only after French had developed into a language with obligatorily expressed subject. This example illustrates the point that as changes occur, e.g. concerning the rules of the expression of arguments, this opens the way for new grammatical oppositions to be exploited, e.g. the non-expression of A2. Thus, Section 4 has illustrated the phenomenon that I have labelled chains of grammaticalisations, chains in the sense that one is presupposed by the other, so that the first (the quasi-obligatoriness of A1) is a

170. See, however, examples (11de) in Section 2. 
(non-causal) presupposition for the second (the emergence of the paradigmatic opposition between \pm expression of A2) to take place.

However important, chains of grammaticalisation have been observed before. They are not a new concept. My focus in this chapter has been on a new way of analysing relations between changes, as proposed in Chapter 4, i.e. changes that are connected in the sense that they create or modify paradigmatically organised parts of grammar and thus form complex paradigms. We have labelled such changes of grammar connecting grammaticalisation processes. We have distinguished two types of connecting grammaticalisation: (a) cases of parallel grammaticalisation in the sense that we find alternative or cooperative systems sharing the semantic frame that they grammaticalise, and (b) different systems that cooperate in forming complex paradigms (or hyperparadigms). Section 4 illustrates the former type and Section 2 and 4 the latter type. In Section 4, I have established that the paradigmatic opposition \pm individuated is found not only in the pronominal paradigm of A2 but also elsewhere, e.g. in the paradigm of determiners. This is a case of connecting grammaticalisation of type (a), i.e. parallel, because the same semantic frame (the same conceptual zone in Hjelmslevian terms), in this case the opposition \pm individuated, is coded in different expression systems. Section 2 and 4 illustrate the type (b), complex paradigms combining e.g. referentiality, morphology: case, case roles, syntactic hierarchy, constructional options and cross-reference, as summed up in Section 5.2 above.

\subsubsection{Theoretical and methodological implications}

In this subsection I will sum up the theoretical and methodological implications of my chapter for the study of language change.

Language change consists of innovation, actuation and actualisation. I accept the following description of a process of change (Andersen 2008:32): “The normal course of events through which a new expression originates, gains currency, and becomes established as part of a tradition of speaking is the following: one or more speakers (i) make a (primary) innovation and (ii) actualize it in usage; other speakers (iii) adopt the new expression and (iv) actualize it in their usage; if the new expression is used widely and long enough, new cohorts of speakers (v) will acquire it as an integral part of their competence, and (vi) actualize it in their usage; the new expression becomes generalized in the community through repeated cycles of (iii)-(vi). One can speak of such a series of overlapping kinds of innovation as a 'change scenario' and of the constituent innovation types (i)-(vi) as 'subchanges."

After having introduced the necessary concepts in Section 1, I have presented a number of change scenarios in Sections 2 to 4 . The most intricate one was that of Latin $a d+$ accusative, which was originally a marked locative alternative to the dative, and which later became the unmarked A3 construction in most Romance languages and the relation between A3 and A2, especially in Peninsular Spanish, resulting in a 
non-human case system opposed to a human case system. The actualisation process of the prepositional marking of human A2 in Spanish and the spreading of crossreference have been shown to conform to Henning Andersen's actualisation theory.

In Sections 3 and 4, I studied in detail less complex cases of change scenarios.

In Section 3, I followed the creation of the A2-dative construction in French. Among other things, I focused on the French verb aider, and I was able to see that the change of the expression of A2 spread in accordance with Henning Andersen's actualisation theory. Thus the change of construction from à $+\mathrm{NP}$ or the dative form of the pronoun to the default direct object construction took place in pronouns before nouns, in animate nouns before inanimate nouns and in unmarked text types before marked text types.

In Section 4, I identified a series of changes concerning the non-expression of A2, and I focused especially on an ongoing change in the zero-representation of A2, which is spreading from unmarked to marked contexts.

In sum, these changes progress in a way which conforms to the scenario presented above and to the theory of actualisation. The changes studied are all regrammations, i.e. changes by which an existing grammatical expression, through reanalysis, is ascribed new grammatical content.

The methodology used to study these changes consists of a series of synchronic distributional investigations of grammatical structures based on large, mainly electronic, corpora. I believe I have shown that such detailed synchronic investigation permits the identification of the paradigmatic structures and establishment of the diachronic correspondences between different periods of time.

\section{Sources:}

\section{Latin:}

http://www.thelatinlibrary.com.

http://www.fh-augsburg.de.

Lewis, Charlton T. \& Charles Short (1879): A Latin Dictionary, Oxford: Clarendon Press.

Old and Middle French electronic corpora:

Lancelot ou le Chevalier de la Charrette Transcriptions (Princeton) http://www.princeton. edu/ lancelot/trans.html.

BFM = "Base de Français Médiéval" de l’UMR 8503, composed by Christiane Marquello-Nizia and her research group, http://ccfm.ens-lsh.fr.

Le nouveau corpus d'Amsterdam, http://www.uni-stuttgart.de/lingrom/stein/corpus.

The Middle French electronic corpus ATILF: Les Chroniques de Froissart, Les Mémoires de Commynes, Les quinze Joies de Mariages, Cleriadus (14th-15th c.).

French of the Renaissance, Classical, Postclassical and Modern French electronic corpus: FRANTEXT http://www.atilf.fr/atilf/produits/frantext.htm.

(c) SA Le Monde-CEDROM-SNi inc. 2001. All rights reserved. 30 décembre 2000, page 1-39. 


\section{Written Sources:}

Rabelais, François: Pantagruel (1532), Texte établi et présenté par Jean Plattard, Société les Belles Lettres: Paris, 1946.

Discours Merveilleux de la vie, actions et deportements de Catherine de Médicis, Royne-mère (1576, anonymous, attributed to Henri Estienne), Edition critique sous la direction de Nicole Cazauran, Droz: Genève, 1995.

Les Serments de Strasbourg, La Prose de Sainte Eulalie, La Vie de Saint Léger, La Vie de Saint Alexis; 2. Le Charroi de Nîmes, ${ }^{171}$ narrative text composed in the 12th c.; 3. Jean d'Antioche, translation of De Inventione and Rhetorica ad Herennium (1282), Dits en quatrains d'Alexandrins Mororimes de Jehan de Saint-Quentin, publiés par B. Munk Olsen SAFT, Paris 1978.

171. A description of the nine mss of Le Charroi de Nimes is found in Schøsler (1984) Chapter 2. The electronic version of the mss is included in Le nouveau corpus d'Amsterdam. 



\section{References}

Akihiro, Hisae. 2004. Contribution à létude de la valence verbale en français contemporain, la non réalisation du complément d'objet direct. Ph.D. Thesis. École Pratique des Hautes Etudes, Paris 2004, Ms.

Andersen, Henning. 1973. "Abductive and deductive change”. Language 49, 4: 765-93.

Andersen, Henning. 1980. "Morphological change: towards a typology". In Historical Morphology, J. Fisiak (ed), 1-50. The Hague, Paris, New York: Mouton Publishers.

Andersen, Henning. 1987. "From auxiliary to desinence". In The historical development of auxiliaries, Martin Harris \& Paolo Ramat (eds), 21-51. Berlin: Mouton de Gruyter.

Andersen, Henning. 1990. “The structure of drift”. In Historical linguistics 1987, Henning Andersen \& Konrad Koerner (eds), 1-20. Amsterdam/Philadelphia: John Benjamins.

Andersen, Henning. 2001a. "Introduction". In Actualization: Linguistic change in progress, Henning Andersen (ed), 1-20.

Andersen, Henning. 2001b. "Markedness and the theory of linguistic change". In Actualization. Linguistic change in progress, Henning Andersen (ed), 21-57. Amsterdam and Philadelphia: John Benjamins.

Andersen, Henning. 2001c. "Actualization and the (uni)directionality of change". In Actualization. Linguistic change in progress, Henning Andersen (ed), 225-249. Amsterdam and Philadelphia: John Benjamins.

Andersen, Henning. 2006a. "Grammation, regrammation and degrammation: Tense loss in Russian”. Diachronica 23: 231-258.

Andersen, Henning. 2006b. "Perifrastic Futures in Slavic. Divergence and Convergence". In Change in Verbal Systems. Issues on Explanation, Kerstin Eksell \& Thora Vinther (eds), 9-45. Frankfurt am Main: Peter Lang.

Andersen, Henning. 2006c. "Synchrony, Diachrony, and Evolution”. In Competing Models of Linguistic Change. Evolution and beyond, Ole Nedergaard Thomsen (ed.), 59-90. Amsterdam and Philadelphia: John Benjamins.

Andersen, Henning. 2008. "Grammaticalization in a speaker-oriented theory of change". In Grammatical Change and Linguistic Theory. The Rosendal papers, Thórhallur Eythórsson (ed), 11-44. Amsterdam and Philadelphia: John Benjamins.

Andersen, Henning (ed.). 2001. Actualization: Linguistic change in progress. Amsterdam: John Benjamins.

Andersson, Lars-Gunnar. 1974. “Om bisatser i svenskan”. In Svenskans beskrivning 8, Christer Platzack (ed), 15-30. Lund: Lunds Universitet, Institutionen för Nordiska Språk.

Arteaga, Deborah. 1998. "On null objects in Old French". In Romance Linguistics. Theoretical Perspectives, Schwegler, Armin, Bernard Tranel \& Myriam Uribe-Etxebarria (eds), 1-11. Benjamins: Amsterdam.

Avanesov, R.I. 1988 etc. Slovar' drevnerusskogo jazyka (XI-XIV vv.) I-X. Moscow: Russkij jazyk. Ayres-Bennett, Wendy. 2004. Sociolinguistic Variation in Seventeenth-Century France. Methodology and Case Studies. Cambridge: CUP.

Banniard, Michel. 2004. "Continuité et discontinuité langagières: autour de la notion d'inversion des hiérarchies (IIIe-VIIIe s.)". Aemilianense 1: 13-31. 
Bascuñán, Silvia Becerra. 2006a. Estudio diacrónico y sincrónico del objeto indirecto en el español peninsular y de América. Etudes Romanes 57, Copenhagen: Museum Tusculanum.

Bascuñán, Silvia B. 2006b. "Grammaticalization of indirect object cross-reference in Spanish as a case of drift”. In Competing models of linguistic change. Evolution and beyond, Ole Nedergaard Thomsen (ed), 133-161. Amsterdam/Philadelphia: John Benjamins.

Bergs, Alexander T. \& Dieter Stein. 2001. "The role of markedness in the actuation and actualization of linguistic change”. In Henning Andersen (ed), 79-93.

Berlinck, Rosane de Andrade. 1996. “The Portuguese dative”. In The Dative, vol 2, Theoretical and Contrastive Studies, Van Belle \& Van Langendonck (eds), 119-151. Amsterdam/Philadelphia: John Benjamins.

Bjerre, Tavs, Eva Engels, Henrik Jørgensen \& Sten Vikner. 2008. "Points of convergence between functional and formal approaches to syntactic analysis". Working Papers in Scandinavian Syntax 82: 131-166.

Bjerrum, Anders et al. (eds.). 1966. Paul Diderichsen. Helhed og Struktur. Udvalgte sprogvidenskabelige Afhandlinger. Copenhagen: C.E.G. Gads forlag.

Blake, Barry J. 1994. Case. Cambridge: Cambridge University Press.

Bondzio, Wilhelm. 1971. "Valenz, Bedeutung und Satzmodelle“. In Gerhard Helbig (ed), 85-104. Boons, Jean-Paul, Alain Guillet \& Christian Leclère. 1976. La structure des phrases simples en français. Constructions intransitives. Genève and Paris: Droz.

Bossong, Georg. 1998a. "Le marquage différentiel de l'objet dans les langues d’Europe”. In Jack Feuillet (ed.), 193-258.

Bossong, Georg. 1998b. "Le marquage de l'expérient dans les langues d'Europe”, In Jack Feuillet (ed), 259-294.

Bossong, Georg. 1998c. "Eléments d'une typologie actancielle des langues romanes". In Jack Feuillet (ed), 769-787.

Bourciez, Edouard. 1967. Eléments de linguistique romane ${ }^{5}$. Paris : Klincksieck.

Boye, Kasper \& Peter Harder. 2007. "Complement-taking predicates: usage and linguistic structure". Studies in Language 31.3: 569-606.

Bräuer, Herbert. 1969. Slavische Sprachwissenschaft II. Formenlehre 1. Teil. Berlin: Walter de Gruyter. Browne, Wayles. 1993. "Serbo-Croat”. In The Slavonic languages, Bernard Comrie \& Greville G. Corbett (eds), 306-87. London/New York: Routledge.

Buridant, Claude. 2000. Grammaire nouvelle de l'ancien français. Sedes.

Bybee, Joan L. 1985. Morphology: A study of the relation between meaning and form. Amsterdam: Benjamins.

Bybee, Joan L. 1998. “Cognitive processes in Grammaticalization”. In Michael Tomasello (ed), $145-167$.

Bybee, Joan. 2001. "Frequency effects on French liaison". In Frequency and the emergence of linguistic structure, Joan Bybee and Paul Hopper (eds), 337-359. Amsterdam and Philadelphia: Benjamins.

Bybee, Joan, Revere Perkins \& William Pagliuca 1994. The Evolution of Grammar. Tense, Aspect and Modality in the Languages of the World. Chicago/London: The University of Chicago Press.

Bybee, Joan \& Paul Hopper (eds.). 2001. Frequency and the emergence of linguistic structure. Amsterdam - Philadelphia: Benjamins.

Bynon, Theodora. 1993 [1977]. Historical linguistics. Cambridge: Cambridge University Press. Christensen, Tanya Karoli. 2007. Hyperparadigmer. En undersøgelse af paradigmatiske samspil $i$ danske modussystemer [Hyperparadigms. An investigation of paradigmatic interplay i Danish mood systems]. Ph.D. dissertation. Department of Culture and Identity. Roskilde University. 
Christoffersen, Marit. 1993. Setning og sammenheng. Syntaktiske studier i Magnus Lagabøters landslov. Agder Distriktshøgskole. Kristiansand.

Christol, Alain. 1998a. “Marquage oblique des actants”. In Jack Feuillet (ed), 457-523.

Christol, Alain. 1998b. “Typologie des langues classiques (latin, grec)”. In Jack Feuillet (ed), 753-767.

Company Company, Concepción (ed.). 2006. Syntaxis histórica de la lengua española, primera parte: la frase verbal. Vol. 1-2. Mexico: Universidad Nacional Autónoma de México.

Comrie, Bernard. 1977. "In defense of spontaneous demotion: the impersonal passive". In Peter Cole \& Jerrold M. Sadock (eds.), Grammatical Relations (Syntax and Semantics 8), 47-58. New York: Academic Press.

Corbett, Greville G. 1991. Gender. Cambridge: Cambridge University Press.

Croft, William \& D. Alan Cruse. 2004. Cognitive Linguistics. Cambridge: Cambridge University Press.

Croft, William. 2001. Radical Construction Grammar. Syntactic Theory in Typological Perspective.

Oxford: Oxford University Press.

Dardel, Robert de. 2001. "Éléments de rection verbale protoromane". Revue de linguistique romane 65: 341-368.

Delbecque, Nicole \& Béatrice Lamiroy. 1996. “Towards a typology of the Spanish dative”, In Van Belle and Van Langendonck (eds), 73-117.

Delbecque, Nicole. 1998. "Why Spanish has two transitive construction frames". Leuvense Bijdragen 87: 387-415.

Delbecque, Nicole. 1999. "Two transitive construction frames in Spanish: The prepositional and the non-prepositional accusative". In Issues in Cognitive Linguistics: 1993 Proceedings of the International Cognitive Linguistics Conference, Leon de Stadler and Christoph Eyrich (eds), 407-423. Mouton de Gruyter: Berlin /New York.

Delsing, Lars-Olof. 1999. "Från OV-ordföljd til VO-ordföljd". Arkiv för nordisk filologi 114: 151-232.

Densusianu, Ovide. 1938. Histoire de la langue roumaine II. Librairie Ernest Leroux: Paris.

Detges, Ulrich. 2001. Grammatikalisierung. Eine kognitiv-pragmatische Theorie, dargestellt am Beispiel romanischer und anderer Sprachen. Habilitationsschrift. Tübingen.

Detges, Ulrich. 2009. "How useful is case morphology? The loss of the Old French two-case system within a theory of preferred argument structure". In The Role of Semantic, Pragmatic, and Discourse Factors in the Development of Case, Johanna Barðdal and Shobhana Chelliah (eds), 93-120. Amsterdam: John Benjamins.

Diderichsen, Paul. 1941. Setningsbygningen i Skaanske Lov. København: Ejnar Munksgaard.

Diderichsen, Paul. 1946. Elementor dansk Grammatik. Copenhagen: Gyldendal.

Diderichsen, Paul. 1966 [1943]. "Logische und topische Gliederung des germanischen Satzes". In Paul Diderichsen. Helhed og Struktur. Udvalgte sprogvidenskabelige Afhandlinger, A. Bjerrum et al. (eds), 52-63. Copenhagen: C.E.G. Gads forlag.

Diderichsen, Paul. 1966 [1964]. “Sætningsleddene og deres stilling - 30 år efter”. In Paul Diderichsen. Helhed og Struktur. Udvalgte sprogvidenskabelige Afhandlinger, Anders Bjerrum et al. (eds), 364-379. Copenhagen: C.E.G. Gads forlag.

Dik, Simon C. 1989. The Theory of Functional Grammar. Part I: The Structure of the Clause. Dordrecht: Foris Publications.

Dik, Simon C. 1997. The Theory of Functional Grammar I, second revised edition, ed. by Kees Hengeveld. Mouton de Gruyter: Berlin-New York.

Dixon, R.M.W. \& Alexandra Y. Aikhenvald. 2000. Changing valency. Case studies in transitivity. Cambridge: Cambridge University Press. 
Dubrovina, Larisa. 2002. Variativnoe glagol'noe upravlenie v russkom jazyke pervoj treti XIX veka. Uppsala: Uppsala University Library.

Durst-Andersen, Per. 1992. Mental grammar. Russian aspect and related issues. Columbus, Ohio: Slavica Publishers.

Durst-Andersen, Per. 2005. "Fra oldrussisk til moderne russisk. Leksikaliseringsmønstre og syntaktiseringsmekanismer”. Grammatikalisering og struktur. In Lars Heltoft, Jens NørgårdSørensen \& Lene Schøsler (eds), 57-84. Copenhagen: Museum Tusculanum.

Durst-Andersen, Per. 2006. "From propositional syntax in Old Russian to situational syntax in Modern Russian”. In Competing models of linguistic change. Evolution and beyond, Ole Nedergaard Thomsen (ed), 211-34. Amsterdam and Philadelphia: John Benjamins.

Durst-Andersen, Per. 2011. Linguistic Supertypes. A Cognitive-Semiotic Theory of Human Communication. Berlin: DeGruyter.

Durst-Andersen, Per \& Michael Herslund. 1996. “The Syntax of Danish Verbs: Lexical and Syntactic Transitivity”. In Content, Expression and Structure. Studies in Danish Functional Grammar, Elisabeth Engberg-Pedersen et al. (eds), 65-102. Amsterdam: Benjamins.

Dyvik, Helge. 1980. "Har gammelnorsk passiv?” In The Nordic Languages and Modern Linguistics. Proceedings of the Fourth International Conference of Nordic and General Linguistics in Oslo 1980, Even Hovdhaugen (ed), 81-107. Oslo: Universitetsforlaget.

Eisenberg, Peter. 1989. Grundriss der deutschen Grammatik. 2. Auflage. Stuttgart: Metzler.

Eisenberg, Peter. 2006. Grundriss der deutschen Grammatik. 3 Auflage. Band 1: Das Wort; Band 2: Der Satz. Stuttgart: Metzler.

Engberg-Pedersen, Elisabeth, Peter Harder, Michael Fortescue, \& Lars Heltoft \& Lisbeth Falster Jakobsen (eds.). 1996. Content, expression and structure. Studies in Danish functional grammar. Amsterdam: John Benjamins.

Engberg-Pedersen, Elisabeth. 1996. "Iconicity and Arbitrariness". In Content, Expression and Structure. Elisabeth Engberg-Pedersen et al. (eds), 453-468. Amsterdam: John Benjamins.

Engelen, Bernhard. 1975. Untersuchungen zu Satzbauplan und Wortfeld in der geschriebenen deutschen Sprache der Gegenwart, Heutiges Deutsch 1/3.1. München: Hueber.

Faarlund, Jan Terje. 1989. "Discourse Functions and Syntax". CLS 25 (= Papers from the 25th Annual Regional Meeting of the Chicago Linguistic Society). Part Two: Language in Context, 30-40. Chicago Linguistic Society.

Faarlund, Jan Terje. 1990. Syntactic change. Toward a theory of historical syntax. Trends in linguistics. Studies and monographs 50. Berlin and New York: Mouton de Gruyter.

Faarlund, Jan Terje. 2004. Old Norse Syntax. Oxford: Oxford University Press.

Falk, Hjalmar \& Alf Torp. 1900. Dansk-norskens syntax i historisk fremstilling. Kristiania: Aschehoug \& co.

Ferm, Ljudmila. 2005. Variativnoe bespredložnoe glagol'noe upravlenie v russkom jazyke XVIII veka. Stockholm: Södertörn högskola.

Feuillet, Jack. 1998. Actance et Valence dans les Langues de l'Europe, Berlin - New York: Mouton de Gruyter.

Fillmore, Charles J., Paul Kay \& Mary Catherine O’Connor. 1998. "Regularity and idiomaticity in grammatical constructions: The case of let alone”. In Michael Tomasello (ed.), 243-270.

Fischer, Olga, Muriel Norde \& Harry Perridon (eds). 2004. Up and down the cline - the nature of grammaticalization. Amsterdam/Philadelphia: John Benjamins.

Flier, Michael. 1974. Aspects of nominal determination in Old Church Slavonic. The Hague Paris: Mouton. 
Fournier, Nathalie. 1998. Grammaire du français classique. Paris: Belin.

Frei, Henri. 1979. “Définition du type 'les Marocaines, vous aimez'? ”. In Festschrift Kurt Baldinger zum 60.Geburtstag, Manfred Höfler, Henri Vernay and Lothar Wolf (eds), 300-303. Tübingen : Niemeyer.

Gadet, Françoise. 1990. "Les outils grammaticaux au risque de l'oral non standard". Travaux de linguistique 21: 13-24.

Gadet, Françoise. 2003. La variation sociale en français. Paris: Ophrys.

Givón, Talmy. 1971. "Historical syntax and synchronic morphology." In Papers from the seventh regional meeting. Chicago Linguistic Society. Chicago, 394-415.

García, Erica C. 1993. "Syntactic diffusion and the irreversibility of linguistic change: personal $a$ in Old Spanish. In Sprachwandel und Sprachgeschichte. Festschrift für Helmuth Lüdtke zum 65. Geburtstag, Jürgen Schmidt-Radefeldt \& Andreas Harder (eds), 33-50. Günter Narr: Tübingen.

Geisler, Hans. 1988. "Das Verhältnis von semantischer und syntaktischer Transitivität im Französischen”. Romanistisches Jahrbuch 39: 22-35.

Givón, Talmy. 1971. "Historical syntax and synchronic morphology." In Papers from the seventh regional meeting. Chicago Linguistic Society. Chicago, 394-415.

Givón, Talmy. 1979. On understanding grammar. New York etc: Academic Press.

Givón, Tom. 1991. "Isomorphism in the grammatical code: Cognitive and biological considerations". Studies in Language 15: 85-114.

Glovinskaja, M. Ja. 1996. “Aktivnye processy v grammatike”. In E. A. Zemskaja (ed), 237-304.

Goldberg, Adele. 1995. A Construction Grammar Approach to Argument Structure. Chicago: The University of Chicago Press.

Goldberg, Adele E. 1998. "Patterns of Experience”. In Michael Tomassello (ed), 203-219.

Gorškova, Klavdija V. \& Georgij A. Xaburgaev. 1981. Istoričeskaja grammatika russkogo jazyka. Moscow: Vysšaja škola.

Goyens, Michèle. 2000. "L'alternance dans les constructions prépositionnelles des verbes français: Une étude historique de l'emploi de la préposition à”. In Actes du XXIIe Congrès International de Linguistique et de Philologie Romanes Volume II: Les nouvelles ambitions de la linguistique diachronique, Annick Englebert, Michel Pierrard, Lorence Rosier \& Dan Van Raemdonck (eds), 203-210. Tübingen: Max Niemeyer.

Goyens, Michèle. 2001. "L’ origine des verbes français a construction dative”. In Lene Schøsler (ed), 43-58.

Gregersen, Frans \& Inge-Lise Pedersen. 1997. “Hovedsætningsordstilling i underordnede sætninger”. Danske Folkemål 39: 55-112.

Gregersen, Frans \& Inge-Lise Pedersen. 2000. "A la Recherche du Word Order Not Quite Perdu. A methodological progress report”. In Textual Parameters in Older Languages, Susan C. Herring, Pieter van Reenen \& Lene Schøsler (eds), 393-431.

Grevisse, Maurice. 1986. Le bon usage. Grammaire française. Douzième édition refondue par André Goose, Paris-Gembloux: Duculot.

Gries, Th. Stefan \& Anatol Stefanowitsch. 2004. "Extending collostructional analysis. A corpus-based perspective on 'alternations' ". International Journal of Corpus Linguistics 9 (1): 97-129.

Haberland, Hartmut \& Lars Heltoft. 2008. "Die schwache Adjektivflexion im Dänischen und Deutschen". Acta Linguistica Hafniensia 40: 23-43.

Halliday, Michael A.K. 1996. An introduction to functional grammar. 2nd ed. London: Edward Arnold. 
Hansen, Erik \& Lars Heltoft 2011. Grammatik over det Danske Sprog [Grammar of the Danish Language]. Det Danske Sprog- og Litteraturselskab. Odense: University of Southern Denmark Press.

Hansen, Anita B. \& Erling Strudsholm. 2006. "Morphological and periphrastic future in French and Italian spoken language: Parallel tendencies?” In La linguistique au coeur. Valence verbale, grammaticalisation et corpus: Mélanges offerts à Lene Schøsler à l'occasion de son 60e anniversaire, Hanne Leth Andersen, Merete Birkelund \& Maj-Britt Mosegaard Hansen (eds), 189-218. Odense: University Press of Southern Denmark.

Happ, Heinz. 1976. Grundfragen einer Dependenz-Grammatik des Lateinsichen. Göttingen: Vandenhoeck and Ruprecht.

Harder, Peter. 1996. Functional Semantics. A Theory of Meaning, Structure and Tense in English. Mouton de Gruyter.

Harris, Alice C. 2003. "Cross-Linguistic Perspectives on Syntactic Change”. In The Handbook of Historical Linguistics, Brian D. Joseph \& Richard D. Janda (eds), 529-551. Oxford: Blackwell Publishing.

Harris, Alice C. \& Lyle Campbell. 1995. Historical Syntax in Cross-Linguistic Perspective. Cambridge: Cambidge University Press.

Haspelmath, Martin. 2003. "The geometry of grammatical meaning: Semantic maps and crosslinguistic comparison”. In Michael Tomasello (ed), 211-242.

Haspelmath, Martin. 2004. "On directionality in language change with particular reference to grammaticalization". In Fischer, Norde \& Perridon (eds), 17-44.

Hawkins, John A. 1983. Word Order Universals. New York: Academic Press.

Helbig, Gerhard 1971. “Theoretische und praktische Aspekte eines Valenzmodells”. In Gerhard Helbig (ed), 31-50.

Helbig, Gerhard (ed.). 1971. Beiträge zur Valenztheorie. Janua Linguarum. Series Minor 115. The Hague/Paris: Mouton.

Heine, Bernd \& Tania Kuteva 2002. World lexicon of grammaticalization. Cambridge: Cambridge University Press.

Heine, Berndt. 2003. “Grammaticalization”. In The Handbook of Historical Linguistics, Brian D. Joseph \& Richard D. Janda (eds), 575-601. Oxford etc.: Blackwell Publishing.

Heltoft, Lars. 1992. "The Topology of Verb Second and SVO Languages. A Study in the Sign Functions of Word Order." In Word Order, Michael Herslund (ed). Copenhagen Studies in Language 15: 13-64.

Heltoft, Lars 1995. "Grammatikaliseringsprocesser i dansk syntakshistorie”. In Sproghistorie i 90’erne, Bente Holmberg (ed), 125-168. Copenhagen: Selskab for Nordisk Filologi.

Heltoft, Lars. 1996. "Paradigms, Word Order and Grammaticalization”. In Content, Expression, and Structure: Studies in Danish Functional Grammar, Elisabeth Engberg Pedersen, Michael Fortescue, Peter Harder, Lars Heltoft \& Lisbeth Falster Jakobsen (eds), 469-494. Amsterdam and Philadelphia: John Benjamins.

Heltoft, Lars. 2001. "Recasting Danish Subjects”. In Grammatical Relations in Change, Jan Terje Faarlund (ed), 171-200. Amsterdam and Philadelphia: John Benjamins.

Heltoft, Lars. 2003. "Iconic and categorical focus systems in Scandinavian". In Structures of focus and grammatical relations, Valéria Molnar \& Jorunn Hedland (eds), 43-87. Tübingen: Max Niemeyer Verlag.

Heltoft, Lars. 2005. "Ledsætning og letled i dansk: OV-rækkefølgens rester”. In Grammatikalisering og Struktur, Lars Heltoft, Jens Nørgård-Sørensen \& Lene Schøsler (eds), 145-166. Copenhagen: Museum Tusculanum. 
Heltoft, Lars. 2006. "Grammaticalisation as Content Reanalysis: The Modal Character of the Danish S-passive”. In Ole Nedergård Thomsen (ed.), Competing Models of Linguistic Change. Evolution and Beyond, 268-288. Amsterdam/Philadelphia: John Benjamins Publishing Company.

Heltoft, Lars. 2007. "Subjektive partiklers grammatikalisering i nyere dansk - eksemplet sikke." Danske Studier 102: 17-42.

Heltoft, Lars. 2008. Grammatik over det Danske Sprog - en radikal dependensgrammatik? C. Bache, A. HoIsting, H. Høgh Müller \& N. Nørgaard (red.), Ny Forskning i grammatik. Fællespublikation 15. (69-94). Odense: Odense Universitetsforlag.

Heltoft, Lars. 2010. "Paradigmatic structure in a usage based theory of grammaticalisation". In Language Usage and Language Structure, Kasper Boye \& Elisabeth Engberg-Pedersen (eds), 145-166. Berlin: Mouton de Gruyter.

Heltoft, Lars \& Erik Hansen. 2005. "Konstruktion og valens: Objekt med verbal infinitiv som eksempel”. In Ny Forskning i grammatik. Follespublikation 12, 99-119. Odense: Odense University Press.

Heltoft, Lars, Jens Nørgård-Sørensen \& Lene Schøsler (eds). 2005. Grammatikalisering og struktur. Copenhagen: Museum Tusculanum.

Heltoft, Lars, Jens Nørgård-Sørensen \& Lene Schøsler. 2005. "Grammatikalisering og struktur”. In Grammatikalisering og struktur, Lars Heltoft, Jens Nørgård-Sørensen \& Lene Schøsler (eds), 9-30. Copenhagen: Museum Tusculanum.

Heltoft, Lars \& Lisbeth Falster Jackobsen. 1996. "Danish Passives and Subject Positions as as Mood System. A Content Analysis”. In Content, Expression, and Structure: Studies in Danish Functional Grammar, Elisabeth Engberg Pederson, Micheal Fortescue, Peter Harder, Lars Heltoft and Lisbeth Falster Jackobsen (eds), 199-234. Amerston and Philadelphia: John Benjamin.

Herman, József. 1998. “La chronologie de la transition: un essai”. In József Herman (ed), 5-26. Herman, József. 2000. Vulgar Latin. University Park: Penn State University Press.

Herman, József. 2002. "La disparition du passif synthétique latin : nouvel essai sur lécrit et le parlé en latin Mérovingien”. Estudis Romànics 24: 31-46.

Herman, József (ed.). 1998. La transizione dal latino alle lingue romanze. Tübingen: Niemeyer

Herslund, Michael. 1980. Problèmes de syntaxe de l'ancien français. Complément datifs et génitifs. Etudes Romanes 21. Copenhagen: Akademisk Forlag.

Herslund, Michael. 1988. Le datif en français, Louvain/Paris: Editions Peeters.

Herslund, Michael. 1997. "Syntaktiske alternationer og funktionelle kategorier”. In Ny Forskning i Grammatik, (Follespublikation 4), Lisbeth Falster Jakobsen \& Gunver Skytte (eds), 49-70.

Odense: Odense Universitetsforlag.

Herslund, Michael. 2001. “The Danish -s genitive: from affix to clitic”. Acta Linguistica Hafniensia 33: 7-18.

Herslund, Michael. 2006. "La topologie du français à la lumière de deux autres systèmes. Le danois et l'ancien français". Lingvisticae Investigationes 29 (1): 103-113.

Hjelmslev, Louis. 1935-37. La Catégorie des Cas 1-2. Étude de grammaire générale. Acta Jutlandica $\mathrm{VII}_{1}$ and IX, ${ }_{2}$. Aarhus: Universitetsforlaget i Aarhus.

Hjelmslev, Louis. 1963. Sproget. En introduktion. Berlingske Forlag: Copenhagen.

Hjelmslev, Louis. 1970 [1939]. "La structure morphologique”. In Essais Linguistiques, Travaux du Cercle Linguistique de Copenhague XII, Gunnar Bech et al. (eds), 111-138. Copenhagen: Nordisk Sprog- og Kulturforlag. 
Hjelmslev, Louis. 1972. "Sprogsystem og sprogforandring”. In Travaux du Cercle Linguistique de Copenhague XV. Copenhagen: Nordisk Sprog- og Kulturforlag.

Hock, Hans H. 2003. “Analogical change”. In Brian Joseph \& Richard Janda (eds), 441-60.

Holmberg, Anders \& Christer Platzack. 1995. The Role of Inflection in Scandinavian Syntax. New York and London: Oxford University Press.

Hooper, Joan B. 1975. “On Assertive Predicates”. In Syntax and Semantics 4, John P. Kimball (ed), 91-124. New York: Academic Press.

Hopper, Paul J. 1991. "On some principles of grammaticalization”. In Approaches to Grammaticalization Vol 1, Elizabeth Closs Traugott \& Bernd Heine (eds), 17-35. Amsterdam/Philadelphia: John Benjamins Publishing Company.

Hopper, Paul J. 1998. "The paradigm at the end of the universe". In The limits of grammaticalization, Anna Giacalone Ramat \& Paul Hopper (eds.), 147-158. Amsterdam: Benjamins.

Hopper, Paul J. \& Sandra A. Thompson. 1980. “Transitivity in Grammar and Discourse”. Language 56: 251-299.

Hopper, Paul J. \& Elizabeth Closs Traugott. 2003. Grammaticalization. Second Edition. Cambridge: Cambridge University Press.

Hummel, Martin. 2004. "Zur Valenz der Witterungsverben”. In Romanische Sprachwissenschaft. Zeugnisse für Vielfalt und Profil eines Faches. Festschrift für Christian Schmitt, Band II, Alberto Gil, Dietmar Osthus \& Claudia Polzin-Haumann (eds), 35-58. Frankfurt am Main: Peter Lang.

Høysgaard, Jens Pedersen. 1752. Methodisk Forsøg til en fuldstoendig dansk Syntax. Ref. made to Danske Grammatikere V, Henrik Berthelsen (ed). Copenhagen: Gyldendalske Boghandel, Nordisk Forlag. 1923.

Il’ina, N.E. 1996. “Rost analitizma v morfologii”. In Zemskaja (ed), 305-25.

Iordanidi, Sof'ja I. 1995. "Suščestvitel'noe”. In Drevnerusskaja grammatika XII-XIII vv., Vjačeslav V. Ivanov (ed), 170-294. Moscow: Nauka.

Isačenko, Alexander V. 1975. Die russische Sprache der Gegenwart. Formenlehre. München: Max Hueber.

Jacob, Daniel. 1990. Markierung von Aktantenfunktionen und 'Prädetermination' im Französischen. Tübingen: Niemeyer.

Jacob, Daniel. 1991. "Dativ im Französischen? Zur Funktionsweise und Semantik der Ergänzungsklasse 'à + NP”' In Peter Koch \& Thomas Krefeld (eds), 157-186.

Jakobson, Roman. 1971 [1959]. "Boas' view on grammatical meaning”. In The anthropology of Franz Boas: Essays on the centennial of his birth, ed. American Anthropological Association, cited from reprint: Selected writings II. Word and language, 489-96. The Hague/Paris: Mouton.

Jensen, Frede. 1990. Old French and Comparative Gallo-Romance Syntax. Tübingen: Max Niemeyer.

Joffre, Marie-Dominique. 1995. Le verbe latin: voix et diathèse. Louvain-Paris: Peeters.

Joseph, Brian D. 2003. "Morphologization from syntax". In Brian Joseph \& Richard Janda (eds), 472-92.

Joseph, Brian D. \& Richard D. Janda. 1988. “The how and why of diachronic morphologization and demorphologization." In Theoretical morphology: approaches in modern linguistics, M. Hammond \& M. Noonan (eds), 193-210. San Diego: Academic Press.

Joseph, Brian D. \& Richard D. Janda (eds.). 2003. The Handbook of Historical Linguistics. Oxford: Blackwell Publishing.

Karker, Allan. 1991. "Jydernes lov på dansk". In Jydske Lov 750 år, Ole Fenger and Christian R. Jansen (eds), 124-143. Viborg: Udgiverselskabet ved Landsarkivet for Nørrejylland. 
Kemmer, Suzanne. 1995. The Middle Voice. Amsterdam: Benjamins.

Kiesler, Reinhard. 2005. "Sull'oggetto zero nel romanzo". In Philologische Grenzfälle oder die Quadratur des Kreises: Festschrift für Wilhelm Pötters, Joachim Christl, Sandra Ellena \& Andrea Landvogt (eds), 255-271. Stuttgart: Ibidem.

Klemensiewicz, Zenon, Tadeusz Lehr-Spławiński \& Stanisław Urbańczyk. 1955. Gramatyka historyczna języka polskiego. Warszawa: Państwowe wydawnictwa naukowe.

Klenin, Emily. 1983. Animacy in Russian: a new interpretation. Columbus Ohio: Slavica Publishers. Koch, Peter. 2001. "As you like it. Les métataxes actantielles entre Expérient et Phénomène". In Lene Schøsler (ed), 59-81.

Koch, Peter \& Wulf Oesterreicher. 2001. Language parlé et langage écrit, Lexikon der romanistischen Linguistik 1, 584-627. Tübingen: Max Niemeyer Verlag.

König, Ekkehard \& Martin Haspelmath. 1998. "Les constructions à possesseur externe dans les langues d'Europe”. In Jack Feuillet (ed), 525-606.

Korzen, Hanne. 1998. "Principper for opstillingen af modus i kompletivsætninger på fransk" [= Principles for the analysis of mood in complement clauses in French]. In Ny forskning i grammatik 6, Carl Bache, Lars Heltoft \& Michael Herslund (eds), 181-204. Odense: Odense University Press.

Kragh, Kirsten. 2006. Le remplacement de l’imparfait du subjonctif par le présent du subjonctif considéré dans une perspective de grammaticalisation. Copenhagen: University of Copenhagen.

Krefeld, Thomas. 1998. “Transitivität aus rollensemantischer Sicht. Eine Fallstudie am Beispiel französischer und italienischer Wahrnehmungsverben”. In Transitivität und Diathese in romanischen Sprachen, Hans Geisler \& Daniel Jacob (eds), 155-173. Tübingen: Max Niemeyer Verlag.

Krötsch, Monique \& Wulf Oesterreicher. 2002. "Dynamique des configurations actancielles. Modifications des constructions verbales en français non standard", in Syntaxe and Sémantique - Valence: perspectives allemandes - no. 4, 109-137.

Krys'ko, Vadim B. (ed.). 2000-2006. Istoričeskaja grammatika drevnerusskogo jazyka I-IV. Moscow: Azbukovnik.

Krys'ko, Vadim B. 1994. Razvitie kategorii oduševlennosti v istorii russkogo jazyka. Moscow: Lyceum.

Krys'ko, Vadim B. 1997. Istoričeskij sintaksis russkogo jazyka. Ob”jekt i perechodnost'. Moscow: Indrik. Kuznecov, P.S. 1953. Istoričeskaja grammatika russkogo jazyka. Moscow: Izdatel'stvo Moskovskogo Universiteta.

Lambrecht, Knud. 1981. Topic, Antitopic and Verb Agreement in Non-Standard French. Pragmatics and Beyond II, 6. Amsterdam/Philadelphia: Benjamins.

Lambrecht, Knud. 2004. "On the interaction of information structure and formal structure in constructions: The case of French right-detached comme-N”. In Construction Grammar in a Cross-Language Perspective, Mirjam Fried and Jan-Ola Östman (eds), 157-199. Amsterdam: John Benjamins.

Larjavaara, Meri. 2000. Présence ou absence de l’objet. Limites du possible en français contemporain. Helsinki : Academia Scientarium Fennica.

Larsen, Karin. 2005. The Evolution of the System of Long and Short Adjectives in Old Russian (Slavistische Beiträge 439). München: Verlag Otto Sagner.

Larsen, Karin. 2006. "The distribution of long and short forms of adjectives in Old Russian (as represented by four Chronicle Texts)." Russian Linguistics 30, vol. 3: 359-400.

Larsen, Karin. 2007. "The loss of the attributive short form in Old Russian as a process of grammaticalization.” Scando-Slavica 53: 33-57. 
Larsen, Karin. 2009. "The Evolution of the System of Long and Short Adjectives in Old Russian as a Process of Grammaticalization. Reanalysis and Actualization”. In Proceedings of the Second International Perspectives on Slavistics Conference, Regensburg 2006: Die Welt der Slaven. Sammelbände 36, Sandra Birzer, Miriam Finkelstein and Imke Mendoza (eds), 75-86. München: Verlag Otto Sagner.

Larsson, Carl. 1931. Ordföljdsstudier över det finita verbet $i$ de nordiska fornspråken, vol. I. Uppsala Universitets Årsskrift, Uppsala: Lundquistska Bokhandeln.

Lass, Roger. 1994. Old English: A historical linguistic companion. Cambridge: Cambridge University Press.

Lehmann, Christian. 1985. "Grammaticalization: Synchronic Variation and Diachronic Change". Lingua e Stile 20: 203-18.

Lehmann, Winfred P. 1974. “The Great Underlying Ground-Plans.” In Syntactic Typology. Studies in the Phenomenology of Language, Winfred. P. Lehmann (ed), 3-56. Austin and London: University of Texas Press.

Lehmann, Winfred P. 1993. Theoretical Bases of Indo-European. New York and London.

Leth Andersen, Hanne \& Christa Thomsen (eds.). 2004. Sept approches à un corpus. Analyses du français parlé. Bern, Berlin etc.: Peter Lang.

Levin, Beth. 2003. "Objecthood and Object Alternations”. Department of Linguistics, UCLA, Los Angeles, Calif., May 2003. 13 pages; pdf. http://www-csli.stanford.edu/ beth/pubs.html.

Levin, Beth \& Malka Rappaport Hovav. 2005. Argument Realization, Research Surveys in Linguistics Series. Cambridge University Press: Cambridge.

Lightfoot, David. 2003. "Grammatical Approaches to Syntactic Change." In The Handbook of Historical Linguistics, Brian D. Joseph and Richard D. Janda (eds), 124-143. Oxford: Blackwell Publishing.

Lüdi, Georges. 1978. "Die Alternanz zwischen Dativ und Akkusativ by “prier", "supplier," "requerir” im 15. und 16. Jahrhundert”, Vox Romanica 37: 160-192.

Lyons, Christopher. 1990. "An agreement approach to clitic doubling”. Transactions of the Philological Society 88 (1): 1-57.

Maiden, Martin. 1998. Storia linguistica dell' italiano. Bologna: Il Mulino. Ediz. originale: A Linguistic History of Italian. Longman 1995.

Maiden, Martin. 2000. "Il sistema desinenziale del sostantivo nell'italo-romanzo preletterario: ricostruzione parziale a partire dai dialetti moderni (il significato storico di plurale del tipo amici)". In La preistoria dell'italiano: Atti della Tavola Rotonda di Linguistica Storica. Università Ca' Foscari di Venezia, 11-13 giugno 1998, József Herman and Anna Marinetti (eds), 167-79. Tübingen: Niemeyer.

Martin, Maiden. 2003 [1995]. A linguistic history of Italian. London: Longman.

Maier, Ingrid. 1997. Verbalrektion in den "Vesti-Kuranty" (1600-1660). Eine historisch-philologische Untersuchung zur mittelrussischen Syntax. Uppsala: Almqvist and Wiksell.

Marchello-Nizia, Christiane. 1995. L'évolution du français. Ordre des mots, démonstratifs, accent tonique. Armand Colin: Paris.

Matthews, Peter H. 1993 [1974]. Morphology. Cambridge: Cambridge University Press.

Mayo, Peter J. 1984. The morphology of aspect in seventeenth-century Russian (Based on texts of the Smutnoe vremja). Columbus Ohio: Slavica Publishers.

Meillet, Antoine. 1897. Recherches sur l'emploi du génitif-accusatif en vieux-slave. Paris: Bouillon.

Meillet, Antoine. 1964 [1937]. Introduction à l'étude comparative des langues indo-européennes. Reprint. University of Alabama Press. 
Meillet, Antoine. 1965 [1912]. “L'évolution des formes grammaticales”. Reprinted in: Linguistique historique et linguistique générale par A. Meillet, 130-148. Paris: Champion.

Meyer-Lübke, Wilhelm. 1897. "Zur Stellung der tonlosen Objektspronomina”. Zeitschrift für romanische Philologie 21: 313-334.

Nikula, Henrik. 1976. Verbvalenz. Untersuchungen am Beispiel des deutschen Verbs mit einer kontrastiven Analyse Deutsch -Schwedisch. Acta Universitatis Upsaliensis. Studia Germanistica Upsaliensia 15. Uppsala: Liber Tryck Stockholm.

Noël, Dirk. 2006. Diachronic construction grammar vs. grammaticalization theory. Preprint nr. 225. Katholieke Universiteit Leuven.

Noël, Dirk. 2007. "Verb valency patterns, constructions and grammaticalization". In Valency. Theoretical, Descriptive and Cognitive Issues, Thomas Herbst \& Katrin Götz-Votteler (eds), 67-84. Mouton de Gruyter: Berlin and New York.

Norde, Muriel. 1997. The history of the genitive in Swedish. A case study in degrammaticalization. Amsterdam: University of Amsterdam.

Nygaard, Marius. 1905. Norrøn Syntax. Kristiania.

Nørgård-Sørensen, Jens. 1997a. "Tense, aspect and verbal derivation in the language of the Novgorod birch bark letters". Russian Linguistics 21 (1): 1-21.

Nørgård-Sørensen, Jens. 1997b. "Vido-vremennye formy v drevnenovgorodskom dialekte v sopostavlenii s sovremennym russkim jazykom”. Trudy aspektologičeskogo seminara Filologičeskogo Fakul'teta MGU im. M. V. Lomonosova, vol. 2, Marina Ju. Čertkova (ed), 83-98. Moscow: Izdatel'stvo Moskovskogo Universiteta.

Nørgård-Sørensen, Jens. 1997c. "Russian nominal morphology: A hierarchy of semantic features”. In Formale Slavistik (= Leipziger Schriften zur Kultur-, Literatur-, Sprach- und Übersetzungswissenschaft, vol. 7.), Uwe Junghanns \& Gerhild Zybatow (eds), 335-46. Frankfurt am Main: Vervuert Verlag.

Nørgård-Sørensen, Jens. 1999. En eller flere? Numerus i dansk og russisk. In Ny forskning $i$ grammatik 6, Carl Bache, Lars Heltoft \& Michael Herslund (eds), 263-83. Odense: Odense Universitetsforlag.

Nørgård-Sørensen, Jens. 2005. “Genus og deklination i det 19. og 20. århundredes russisk. En ny fortolkning”. In Heltoft, Nørgård-Sørensen \& Schøsler (eds), 185-200.

Nørgård-Sørensen, Jens. 2006. "Aspect and animacy in the history of Russian: Developing the idea of parallel grammaticalization". In Competing models of linguistic change. Evolution and beyond, Ole Nedergaard Thomsen (ed), 289-305. Amsterdam and Philadelphia: John Benjamins.

Nørgård-Sørensen, Jens. 2011. Russian nominal semantics and morphology. Bloomington, Indiana: Slavica Publishers.

Palmer, L.R. 1954. The Latin Language. Faber and Faber: London.

Paul, Hermann. 1880 [1975]. Prinzipien der Sprachgeschichte. Tübingen: Max Niemeyer Verlag. Pedersen, Karen Margrethe. 1993. "Letledsreglen og lighedsreglen - Novation, ekspansion og resistens”. In Jyske Studier, Karen Margrethe Pedersen and Inge Lise Pedersen (eds), 199-218. København: C.A. Reitzel.

Penny, Ralph. 2002. A History of the Spanish Language, second edition. Cambridge University Press: Cambridge.

Pinkster, Harm. 1990. Latin Syntax and Semantics. New York: Routledge.

Pintzuk, Susan. 2003. "Variationist Approaches to Syntactic Change". In The Handbook of Historical Linguistics, Brian D. Joseph \& Richard D. Janda (eds), 509-528. Oxford: Blackwell Publishing. 
Platzack, Christer. 1985. "A survey of generative analyses of the verb second phenomenon in Germanic". Nordic Journal of Linguistics 8, 49-73.

Prokopova, T.I. 1991. “Glagol'naja kategorija vremeni”. In Drevnerusskij jazyk domongol'skoj pory, Vladimir V. Kolesov (ed), 48-72. Leningrad: Izd. Leningradskogo universiteta.

Reenen, Pieter van \& Lene Schøsler. 2000. “The pragmatic functions of the old French particles AINZ, APRS, DONC, LORS, OR, PUIS, and SI”. In Textual parameters in older languages, Susan C. Herring, Pieter van Reenen \& Lene Schøsler (eds), 59-105. Amsterdam: John Benjamins.

Remneva, Marina L. 1995. Istorija russkogo literaturnogo jazyka. Moscow: Filologija.

Riegel, Martin, Jean-Christophe Pellat and René Rioul. 19995. Grammaire méthodique du français. Paris: PUF.

Roberge, Yves \& Michelle Troberg. 2006. “Arguments indirects et modes d'association”. In Actes du congrès annuel de l'Association canadienne de linguistique, http://ling.uwo.ca/publications/CLA2006/Roberge_Troberg.pdf.

Rohlfs, Gerhard. 1969. Grammatica storica della lingua italiana e dei suoi dialetti, 3 : Sintassi e formazione delle parole. Torino: Einaudi.

Rosenbach, Anette. 2004. “The English s-genitive. A case of degrammaticalization?” In Up and Down the Cline - The Nature of Grammaticalization, Olga Fischer, Muriel Norde \& Harry Perridon (eds), 73-95. Amsterdam and Philadelphia: John Benjamins.

Rotaetxe, Karmele. 1998. "Constructions triactancielles et datif”. In Jack Feuillet, Jack (ed), 391-456.

Rusinov, Nikolaj D. 1977. Drevnerusskij jazyk. Moscow: Vysšaja škola.

Rögnvaldsson, Eiríkur. 1996. Word Order Variation in the VP in Old Icelandic. Working Papers in Scandinavian Syntax 58: 55-86.

Sandfeld, Kristian. 1928. Syntaxe du français contemporain, vol 1: Les pronoms. Paris: Champion. Sasse, Hans-Jürgen. 1987. “The Thetic/Categorical Distinction Revisited”. Linguistics 25: 511-580.

Šachmatov, Aleksej A. 1957. Istoričeskaja morfologija russkogo jazyka. Moscow: Akademija Nauk SSSR.

Schelesniker, Herbert 1964. Beiträge zur historischen Kasusentwicklung des Slavischen. GrazKöln: Hermann Böhlaus Nachf.

Schwegler, Armin. 1990. Analyticity and syntheticity. A diachronic perspective with special reference to Romance languages. Berlin and New York: Mouton de Gruyter

Schøsler, Lene \& Sabine Kirchmeier-Andersen. 1998. "The role of the Object in a SyntacticoSemantic Classification of Danish Verbs". In Objects: grammatical relations and semantic roles, Kristin Davidse \& Anne-Marie Simon-Vandenbergen (eds). Themanummer Leuvense beidragen. Leuven contributions in linguistics and philology 86 (4): 391-412.

Schøsler, Lene. 1984. La déclinaison bicasuelle de l'ancien français, son rôle dans la syntaxe de la phrase, les causes de sa disparition. Etudes romanes de l'Université d'Odense 19. Odense: Odense University Press.

Schøsler, Lene. 1999. "Réflexions sur optionnalité des compléments d’objet direct, en latin, en ancien français, en moyen français et en français moderne”. Etudes Romanes 44, 9-28. Copenhagen: Museum Tusculanum Press.

Schøsler, Lene. 2000. "Le statut de la forme zéro du complément d’objet direct en français moderne”. Etudes Romanes 47, 105-129. Copenhagen: Museum Tusculanum Press.

Schøsler, Lene. 2001. "La valence verbale dans une perspective diachronique: Quelques problèmes méthodologiques”. In Lene Schøsler (ed), 98-112. 
Schøsler, Lene. 2008. "Argument marking from Latin to Modern Romance languages. An illustration of 'combined grammaticalisation processes"'. In Grammatical Change and Linguistic Theory. The Rosendal papers. Thórhallur Eythórsson (ed), 411-438. Amsterdam: John Benjamins.

Schøsler, Lene. 2009. "Les verbes exprimant la notion d'aide». In Le français, d'un continent à l'autre, Luc Baronian and France Martineau (eds), 443-465. Sainte-Foy: Presses de L'Université Laval.

Schøsler, Lene. Forthcoming. "Grammaticalisation et constructions”. Actes de Fribourg.

Schøsler, Lene (ed.). 2001. La valence, perspectives romanes et diachroniques, ZFSL Beihefte 30. Stuttgart: Franz Steiner Verlag.

Schøsler, Lene \& Michael Skovgaard-Hansen. 2007. Undersøgelse over komplekse nominalsyntagmer i latin. In Fra Plautus over klassisk latin, senlatin til humanismen, ALBVM AMICORVM. Festskrift til Karsten Friis-Jensen i anledning af hans 60 års fødselsdag/Studies in Honour of Karsten Friis-Jensen on the Occasion of his Sixtieth Birthday. Marianne Pade (ed), in collaboration with Eric Jacobsen, Hannemarie Ragn Jensen, Lene Waage Petersen, Lene Schøsler, Minna Skafte Jensen, Peter Zeeberg, Lene Østermark-Johansen, 39 pages. Renæssanceforum 3 • 2007 http://www.renaessanceforum.dk/rf_3_2007.htm

Searle, John R. 1969. Speech Acts. Cambridge: Cambridge University Press.

Searle, John R. 1979. Expression and meaning. Studies in the theory of speech acts. Cambridge: Cambridge University Press.

Seguin, Jean-Pierre. 1972. La langue française au XVIIIe siècle, Paris : Bordas.

Selig, Maria. 1991. "Inhaltskonturen des 'Dativs'. Zur Ablösung des lateinischen Dativs durch ad und zur differentiellen Objektmarkierung”. In Peter Koch \& Thomas Krefeld (eds), 187-211.

Siertsema, Bertha. 1965. A study of glossematics. Critical survey of its fundamental concepts. The Hague: Martinus Nijhoff.

Sihler, Andrew L. 1995. New comparative grammar of Greek and Latin. New York and Oxford: Oxford University Press.

Silina, Vera B. 1987. "Specifika vyraženija vidovych različij v drevnerusskom literaturnom jazyke”. In Drevnerusskij literaturnyj jazyk v ego otnošenii $k$ staroslavjanskomu, Lidija P. Žukovskaja (ed), 196-208. Moscow: Nauka.

Skautrup, Peter. 1968 [1947]. Det danske Sprogs Historie, vol 2. Copenhagen: Gyldendal.

Skårup, Povl. 1975. Les premières zones de la proposition en ancient français. Études Romanes de l'Universitè de Copenhague. Revue Romane, Numero Special 6. Copenhagen: Akademisk Forlag.

Sornicola, Rosanna. 2007. "Riflessioni sullo studio del cambiamento morfosintattico dalla prospettiva di un Romanista : sincronia e diacronia rivisitate". Revue de linguistique romane 71: 5-64. Stefanowitsch, Anatol \& Th. Stefan Gries. 2003. "Collostructions: Investigating the interaction of words and constructions”. International Journal of Corpus Linguistics 8 (2): 209-243.

Streicher, Jeanne. 1936. Commentaires sur les Remarques de Vaugelas. Paris: Droz.

Sweetser, Eve E. 1988. "Grammaticalization and semantic Bleaching”. Proceedings of the Fourteenth Annual Meeting of the Berkeley Linguisitic Society, Shelly Axmaker, Annie Jaisser \& Helen Singmaster (eds), 389-405. Berkeley: Berkeley Linguistics Society.

Szober, Stanisław. 1963. Gramatyka języka polskiego. Warszawa: Państwowe wydawnictwo naukowe.

Taylor, John R. 1998. “Syntactic Constructions as Prototype Categories”. In Michael Tomasello (ed), 177-202.

Tesnière, Lucien. 1965 [1959]. Eléments de syntaxe structurale. Paris: Klinksieck. 
Théoret, Michel. 1982. Les discours de Cicéron. La concurrence du tour casuel et du tour prépositionnel. Canada: Presses de l'Université de Montréal, Editions de l'Université de Sherbrooke.

Thomasset, Claude \& Karin Ueltschi. 1993. Pour lire l'ancien français. Paris: Nathan.

Thompson, Sandra A. \& Paul J. Hopper. 2001. "Transitivity, clause structure, and argument structure: Evidence from conversation". In Frequency and the emergence of linguistic structure, Joan Bybee \& Paul Hopper (eds), 27-60. Amsterdam and Philadelphia: Benjamins.

Tolstoj, N.I. 1957. "Značenie kratkix i polnyx form prilagatel’nyx v staroslavjanskom jazyke (na materiale evangel'skix kodeksov).” Voprosy slavjanskogo jazykoznanija 2: 43-122.

Tomasello, Michael. 1998. "Introduction: A cognitive-functional perspective on language structure". In Michael Tomasello (ed), vii-xxiii.

Tomasello, Michael (ed.). 1998. The new psychology of language. Cognitive and functional approaches to language structure. Mahwah, New Jersey and London: Lawrence Erlbaum Associates.

Tomasello, Michael (ed.). 2003. The new psychology of language. Cognitive and functional approaches to language structure, volume 2. Mahwah, New Jersey and London: Laurence Erlbaum associates.

Trask, Robert Lawrence. 1996. Historical Linguistics. Bristol: Arnold.

Traugott, Elizabeth. 2003. Constructions in Grammaticalization. In Brian D. Joseph \& Richard D. Janda (eds), 624-647.

Traugott, Elizabeth Closs. 2007. "The concepts of constructional mismatch and type-shifting from the perspective of grammaticalization”. In Cognitive Linguistics 18 (4): 523-557.

Traugott, Elizabeth Closs. 2008a. "Grammaticalization, constructions and the incremental development of language: Suggestions from the development of degree modifiers in English". In Variation, Selection, Development - Probing the Evolutionary Model of Language Change, (Trends in Linguistics 197), Regine Eckardt, Gerhard Jäger \& Tonjes Veenstra (eds), 219-250. Berlin/New York: Mouton de Gruyter.

Traugott, Elizabeth Closs. 2008b. "All that he endevoured to prove was ...: On the emergence of grammatical constructions in dialogic contexts". In Language in Flux: Dialogue Coordination, Language Variation, Change and Evolution, Robin Cooper \& Ruth Kempson (eds), 143-177. London: Kng's College Publications.

Traugott, Elizabeth C. \& Richard B. Dasher. 2005. Regularity in Semantic Change. Cambridge: Cambridge University Press.

Troberg, Michelle. 2006. "Une étude diachronique des verbes bivalents datifs en français", paper read at Diachro III, Paris, September 2006.

Valgina, N.S. 2003. Aktivnye processy v sovremennom russkom jazyke. Moskva: Logos.

Van Belle, William \& Willy van Langendonck (eds.). 1996. The Dative. Volume 1, Descriptive Studies, Amsterdam/Philadelphia:Benjamins.

Van Hoecke, Willy. 1996. “The Latin dative”. In Van Belle \& Van Langendonck (eds), 3-37.

Vance, Barbara. 1997. Syntactic Changes in Medieval French: Verb-Second and Null Subjects. Dordrecht: Kluwer Academic Publications.

Vaugelas, Claude Favre de. Remarques sur la langue françoise (1647), facsimile de l'édition originale par Jeanne Streicher. Paris: Droz 1934/Slatkine 2000.

Vennemann, Theodor. 1974. “Topics, Subjects and Word order: from SXV to SVX via TVX." In Proceedings of the First International Conference on Historical Linguistics 1: Syntax, Morphology, Internal and Comparative Reconstruction, J.M. Anderson \& Charles Jones (eds), 339-76. Amsterdam. North Holland. 
Vikner, Sten. 1995. Verb Movement and Expletive Subjects in the Germanic Languages. New York: Oxford University Press.

Wackernagel, Jakob. 1892. "Über ein Gesetz der indogermanischen Wortstellung”. Extract reprinted in Probleme der lateinischen Grammatik, Klaus Strunk (ed). Darmstadt: Wissenschaftliche Buchgesellschaft. 1973.

Wanner, Dieter. 1987. The Development of Romance Clitic Pronouns. Mouton de Gruyter: Berlin, New York, Amsterdam.

Wilmet, Marc. 1998. Grammaire critique du français ${ }^{2}$, Hachette/Duculot : Paris/Bruxelles.

Wright, Roger. 1982. Late Latin and Early Romance in Spain and Carolingian France. Francis Cairns: Liverpool.

Wright, Roger. 1995. Early Ibero-Romance. Newark: Juan de la Cuesta.

Wright, Roger. 2004. “¿Nuevo sistema, o nueva colección de rasgos?”, Aemilianense 1: 665-687.

Wright, Roger. 2006a. "History repeats itself. Reflexive grammar, agentless semantics and morphological flags in English and Early Romance". In La linguistique au cœur, Hanne Leth Andersen, Merete Birkelund \& Maj-Brit Mosegaard Hansen (eds), 55-74. University Press of Southern Denmark: Odense.

Wright, Roger. 2006b. "Divergence, Fragmentation, and the "Locus" of Change". In Studies in Basque and historical linguistics in memory of R.L. Trask, Joseba A. Lakarra \& José Ignacio Hualde (eds), 993-1004. Anuario del Seminario de Filología Vasca "Julio de Urquijo" XL:1-2. Wurzel, Wolfgang U. 1980. "Ways of morphologizing phonological rules". In Historical morphology, Jacek Fisiak (ed), 443-62. The Hague: Mouton.

Xaburgaev, Georgij A. 1990. Očerki istoričeskoj morfologii russkogo jazyka: Imena. Moscow: Izdatel'stvo Moskovskogo Universiteta.

Yaguello, Marina. 1998. "La réalisation zéro des clitiques objet dans les constructions di-transitives du français parlé”. In Analyse linguistique et approches de l'oral. Recueil d'études offert en hommage à Claire Blanche-Benveniste. Orbis Supplementa, 267-274. Peeters: Leuven.

Zaliznjak, Andrej A. 1995. Drevnenovgorodskij dialekt. Moscow: Jazyki russkoj kul'tury.

Zemskaja, E.A. (ed.). 1996. Russkij jazyk konca XX stoletija (1985-1995). Moskva: Jazyki russkoj kul'tury. 



\section{Language index}

B

Bosnian/Croatian/Serbian 22, 131, 149

Bulgarian 3, 9, 25, 116, 155

Old Bulgarian 9, 116, 155

C

Common Slavic 3, 9, 11, 17-21, 33-34, 135-136, 140, 143-144, 146, 148-150, 166,168

D

Danish 14, 29-32, 38, 44-47, $51,53,58-59,61-64,67$, $71-76,78-81,83-84,86$, 94-98, 101, 103-106, 108, 110-111, 172-173, 175-193, 195, 198-204, 206, 208-212, 214, 216-220, 222-223, 227, 231-232, 243 , $245,282,317$

Middle Danish 47, 61, 94, 172, 183-184, 187

E

English 32, 38, 43-44, 51, 53, $55-57,59,71,74-76,78-81$, 83-84, 91, 93, 97, 99-100, 103-104, 109, 141, 150, 221, 245-246, 260, 265, 282, 301, 309

Old English 51, 53, 55-57, 104

F

Finnish 72, 86, 88-91

French 6, 8, 36-39, 43-44, 50, $67-71,76,78,80-81,91$, 98-100, 150, 172, 180-184, 186, 190-191, 195, 203, 237-238, 240-241, 257, 259-261, 263, 274-283,
286, 288, 290-293,

295-298, 300-312,

314-322, 324

Old French 44, 50, 67-70, 172, 180-184, 186, 191, 195, 203, 238, 257, 288, 290-293, 305-309

Middle French 186, 283, 286, 288, 290, 292-293, 296, 305, 308-309

Renaissance French 283, 293

Classical French 37, 280, 283, 292-293, 305, 310-312, 315-317, 319

Modern French 37-38, 43, $67,70,80,99,191,240$, 275-276, 279-280, 283, 286, 291-292, 297, 300, 302-305, 312, 315-321

Colloquial French 274, 308, 310, 312, 314, 319

G

Greek 12, 121, 124, 150

I

Italian $6-8,12,20,37,67$, 70, 81, 190-191, 206, 258-264, 266, 274-276, $278-281,318$

L

Latin $6,8,20,36-37,43-44$, 65-66, 72, 88-92, 103-104, 122, 237-242, 248-257, 259, 262-266, 269-272, 275-278, 280-289, 292-293, 296, 298-299, 301, 303, 305-309, 316, 318, $320-321,323$

M

Macedonian 25
$\mathrm{N}$

Norwegian 48, 110, 173, 176, 186, 196, 223

Old Norwegian 48, 173, 176, 196, 223

O

Old Church Slavonic 3, 9, 17, 135, 149, 155

Old Icelandic 31-32, 48, 194

Old Norse $30-31$

P

Polish 9, 17-20, 24, 39, 149-150, 155

Portuguese 23, 263-265, 267, 269, 272-273, 277, 280

R

Romanian 239, 255, 259, 262-269, 272, 274, 277-278, 280

Russian 3-5, 14-15, 22, 24-28, $30,33-34,72,86-88$, 91, 108-109, 115-117, 119, 122-124, 127-134, 140-141, $146,148-151,153-156,162$, $165-168,170$

Old Russian 3-5, 14-15, 34, $88,115-116,124,127,132$, 140, 146, 166

$S$

Scanic 58, 60-61, 173, 179-180, 194-196, 198-200, 207-208, 217

Swedish 38-39, 110-111, 123, 176, 186, 209, 212

Spanish 23, 106-107, 191, 257-258, 263-272, 276-278, 280-281, 303, 320-324

Old Spanish 23, 269 



\section{Subject index}

A

actualisation 10-11, 16, 38, 44, 95-98, 120, 123, 128, 138, 147-149, 165, 169, 191, 265, 272, 293-302, 323-324

addressee $69,90,290$

analogy 3, 33-34, 38, 100-101, 229, 298

animacy $25-28,108-109$, $115-116,128-133,135-138$, 144-149, 167-170, 266 aspect $15-16,36,108-109$, 115-116, 149-156, 158-170, $234,245,303,311,315$

atelic $73-76,78,84,86,93$

\section{B}

background 60-62, 161, 167, 197-201, 203, 213-215, 218, 221, 230

beneficiary 83, 256-257, 259, 261-263, 270, 282

C

case $3-6,25-32,34,36,44,51$, 69, 76-77, 86-92, 116-128, 131-135, 138-140, 142-145, $148,149,168,229,230,232$, 233, 238-241, 248, 250-251, 253, 255-256, 260-262, $271,276-277,282-285$, 287-288, 290, 292-293, 296-297, 300, 302, 307, 321-324

case roles 117, 238, 240-241, 261, 282-283, 296-297, $300,317-319,323$

causative 77, 79, 86, 94-95, 99 cline $11-12,16-21,24,32,62$, $225,231,247,276$

clitic $8,11,18-19,21-24,30,32$, 62-63, 65-67, 181, 215, 249, $258,272,274-278,281,314$, 318,321 cohesion 180, 184-185, 208-209, 220, 226, 228-230, 232-233

cohesive $46-47,179-180$, 184-187, 191-192, 201, 203-210, 213, 227, 232-233

connecting grammaticalisation 33 , 41, 44, 63, 67, 103, 105, 115, $144,167,170,172,175,185$, 192, 194, 226, 234, 237-238, $241,248,282,317-318$, 322-323

connecting paradigm 111, 209 Construction Grammar (CG) 75, 101, 243, 247 construction $21,27,72-81$, 83-84, 86, 88-89, 91-101, 103-105, 110, 116, 118-120, 122-128, 134-135, 137, 139-140, 142-146, 154, 170, 224, 228, 241, 243-247, 249-251, 253-257, 261, $263,267,271,282-286$, 288-304, 311-313, 315-324

content $3,5,8-9,11-12,16$, $18-20,24-25,32-33,36$, $44,46-47,51-53,62-64$, $67,70-73,75-77,80-81$, $83,88,92-93,97-101$, 105, 107-110, 121, 124, $136-138,146,162,170-172$, 175-176, 179, 184, 188-189, 193, 205-206, 208-209, 222, 224, 226-232, 238, 244-247, 251, 253-254, 256, 270, 285-289, 296-297, 300-301, 304, 311-314, 317, 319-320, 324

complex paradigm $27,47,63$, 190, 192, 219-220, 227, 234, 261, 270, 320 cross-reference 106, 237, 241, 249, 264, 268, 271-272, 274-278, 280-282, 318, 321, 323-324

D

dative $23,25-26,52,67,89-91$, 96, 104, 106-107, 117, 119-121, 123, 125, 239, 241-242, 249-263, 267-271, 279, 282-302, $308,310,320-324$

definiteness 29-30, 141, 233, 266

degrammation $44,51,58$, $60,62-63,105,107,185$, 229, 256

domain $4-5,27,30-32$, 71-73, 75, 77, 92, 109, 111, 126-128, 131, 136-138, 146, 149, 154, 168, 186, 192, 244, $247,282,300$

E

emotive 105, 178, 187, 189, 192, 216-221, 225-227, 234

ergativity 76,82

experiencer 241, 283-290, 292, 296-302, 320-321

expression 3, 10-11, 13, 16, $19,24-25,27,30,34,36$, $44,47,51-53,62-64$, $67,71-72,75-77,79$, 83-84, 86-87, 91-92, 94, 100-101, 103, 107-108, 110, 121, 135-137, 141, 146, 149, 171-173, 175-177, 181, 185-186, 188-189, 193, 197, 204-206, 219, 222, 224, 226-227, 229, 232-234, 241, 243-247, 251, 253-257, 261-262, 270, 284, 287-290, 297, 300-301, 303-319, 322-324 
F

field $45,50,54-57,60,68,179$, $181,194,200,208$

focus $49,53,59-62,67$, 197-203, 208, 212-214, 216, 230-231, 233

focus, semantic 153

frame $5-7,29,44-45,49,52$, $54,68,72-73,75,77-78$, 99, 105, 108, 115, 176, 179-180, 183, 185-188, 192, 208-210, 213-214, 216, 219, 226-227, 230, 232, 238, 244-245, 247, 249, 253, 282, 301, 317

function $7-8,24,27-28,31-34$ function in identifying arguments 238-240, 243, 251, 256-257, 262, 271-272, 274-275, 280-281, 283-285, 291-292, 296-297, 304, 307, 321

function of positions 177 , 179-180, 186-189, 196-197, 203-205, 210, 214-215

predicative function

141-142

sign function 47, 204

fundamental field 45,50 , 68,179

\section{G}

gender 25, 27-30, 109, 129-132, $136,142-149,167-170$, 276-277, 316

generative grammar 49 , 59, 205

genitive $3-5,25-28,30-34$, 87-88, 117-122, 125-128, 130, 132-140, 142-149, $168-169,239,253,256$, 262, 267

grammation $7-12,16,24,28$, $34,51-53,62,105,107,171$, $185,187,192,226$

grammaticalisation 1,3 , 5-6, 9-12, 16-17, 20, 22, 24, 33-34, 37, 41, 43-45, $62-63,67,93,101,103,105$, $110,115,144,162,167-172$, $175,185,187-188,192$, 194, 209, 223-226, 228, 231, 234, 237-238, 241,
243-244, 247-248, 263, 276, 282, 286, 301-302, $317-318,320,322-323$

\section{$\mathrm{H}$}

hyperparadigm 52, 70, 91-92, 109, 186, 192, 300

hyperparadigmatic structure 28,192

I

iconicity 197

iconic 60-61, 197, 200, 202, 212 illocution 105, 190, 227, 233 illocutionary $47-48,50,59$, $62,65,105-106,176-177$, 180, 183, 187-190, 192, 210, 216, 219-222, 225-227, 230-234

indefinite $4-5,30,108,111,233$, 266,280

indexicality 206

indexical meaning 62, 177, 204, 207, 210

indicative $40,46,50,172$, 176-177, 179-180, 182-183, $185,190,204,217,231-232$

indirect object $52,64,79$, 83-84, 96-98, 106, 174, 196,242

inversion 181, 183-185, 191, 227, 232, 277

inversion, narrative $183-184$

L

layering 75, 109, 111

M

markedness 4, 6, 16, 18-19, 34-41, 104-105, 119-120, $123,125-127,134,138,140$, 154-159, 161-166, 169, 178-179, 183-184, 186-187, 190, 191, 192, 194-197, 200, 208-209, 212, 216, 219-220, 226, 231, 253, 256, $263,265,266,281,285$, $296,302,321,323-324$

merger 139, 149, 239, 242, 257, $269,281,321$

middle 47, 53-57, 60-61, 94, 104-105, 110, 121, 132, 155, 172, 183-184, 186-187, 258, 283, 286, 288, 290,
292-293, 296, 301, 305, 308-309

minimalism 173

mood 44, 46, 50, 67, 104-105, 108, 110, 172, 175-176, 179, 182, 185-187, 189-192, 202, 204, 208, 210, 227, 230-234

P

particle 24, 46, 65, 162, 176-178, 189, 192, 217, 220, 222, 224, 226, 229, 231, 298

passive $82-83,90-91,103-104$, 108, 110, 231, 250, 254

pattern $72,74,76-77,80-81$, 83, 90, 97, 99, 134, 140, 142 pattern of syncretism 130-132, 146-147 valency pattern 245 , 250-261, 273, 287, 289, 292-294, 296, 299, 301-302, 314, 320 word order pattern 43-44, 47-48, 59, 172, 174-179, 184, 186-190, 193-196, 212, 216-217, 225, 227, 231-232 patient 79-80, 103, 241, 256-257, 259, 261-263, 269-270, 282, 285-286, 289-290, 296-297, 300, $302,304,320-321$

personal pronoun 65,120 ,

255-257, 270-271, 290-291, 304 prepositional object 73 , $84-85,265,267$

R

reanalysis $8,10-11,13-14$, $16-17,20,27,30,33-34$, 44, 52, 57, 61, 92-93, 96-99, 101, 108, 134, 136, 138, 146-149, 158, 162, 165-171, 175, 185-187, 192-193, 201, 205, 208, 211-213, 215, 224-231, 233-234, 253, 255, 280, 292-293, 324

recipient 79, 96-97, 241-242, 251, 253-257, 259, 261-263, 270, 281-283, 286, 289-291, 300, 321 
regrammation $8-11,16,34$, $51,53,62,92,94,96,101$, 105, 107, 111, 138, 168, 171, 185, 187, 190-192, 209, 227-228, 231, 234, 283, 286, 302

referentiality $271,281,312-313$, 319,322

\section{S}

stress reduction $44,57,59,61$, 63-65

subject $45-47,52,59-61$, 68-70, 76-81, 84, 87, 90, 103-104, 107-109, 133, $165,170,174,178-180,183$, 188, 193, 195, 197, 199-203, 208, 213-216, 218, 221, 226, 228-229, 232, 234, 242, 248, 254, 262, 275-278, 290-291, 297, 301, 304, 311, $317,320-321$

subjective 105-106, 178, 187, 189-190, 209, 216, 219-220, 222, 224-227, 234 subjunctive $40,48,150,172$, 179-180, 182, 185, 190, 217, 223-224, 232

subjunction 49, 173-174, 177-178, 185, 187-189,
191-193, 195-197, 201-210, 213-214, 216, 218-219, 221-222, 226

symbolic meaning 204, 207

$\mathrm{T}$

telic $73-74,76,78,84,86$, 93,311

telicity $72-73,75,82,84,86$, $101,153,159,169,303$

topic 53, 253-255

topology 6, 43-45, 51-53, 55, $60,63,65,67,70-72$, 104-106, 172-173, 175, 181, 188, 193-195, 199, 205-206, 208-211, 216, 218, 234, 244

transitive $72-80,82,90$, 99-100, 122, 154, 170, 229, 245-246, 298, 302, 304, $307,312,317$

transitivity $73,80-81,83,154$, 270, 296

V

valency $57,61,71,75,83$, 99, 103, 116, 118-124, 126-128, 154, 170, 175, 188, 192, 194, 208, 212-216, 226, 234, 238,
$242,245,247,250$, 254-255, 283, 319

variation $27,36,41,100-101$, 124-125, 130, 144, 248, 251-252, 256, 277, 289, 292, 294-295, 315

verb second $45,47-50$, 53-58, 67, 69-70, 105, 171-172, 174-18o, 182-183, 185-195, 203-205, 207-208, 210, 212-213, 216-221, 225-228, 230, 233-234 voice 54, 90-92, 103-105, 121, 305

W

Wackernagel's Law, Wackernagel 18, 23, 40, $44,55-57,65-67$

word order $6,16-17,21$, $38,43-48,50-53,56-59$, 61-62, 68, 70-71, 103, 105-106, 134, 140, 145, 171-177, 180-194, 196-197, 204-205, 208, 211-212, 219-220, 222, $225,227,229-233,237$, 240-241, 277-278, 282, 309, 317-319 